\title{
The role of primary and secondary care in the management of pulmonary embolism: A shifting paradigm? Developments in diagnosis and treatment
}

Citation for published version (APA):

Erkens, P. M. G. (2013). The role of primary and secondary care in the management of pulmonary embolism: A shifting paradigm? Developments in diagnosis and treatment. [Doctoral Thesis, Maastricht University]. Universitaire Press. https://doi.org/10.26481/dis.20130220pe

Document status and date:

Published: 01/01/2013

DOI:

10.26481/dis.20130220pe

Document Version:

Publisher's PDF, also known as Version of record

Please check the document version of this publication:

- A submitted manuscript is the version of the article upon submission and before peer-review. There can be important differences between the submitted version and the official published version of record.

People interested in the research are advised to contact the author for the final version of the publication, or visit the DOI to the publisher's website.

- The final author version and the galley proof are versions of the publication after peer review.

- The final published version features the final layout of the paper including the volume, issue and page numbers.

Link to publication

\footnotetext{
General rights rights.

- You may freely distribute the URL identifying the publication in the public portal. please follow below link for the End User Agreement:

www.umlib.nl/taverne-license

Take down policy

If you believe that this document breaches copyright please contact us at:

repository@maastrichtuniversity.nl

providing details and we will investigate your claim.
}

Copyright and moral rights for the publications made accessible in the public portal are retained by the authors and/or other copyright owners and it is a condition of accessing publications that users recognise and abide by the legal requirements associated with these

- Users may download and print one copy of any publication from the public portal for the purpose of private study or research.

- You may not further distribute the material or use it for any profit-making activity or commercial gain

If the publication is distributed under the terms of Article $25 \mathrm{fa}$ of the Dutch Copyright Act, indicated by the "Taverne" license above, 
The role of primary and secondary care in the management of pulmonary embolism

\author{
A shifting paradigm?
}


(C) Petra Mathilda Gerardus Erkens, Maastricht 2013

ISBN: 978-94-6159-129-6

Production: Datawyse | Universitaire Pers Maastricht

Alle rechten voorbehouden.

Niets uit deze uitgave mag worden verveelvoudigd, opgeslagen in een geautomatiseerd gegevensbestand en/of openbaar gemaakt in enige vorm of op enige wijze, hetzij elektronisch, mechanisch, door fotokopieën, opnamen of op enige andere manier zonder voorafgaande schriftelijke toestemming van de uitgever. 


\title{
The role of primary and secondary care in the management of pulmonary embolism
}

\author{
A shifting paradigm?
}

\section{Developments in diagnosis and treatment}

\author{
PROEFSCHRIFT
}

ter verkrijging van de graad van doctor aan de Universiteit Maastricht, op gezag van de Rector Magnificus, Prof. dr. L.L.G. Soete, volgens het besluit van het College van Decanen,

in het openbaar te verdedigen

op woensdag 20 februari 2013 om 14.00 uur

door

\section{Petra Mathilda Gerardus Erkens}

geboren te Sittard

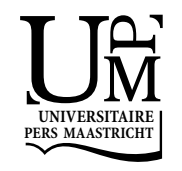




\section{Promotores}

Prof. dr. M.H. Prins

Prof. dr. H. ten Cate

\section{Co-promoter}

Dr. H.E.J.H. Stoffers

\section{Beoordelingscommissie}

Prof. dr. G.J. Dinant (voorzitter)

Prof. dr. F.J.V.M. Buntinx

Prof. dr. A. Falanga (Ospedali Riuniti de Bergamo)

Dr. P.W. Kamphuisen (Universitair Medisch Centrum Groningen)

Prof. dr. P.W. de Leeuw 


\section{Contents}

$\begin{array}{lll}\text { Chapter } 1 & \text { General introduction and outline of the thesis } & 7\end{array}$

Part I Diagnostics of Pulmonary Embolism in Primary Care $\quad 19$

Chapter 2 Safe exclusion of pulmonary embolism using the Wells rule and 21

D-dimer testing in primary care: a diagnostic validation study

Chapter $3 \quad$ Alternative diagnoses of pulmonary embolism in primary care $\quad 37$

Chapter 4 Clinical decision rules for excluding pulmonary embolism: $\quad 49$

a meta analysis

Part II $\quad$ Treatment of Pulmonary Embolism in Secondary Care 71

Chapter $5 \quad$ Fixed dose subcutaneous low molecular weight heparins $\quad 73$

versus adjusted dose unfractionated heparin for venous

thromboembolism: a systematic review

Chapter 6 Safety of outpatient treatment in acute pulmonary embolism

Chapter 7 Does the pulmonary embolism severity index accurately

identify low risk patients eligible for outpatient treatment?

Chapter 8 Benchmark for time in therapeutic range in venous

thromboembolism: a systematic review

$\begin{array}{lll}\text { Chapter } 9 \quad \text { General discussion } & 165\end{array}$

$\begin{array}{ll}\text { Summary } & 177\end{array}$

$\begin{array}{ll}\text { Nederlandse samenvatting } & 185\end{array}$

Appendix 1 Different clinical decision rules for pulmonary embolism 195

$\begin{array}{ll}\text { Dankwoord } & 203\end{array}$

$\begin{array}{ll}\text { Publications } & 211\end{array}$

$\begin{array}{ll}\text { Curriculum Vitae } & 215\end{array}$ 



\section{Chapter 1}

General introduction and outline of the thesis 
Chapter 1 


\section{Introduction and outline of the thesis}

\section{General introduction}

In countries with highly developed systems of primary care, such as in the Netherlands, more and more procedures are being transferred from hospital to community settings. Such development is also occurring in the management of pulmonary embolism (PE). Whereas the diagnosis and treatment of PE is mainly a secondary care problem nowadays, it seems likely that in the future PE will be increasingly managed in primary care. A careful and evidence based approach to this development is necessary since PE is a potential life-threatening disease if diagnosed and treated inadequately. This thesis concerns the management of PE at the interface of community and hospital based health care, i.e. primary and secondary care, and discusses advances in PE diagnosis and treatment.

\section{Definition and epidemiology of pulmonary embolism}

\section{Definition}

Venous thromboembolism (VTE) includes both deep vein thrombosis (DVT) and pulmonary embolism (PE) and is characterized by the formation of a blood clot, also called thrombus, that blocks or partially blocks a blood vessel. Venous thrombi, composed predominantly of red blood cells but also platelets and leukocytes all bound together by fibrin, form in sites of vessel damage and areas of stagnant blood flow such as the valve pockets of the deep veins of the calf or thigh. Thrombi either remain in the peripheral veins, where they eventually undergo endogenous fibrinolysis and recanalization, or they embolize to the pulmonary arteries and cause PE. PE is defined as a thrombus that blocks the main artery of the lung or one of its branches. This thesis will focus on PE.

\section{Epidemiology}

PE is the third most common cause of death from cardiovascular disease after heart attack and stroke. ${ }^{1}$ Although the exact incidence of PE is unknown, cohort studies among western populations show consistency in incidence estimates. It is believed that the annual incidence of VTE is 1.50 per 1000 inhabitants and that approximately one third of these patients have PE. ${ }^{2,3} \mathrm{PE}$ results from a combination of hereditary and acquired risk factors. (Table 1.1) 
Table 1.1 Risk factors for $\mathrm{PE}^{2}$

\begin{tabular}{|c|c|}
\hline Risk factors for PE & \\
\hline Environmental & Long-haul air travel, obesity, cigarette smoking, hypertension, immobility \\
\hline Natural & Increasing age \\
\hline Women's health & Oral contraceptives, pregnancy, hormone replacement therapy \\
\hline Medical illness & $\begin{array}{l}\text { Previous PE or DVT, cancer, congestive heart failure, chronic obstructive pulmonary } \\
\text { disease, diabetes mellitus, acute and chronic inflammatory diseases, antipsychotic } \\
\text { drug use, chronic in-dwelling central venous catheter, permanent pacemaker, } \\
\text { internal cardiac defibrillator, stroke with limb paresis, nursing-home confinement or } \\
\text { current or repeated hospital admission, varicose veins }\end{array}$ \\
\hline Surgical & $\begin{array}{l}\text { Trauma, orthopaedic surgery, especially total hip replacement, total knee } \\
\text { replacement, hip fracture surgery, knee arthroscopy, general surgery, } \\
\text { gynaecological and urological surgery, neurosurgery }\end{array}$ \\
\hline Thrombophilia & $\begin{array}{l}\text { Factor V Leiden mutation, prothrombin gene mutation, hyperhomocysteinaemia, } \\
\text { antiphospholipid antibody syndrome, deficiency of antithrombin III, deficiency of } \\
\text { protein C, deficiency of protein S, high concentrations of factor VIII or Xi }\end{array}$ \\
\hline Non-thrombotic & $\begin{array}{l}\text { Particulate matter / air pollution, foreign particles, amniotic fluid, bone fragments, } \\
\text { bone marrow, fat, cement }\end{array}$ \\
\hline
\end{tabular}

$\mathrm{PE}=$ pulmonary embolism; DVT= deep vein thrombosis.

The overall 3-month mortality rate in patients with PE is approximately $17 \% .{ }^{4}$ Many of these patients die from underlying comorbid disorders, especially cancer and cardiorespiratory diseases. ${ }^{5}$ Adequate diagnostics and therapy are crucial in reducing the mortality rate. Without treatment PE is fatal in approximately $30 \%$, whereas the mortality rate for PE is only $2 \%$ to $8 \%$ with adequate therapy. ${ }^{6}$

In addition, $2 \%$ to $4 \%$ of all PE patients develop chronic thromboembolic hypertension (CTEPH) within the second year following their event. ${ }^{7}$ CTEPH is defined as a mean pulmonary-artery pressure greater than $25 \mathrm{mmHg}$ that persists 6 months after PE is diagnosed. ${ }^{7}$ It often presents with exercise intolerance, fatigue and dyspnoea and has a major impact on the quality of life of patients.

\section{Diagnosing pulmonary embolism in primary care}

Diagnosis of PE is a major challenge because patients often present with non-specific symptoms such as sudden unexplained dyspnoea, pain on inspiration and unexplained cough. With increasing age, PE tends to masquerade as other illnesses such as acute coronary syndrome or exacerbation of chronic obstructive pulmonary disease. ${ }^{2}$ Additionally, accurate diagnosis of PE is particularly difficult when patients present with concurrent illnesses, such as pneumonia or congestive heart failure. ${ }^{2}$

Catheter guided pulmonary angiography has been the gold standard reference test for PE for many years. However, this technique is invasive, expensive, not readily available and labor intensive. Consequently, non-invasive ventilation-perfusion 
scanning was performed first in patients with suspected PE. A major problem, however, was that in $28 \%$ to $46 \%$ of all patients with suspected PE the test results were inconclusive. Nowadays, computed tomography pulmonary angiography (CTPA) is the first-line imaging test in patients suspected for PE. CTPA has a high sensitivity (96\% to $100 \%)$ and specificity (97\% to $98 \%) .{ }^{8}$ Nevertheless, since there are some concerns regarding the risk of cancer following radiation exposure with CTPA scanning, a potential harmful CTPA scan should be avoided in patients with a low probability of $\mathrm{PE} .{ }^{9,10}$ Clinical decision rules can help in discriminating between patients who have a high probability of PE and patients with a low probability. The most widely used and validated clinical decision rule for PE is the Wells rule. ${ }^{11}$ The Wells rule is a seven-item bedside assessment that classifies patients as 'PE likely' or 'PE unlikely'. (Table 1.2)

Table 1.2 Wells clinical decision rule for pulmonary embolism.

\begin{tabular}{ll}
\hline Variable & Points \\
\hline Clinical signs and symptoms of DVT (minimum of leg swelling and pain with & 3.0 \\
palpation of the deep veins) & 3.0 \\
PE more likely than an alternative diagnosis & 1.5 \\
Heart rate >100/min & 1.5 \\
Immobilization (>3days) or surgery in the previous 4 weeks & 1.5 \\
Previous PE or DVT & 1.0 \\
Haemoptysis & 1.0 \\
Malignancy (receiving treatment, treated in the last 6 months or palliative) & \\
\hline
\end{tabular}

Wells score $>4$, PE likely; Wells score $\leq 4, \mathrm{PE}$ unlikely. DVT= deep vein thrombosis; PE= pulmonary embolism.

For optimum diagnostic accuracy the Wells clinical decision rule should be combined with D-dimer testing. ${ }^{11}$ Plasma D-dimers are cross-linked fibrin derivatives produced when fibrin is degraded by plasmin. ${ }^{12}$ Large diagnostic management studies in secondary care showed that a negative laboratory based quantitative D-dimer test in patients with a Wells-score $\leq 4$ safely excluded PE without the need for additional work-up by imaging and resulted in the following diagnostic algorithm for suspected PE. ${ }^{13,14}$ (Figure 1.1)

The diagnostic strategy of assessing the probability of PE by using the Wells rule and D-dimer testing seems also ideal for primary care to decide which patients need to be referred to secondary care for further diagnostic work-up, in particular since easy-touse point-of-care D-dimer tests are available for use at the office or in the patient's home. Use of the Wells rule for PE combined with point-of-care D-dimer testing might be a simple, safe, efficient and inexpensive diagnostic strategy to exclude PE in primary care. However, due to differences in disease spectrum, symptomatology and physician experience, results from secondary care cannot be translated to primary care without thorough research. Before implementing such a diagnostic strategy it must be validated in the proper setting, i.e. primary care. 


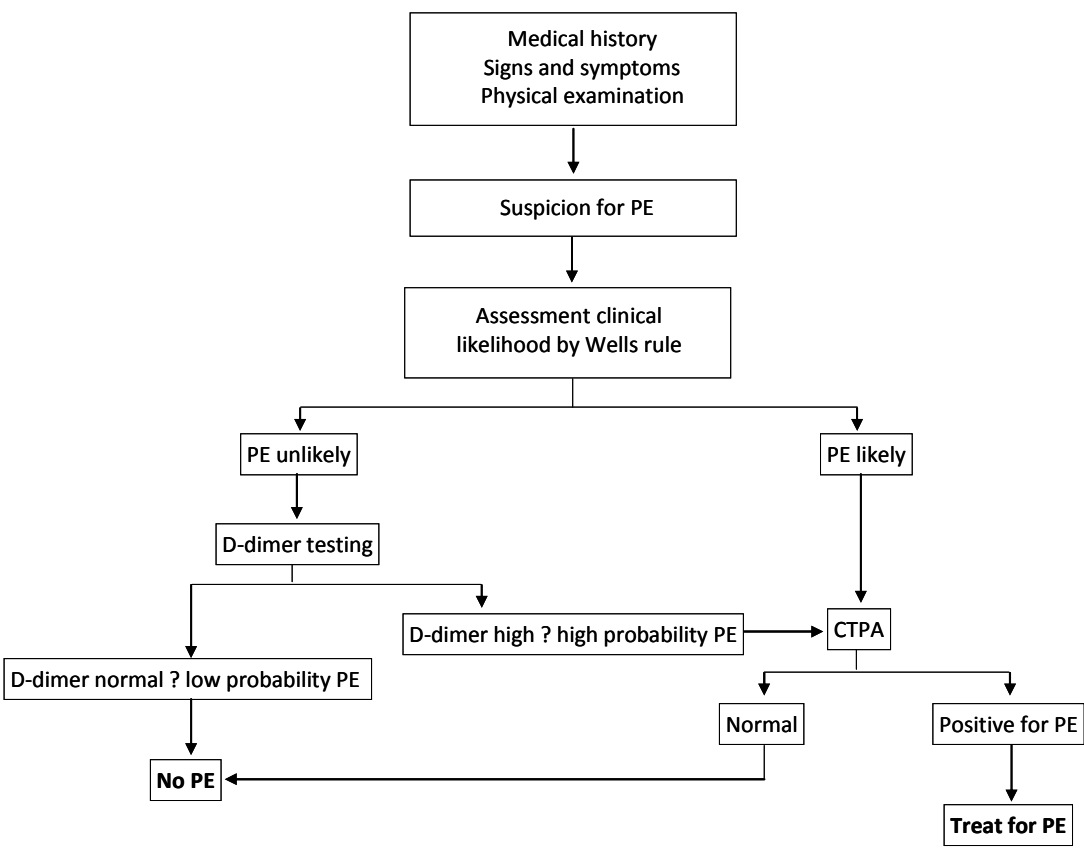

Figure 1.1 Diagnostic algorithm for suspected PE.

$\mathrm{PE}=$ pulmonary embolism; CTPA= computed tomography pulmonary angiography.

\section{Rationale and aim of part I: 'Diagnosing pulmonary embolism in primary care'}

In the Netherlands, the primary care physician is commonly the first to encounter outpatients suspected of PE. It is the primary care physician's task to triage these patients: i.e. to discriminate between those who probably have PE and need to be referred to secondary care and those who can safely be kept under the surveillance of the primary care physician without further diagnostic work-up. To increase the safety and efficiency in the management of patients suspected of $P E$, primary care physician's require an accurate diagnostic tool. The aim of the Amsterdam Maastricht Utrecht Study on thromboembolism (AMUSE-2) was to assess the accuracy and safety of the Wells clinical decision rule combined with point-of-care D-dimer testing for excluding PE in the primary care setting.

\section{Treatment of pulmonary embolism in secondary care}

Nowadays PE is primarily treated by anticoagulation, but anticoagulants did not appear until 1940. Up till then surgical procedures focused on the removal of the 
embolus were performed for the management of PE. ${ }^{15}$ Although the utility of heparin in the management of VTE was confirmed in the thirties of the $20^{\text {th }}$ century, the evidence that a regimen of intravenous unfractionated heparin plus vitamin $K$ antagonists (VKA) is more effective in preventing recurrence than VKA alone came from a randomized control trial in $1992 .{ }^{15,16}$ In the same decade a number of low molecular weight heparins (LMWH) were developed for clinical use. Compared with unfractionated heparin, LMWH preparations have less inter-individual variability in anticoagulant response and as a result of their pharmacokinetic properties, a stable and sustained anticoagulant effect is achieved without laboratory monitoring and dose adjustments when LMWH is administered subcutaneously once or twice daily, ${ }^{17,18}$ Due to the subcutaneous administration and no need for laboratory monitoring LWMH can be administered at home and thus enables outpatient treatment of PE. Outpatient treatment in patients with PE may be important to reduce hospitalizations and medical costs and hence save health care resources. $A$ prognostic model, such as the PE severity index, that accurately predicts short-term adverse outcomes may help in the identification of patients appropriate for outpatient treatment. (Table 1.3)

Table 1.3 Pulmonary embolism severity index.

\begin{tabular}{|c|c|c|}
\hline Predictors & Original score* & Simplified score ${ }^{\pi}$ \\
\hline \multicolumn{3}{|l|}{ Demographic characteristics } \\
\hline Age $>80$ years & Age, in years & 1 \\
\hline Male sex & +10 & \\
\hline \multicolumn{3}{|l|}{ Comorbid illnesses } \\
\hline Cancer $^{\dagger}$ & +30 & 1 \\
\hline Heart failure & +10 & \multirow{2}{*}{$1^{* *}$} \\
\hline Chronic lung disease & +10 & \\
\hline \multicolumn{3}{|l|}{ Clinical findings } \\
\hline Pulse $\geq 110 / \mathrm{min}$ & +20 & 1 \\
\hline Systolic blood pressure $<100 \mathrm{mmHg}$ & +30 & 1 \\
\hline Respiratory rate $\geq 30 / \mathrm{min}$ & +20 & \\
\hline Temperature $<36^{\circ} \mathrm{C}$ & +20 & \\
\hline Altered mental status ${ }^{\ddagger}$ & +60 & \\
\hline Arterial oxygen saturation $<90 \%{ }^{\S}$ & +20 & 1 \\
\hline
\end{tabular}

* A total point score for a given patient is obtained by summing the patient's age in years and the points for each predictor when present. The score corresponds with the following risk classes: <65, class I; 66-85, class II; 86-105, class III; 106-125, class IV; and $\geq 125$, class V. Patients in risk class I and II are defined as being at low risk. ${ }^{\dagger}$ Cancer defined as a history of cancer or active cancer; ${ }^{\ddagger}$ Defined as disorientation, lethargy, stupor or coma; ${ }^{\S}$ With and without the administration of supplemental oxygen. " A total point score for a given patient is obtained by summing the points. The score corresponds with the following risk classes: 0 , low risk; $\geq 1$, high risk. Empty cells indicate that the variable was not included. ${ }^{* *}$ The variables were combined into a single category of chronic cardiopulmonary disease. 
As mentioned earlier anticoagulant therapy is the treatment of choice for most patients with PE. Patients are usually treated with LMWH for 5 to 10 days simultaneously with VKA. LMWH is discontinued if the International Normalized Ratio (INR) is above 2.0 on two consecutive readings. ${ }^{19}$ The guidelines of the American College of Chest Physicians recommend to treat patients with a first provoked PE for 3 months, patients with a first episode of idiopathic PE at least 6 to 12 months and patients with two or more objectively documented PE indefinitely. ${ }^{19}$

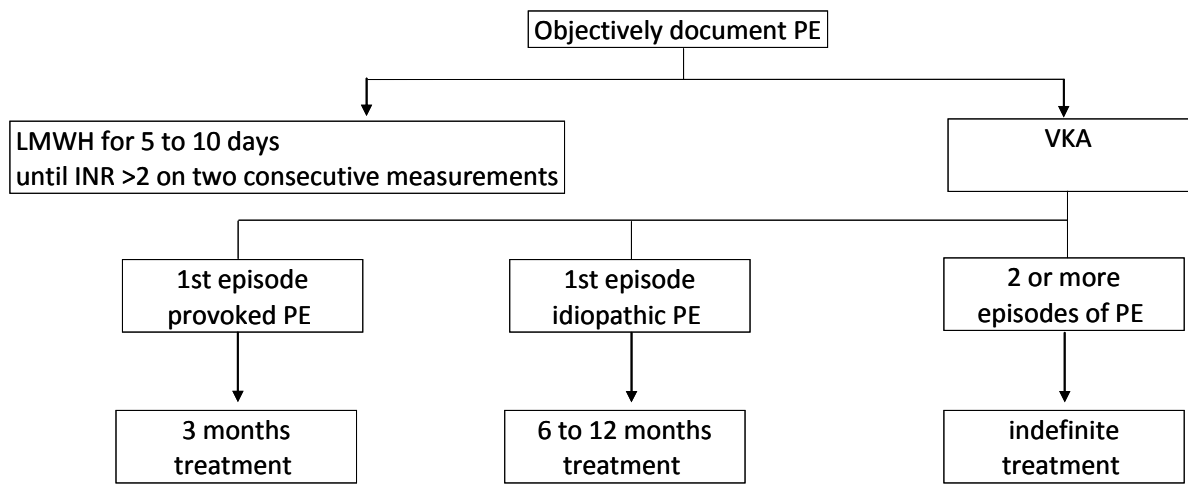

Figure 1.2 Treatment of pulmonary embolism.

$\mathrm{PE}=$ pulmonary embolism; $\mathrm{LMWH}=$ low molecular weight heparin; INR= international normalized ratio; $\mathrm{VKA}=$ vitamin $\mathrm{K}$ antagonist.

Although VKA therapy is highly effective in the treatment of PE, the effect depends on many factors including variation in dose response between patients, individual variation in pharmacokinetics and pharmacodynamic response, multiple interactions with food, co- medication and finally also by variation in adherence. ${ }^{19,20}$ Moreover, VKA have a narrow therapeutic index, which needs to be monitored carefully in order to reduce the risk of tromboembolic events as well as bleeding complications. The International Normalized Ratio (INR) is established by the World Health Organization and the International Committee on Thrombosis and Hemostasis for monitoring the effects of VKA. A target INR range of 2.0 to 3.0 is recommended for the treatment of VTE. ${ }^{19}$ The most recognized way to measure the therapeutic effectiveness of VKA over time is to measure the percentage of time in the therapeutic range (TTR). TTR has been shown to strongly correlate with the clinical outcomes of hemorrhage or thrombosis and, thus, TTR is a reliable measure of the quality of anticoagulation management. $^{21}$

Recently, new direct acting anticoagulant medication, such as rivaroxaban and dabigatran, with a similar efficacy as VKA has been developed and approved in many countries worldwide. ${ }^{22-26}$ The main advantage of these novel drugs is that there is no 
need for laboratory monitoring and dose adjustments anymore due to a more stable pharmacokinetics. In the future, as the novel anticoagulants become the standard treatment of DVT and PE, the role of primary care physicians in the management of PE may increase. However, first the effectiveness of the novel drugs in daily clinical practice needs to be investigated.

Rationale and aim of the second part 'Treatment of pulmonary embolism in secondary care'

Patients with DVT can be safely managed and treated as outpatients using subcutaneous LMWH. The role of outpatient therapy in patients with $\mathrm{PE}$, however, is unclear and has been a matter of debate in literature. Physicians are reluctant to treat patients with PE at home due to uncertainty on how to safely identify patients who are at low risk for short-term adverse events, irrespective of whether the adverse events could be averted by hospitalization. We aimed to investigate whether patients with hemodynamically stable PE could be safely treated out of the hospital and whether the pulmonary embolism severity index, a prognostic model for prediction of short-term adverse outcomes, could help in the identification of appropriate patients for outpatient management.

Outpatient treatment may become more convenient if novel drugs, such as rivaroxaban and dabigatran, which do not need laboratory monitoring, become the standard treatment. Several recent large randomized controlled trials have shown non-inferiority in effectiveness and safety of the new anticoagulants compared to VKA treatment. However, the percentage of time within therapeutic range in the VKAgroup, representing the quality of the control group, appears to vary considerably among these studies. In order to adequately compare all treatment options, including novel anticoagulants and VKA, and to interpret the relative efficacy, effectiveness and safety of these novel anticoagulants, it is important to properly assess the quality of anticoagulant control, i.e. time in therapeutic range (TTR), in the VKA group. We performed a systematic review and meta-analysis to provide a benchmark of TTR in patients with VTE receiving VKA and discuss the pros and cons of various ways to calculate TTR.

\section{Outline of the thesis}

This thesis consists of two parts. The first part focuses on the diagnosis of PE. Chapter 2 describes the Amsterdam Maastricht Utrecht study on thromboembolism (AMUSE-2) in which we investigated the safety of using the Wells clinical decision rule for PE combined with point-of-care D-dimer testing to exclude PE in primary care. The Wells rule for PE includes the attending physician's judgement of whether an alternative diagnosis is less or more likely than PE. In order to estimate the probability of PE primary care physicians need information on the alternative diagnoses of PE as 
seen in primary care in patients suspected for PE. The final alternative diagnoses in patients in whom PE was excluded are shown in chapter 3.

A frame of reference is needed to interpret the results of the AMUSE-2 study. To see whether the Wells rule for PE in primary care has a similar accuracy as clinical decision rules in secondary care an overview of clinical decision rules used in secondary care is presented in chapter 4.

The second part of this thesis focuses on the treatment of PE. In chapter 5 the literature is reviewed to determine the effect of LMWH compared with unfractionated heparin for the initial treatment of VTE. The use of subcutaneous LMWH enables outpatient treatment of PE. In chapter 6 the safety of outpatient treatment in hemodynamically stable patients with acute PE is investigated. Since physicians are reluctant to treat patients with PE at home due to uncertainty on how to safely identify patients who are at low risk of short-term adverse events, we study in chapter 7 whether the pulmonary embolism severity index can help in identifying low risk patients. In chapter 8 a benchmark for TTR in VKA treatment of VTE is presented. The introduction of novel oral anticoagulants will cause major changes in the management of thrombosis in the near future. In order to adequately compare all treatment options it is important to properly assess the quality of anticoagulant control in VKA.

The thesis ends with chapter 9. This chapter discusses the overall methodological considerations of the presented studies and addresses possible implications for clinical practice and future research. 


\section{References}

1. Goldhaber SZ, Bounameaux H. Pulmonary embolism and deep vein thrombosis. Lancet 2012;379:1835-1846.

2. Goldhaber SZ. Pulmonary embolism. Lancet. 2004;363:1295-1305.

3. Wong P, Baglin T. Epidemiology, risk factors and sequelae of venous thromboembolism. Phlebology 2012;27 Suppl 2:2-11.

4. Goldhaber SZ, Visani L, De Rosa M. Acute pulmonary embolism: clinical outcomes in the International Cooperative Pulmonary Embolism Registry (ICOPER). Lancet 1999;353:1386-1389.

5. van Beek EJ, Kuijer PM, Büller HR, Brandjes DP, Bossuyt PM, ten Cate JW. The clinical course of patients with suspected pulmonary embolism. Arch Intern Med 1997;157:2593-2598.

6. Carson JL, Kelley MA, Duff A, Weg JG, Fulkerson WJ, Palevsky HI, et al. The clinical course of pulmonary embolism. N Engl J Med 1992;326:1240-1245.

7. Piazza G, Goldhaber SZ. Chronic thromboembolic pulmonary hypertension. N Engl J Med 2011;364: 351-360.

8. Mos IC, Klok FA, Kroft LJ, de Roos A, Huisman MV. Imaging tests in the diagnosis of pulmonary embolism. Semin Respir Crit Care Med 2012;33:138-143.

9. Brenner DJ, Hall EJ. Computed tomography--an increasing source of radiation exposure. N Engl J Med 2007;357:2277-2284.

10. Einstein AJ, Henzlova MJ, Rajagopalan S. Estimating risk of cancer associated with radiation exposure from 64-slice computed tomography coronary angiography. JAMA 2007;298:317-323.

11. Wells PS, Anderson DR, Rodger M, Ginsberg JS, Kearon C, Gent M, et al. Derivation of a simple clinical model to categorize patients probability of pulmonary embolism: increasing the models utility with the SimpliRED D-dimer. Thromb Haemost 2000;83:416-420.

12. Kelly J, Rudd A, Lewis RR, Hunt BJ. Plasma D-dimers in the diagnosis of venous thromboembolism. Arch Intern Med 2002;162:747-756.

13. Douma RA, Mos IC, Erkens PM, Nizet TA, Durian MF, Hovens MM, van Houten AA, Hofstee HM, Klok FA, ten Cate H, Ullmann EF, Büller HR, Kamphuisen PW, Huisman MV; Prometheus Study Group. Performance of 4 Clinical Decision Rules in the Diagnostic Management of Acute Pulmonary Embolism: A Prospective Cohort Study. Ann Intern Med 2011;154:709-718.

14. van Belle A, Büller HR, Huisman MV, Huisman PM, Kaasjager K, Kamphuisen PW, Kramer MH, Kruip MJ, Kwakkel-van Erp JM, Leebeek FW, Nijkeuter M, Prins MH, Sohne M, Tick LW; Christopher Study Investigators. Effectiveness of managing suspected pulmonary embolism using an algorithm combining clinical probability, D-dimer testing, and computed tomography. JAMA 2006;295:172-179.

15. McFadden $\mathrm{P}$, Ochsner J. A history of diagnosis and treatment of venous thrombosis and pulmonary embolism. The Ochsner Journal 2002;4:9-13.

16. Brandjes DP, Heijboer H, Büller HR, de Rijk M, Jagt $H$, ten Cate JW. Acenocoumarol and heparin compared with acenocoumarol alone in the initial treatment of proximal-vein thrombosis. $\mathrm{N}$ Engl J Med 1992;327:1485-1489.

17. Hirsh J. From unfractionated heparins to low molecular weight heparins. Acta Chir Scand Suppl 1990;556:42-50.

18. Hirsh J, Levine MN. Low molecular weight heparin. Blood 1992;79:1-17.

19. Büller HR, Agnelli G, Hull RD, Hyers TM, Prins MH, Raskob GE. Antithrombotic therapy for venous thromboembolic disease: the Seventh ACCP Conference on Antithrombotic and Thrombolytic Therapy. Chest 2004;126(3 Suppl):401S-428S.

20. Hirsh J, Fuster V. Guide to anticoagulant therapy. Part 2: Oral anticoagulants. American Heart. Circulation 1994;89:1469-1480.

21. Phillips KW, Ansell J. Outpatient management of oral vitamin K antagonist therapy: defining and measuring high-quality management. Expert Rev Cardiovasc Ther 2008;6:57-70.

22. Botticelli-Investigators, Büller H, Deitchman D, Prins M, Segers A. Efficacy and safety of the oral direct factor Xa inhibitor apixaban for symptomatic deep vein thrombosis. The Botticelli DVT dose-ranging study. J Thromb Haemost 2008;6:1313-1318. 
23. Schulman S, Kearon C, Kakkar AK, Mismetti P, Schellong S, Eriksson H, Baanstra D, Schnee J, Goldhaber SZ; RE-COVER Study Group. Dabigatran versus warfarin in the treatment of acute venous thromboembolism. N Engl J Med 2009;361:2342-2352.

24. Einstein Investigators, Bauersachs R, Berkowitz SD, Brenner B, Buller HR, Decousus $H$, Gallus AS, Lensing AW, Misselwitz F, Prins MH, Raskob GE, Segers A, Verhamme P, Wells $P$, Agnelli G, Bounameaux H, Cohen A, Davidson BL, Piovella F, Schellong S.. Oral rivaroxaban for symptomatic venous thromboembolism. N Engl J Med 2010;363:2499-2510.

25. Connolly SJ, Ezekowitz MD, Yusuf S, Eikelboom J, Oldgren J, Parekh A, Pogue J, Reilly PA, Themeles E, Varrone J, Wang S, Alings M, Xavier D, Zhu J, Diaz R, Lewis BS, Darius H, Diener HC, Joyner CD, Wallentin L; RE-LY Steering Committee and Investigators. Dabigatran versus warfarin in patients with atrial fibrillation. N Engl J Med 2009;361:1139-1151.

26. ROCKET-AF-Study-Investigators. Rivaroxaban-once daily, oral, direct factor Xa inhibition compared with vitamin $\mathrm{K}$ antagonism for prevention of stroke and Embolism Trial in Atrial Fibrillation: rationale and design of the ROCKET AF study. Am Heart J 2010;159:340-347 e1. 


\section{Part}

Diagnostics of Pulmonary Embolism in Primary Care 



\section{Chapter}

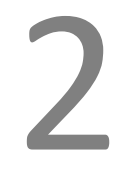

\section{Safe exclusion of pulmonary embolism using the Wells rule and D-dimer testing in primary care: a diagnostic validation study}

PMG Erkens*, GJ Geersing*, WAM Lucassen *, HR Büller, H ten Cate, AW Hoes, KGM Moons, MH Prins, R Oudega, HCPM van Weert, HEJH Stoffers

* These three authors contributed equally British Medical Journal 2012; 345: e6564 


\section{Abstract}

\section{Background}

For the primary care setting no clinical decision rule for the diagnosis pulmonary embolism (PE) is available. To validate the Wells PE-rule combined with D-dimer testing with the aim to safely exclude PE in primary care.

\section{Methods}

A prospective multicenter diagnostic validation study in primary care. We included 598 adult patients with suspected PE. After medical history and physical examination, primary care physicians scored the seven variables of the Wells PE-rule, and performed a point-of-care D-dimer test. All patients were referred to secondary care and diagnosed according to local protocols. PE was confirmed or refuted based on a composite reference standard, including spiral CT and 3 months of follow-up. The proportion of 'low-risk' patients (efficiency) and the number of missed PE cases in the low-risk category (failure rate) were calculated.

\section{Results}

PE was present in 73 patients (prevalence 12\%). Using a threshold score $\leq 4$ on the Wells PE rule and a negative point-of-care D-dimer test, 272 of these patients were classified as 'low-risk' (efficiency 45\%). In these patients 4 PE cases were observed (false negative rate $1.5 \%, 95 \% \mathrm{Cl} 0.4$ to 3.7 ). The sensitivity and specificity of this diagnostic approach were $94.5 \%(95 \% \mathrm{Cl} 86.6$ to 98.5$)$ and $51.0 \%(95 \% \mathrm{Cl} 46.7$ to 55.4).

\section{Conclusions}

Excluding PE using a Wells score $\leq 4$ combined with a negative qualitative or quantitative D-dimer test is safe and efficient when used in primary care. 


\section{Introduction}

For many physicians, patients with unexplained shortness of breath or pleuritic chest pain pose a diagnostic dilemma. In particular primary care physicians (PCPs) - who in many countries are the physicians whom patients consult first with these symptoms have to differentiate between the frequently occurring self-limiting diseases (e.g. myalgia or respiratory infections) and the more rare possibility of a life threatening disease such as pulmonary embolism (PE). As symptoms can be relatively mild, $P E$ is an easily missed diagnosis. ${ }^{1,2}$ When a PE diagnosis is initially missed, physicians do not always get a second chance due to its high mortality rate if left untreated. ${ }^{3}$ As a consequence, most physicians working in primary care have a low threshold for referral for further work-up of patients suspected of having PE. Consequently, PE is actually diagnosed in only $10-15 \%$ of referred patients. ${ }^{4}$

To stratify patients with suspected PE between "high probability" (need for referral) versus "low probability" of having PE clinical decision rules (CDRs) - combining different patient and disease characteristics into a score - have been developed. The CDR developed by Wells and colleagues is the most widely known, validated and implemented CDR for PE in secondary care (the 'Wells PE rule'; Table 2.1). This rule combines seven items into a score ranging from 0 to $12 \cdot 5$. Based on many previous studies in secondary care, a threshold was introduced at either $<2$ or $\leq 4$. ${ }^{5}$ Below these respective levels, patients are classified as being at 'very low-risk' or 'low-risk' of having $\mathrm{PE}$, respectively. A large diagnostic management study in secondary care concluded that a negative laboratory based quantitative D-dimer (degradation product of fibrin) test in patients with a Wells-score $\leq 4$ safely excluded PE without the need for additional work-up by imaging. ${ }^{6}$

Table 2.1 Items of the Wells PE Rule.

\begin{tabular}{lc}
\hline Variable & Points \\
\hline Clinical signs and symptoms of DVT (minimum of leg swelling and pain with palpation of the & 3.0 \\
deep veins) & 3.0 \\
PE more likely than an alternative diagnosis & 1.5 \\
Heart rate > 100/min & 1.5 \\
Immobilization (>3days) or surgery in the previous 4 weeks & 1.5 \\
Previous PE or DVT & 1.0 \\
Haemoptysis & 1.0 \\
Malignancy (receiving treatment, treated in the last 6 months or palliative)
\end{tabular}

DVT= deep vein thrombosis; $\mathrm{PE}=$ pulmonary embolism.

Such a diagnostic strategy seems ideal for primary care for decide on referral to secondary care, in particular since easy-to-use point-of-care D-dimer tests - providing results within minutes - are available for use at the office or in the patient's home. ${ }^{7}$ Yet, before implementing such a diagnostic strategy it must be validated in the proper 
setting, i.e. primary care. ${ }^{8,9}$ Due to differences in disease spectrum, symptomatology and physician experience, encouraging results from those in referral centers may not readily be applicable in primary care. ${ }^{10,11}$

Therefore, we performed a formal external validation study of the Wells PE rule combined with a point-of-care D-Dimer test, in primary care. The aim of this study was to evaluate the safety of excluding PE with the Wells PE rule (using both available thresholds; $\leq 4$ or $<2$ ), combined with a negative point-of-care D-dimer test. Also, we assessed the efficiency of such a PE rule-out strategy, in primary care.

\section{Methods}

\section{Study design and participants}

AMUSE-2 (the Amsterdam Maastricht Utrecht Study on thrombo-Embolism) was a prospective cohort study in primary care, evaluating a diagnostic strategy consisting of the Wells PE rule (see Table 2.1) and a point-of-care D-dimer test (Clearview Simplify, Inverness Medical, Bedford, UK). Patients were included during and outside of office hours by more than 300 primary care physicians across three different regions of the Netherlands (Amsterdam, Maastricht, and Utrecht).

Eligible for inclusion were consecutive adult patients ( $\geq 18$ years) with suspected PE, based on the presence of at least one of the following symptoms: unexplained (sudden) dyspnoea, deteriorating of existing dyspnoea, pain on inspiration, or unexplained cough. Patients were excluded from the study if they received anticoagulant treatment (i.e. vitamin $\mathrm{K}$ antagonists or heparin) at presentation, if they were pregnant, if follow-up was not possible or if patients were unwilling or unable to provide written informed consent.

Detailed instruction took place immediately before the start of the project. One of the researchers (GJG, PE, or WL) contacted all primary care physicians willing to cooperate with the study and explained the logistics, the use of study forms and the point-ofcare D-dimer test.

The study was executed between July 1, 2007 and December 31, 2010. The protocol was approved of by the medical ethical committee of the University Medical Center Utrecht, the Netherlands.

\section{Diagnostic strategy under study}

After written informed consent, the primary care physician documented information on the patient's history, physical examination and applied the Wells PE rule using a standard form. 
Subsequently the point-of care Simplify D-dimer test (Clearview, Inverness Medical, Bedford, UK) was performed. The Simplify D-dimer test is a qualitative test and is performed by mixing $35 \mu \mathrm{l}$ of capillary or venous blood with two drops of test reagent in a disposable device. ${ }^{7}$ A positive test result - occurring when the D-dimer level exceeds $80 \mathrm{ng} / \mathrm{ml}$ - is indicated by a pink-purple colored line. The test can be read at 10 minutes. Before the start of the project, all primary care physicians received a written hands-on instruction on how to perform the test.

Regardless of the outcome of the Wells PE rule and the point-of-care D-dimer test, primary care physicians were asked to refer all patients to secondary care for reference testing. In addition, to avoid interference with our aim to externally validate the Wells PE rule combined with point-of-care D-dimer testing, we explicitly provided no guidance on how to use the score (which score thresholds) to guide subsequent management. ${ }^{8,9}$ Hence, secondary care physicians were asked to perform the diagnostic procedures (at their own discretion based on local hospital guidelines), and independent of the results from the point-of-care D-dimer assay, or Wells PE rule as scored in primary care.

\section{Reference standard}

In secondary care, the diagnostic strategy was based on current guidelines and routine care protocols. In the Netherlands, this mostly is a combination of probability estimation and quantitative laboratory based D-dimer testing, followed by CT-scanning if indicated. Following most diagnostic studies in this field $d^{5,6,12,13}$ we used a composite reference standard of spiral CT-scanning, ventilation-perfusion (V/Q) scanning, pulmonary angiography, leg ultrasonography, and clinical probability assessment as done in secondary care (with or without D-dimer testing).

We retrieved medical information about the investigations done to establish or refute a diagnosis of $\mathrm{PE}$, including hospital discharge letters. In addition, all patients were followed up for 3 months. During these 3 months, primary care physicians were asked to document the occurrence of any potential (recurrent) venous thromboembolic events and bleeding complications associated with anticoagulant therapy (if given). Finally, an independent adjudication committee evaluated all patients with a diagnosis of PE despite a negative Wells PE rule and a negative point-of-care D-dimer test (see Table 2.2 for a full description of our reference standard strategy).

The primary outcome of the study was the presence of symptomatic venous thromboembolism (VTE), based on our composite reference standard, including the follow-up period of 3 months. 
Table 2.2 Composite reference standard used in AMUSE-2.

PE confirmed
Spiral CT scanning demonstrating central, or (sub)
segmental PE
Ventilation-perfusion scanning findings
demonstrating PE, in accordance with the PIOPED II
study protocol \#

Digital subtraction angiography demonstrating PE

Compression ultrasonography demonstrating proximal deep vein thrombosis in a patient with clinical symptoms and signs of PE
$P E$ refuted - no anticoagulant treatment Spiral CT scanning demonstrating no signs of PE, plus 3 months of uneventful follow-up in primary care

Ventilation-perfusion scanning findings without signs of PE, in accordance with the PIOPED II study protocol \#, plus 3 months of uneventful follow-up in primary care

Digital subtraction angiography without signs of $P E$, plus 3 months of uneventful follow-up in primary care

If no imaging test was performed in secondary care $¥$, PE was also considered refuted if uneventful follow-up of at least three months in primary care demonstrated no signs of acute venous thromboembolism \$

Wells-PE rule $\leq 4$ AND negative quantitative $D$-dimer test, but with a VTE event during 3 months of followup in primary care

Wells-PE rule $\leq 4$ AND negative quantitative $D$-dimer test, and 3 months of uneventful follow-up in primary care

$\$$ Patients received follow-up in primary care; follow-up was considered uneventful if a patient was not diagnosed with acute PE or deep vein thrombosis during 3 months of follow-up; ¥ For example because of a low clinical probability assessment plus a negative D-dimer test as performed in secondary care, or because after referral an alternative diagnosis was found that completely explained the symptoms of an included patient (at the discretion of the attending physician); \# Sostman, H.D., et al., Acute pulmonary embolism: sensitivity and specificity of ventilation-perfusion scintigraphy in PIOPED I/ study. Radiology, 2008;246:941946.

\section{Statistical analysis}

All statistical analyses were performed using the Statistical Package for the Social Sciences Software (PASW version 17; SPSS, IBM, Somers, NY, USA).

We quantified the safety and efficiency of ruling out PE based on a 'low risk score' by our diagnostic strategy. Patients at 'low-risk' were initially defined by a Wells PE rule score of $\leq 4$ and a negative point-of-care D-dimer test. The 'Failure Rate' was defined as the proportion of patients with a missed symptomatic and proven VTE during 3 months follow-up in those patients who were initially classified by the strategy to be at 'low-risk for PE', including a 95\% confidence interval (using Fischer's exact test). In contrast to therapeutic or intervention studies, formal sample size calculations based on power assumptions for diagnostic (or prognostic) modeling cohort studies do not exist, and are seldom considered. However, for single dichotomous tests, such calculations can be done for the expected positive or negative predictive values or their complements (false positive or false negative proportion, respectively). ${ }^{14}$ To obtain some insight a-priori what number of patients and thus physicians had to be included, we considered the original continuous Wells rule plus D-dimer test result as one overall single test and dichotomized its result. We focused clearly on the 
exclusion of PE with a minimum of missed of PE cases (false negative proportion or failure rate). Based on various previous studies performed in secondary care (notably the Christopher study ${ }^{6}$ ), we assumed that the point estimate of this failure rate would be around $0.5 \%$. We subsequently used this estimate to calculate the number of patients for our study ${ }^{14}$, where we selected a stringent upper limit of the confidence interval of this estimate at $2.0 \%$, even though previous studies addressed higher upper limits (4\%). ${ }^{5,15}$ Accordingly, expecting a PE failure rate of $0.5 \%$ and being able to exclude a percentage of (maximally) 2.0\% PE cases, and using a type I error of 0.05 (one sided, since any value below $0.5 \%$ is desired) and type 2 error of 0.2 , about 335 patients with a low-risk of PE needed to be included.

Next, we calculated the efficiency of the ability to exclude PE using the Wells PE rule. Efficiency was defined as the proportion of patients at 'low-risk for PE' among all study patients. Subsequently, we similarly estimated the failure rate and efficiency, using a Wells threshold score of $<2$ plus a negative point-of-care D-dimer assay (i.e. the 'very low-risk' patients).

In addition to the failure rate and efficiency, we calculated the conventional diagnostic accuracy measures (sensitivity, specificity and predictive values) for the different thresholds on the Wells PE-rule, in combination with point-of-care D-dimer testing.

Missing values on items of the Wells PE rule or point-of-care Simplify D-dimer results were observed in 24 patients $(4.0 \%$ for missing values on any of the Wells PE rule items or point-of-care D-dimer test; range $0.5 \%$ for heart rate $>100$ beats per minute to $2.7 \%$ for results of the point-of-care D-dimer test). To minimize the effect of the bias associated with selectively "ignoring" these 24 patients, we imputed these missing values using multiple imputation techniques. Imputation techniques are based on the correlation between each variable with missing values and all other variables as estimated from the set of complete subjects, using all available observed data. ${ }^{16,17}$

\section{Role of the funding source}

The Netherlands Heart Foundation funded the study (NHS-2006B237). GlaxoSmithKline and Inverness Medical co-funded the study with unrestricted research grants. All funding sources had no role in the design, conduct, analyses or reporting of the study or in the decision to submit the manuscript for publication.

\section{Results}

\section{Participants}

We prospectively collected data on 662 patients suspected of PE by their primary care physician (Figure 2.1). In 64 patients one or more of the pre-defined exclusion criteria 
were met: 28 patients used vitamin $\mathrm{K}$ antagonists or low-molecular weight heparin at the time of inclusion, 15 patients were pregnant, 3 patients were below 18 years of age, and in 18 patients follow-up was not possible (due to logistic reasons). Therefore, our study population consisted of 598 patients. Mean age was 48 years, and $71 \%$ were females.

PE was diagnosed in 68 patients, directly after referral, and in an additional 5 patients either PE or DVT was diagnosed during 3 months of follow-up (1 DVT and 4 PE, no fatal events). Hence, a total number of 73 patients (12.2\%) were diagnosed with VTE. Table 2.3 details the patient characteristics.

Table 2.3 Characteristics of all study participants $(n=598)$.

\begin{tabular}{|c|c|}
\hline Characteristic & Value \\
\hline \multicolumn{2}{|l|}{ Age - years } \\
\hline Mean \pm SD & 48 years \pm 16 \\
\hline Range & 18-91 years \\
\hline Females - no. (\%) & $425(71.0 \%)$ \\
\hline Diagnosis of VTE $\$-$ no. (\%) & $73(12.2 \%)$ \\
\hline Unexplained sudden onset dyspnoea - no. (\%) & $329(55.0 \%)$ \\
\hline Pain on inspiration - no. (\%) & $465(77.8 \%)$ \\
\hline Unexplained cough - no. (\%) & $188(31.4 \%)$ \\
\hline Signs and symptoms suggestive for DVT - no. (\%) & $57(9.5 \%)$ \\
\hline PE most likely diagnosis - no. (\%) & $333(55.7 \%)$ \\
\hline Heart rate $>100$ bpm - no. (\%) & $111(18.6 \%)$ \\
\hline Immobilisation or surgery - no. (\%) & $94(15.7 \%)$ \\
\hline Previous DVT or PE - no. (\%) & $84(14.0 \%)$ \\
\hline Haemoptysis - no. (\%) & $21(3.5 \%)$ \\
\hline Active malignancy - no. (\%) & $26(4.3 \%)$ \\
\hline \multicolumn{2}{|l|}{ Wells PE rule } \\
\hline Score $\geq 2-$ no. (\%) & $361(60.4 \%)$ \\
\hline Score >4 - no. (\%) & $176(29.4 \%)$ \\
\hline Simplify point-of care D-dimer positive - no. (\%) & $220(36.8 \%)$ \\
\hline
\end{tabular}

$\mathrm{SD}=$ standard deviation; $\mathrm{PE}=$ pulmonary embolism; $\mathrm{DVT}=$ deep vein thrombosis; $\mathrm{VTE}=$ venous thromboembolism. \$VTE composite reference standard, including 3 months of follow-up.

\section{Results of the Wells PE rule}

In 422 patients the score was $\leq 4$, and in 237 patients the score was $<2$. In these patients, 21 (5.0\%; 95\% $\mathrm{Cl} 3.1-7.5)$ and 7 (3.0\%; 95\%Cl 1.2-6.0) VTE events were observed, respectively. In patients with a score $>4$ on the Wells PE rule, 52 (29.5\%; 95\% Cl 22.9-36.9) VTE events were noted. (Figure 2.1) 


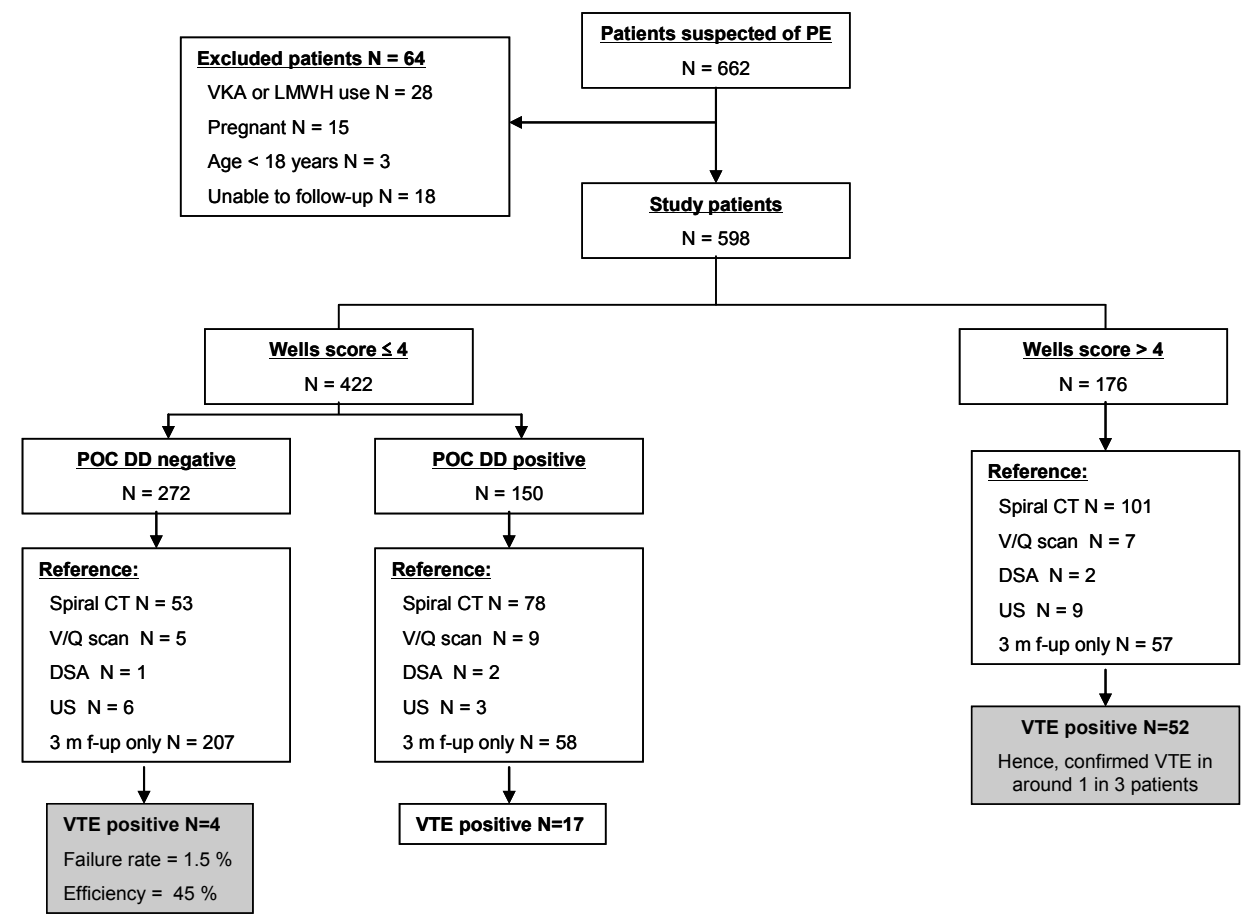

Figure 2.1 Flowchart of all study patients.

$\mathrm{PE}=$ pulmonary embolism; $\mathrm{VKA}=$ vitamin $\mathrm{K}$ antagonist; $\mathrm{LMWH}=$ low-molecular weight heparin; $\mathrm{CT}=$ computed tomography; $\mathrm{V} / \mathrm{Q}=$ ventilation perfusion; $\mathrm{DSA}=$ digital substraction angio-

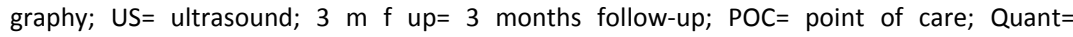
quantitative; $\mathrm{DD}=$ dimer; $\mathrm{VTE}=$ venous thrombo-embolism.

\section{Combining the Wells PE rule with D-dimer testing}

Uninterpretable (Clearview Simplify) point-of-care D-dimer test results occurred in 39 patients (6.5\% of all patients). According to the study protocol, these tests were evaluated as positive test results in all analyses.

If a Wells threshold at $\leq 4$ was combined with a negative point-of-care D-dimer test, $4 / 272$ patients in this low-risk category were diagnosed with PE: failure rate $1.5 \%$ (95\% Cl 0.4-3.7; Table 2.4). The efficiency of this strategy was $45 \%$ (272/598). The sensitivity and specificity of Wells $\leq 4$ combined with a negative Simplify D-dimer test were $94.5 \%(95 \% \mathrm{Cl} 86.6-98.5)$ and $51.0 \%$ (95\% Cl 46.7-55.4) respectively. In 168 patients with a score $<2$ on the Wells PE rule, the point-of-care D-dimer test was also negative. In these 'very low-risk' patients, 2 cases of PE were observed, yielding a failure rate of $1.2 \%(95 \% \mathrm{Cl} 0.1-4.2)$ and an efficiency of $28 \%(168 / 598)$. The sensitivity and specificity of this strategy were $97.3 \%(95 \% \mathrm{Cl} 90.5-99.7)$ and $31.6 \%$ (95\% Cl 27.7-35.8) respectively. See Table 2.4 . 
Table 2.4 Diagnostic parameters of the Wells rule with a qualitative POC or a quantitative D-dimer test in primary care

\begin{tabular}{lcc}
\hline Parameter \% $(95 \% \mathrm{Cl})$ & $\begin{array}{c}\text { Simplify POC D-dimer test } \\
\text { Wells } \leq 4\end{array}$ & $\begin{array}{c}\text { Simplify POC D-dimer test } \\
\text { Wells <2 }\end{array}$ \\
\hline Efficiency $\$$ & $45.5 \%(41.4-49.6)$ & $28.1 \%(24.5-31.9)$ \\
Failure rate $¥$ & $1.5 \%(0.4-3.7)$ & $1.2 \%(0.1-4.2)$ \\
Sensitivity & $94.5 \%(86.6-98.5)$ & $97.3 \%(90.5-99.7)$ \\
Specificity & $51.0 \%(46.7-55.4)$ & $31.6 \%(27.7-35.8)$ \\
PPV & $21.2 \%(16.9-26.0)$ & $19.8 \%(15.8-24.3)$ \\
NPV & $98.5 \%(96.3-99.6)$ & $98.8 \%(95.8-99.9)$ \\
\hline
\end{tabular}

$\mathrm{POC}=$ point-of-care; $\mathrm{DD}=\mathrm{D}$-dimer $\mathrm{Cl}=$ confidence interval; $\mathrm{PPV}=$ positive predictive value; $\mathrm{NPV}=$ negative predictive value; $\$$ Efficiency is defined as the proportion of all study patients in whom PE was excluded based on Wells below various cut-off values and a negative D-Dimer test; $¥$ The PE failure rate is defined as the proportion of patients in whom PE was excluded based on Wells below various cut-off values and a negative D-Dimer test, with symptomatic and proven VTE during 3 months follow-up

\section{Low-risk patients with PE}

Four patients classified as 'low-risk' (Wells score $\leq 4$ and a negative point-of-care D-dimer) were diagnosed with PE. These cases are described in more detail in Table 2.5. They were adjudicated by an independent adjudication committee at the end of the study. The committee concluded that in one case (patient \#3 in Table 2.5) a diagnosis of PE was questionable. In this patient, doubt was based upon a reevaluation of the spiral CT scan images, which were non-conclusive due to an inadequate amount of contrast. Reanalyzing our results with this patient as not having PE yielded a lower failure rate: the PE failure rate became $1.1 \%(95 \% \mathrm{Cl} 0.2-3.2)$ and $0.6 \%(95 \% \mathrm{Cl} 0.0-3.3)$ for the thresholds of $\leq 4$ and $<2$ on the Wells PE rule, respectively.

Table 2.5 Detailed description of 5 patients classified as 'low-risk' (Wells PE rule score $\leq 4$ and a negative - either qualitative point-of-care or quantitative - D-dimer test) but diagnosed as PE.

\begin{tabular}{|c|c|c|c|}
\hline Patient \# & Description & POC DD & PE diagnosed by \\
\hline$\# 1$ & $\begin{array}{l}\mathrm{F}, 63 \text { years. Acute onset of pain on inspiration, but no } \\
\text { shortness of breath. Wells } \mathrm{PE} \text { rule }{ }^{*}=0 \text { points }\end{array}$ & Uninterpretable $¥$ & $\begin{array}{l}\text { Spiral CT, directly } \\
\text { after referral. }\end{array}$ \\
\hline$\# 2$ & $\begin{array}{l}\text { M, } 75 \text { years. Acute onset of pain on inspiration, no } \\
\text { shortness of breath. Wells PE rule* }=1.5 \text { points (prior VTE). }\end{array}$ & Negative & $\begin{array}{l}\text { Spiral CT, directly } \\
\text { after referral. }\end{array}$ \\
\hline \# 3 & $\begin{array}{l}\mathrm{F}, 25 \text { years. Acute onset of pain on inspiration and } \\
\text { shortness of breath. Patient used oral contraceptives. } \\
\text { Wells PE rule* }=0 \text { points }\end{array}$ & Negative & $\begin{array}{l}\text { Spiral CT, directly } \\
\text { after referral. }\end{array}$ \\
\hline \# 4 & $\begin{array}{l}\mathrm{F}, 80 \text { years. Subacute progressive shortness of breath, } \\
\text { after a flight trip. Wells PE rule* }=3 \text { points (prior VTE and } \\
\text { immobilisation). }\end{array}$ & Negative & $\begin{array}{l}\text { Spiral CT, directly } \\
\text { after referral. }\end{array}$ \\
\hline \# 5 & $\begin{array}{l}\mathrm{F}, 30 \text { years. Acute onset of pain on inspiration, but no } \\
\text { shortness of breath. Patient used oral contraceptives. } \\
\text { Wells PE rule* }=3 \text { points (PE most likely diagnosis). }\end{array}$ & Negative & $\begin{array}{l}\text { Spiral CT, directly } \\
\text { after referral. }\end{array}$ \\
\hline
\end{tabular}

$\mathrm{POC}=$ point-of-care; $\mathrm{DD}=\mathrm{D}$-dimer; $\mathrm{VTE}=$ venous thrombo-embolism; $\mathrm{PE}=$ pulmonary embolism; $\mathrm{CT}=$ computed tomography, $\mathrm{M}=$ male, $\mathrm{F}=$ female, * Wells-PE-rule as scored by primary care physician, \#= number, $¥$ Uninterpretable Simplify results were analyzed as a positive test result. 


\section{Discussion}

The present study validated the Wells PE rule combined with a qualitative point-ofcare D-dimer test in 598 patients suspected of PE in a primary care setting. Using this strategy $45 \%$ of these patients were classified as being at 'low-risk for PE', based on a threshold score $\leq 4$ on the Wells PE rule and a negative point-of-care D-dimer test. In these patients a proportion of $1.5 \%$ PE cases was observed. In addition, lowering the threshold of the Wells PE rule to $<2$ combined with qualitative point-of-care D-dimer testing yielded an even lower failure rate (1.2\%), but at the cost of a lower efficiency (28\%). These results are in accordance with studies performed in secondary care, as documented in a recent meta-analysis on the performance of several clinical decision rules, including the Wells PE rule combined with a qualitative and quantitative D-dimer test. ${ }^{18}$

\section{Strengths and limitations}

This is the first study to validate the Wells PE rule in a primary care setting, in a large population of almost 600 patients with suspected PE. Yet, for full appreciation of the observed results some aspects require comments.

First, the reference standard of PE consisted of various combinations of laboratory and imaging procedures - including 3 months of follow-up - to diagnose or refute a case of PE - this is differential verification bias. Although primary care physicians were asked to refer all patients to secondary care regardless of the result of point-of-care D-dimer assay or the score of the Wells PE rule - secondary care physicians were not explicitly blinded to these results obtained in primary care. Consequently, differential verification was (at least partly) dependent upon our index test under study: patients with a low score on the Wells PE rule and a negative D-dimer test more often did not undergo imaging tests for PE. Although such a combined reference approach is common in the field of diagnostic studies in PE, differential verification could lead to an over optimistic estimate of the PE failure rate. ${ }^{19}$ For example, in patients with a low score on the Wells PE rule and a negative D-dimer test smaller, subsegmental, PE could be missed if these patients only received follow-up as a reference. However, missing such subsegmental PE is less relevant from a clinical perspective. ${ }^{20}$

Moreover, our study followed common clinical practice from both academic and nonacademic hospitals in many parts of the world, increasing the generalizability of our results.

Second, in 57 patients no initial imaging to diagnose or refute acute PE was performed in secondary care - despite a high Wells score and despite the fact that both national and international guidelines recommend to do so. Rather, these patients were followed-up in primary care. All final diagnoses made in these patients are summarized in Table 2.6. During follow-up, in 2 of these patients VTE was diagnosed: both with confirmed DVT shortly after referral (Wells score in primary care 6.0 in both 
patients). Although we do not know all results of the Wells score and D-dimer testing in secondary care, a reason for not subjecting the referred high risk patients to imaging could be a discrepancy in the clinical probability assessment between the primary care physician and the hospital. This discrepancy may be explained by differences in scoring the subjective item of the Wells rule "PE more likely than an alternative diagnosis" and differences in the result of the primary care point-of-care D-dimer test used in our study and the quantitative D-dimer tests used in secondary care.

Third, an independent adjudication committee re-evaluated all 4 patients that were "missed" by a low score on the Wells PE rule $(\leq 4$ or $<2)$ in combination with a negative point-of-care D-dimer assay. They concluded that in 1 case a diagnosis of PE was questionable. Reanalyzing this patient as not having PE would result in an - albeit small - decrease of the PE failure rates. As in reality this patient was treated with anticoagulants based on the presumed diagnosis of $P E$, we chose to analyze this patient as having PE for the main analyses, yielding the failure rates as presented in Figure 2.1 and Table 2.4. However, possibly, our results can be even more optimistic than the presented failure rates of Figure 2.1 and Table 2.4

Table 2.6 Final diagnoses made in 57 patients where no initial imaging was performed, despite a high Wells score (see also Figure 2.1).

\begin{tabular}{lc}
\hline Final diagnosis & $\mathrm{n}$ \\
\hline Myalgia or thoracic chest pain & 26 \\
Pneumonia or respiratory tract infection & 16 \\
Thoracic trauma & 2 \\
Heart failure & 2 \\
Acute coronary syndrome & 1 \\
Pericarditis & 1 \\
Exacerbation COPD & 1 \\
Panic disorder & 1 \\
Obesity (Pickwick syndrome) & 1 \\
Diabetic ketoacidosis & 1 \\
Sarcoidosis & 1 \\
Airway obstruction & 1 \\
Unknown & 1 \\
Venous thrombo-embolism during follow-up \# & 1 \\
\end{tabular}

\# both patients diagnosed with DVT shortly after referral

Fourth, results of the point-of-care Simplify D-dimer were uninterpretable in 39 patients $(6.5 \%$ of all study patients). This indicates that, although point-of-care D-dimer testing can be easily performed in a primary care domain, interpretation of a result for this qualitative assay can sometimes be difficult. In a meta-analysis on pointof-care D-dimer testing, it was shown that this difficulty in reading a test result for an older qualitative point-of-care D-dimer assay (SimpliRED D-dimer assay) resulted in much heterogeneity in the pooled analysis for this assay. ${ }^{7}$ As a consequence, most 
experts agree that this older SimpliRED D-dimer assay should no longer be recommended for use in daily clinical practice. Theoretically, the same problem could arise in the future for the qualitative Simplify D-dimer assay as more studies become available for this assay. However, in the present study, the results of most Simplify D-dimer tests were easily interpreted. In addition - as we did in all our analyses - we believe a solution for this difficulty in reading some of the Simplify D-dimer tests is to classify uninterpretable results as "positive". This effectively prevents missing a PE diagnosis because of uninterpretable Simplify D-dimer test results, and is only needed in a small minority of all tested patients.

Finally, at the end of our inclusion phase we were confronted with a gradual decline in inclusion rates. We were able to include 272 low-risk patients, $81 \%$ of our predefined sample size. The expected number of PE cases was a bit higher than expected and thus the confidence limits were wider as well. Accordingly, while the point estimate of our failure rate $(1.5 \%)$ was lower than $2.0 \%$, the confidence interval did cross the predefined $2.0 \%$ limit. However, as described above, there are no formal methods for power calculations of model validation studies and, moreover, there is much discussion among clinicians on what proportion is still acceptable as upper limit.

Where many previous studies addressed an upper limit of $4 \%$ being still acceptable $e^{5,15}$, we were conservative in our a-priori sample size considerations by setting it at $2.0 \%$. It was based on the aim of the original derivation study of the Wells PE rule, which was to determine a score that is able to designate PE unlikely such that a negative D-dimer in these patients would result in a rate (i.e. point estimate) of PE close to $2.0 \% "{ }^{5}$ In this original derivation study their PE failure rate was $2.2 \%$ with a $95 \%$ confidence interval of $1 \%$ to $4 \%$. In addition, in the PIOPED II study on the diagnostic accuracy of spiral CT-scanning in suspected PE, the failure rate was $1.7 \%$ with a $95 \%$ confidence interval of $0.7 \%$ to $3.9 \% .{ }^{15}$ Our results are in line with these previous studies. Increasing the number of included patients would (very likely) not change our point estimate of the failure rate but only narrow the confidence interval. Considering all above aspects and the undefined acceptable proportions - as applies to most diagnostic contexts - we believed that including more patients would not lead to different inferences about the rule's benefits in primary care.

\section{Clinical implications}

$P E$ is a potentially life threatening disease. At the same time, its diagnosis is difficult as signs and symptoms can be relatively mild. In our previous study on excluding deep vein thrombosis with a clinical decision rule and D-dimer testing ${ }^{21}$, many participating physicians asked whether a similar approach would be possible for suspected PE. The present validation study indeed demonstrated that such an approach would also be feasible for PE in primary care: a Wells score $\leq 4$ combined with a qualitative point-ofcare D-dimer test ruled out PE in 4-5 out of 10 patients, with a failure rate of less than $2 \%$, that is considered safe by most published consensus statements. ${ }^{5,15}$ Such a PE 
rule-out strategy makes it possible for primary care physicians to safely exclude PE in a large proportion of suspected patients during the consultation of the patient, thereby reducing costs and patient burden (e.g. contrast nephropathy with spiral CT scanning) that are associated with an unnecessary referral to secondary care.

\section{Conclusion}

Excluding PE using a Wells score $\leq 4$ combined with a negative qualitative D-dimer test, is safe whereas using a threshold $<2$ is even safer. Future studies, in which patient management is actually guided by the Wells PE rule and point-of-care D-dimer testing, are indicated to evaluate the feasibility of such an approach in reducing costs and patient burden. 


\section{References}

1. Meyer G, Roy PM, Gilberg S, Perrier A. Pulmonary embolism. BMJ 2010; 340:c1421.

2. Schiff GD, Hasan O, Kim S, Abrams R, Cosby K, Lambert BL et al. Diagnostic error in medicine: analysis of 583 physician-reported errors. Arch Intern Med 2009;169:1881-1887.

3. Chunilal SD, Eikelboom JW, Attia J, Miniati M, Panju AA, Simel DL et al. Does this patient have pulmonary embolism? JAMA 2003;290:2849-2858.

4. Le Gal G., Bounameaux H. Diagnosing pulmonary embolism: running after the decreasing prevalence of cases among suspected patients. J Thromb Haemost 2004;2:1244-1246.

5. Wells PS, Anderson DR, Rodger M, Ginsberg JS, Kearon C, Gent M et al. Derivation of a simple clinical model to categorize patients probability of pulmonary embolism: increasing the models utility with the SimpliRED D-dimer. Thromb Haemost 2000;83:416-420.

6. van Belle A., Büller HR, Huisman MV, Huisman PM, Kaasjager K, Kamphuisen PW et al. Effectiveness of managing suspected pulmonary embolism using an algorithm combining clinical probability, D-dimer testing, and computed tomography. JAMA 2006;295:172-179.

7. Geersing GJ, Janssen KJ, Oudega R, Bax L, Hoes AW, Reitsma JB et al. Excluding venous thromboembolism using point of care D-dimer tests in outpatients: a diagnostic meta-analysis. BMJ 2009;339:b2990.

8. Altman DG, Vergouwe $\mathrm{Y}$, Royston $\mathrm{P}$, Moons KG. Prognosis and prognostic research: validating a prognostic model. BMJ 2009;338:b605.

9. Reilly BM, Evans AT. Translating clinical research into clinical practice: impact of using prediction rules to make decisions. Ann Intern Med 2006;144:201-209.

10. Knottnerus JA. Between iatrotropic stimulus and interiatric referral: the domain of primary care research. J Clin Epidemiol 2002;55:1201-1206.

11. Oudega R, Hoes AW, Moons KG. The Wells rule does not adequately rule out deep venous thrombosis in primary care patients. Ann Intern Med 2005;143:100-107.

12. Kline JA, Courtney DM, Kabrhel C, Moore CL, Smithline HA, Plewa MC et al. Prospective multicenter evaluation of the pulmonary embolism rule-out criteria. J Thromb Haemost 2008;6:772-780.

13. Klok FA, Kruisman E, Spaan J, Nijkeuter M, Righini M, Aujesky D et al. Comparison of the revised Geneva score with the Wells rule for assessing clinical probability of pulmonary embolism. J Thromb Haemost 2008;6:40-44.

14. Simel DL, Samsa GP, Matchar DB. Likelihood ratios with confidence: sample size estimation for diagnostic test studies. J Clin Epidemiol 1991;44:763-770.

15. Perrier A, Roy PM, Sanchez O, Le GG, Meyer G, Gourdier AL et al. Multidetector-row computed tomography in suspected pulmonary embolism. N Engl J Med 2005;352:1760-1768.

16. Janssen KJ, Vergouwe $\mathrm{Y}$, Donders AR, Harrell FE, Jr., Chen Q, Grobbee DE et al. Dealing with missing predictor values when applying clinical prediction models. Clin Chem 2009;55:994-1001.

17. Rubin DB, Schenker N. Multiple imputation in health-care databases: an overview and some applications. Stat Med 1991;10:585-598.

18. Lucassen W, Geersing GJ, Erkens PM, Reitsma JB, Moons KG, Büller H et al. Clinical decision rules for excluding pulmonary embolism: a meta-analysis. Ann Intern Med 2011;155:448-460.

19. Whiting P, Rutjes AW, Reitsma JB, Glas AS, Bossuyt PM, Kleijnen J. Sources of variation and bias in studies of diagnostic accuracy: a systematic review. Ann Intern Med 2004;140:189-202.

20. Carrier M, Righini M, Wells PS, Perrier A, Anderson DR, Rodger MA et al. Subsegmental pulmonary embolism diagnosed by computed tomography: incidence and clinical implications. A systematic review and meta-analysis of the management outcome studies. J Thromb Haemost 2010;8: 1716-1722.

21. Büller HR, Ten Cate-Hoek AJ, Hoes AW, Joore MA, Moons KG, Oudega R et al. Safely ruling out deep venous thrombosis in primary care. Ann Intern Med 2009;150:229-235. 



\section{Chapter}

\section{Alternative diagnoses of pulmonary embolism \\ in primary care}

PMG Erkens, WAM Lucassen, GJ Geersing, HCPM van Weert, M Kuijs, $M$ van Heugten, L Rietjens, $\mathrm{H}$ ten Cate, MH Prins, HR Büller, AW Hoes, KGM Moons,

R Oudega, HEJH Stoffers 


\section{Abstract}

\section{Introduction}

Pulmonary Embolism (PE) often presents with non-specific symptoms and is a frequently missed diagnosis. A list of alternative diagnoses of PE might help the primary care physician when his differential diagnosis includes PE. This study aims to report the most common alternative diagnoses in patients in whom the primary care physician suspected PE. Additionally, we investigate whether the Wells rule combined with a point-of-care D-dimer test not only may exclude PE but also other serious diagnoses.

\section{Methods}

This study is a secondary analysis of the Amsterdam Maastricht Utrecht study on thromboembolism that validated the use of the Wells clinical decision rule for PE combined with point-of-care D-Dimer testing in patients suspected of PE in primary care. After medical history and physical examination, all patients were referred to secondary care and diagnosed according to local hospital protocols. Patients were followed-up for 3 months.

\section{Results}

The most frequent alternative diagnoses after excluding PE $(n=516)$ were: nonspecific thoracic pain / dyspnoea (42.6\%), pneumonia (13.0\%), myalgia (11.8\%), asthma/COPD $(4.8 \%)$, panic disorder/hyperventilation $(4.1 \%)$ and respiratory tract infection $(2.3 \%)$. Patients with a Wells score of $>4$ or a positive D-Dimer test were significantly more often diagnosed with a clinically serious disease that needs immediate medical treatment.

\section{Conclusion}

In primary care patients suspected of $\mathrm{PE}$, the most common alternative diagnoses besides PE were thoracic pain/dyspnoea e.c.i., pneumonia and myalgia. A low probability of $\mathrm{PE}$ according the Wells rule and point-of-care D-dimer testing may also help to exclude other serious diseases than PE. 


\section{Introduction}

Pulmonary embolism (PE) often presents with non-specific mild symptoms and is a frequently missed but potentially life-threatening diagnosis. In patients presenting with sudden unexplained (or deterioration of existing) dyspnoea, pain on inspiration and/or unexplained cough symptoms primary care physicians have to differentiate between frequently occurring clinically less serious diseases such as myalgia and more rare serious diseases such as PE and pneumonia. Several clinical decision rules to exclude PE have been proposed and validated. ${ }^{1}$ One of the most validated and used clinical decision rule is the Wells rule. ${ }^{2}$ The Amsterdam Maastricht Utrecht Study on thrombo-embolism (Amuse-2) recently showed the safety of the use of the Wells clinical decision rule for PE combined with D-dimer testing in primary care. ${ }^{3}$

The Wells rule combines 7 items into a score to calculate the pretest probability of PE. (Table 3.1) The rule includes the attending physician's judgment of whether an alternative diagnosis is less or more likely than PE. The subjective character of this specific criterion and its moderate reproducibility is the main point of criticism to the Wells rule. ${ }^{4}$ However, clinical judgment has been shown to improve the accuracy of clinical decision rules for PE. ${ }^{5}$ Furthermore, Klok et al. showed that the subjective criterion has a high predictive value in comparison to the other variables of the Wells rule. $^{6} \mathrm{~A}$ list of alternative diagnoses of PE might thus help physicians in judging this subjective criterion and in judging the probability of PE in suspected patients.

Bagattini et al. investigated common alternative diagnoses of PE in secondary care. They found that the most frequent discharge diagnoses in emergency ward patients in whom PE was ruled out were nonspecific chest pain, bronchopneumonia, and heart failure. ${ }^{7}$ Alternative diagnoses of PE as seen in primary care, however, have not been investigated yet. In this secondary analysis of the Amuse-2 study we aim to report the most common alternative diagnoses in patients in whom the primary care physician suspected PE. Additionally, we investigated whether the Wells rule combined with a point-of-care D-dimer test may not only exclude PE but also other serious diagnoses.

Table 3.1 Wells clinical decision rule for pulmonary embolism.

\begin{tabular}{lc}
\hline Variable & Points \\
\hline Clinical signs and symptoms of DVT (minimum of leg swelling and pain with & 3.0 \\
palpation of the deep veins) & 3.0 \\
PE more likely than an alternative diagnosis & 1.5 \\
Heart rate $>100 / \mathrm{min}$ & 1.5 \\
Immobilization (>3days) or surgery in the previous 4 weeks & 1.5 \\
Previous PE or DVT & 1.0 \\
Haemoptysis & 1.0 \\
Malignancy (receiving treatment, treated in the last 6 months or palliative) & \\
\hline
\end{tabular}

DVT= deep vein thrombosis; $\mathrm{PE}=$ pulmonary embolism. 


\section{Methods}

\section{Study design and population}

This study is a preplanned sub-analysis of the Amuse- 2 data: a prospective cohortstudy evaluating the safety of the diagnostic strategy of the Wells PE rule and a pointof-care D-dimer test in ruling out PE in primary care patients in the Netherlands between July 2007 and December 2010. , $^{2}$ We enrolled patients suspected of PE. Suspicion of PE was based on the presence of at least one of the following symptoms: unexplained (sudden) dyspnoea, deterioration of existing dyspnoea, pain on inspiration, or unexplained cough.

\section{Data collection}

After written informed consent, the primary care physician documented information on the patient's history and physical examination and applied the Wells PE rule using a standard form. Subsequently the point-of care Simplify D-dimer test (Clearview, Inverness Medical, Bedford, UK) was performed. Primary care physicians were asked to refer all patients to secondary care for further diagnostic work-up regardless of the outcome of the Wells rule and the point-of-care D-dimer test. In secondary care, the diagnostic strategy was based on current guidelines and routine care protocols. We retrieved medical information, including hospital discharge letters, about the investigations done to establish the diagnosis. In addition, all patients were followed up for 3 months. After these 3 months, primary care physicians were asked to document the final diagnosis of each patient by completing a case record form. The primary care physician could choose one or more of the following predefined diagnoses: PE, deep vein thrombosis (DVT), pneumonia, (exacerbation of) chronic obstructive pulmonary disease (COPD), coronary insufficiency, aneurysm aortae, trauma thorax, malignancy, pneumothorax, myalgia, panic disorder, nonspecific thoracic pain / dyspnoea or other. When 'other' was chosen, the primary care physician was asked to write down the patient's final diagnosis. No criteria for the clinical diagnoses were provided. If more than one final diagnosis was reported, the main diagnosis explaining the signs and symptoms which originally resulted in $\mathrm{PE}$ suspicion was included in the current analyses.

\section{Outcomes}

The primary outcome of this sub-study is the prevalence of each alternative diagnosis after excluding PE in primary care patients suspected of PE. In order to analyze the association between the clinical probability for PE (as assessed by Wells-score and result of D-dimer test) and the type or severity of the final diagnosis, we divided the alternative diagnoses in two categories: 
1) Clinical serious diseases, leading to immediate medical treatment including pneumonia, pneumothorax, pleuritis, pericarditis, atelectasis, aneurysm aortae thoracalis, heart failure, asthma / COPD, respiratory tract infection, endocarditis, atrial fibrillation and lung cancer,

2) Clinical less serious diseases, not leading to any treatment other than supportive care (e.g. pain-killing in case or musculoskeletal pain) including nonspecific thoracic pain / dyspnoea, myalgia and panic disorder / hyperventilation.

At least two investigators assessed the 3-months follow-up forms completed by the primary care physician and hospital discharge letters before assigning patients to one of the two above described categories. In case of disagreement a third investigator was involved and disagreements were resolved by discussion. ${ }^{8}$

\section{Statistical analysis}

Statistical analyses were performed by using IBM Statistical Package for the Social Sciences software (version 19; SPSS; Chicago, IL, USA).

Descriptive statistics were used to describe the baseline characteristics and to report the prevalence of the alternative diagnoses. Corresponding ninety-five percent confidence intervals $(95 \% \mathrm{Cl})$ were calculated for each alternative diagnosis by using Fisher's exact test. In order to investigate the association between the probability of $P E$ and type or severity of the alternative diagnosis, we performed subgroup analyses for patients with a Wells score $>4$ or a positive point-of-care D-Dimer test and patients with a Wells score of $\leq 4$ and a negative point-of-care D-Dimer test. A threshold of 4 was introduced based on previous studies showing a high efficiency and safety at this cut-off point. ${ }^{2,3}$ Odds ratios (OR) and corresponding $95 \% \mathrm{Cl}$ for the alternative diagnoses by probability of PE were calculated by Mantel-Haenszel common odds ratio.

Missing values on items of the Wells PE rule or point-of-care Simplify D-dimer test results were observed in 24 patients. Missing data was not completely at random and therefore deletion of the subjects with missing values would not only lead to a loss of statistical power but also to biased results. ${ }^{9}$ To minimize the effect of selective missing, we imputed missing values using multiple imputation techniques. Imputation techniques are based on the correlation between each variable with missing values and all other variables as estimated from the set of complete subjects. ${ }^{10,11}$

\section{Results}

Over a three-year period, primary care physicians collected data of 662 patients suspected of PE. One or more of the predefined exclusion criteria were met in 64 patients, leaving 598 patients. VTE was present in 73 patients (prevalence 12.2\%). Since a clear final diagnosis was missing in 9 (1.5\%) patients, a total of 516 patients in 
whom PE was excluded were included in the analyses of the current study. One hundred and forty-nine patients (29\%) were classified as having a clinically serious disease and 367 patients (71\%) as having a clinically less serious disease. (Figure 3.1)

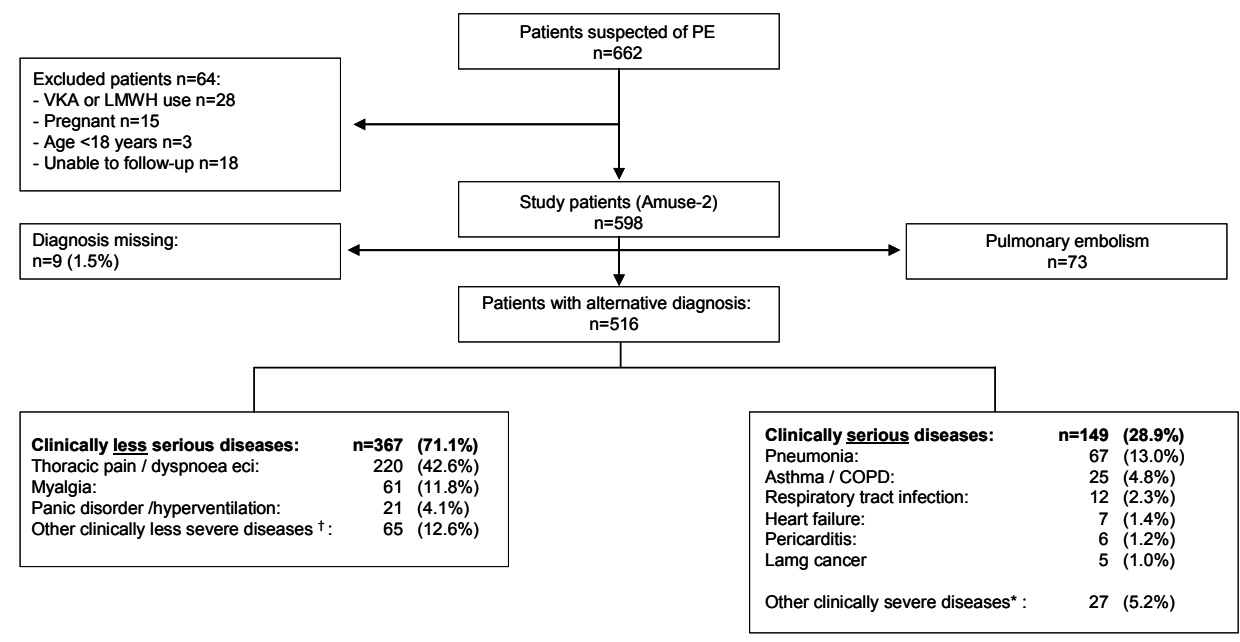

Figure 3.1 Flow chart study population.

$\mathrm{PE}=$ Pulmonary Embolism; VKA= Vitamin $\mathrm{K}$ Antagonist; LMWH= Low Molecular Weight Heparin; COPD= Chronic Obstructive Pulmonary Disease.

* other clinically severe diseases: coronary insufficiency $(n=3)$, atrial fibrillation $(n=3)$, pleuritis $(n=3)$, pneumothorax $(n=2)$, atelectasis $(n=2)$, rib fracture $(n=2)$, obstructive sleep apnoea syndrome $(n=2)$, multiple myeloma $(n=1)$, metastatic colon carcinoma $(n=1)$, endocarditis $(n=1)$, lymphadenopathy eci $(n=1)$, urosepsis diabetes $(n=1)$, diabetes mellitus de novo $(n=1)$, sarcoidosis $(n=1)$, acute aortic dissection $(n=1)$, systemic lupus erythematosus $(n=1)$, Langerhans cell histiocytosis $(n=1){ }^{\dagger}{ }^{\dagger}$ other clinically less severe diseases: other diagnoses (e.g. bronchial hyperactivity, collaps eci, trauma thorax, influenza, sinusitis) made by a PCP or hospital physician not leading to any treatment other than supportive care (e.g. painkilling).

Baseline characteristics of both groups are shown in Table 3.2. The mean age was 47 years and $72 \%$ was female. Patients with a clinically less serious disease were younger than patients with a clinically serious disease. Patients diagnosed with a serious disease were more likely to have presented with an unexplained sudden onset of dyspnoea, unexplained cough, a heart rate of more than 100 beats per minute and haemoptysis. Furthermore, patients with a clinically serious disease were more likely to have a Wells risk score of more than 4 points or a positive point-of-care D-Dimer test than patients with a less serious disease. (Table 3.2) 
Table 3.2 Baseline characteristics of the study population.

\begin{tabular}{|c|c|c|c|}
\hline \multirow[b]{2}{*}{ Baseline characteristics: } & \multicolumn{3}{|c|}{ Alternative final diagnoses } \\
\hline & $\begin{array}{c}\text { Clinically serious } \\
\text { disease } \\
n=149\end{array}$ & $\begin{array}{c}\text { Clinically less } \\
\text { serious disease } \\
n=367\end{array}$ & $\begin{array}{c}\text { OR } \\
(95 \% \mathrm{Cl})\end{array}$ \\
\hline \multicolumn{4}{|l|}{ Demographics } \\
\hline \multicolumn{4}{|l|}{ Age - years } \\
\hline mean \pm SD & $52 \pm 16$ & $45 \pm 16$ & - \\
\hline range & $18-88$ & $17-91$ & - \\
\hline Females - no. (\%) & $99(66.4 \%)$ & $270(73.6 \%)$ & - \\
\hline \multicolumn{4}{|l|}{ Signs and symptoms } \\
\hline Unexplained sudden onset dyspnoea - no. (\%) & $94(63.1 \%)$ & $189(51.5 \%)$ & $1.6(1.1-2.4)$ \\
\hline Pain on inspiration - no. (\%) & $116(77.9 \%)$ & $294(80.1 \%)$ & $0.9(0.5-1.4)$ \\
\hline Unexplained cough - no. (\%) & $63(42.3 \%)$ & $98(26.7 \%)$ & $2.0(1.3-3.0)$ \\
\hline \multicolumn{4}{|l|}{ Wells CDR for PE } \\
\hline Signs and symptoms suggestive for DVT - no. (\%) & $11(7.4 \%)$ & $18(4.9 \%)$ & $1.5(0.7-3.4)$ \\
\hline PE most likely diagnosis - no. (\%) & $88(59.1 \%)$ & $179(48.8 \%)$ & $1.5(1.0-2.2)$ \\
\hline Heart rate $>100$ bpm - no. (\%) & $51(34.2 \%)$ & $34(9.3 \%)$ & $5.1(3.1-8.3)$ \\
\hline Immobilisation or surgery - no. (\%) & $20(13.4 \%)$ & $50(13.6 \%)$ & $1.0(0.6-1.7)$ \\
\hline Previous DVT or PE - no. (\%) & $9(6.0 \%)$ & $56(15.3 \%)$ & $0.4(0.2-0.7)$ \\
\hline Haemoptysis - no. (\%) & $9(6.0 \%)$ & $7(1.9 \%)$ & $3.3(1.2-9.0)$ \\
\hline Active malignancy - no. (\%) & $7(4.7 \%)$ & $13(3.5 \%)$ & $1.3(0.5-3.4)$ \\
\hline Wells PE rule score $>4-$ no. (\%) & $44(29.5 \%)$ & $78(21.3 \%)$ & $1.6(1.0-2.4)$ \\
\hline Simplify point-of-care D-Dimer positive - no. (\%) & $64(43.0 \%)$ & $100(27.2 \%)$ & $2.0(1.4-3.0)$ \\
\hline
\end{tabular}

$\mathrm{OR}=$ odds ratio; $\mathrm{Cl}=$ confidence interval; $\mathrm{SD}=$ standard deviation; $\mathrm{CDR}=$ clinical decision rule; $\mathrm{PE}=$ pulmonary embolism; DVT= deep vein thrombosis; bpm= beats per minute.

\section{Common alternative diagnoses}

The most common alternative diagnoses after excluding PE were thoracic pain / dyspnoea e.c.i. (42.6\%), pneumonia (13.0\%), myalgia (11.8\%), asthma/COPD (4.8\%), panic disorder/hyperventilation (4.1\%), respiratory tract infection (2.3\%), heart failure $(1.4 \%)$, pericarditis $(1.2 \%)$ and lung cancer (1.0\%). Other less frequent clinically severe diagnoses were coronary insufficiency, atrial fibrillation, pleuritis, pneumothorax, atelectasis, rib fracture, obstructive sleep opnoea sundrome, multiple myeloma, metastatic colon carcinoma, endocarditis, lymphadenopatihy e.c.i., diabetes mellitus de novo, urosepsis in a patient with diabetes mellitus, sarcoidosis, acute aortic dissection, systemic lupus erythematosus and Langerhans cell histiocytosis. Other diagnoses in the group of clinically less severe diseases were bronchial hyperreactivity, collaps e.c.i., trauma thorax, influenza, sinusitis and other diagnoses made by a PCP or hospital physician not leading to any treatment other than supportive care, e.g. painkilling. (Figure 3.1) 


\section{Alternative diagnoses by probability for PE}

There was a significant association between probability for PE and severity of the alternative diagnoses, $p=0.001$. This seems to represent that patients with a Wells score of $>4$ or a positive point-of-care D-Dimer test were 1.9 (95\% Cl 1.3-2.9) times more likely to have a clinical severe disease leading to medical treatment than patients with a Wells score of $\leq 4$ and a negative point-of-care D-Dimer test. Mainly pneumonia was strongly associated with a high risk class (OR 2.6; 95\% Cl 1.5-4.5, $p=0.001$ ). No difference was seen in the prevalence of respiratory tract infection between high risk and low risk patients. Patients with a high probability of PE seemed to be diagnosed $70 \%$ less often (OR $0.3 ; 95 \% \mathrm{Cl} 0.2-0.5)$ with a clinically less severe disease than patients with a low probability. (Table 3.3)

Table 3.3 Odds Ratios for alternative diagnoses by probability for pulmonary embolism.

\begin{tabular}{|c|c|c|c|}
\hline & $\begin{array}{c}\text { High probability: } \\
\text { Wells }>4 \text { or positive } \\
\text { D-dimer } \\
n=254 \\
n(\% ; 95 \% \mathrm{Cl})\end{array}$ & $\begin{array}{c}\text { Low probability: } \\
\text { Wells } \leq 4 \text { and negative } \\
\text { D-dimer } \\
n=262 \\
n(\% ; 95 \% \mathrm{Cl})\end{array}$ & $\begin{array}{c}\text { OR (95\% Cl; } \\
\text { p-value) }\end{array}$ \\
\hline Clinically less serious diagnoses & $161(63.4 \% ; 57.1-69.3)$ & $206(78.6 \% ; 73.2-83.4)$ & $0.5(0.3-0.7)$ \\
\hline Nonspecific thoracic pain / dyspnoea & 97 (38.2\%; 32.2-44.5) & $123(46.9 \% ; 40.8-53.2)$ & $0.7(0.5-1.0)$ \\
\hline Myalgia & $23(9.1 \% ; 5.8-13.3)$ & 38 (14.5\%; 10.5-19.4) & $0.6(0.3-1.0)$ \\
\hline Panic disorder / hyperventilation & $8(3.1 \% ; 1.4-6.1)$ & $13(5.0 \% ; 2.7-8.3)$ & $0.6(0.3-1.5)$ \\
\hline Other clinical less serious diagnosis* & 33 (13.0\%; 9.1-17.8) & 32 (12.2\%; 8.5-16.8) & $1.1(0.6-1.8)$ \\
\hline Clinically serious diagnoses & 93 (36.6\%; 30.7-42.9) & 56 (21.4\%; 16.6-26.8) & $2.1(1.4-3.1)$ \\
\hline Pneumonia & 47 (18.5\%; 13.9-23.8) & $20(7.6 \% ; 4.7-11.5)$ & $2.7(1.6-4.8)$ \\
\hline Asthma / COPD & $10(3.9 \% ; 1.9-7.1)$ & 15 (5.7\%; 3.2-9.3) & $0.7(0.3-1.5)$ \\
\hline Respiratory tract infection & $6(2.4 \% ; 0.9-5.1)$ & $6(2.3 \% ; 0.8-4.9)$ & $1.0(0.3-3.2)$ \\
\hline Other clinical serious diagnosis $^{+}$ & $30(32.3 \% ; 22.9-42.8)$ & $15(16.1 \% ; 9.3-25.2)$ & $2.2(1.2-4.2)$ \\
\hline
\end{tabular}

$\mathrm{COPD}=$ chronic obstructive pulmonary disease; $\mathrm{Cl}=$ confidence interval. " adjusted for age. * other clinical less severe diagnoses: other diagnoses (e.g. bronchial hyperactivity, collaps eci, trauma thorax, influenza, sinusitis) made by a PCP or hospital physician not leading to any treatment other than supportive care (e.g. painkilling). ${ }^{\dagger}$ other clinical severe diagnoses: coronary insufficiency $(n=3)$, atrial fibrillation $(n=3)$, pleuritis $(n=3)$, pneumothorax $(n=2)$, atelectasis $(n=2)$, rib fracture $(n=2)$, obstructive sleep apnoea syndrome $(n=2)$, multiple myeloma $(n=1)$, metastatic colon carcinoma $(n=1)$, endocarditis $(n=1)$, lymphadenopathy eci $(n=1)$, urosepsis diabetes $(n=1)$, diabetes mellitus de novo $(n=1)$, sarcoidosis $(n=1)$, acute aortic dissection $(n=1)$, systemic lupus erythematosus ( $n=1)$, Langerhans cell histiocytosis $(n=1)$.

\section{Discussion}

\section{Main findings}

In this analysis of a large prospective study performed in primary care including patients suspected of $\mathrm{PE}$, we found that the most common alternative diagnoses of $\mathrm{PE}$ were thoracic pain / dyspnoe e.ci., myalgia and pneumonia. To our knowledge, this is 
one of the first studies presenting alternative diagnoses of PE in suspected primary care patients and our results correspond to reported alternative diagnoses in secondary care in the literature. ${ }^{7}$

Furthermore, we showed that high risk patients, with either a positive Wells-rule or positive D-dimer test, in whom the diagnosis of PE was excluded, were more often diagnosed with clinically serious diseases than low risk patients. More than $60 \%$ of the patients with a clinically serious disease had a Wells score of $>4$ or a positive D-Dimer test.

\section{Interpretation}

Our results are consistent with previously published studies showing a high proportion of patients with clinically serious diseases in patients with a high clinical probability of PE. ${ }^{12,13}$ The association in our study between risk class and severity of the final diagnosis may be partly explained by high D-dimer levels. It is known from literature that pneumonia ${ }^{14}$, malignancy ${ }^{12,15}$, coronary syndromes ${ }^{16,17}$ and heart failure ${ }^{18}$ is associated with high D-dimer levels. This corresponds with our finding of an increased proportion of having pneumonia in patients with a positive D-Dimer test result. Unfortunately, a significant association between D-dimer and malignancy, heart failure or coronary syndrome could not be noted due to the small number of patients in the subgroups resulting in large $95 \% \mathrm{Cl}$. Additional to D-Dimer, also the items 'heart rate $>100$ beats per minute' and 'haemoptysis' of the Wells clinical decision rule have contributed to the association between the probability for PE and severity of the alternative diagnosis. From these results we may conclude that a low Wells score and negative D-dimer test not only exclude $\mathrm{PE}$, but also reduces the probability of other clinically serious diseases for which patients need to be referred to the hospital. This emphasizes the usefulness of the diagnostic strategy of the Wells rule combined with point-of-care D-dimer testing in primary care.

\section{Limitations}

Some limitations of this study have to be mentioned. First, although we asked primary care physicians to refer all patients to secondary care, $17 \%$ of the patients were not sent to the hospital for further diagnostic work-up. No referral to secondary care usually means less systematic diagnostic work-up. This may have resulted in an underreporting of less clinically serious diagnoses in those patients without referral and thus selection bias can not be excluded. Nevertheless, all patients were followedup in primary care for three months and the reported final diagnosis according to the primary care physician for these patients was included in the present analysis. For $1.5 \%$ of the patients no alternative diagnosis was reported. All these patients had a follow-up without VTE. 
Second, in $30 \%$ of the patients without a confirmed PE but with a clinically serious alternative diagnosis, it was not clear if objective testing was performed to confirm these diagnoses. In these patients the presence of the alternative diagnoses may thus be mainly based on clinical features. Since this also occurs in daily clinical primary care, we think that our study is still a good representation of daily practice.

Third, the original study was designed to validate the diagnostic strategy of excluding $\mathrm{PE}$ in primary care by using the Wells clinical decision rule for PE and point-of-care D-dimer testing. Therefore, potentially important characteristics of the alternative diagnoses may not have been recorded. Hence, we were not able to identify risk factors and predictors for the alternative diagnoses. This deserves more attention in future studies.

\section{Conclusion}

In conclusion, we found that the most common alternative diagnoses, besides PE, in primary care patients suspected of PE were nonspecific thoracic pain / dyspnoea, pneumonia and myalgia. Furthermore, we found that a low probability of PE may not only exclude PE but also other serious diseases. Otherwise, patients with a high probability of PE but without PE, often have a clinically serious diagnosis that needs medical treatment. This emphasizes the usefulness of the Wells rule and D-dimer point-of-care testing in the differentiation between high and low risk patients for clinically serious diseases in primary care patients suspected of PE. Although approximately $80 \%$ of the primary care patients with a high probability of PE will be not diagnosed with $\mathrm{PE}$, referral to secondary care seems still warranted to diagnose and treat potential other clinical serious diseases. 


\section{References}

1. Lucassen W, Geersing GJ, Erkens PM, Reitsma JB, Moons KG, Büller H, van Weert HC. Clinical decision rules for excluding pulmonary embolism: a meta-analysis. Ann Intern Med 2011;155:448-460.

2. Wells PS, Anderson DR, Rodger M, Ginsberg JS, Kearon C, Gent M, Turpie AG, Bormanis J, Weitz J, Chamberlain M, Bowie D, Barnes D, Hirsh J. Derivation of a simple clinical model to categorize patients probability of pulmonary embolism: increasing the models utility with the SimpliRED Ddimer. Thromb Haemost 2000;83:416-420.

3. Geersing GJ, Erkens PM, Lucassen WA, Büller HR, Cate HT, Hoes AW, Moons KG, Prins MH, Oudega R, van Weert HC, Stoffers HE. Safe exclusion of pulmonary embolism using the Wells rule and D-dimer testing in primary care. BMJ. 2012;345:e6564.

4. Leclercq MG, Kruip MJ, Mac Gillavry MR, Van Marwijk Kooy M, Büller HR. Observer variability in the assessment of clinical probability in patients with suspected pulmonary embolism. J Thromb Haemost 2004;2:1204-1206.

5. Chagnon I, Bounameaux H, Aujesky D, Roy PM, Gourdier AL, Cornuz J, Perneger T, Perrier A. Comparison of two clinical prediction rules and implicit assessment among patients with suspected pulmonary embolism. Am J Med 113: 269-275.

6. Klok FA, Karami Djurabi R, Nijkeuter M, Huisman MV. Alternative diagnosis other than pulmonary embolism as a subjective variable in the Wells clinical decision rule: not so bad after all. J Thromb Haemost 2007;5: 1079-1080.

7. Bagattini SB, Bounameaux H, Perneger T, Perrier A. Suspicion of pulmonary embolism in outpatients: nonspecific chest pain is the most frequent alternative diagnosis. J Intern Med 2004;256: 153-160.

8. Lucassen W, Kuijs-Augustijn M, Erkens P, Geersing G, Büller $H$, et al.. The additional value of the CRPtest in patients in whom the primary care physician excluded pulmonary embolism. Eur J General Practice. Submitted.

9. Donders AR, van der Heijden GJ, Stijnen T, Moons KG. Review: a gentle introduction to imputation of missing values. J Clin Epidemiol 2006;59:1087-1091.

10. Janssen KJ, Vergouwe Y, Donders AR, Harrell FE Jr, Chen Q, Grobbee DE, Moons KG. Dealing with missing predictor values when applying clinical prediction models. Clin Chem 2009;55:994-1001.

11. Rubin DB, Schenker N. Multiple imputation in health-care databases: an overview and some applications. Stat Med 1991;10:585-598.

12. Douma RA, van Sluis GL, Kamphuisen PW, Söhne M, Leebeek FW, Bossuyt PM, Büller HR. Clinical decision rule and D-dimer have lower clinical utility to exclude pulmonary embolism in cancer patients. Explanations and potential ameliorations. Thromb Haemost 2010;104:831-836.

13. Sohne M, Kruip MJ, Nijkeuter M, Tick L, Kwakkel H, Halkes SJ, Huisman MV, Buller HR; Christoper Study Group. Accuracy of clinical decision rule, D-dimer and spiral computed tomography in patients with malignancy, previous venous thromboembolism, COPD or heart failure and in older patients with suspected pulmonary embolism. J Thromb Haemost 2006;4:1042-1046.

14. Querol-Ribelles JM, Tenias JM, Grau E, Querol-Borras JM, Climent JL, Gomez E, Martinez I. Plasma ddimer levels correlate with outcomes in patients with community-acquired pneumonia. Chest 2004;126: 1087-1092.

15. Righini M, Le Gal G, De Lucia S, Roy PM, Meyer G, Aujesky D, Bounameaux H, Perrier A. Clinical usefulness of D-dimer testing in cancer patients with suspected pulmonary embolism. Thromb Haemost 2006;95:715-719.

16. Bayes-Genis A, Mateo J, Santaló M, Oliver A, Guindo J, Badimon L, Martínez-Rubio A, Fontcuberta J, Schwartz RS, De Luna AB. D-Dimer is an early diagnostic marker of coronary ischemia in patients with chest pain. Am Heart J 2000;140:379-384.

17. Morrow DA, Braunwald E. Future of biomarkers in acute coronary syndromes: moving toward a multimarker strategy. Circulation 2003;108:250-252.

18. Chung I, Choudhury A, Lip GY. Platelet activation in acute, decompensated congestive heart failure. Thromb Res 2007;120:709-713. 



\section{Chapter 4}

Clinical decision rules for excluding pulmonary embolism: a meta-analysis

WAM Lucassen, GJ Geersing, PMG Erkens, JB Reitsma, KGM Moons, HR Büller, HCPM van Weert

Annals of Internal Medicine 2011;155:448-460 


\section{Abstract}

\section{Background}

Clinical probability assessment combined with D-dimer testing is used to exclude pulmonary embolism (PE). To compare test-characteristics of gestalt (physicians' unstructured estimate) and clinical decision rules for evaluating adults with suspected pulmonary embolism and to assess failure-rate (missed cases) when used in combination with D-dimer testing.

\section{Methods}

We searched Medline and Embase for articles in English, French, German, Italian, Spanish and Dutch, published between 1966 and June 2011. Three reviewers operating in pairs of two selected prospective studies conducted in consecutive patients suspected of PE. Studies provided PE-probability estimate using gestalt or decision rule as compared to an appropriate reference standard. We extracted data on study characteristics, test performance and prevalence, constructed $2 * 2$-tables and assessed methodological quality.

\section{Results}

Fifty-two studies, including 55268 patients were selected. Meta-analysis was performed on studies investigating gestalt ( $n=15$; sensitivity $0.85 /$ specificity 0.51 ), Wells-rule at cut-off $<2$ ( $n=19 ; 0.84 / 0.58)$, Wells-rule at cut-off $\leq 4$ ( $n=11 ; 0.60 / 0.80)$, Geneva-rule $(n=5 ; 0.84 / 0.50)$ and revised Geneva-rule $(n=4 ; 0.91 / 0.37)$. Increasing prevalence of PE was associated with higher sensitivity and lower specificity. Combining a decision rule or gestalt with a D-dimer test seemed safe for all strategies except for combining the less sensitive Wells4 with the less sensitive qualitative Ddimer.

\section{Conclusions}

Combined with sensitive D-dimer tests all rules and gestalt are safe to exclude PE .We advocate physicians to use a standardized rule because of the lower specificity of gestalt. The choice of rule and D-dimer test must be different for physicians working in different settings. 


\section{Introduction}

Pulmonary embolism (PE) has an estimated annual incidence of 2-3 cases per 1000 persons and has a high fatality rate if left untreated. ${ }^{1} \mathrm{~A}$ major problem in diagnosing $P E$ is that signs and symptoms are often non-specific and the vast majority of suspected patients does not have PE. ${ }^{2}$ Every day a wide variety of doctors - such as primary care physicians, pulmonologists, internists, surgeons and emergency physicians - are facing the diagnostic dilemma of not missing PE while avoiding expensive and possible harmful diagnostic procedures like multi-detector computerised tomography-scanning. Diagnostic strategies in patients suspected of PE initially focus on identifying patients in whom PE can be ruled out. ${ }^{3}$ In these strategies the first step is to assess clinical probability using either empirical clinical assessment ('gestalt') or a standardized clinical decision rule. The most widely used clinical decision rule is the Wells rule which includes the physician's judgment of whether PE is more likely than an alternative diagnosis. This criterion however is subjective. New rules, such as the Geneva-, Pisa-, Charlotte- and PERC-rules, containing only objective items were developed. (see appendix I for a full description of rules) Only if clinical probability is low an additional D-dimer test is performed. If clinical probability is not low the patient is referred for additional pulmonary vascular imaging without performing D-dimer testing. ${ }^{4}$ Both quantitative and qualitative D-dimer tests are used. Quantitative tests are more sensitive but less specific than qualitative tests. ${ }^{5}$ Qualitative tests can be used as a point-of-care test.

Because dispute about the relative merits of gestalt and different rules remained, we performed a systematic review and meta-analysis to compare the sensitivity and specificity of gestalt and different clinical decision rules, using the novel bivariate analysis approach. ${ }^{6}$ Moreover we assessed the failure-rate and efficiency of gestalt and rules when used in combination with a D-dimer test. We focussed on their role as a triage tool to exclude PE without referral for imaging tests.

\section{Methods}

\section{Data sources and searches}

We performed a systematic search to identify studies using gestalt or a decision rule in assessing clinical probability of PE. We searched Medline and Embase for articles in English, French, German, Italian, Spanish and Dutch, published between 1966 and June 2011.

Key-words were: pulmonary embolism, epidemiologic research design, epidemiologic studies, predictive value of tests, probability, sensitivity and specificity (the full search strategy is available at www.annals.org). Finally, we examined reference lists of selected articles. 


\section{Study selection}

To be eligible for inclusion, studies had to fulfil the following criteria:

1. Study population consisted of consecutive patients (age $\geq 16$ years) with symptoms or signs suspected by a physician to be caused by acute pulmonary embolism (PE).

2. Original, prospectively collected data.

3. Containing an estimate of the clinical probability of PE using gestalt or a clinical decision rule. Gestalt was defined as a physicians' unstructured clinical probability estimate after collecting routine-data (data from patient history, physical examination with or without basic laboratory tests, electrocardiography or a chest $x$-ray). A clinical decision rule had to be based on a multivariable logistic regression model and had to provide a structured estimate of the probability of PE.

4. Assessment of clinical probability was performed blinded to the results of a Ddimer test or any pulmonary vascular imaging.

5. Studies that derived a clinical decision rule should have included a sufficient number of patients with confirmed pulmonary embolism $(n>50)$ to ensure a minimum level of accuracy of the derived rule. ${ }^{7}$

6. Diagnosis of pulmonary embolism was confirmed by an appropriate (composite) reference standard (such as ventilation-perfusion lung scanning, computerised tomography, pulmonary angiography or autopsy). Diagnosis of deep venous thrombosis as surrogate for the diagnosis of PE was also accepted. ${ }^{8}$ In case the diagnosis was refuted without pulmonary imaging (for example in patients with a negative D-dimer test result) we required a clinical follow-up period of at least 45 days.

7. Allowing construction of a $2 * 2$ table from which we could extract the number of patients with a true-positive-, false-positive-, true-negative- and false-negative test result.

8. To be included in the meta-analysis of rule and gestalt in combination with D-dimer testing we required that D-dimer testing was performed in all patients with low-probability assessment.

Three reviewers operating in pairs of two identified potentially eligible articles. They participated equally. Any disagreements were resolved by discussion between the reviewers.

\section{Data extraction and quality assessment}

Three reviewers operating in pairs of two extracted independently studycharacteristics from each included study including: mean (or median) age of patients, proportion outpatients, prevalence of PE (including follow-up period) and type of verification (full description of study-characteristics is available at www.annals.org). If information on any of these predefined characteristics was missing in the original 
publication, authors were contacted to provide these data. To construct $2 * 2$ tables, PE-probability assessment had to be dichotomized. In studies not reporting dichotomized data, we dichotomized by taking the lowest probability-category (Wells $<2$, Geneva $<5$, revised Geneva $<4$, simplified revised Geneva $\leq 1$, Pisa $\leq 10 \%$, (see appendix I) versus the other probability categories. Between studies using gestalt the cut-off score for the lowest probability category varied between $<10 \%$ and $<40 \%$.

Finally, based on the constructed $2 * 2$ tables, the number of true-positives, falsepositives, true-negatives and false-negatives were extracted from each study.

The methodological quality of the selected studies was assessed independently by three reviewers operating in pairs of two using the Quadas instrument. ${ }^{9}$ The instrument includes 14 quality items, which are all scored as "Yes" (indicating absence of bias), "No" (risk of bias present), or "Unclear". All discrepancies were resolved by discussion between the three reviewers.

\section{Data synthesis and analysis}

\section{Meta-analysis of data from gestalt and rules alone}

Based on the number of true-positives, false-positives, true-negatives and falsenegatives sensitivity and specificity together with $95 \%$ confidence intervals $(95 \% \mathrm{Cl})$ were calculated (Wilson's method) and presented in forest plots.

The bivariate model for diagnostic meta-analysis was used to obtain summary estimates of sensitivity and specificity. ${ }^{6,10}$ The bivariate approach simultaneously models pairs of (logit transformed) sensitivity and specificity from studies, thereby incorporating any correlation that might exist between sensitivity and specificity. The model uses a random effects approach for both sensitivity and specificity, allowing for heterogeneity beyond chance due to clinical and methodological differences between studies. We analyzed data from different rules within a single model in order to obtain summary estimates of sensitivity and specificity for each rule and to subsequently test whether these summary values were significantly different from each other. This model was fitted allowing the between-study variation in sensitivity and specificity to be different across rules. For a rule to be included in the meta-analysis we required a minimum of four studies to account for inter-study variability and assure a reliable assessment of summary estimates of sensitivity and specificity using the bivariate approach.

We extended the basic bivariate model with study-level covariates to assess the impact of bias caused by specific design and patient population characteristics on sensitivity, specificity or both. Three study characteristics, this is type of study (derivation-study: a study for developing the rule or management-study: a study in which the rule was actually used in clinical practice), type of verification method and prevalence, were examined. 
This combination of tests is used as a diagnostic strategy to exclude PE. Studies therefore address the question whether it is safe to exclude PE and send patients home without anticoagulant treatment when the rule shows low probability and the D-dimer test is negative.

As these studies aim to evaluate a diagnostic strategy, rather than the characteristics of a specific test, failure rate is the outcome measure used in such studies. ${ }^{4}$ Failure rate is defined as the proportion of patients with symptomatic and confirmed venous thrombo-embolism during follow-up divided by the total number of patients with negative test results on both rule and D-dimer test ('missed cases') We used a random-effects model to combine these logit transformed proportions to estimate the overall failure rate for each combination of gestalt or decision rule with D-dimer. Covariates were added to the model to examine whether summary failure rates were different depending on the type of rule or type of D-dimer test used. We considered a strategy using clinical probability assessment in combination with a D-dimer test to exclude PE safe if the failure rate was below $2 \%$ with a maximum upper confidence limit of $2.7 \%$ (being the upper confidence limit of the three-month thrombo-embolic rate of patients suspected of PE but with a normal pulmonary angiography). ${ }^{11}$ Another outcome measure that is relevant is the efficiency of the diagnostic strategy. Efficiency is expressed as the number of patients that receive a negative test result on both the rule and the D-dimer test among all included patients ('successful avoidance of imaging').This is also a proportion and was analysed in the same manner as the failure rate. SAS 9.1, in particular the non-linear mixed models procedure (PROC NLMIXED), was used in the analyses.

\section{Role of funding source}

The study was funded by the Dutch Heart Foundation. The funder played no role in question formulation, searches and data collection, data interpretation, manuscript preparation or approval of the manuscript for publication.

\section{Results}

\section{Study selection}

The search yielded 14642 citations and 313 studies were retrieved for detailed reading of which 52 studies met our inclusion criteria. 


\section{Study characteristics}

Included studies were all published in English between 1990 and 2011. In 52 studies 55268 patients (median 753, range 77-8138) were included. PE was diagnosed in 8987 patients (overall prevalence $16 \%$, range $4-44 \%$ ). The mean age of included patients ranged from 45-72 years (full description of study-characteristics of included studies is availabe at www.annals.org).

\section{Index tests (clinical decision rules) under study}

Five different clinical decision rules were identified: the Wells rules (Wells2 (cutoff $<2$ ), Wells4 (cut-off $\leq 4)^{12}$ and the simplified Wells rule ${ }^{13}$, the Geneva rules (original $^{14}{ }^{\text {, revised }}{ }^{15}$ and simplified revised ${ }^{16}$ ), the Pisa-rules (original ${ }^{17}$ and revised $^{18}$ ), the Charlotte rule $^{19}$ and the PERC-rule (Pulmonary Embolism Rule-out Criteria). ${ }^{20}$ (Appendix I of this thesis). The Geneva-rule (original) and Pisa-rules use additional diagnostics (electrocardiography, chest x-ray); the other rules all use clinical data only.

\section{Quality assessment}

All studies used the appropriate cross-sectional study design and collected data prospectively. Differential disease verification as potential source of bias was present in $63 \%$ of the studies. This means, for example, that patients with a positive clinical decision rule underwent pulmonary vascular imaging as reference test, whereas patients with a negative decision rule and a negative D-dimer test did not undergo this reference test but only received follow-up. In addition uninterpretable test results were not always reported (37\%).

\section{Results of individual studies}

Figures 4.1 and 4.2 show the forest plots of sensitivity and specificity of individual studies. Results varied considerably both between and within rules. The confidenceintervals for specificity were substantially smaller than for sensitivity due to the larger numbers of patients not having PE. The low sensitivity of the Charlotte-studies and the high sensitivity of the Pisa-studies was striking. Outliers were (partly) explained by cut-off differences. For example, Perrier $2005^{21}$ (Geneva-rule), Righini ${ }^{22}$ (revised Geneva), Parent ${ }^{23}$ (gestalt) and Elias ${ }^{24}$ (gestalt) used high cut-off levels. Accordingly, fewer patients were classified as false-positives but more patients as false-negatives, leading to higher specificities and lower sensitivities respectively.

The forest-plot for specificity clearly shows the lower specificity of gestalt-studies (with a low cut-off) and PERC-studies versus the studies using other decision rules. 


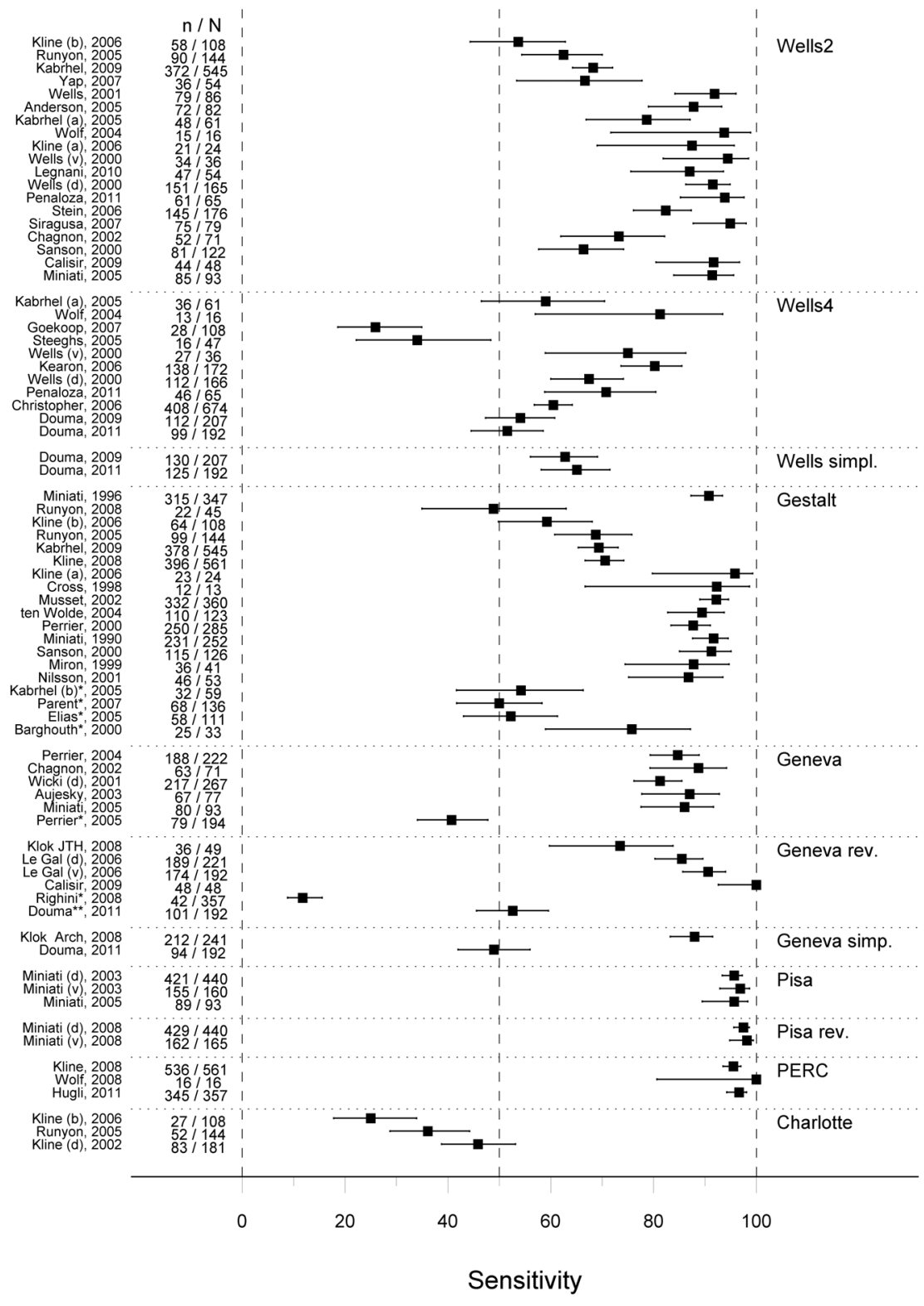

Figure 4.1 Forest plot of sensitivity of gestalt and different decision rules. Studies ordered from low to high prevalence of pulmonary embolism, and by type. $\mathrm{n} / \mathrm{N}=$ proportion of patients with pulmonary embolism $(\mathrm{N})$ who have a positive test $(\mathrm{n})$. Wells $2=$ Wells with cut-off $<2$, Wells $4=$ Wells with cut-off $\leq 4$, Wells simpl.=Wells simplified,Geneva rev.= revised Geneva with trichotomized cut-off, Geneva simp.=revised Geneva simplified, Pisa rev.= Pisa revised, PERC=Pulmonary Embolism Rule-out Criteria, (d): derivation-study, (v) validation-study, (a,b) author published two studies in same year, * study with high-cut-off excluded from metaanalysis, ${ }^{* *}$ study with revised Geneva dichotomized cut-off. 


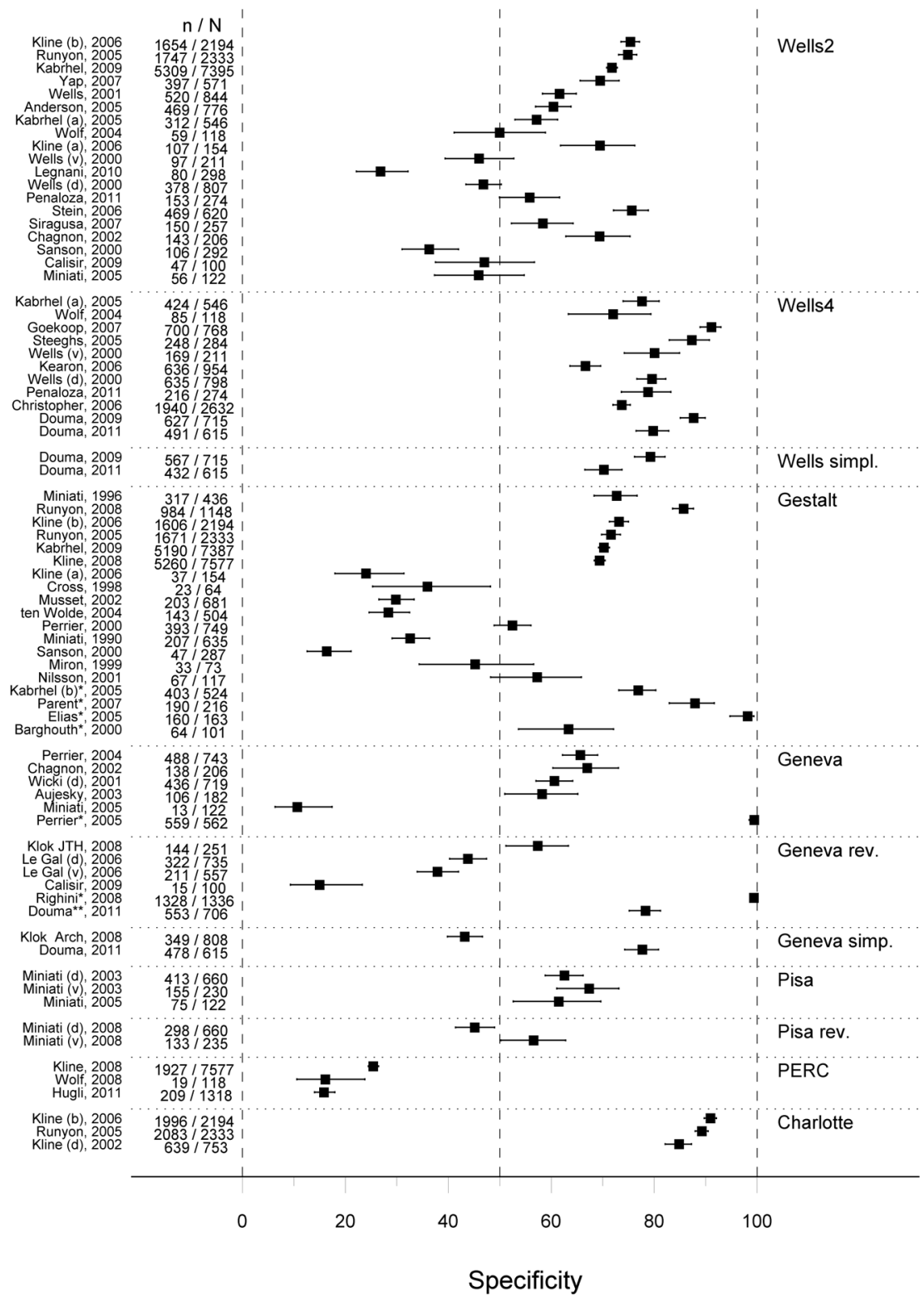

Figure 4.2 Forest plot of specificity of gestalt and different decision rules. Studies ordered from low to high prevalence of pulmonary embolism, and by type of rule. $\mathrm{n} / \mathrm{N}=$ proportion of patients without pulmonary embolism $(\mathrm{N})$ who have a negative test $(\mathrm{n})$. Wells2= Wells with cut-off $<2$, Wells4= Wells with cut-off $\leq 4$, Wells simpl.=Wells simplified ,Geneva rev.= revised Geneva with trichotomized cut-off, Geneva simp.=revised Geneva simplified, Pisa rev.= Pisa revised, PERC=Pulmonary embolism Rule-out Criteria, $(d)=$ derivation-study, $(v)=$ validationstudy, $(a, b)=$ author published two studies in same year, ${ }^{*}$ study with high-cut-off excluded from meta-analysis, $* *$ study with revised Geneva dichotomized cut-off. 


\section{Sensitivity and specificity of gestalt and different clinical decision rules}

A pooled analysis using the bivariate model was performed in studies using gestalt $(n=19)$, Wells2 $(n=19)$, Wells4 $(n=11)$, Geneva $(n=6)$ and revised Geneva $(n=6)$. For the other clinical decision rules less than four studies were available and therefore could not be included in the meta-analysis.

For gestalt, Geneva and revised Geneva the meta-analysis was performed with 15 instead of 19 studies, 5 instead of 6 and 4 instead of 6 studies, respectively. One study used revised Geneva with a dichotomized cut-off ${ }^{25}$ and in six studies ${ }^{21-24,26,27}$ the cutoff was regarded too high (probability $>40 \%$ ) to be useful for excluding PE and were excluded from meta-analysis.

Table 4.1 shows the pooled sensitivity and specificity of gestalt, Wells2, Wells4, Geneva and revised Geneva. For both sensitivity and specificity differences between Wells 4 and the other rules/gestalt were statistically significant $(p<0.01)$. For specificity also the difference between Wells 2 and the revised Geneva was statistically significant $(p=0.026)$. Other differences between the rules or gestalt were not significant.

The summary estimates of sensitivity indicate that a negative test result from any clinical decision rule alone is insufficient for decision-making. Even for the revised Geneva it would mean that $9 \%$ (1 minus sensitivity) of patients with PE are classified as false negatives and therefore would be left untreated.

The between study variability for sensitivity and specificity was substantial for all rules and gestalt.

Table 4.1 Pooled sensitivity and specificity of gestalt and different decision rules.

\begin{tabular}{|c|c|c|c|c|c|c|}
\hline $\begin{array}{l}\text { Type of decision } \\
\text { rule }\end{array}$ & $\begin{array}{l}\text { No. of } \\
\text { studies }\end{array}$ & $\begin{array}{c}\text { Prevalence } \\
\text { in } \%\end{array}$ & $\begin{array}{c}\text { Pooled } \\
\text { sensitivity } \\
(95 \% \mathrm{Cl})\end{array}$ & $\begin{array}{c}\text { Pooled } \\
\text { specificity } \\
(95 \% \mathrm{Cl})\end{array}$ & $\begin{array}{c}\text { Estimated } \\
\text { sensitivity at } \\
\text { prevalence } 15 \% \\
\#(95 \% \mathrm{Cl}) \\
\end{array}$ & $\begin{array}{c}\text { Estimated } \\
\text { specificity at } \\
\text { prevalence } 15 \% \\
\#(95 \% \mathrm{Cl}) \\
\end{array}$ \\
\hline Gestalt & 15 & 16.7 & $\begin{array}{c}0.85 \\
(0.78-0.90)\end{array}$ & $\begin{array}{c}0.51 \\
(0.39-0.63)\end{array}$ & $\begin{array}{c}0.83 \\
(0 \cdot 81-0 \cdot 84)\end{array}$ & $\begin{array}{c}0.52 \\
(0.43-0.62)\end{array}$ \\
\hline Wells2* & 19 & 14.7 & $\begin{array}{c}0.84 \\
(0.78-0.89)\end{array}$ & $\begin{array}{c}0.58 \\
(0.52-0.65)\end{array}$ & $\begin{array}{c}0.85 \\
(0 \cdot 80-0 \cdot 89)\end{array}$ & $\begin{array}{c}0.58 \\
(0.52-0.63)\end{array}$ \\
\hline Wells $4 * *$ & 11 & 16.3 & $\begin{array}{c}0.60 \\
(0.49-0.69)\end{array}$ & $\begin{array}{c}0.80 \\
(0 \cdot 75-0 \cdot 84)\end{array}$ & $\begin{array}{c}0.58 \\
(0.47-0.68)\end{array}$ & $\begin{array}{c}0.81 \\
(0 \cdot 76-0 \cdot 85)\end{array}$ \\
\hline Geneva & 5 & 29.0 & $\begin{array}{c}0 \cdot 84 \\
(0 \cdot 81-0 \cdot 87)\end{array}$ & $\begin{array}{c}0 \cdot 50 \\
(0 \cdot 29-0 \cdot 72)\end{array}$ & $\begin{array}{c}0 \cdot 76 \\
(0 \cdot 71-0 \cdot 79)\end{array}$ & $\begin{array}{c}0.61 \\
(0 \cdot 41-0 \cdot 78)\end{array}$ \\
\hline Revised Geneva & 4 & 23.7 & $\begin{array}{c}0.91 \\
(0.73-0.98)\end{array}$ & $\begin{array}{c}0.37 \\
(0.22-0.55)\end{array}$ & $\begin{array}{c}0.82 \\
(0.78-0 \cdot 86)\end{array}$ & $\begin{array}{c}0.45 \\
(0.32-0.59)\end{array}$ \\
\hline
\end{tabular}

\# A theoretical population with PE-prevalence of $15 \%$; * Wells $2=$ Wells-rule with cut-off $<2 ; * *$ Wells4= Wells-rule with cut-off $\leq 4$. 


\section{Covariate analysis}

The prevalence of PE in the included studies had a significant impact on sensitivity and specificity for gestalt, Wells-,and Geneva-rules. The direction of the effect was similar across the rules: increasing prevalence was associated with higher sensitivity and lower specificity. For example a change in prevalence from $5 \%$ to $30 \%$ is accompanied by an increase in sensitivity for the gestalt from 0.63 to 0.90 , Wells2 from 0.67 to 0.91 , Wells 4 from 0.34 to 0.72 , Geneva from 0.53 to 0.85 and revised Geneva from 0.63 to 0.90 .

Because overall prevalence for PE was different between gestalt, Wells-, and Genevarules we performed an additional analysis adjusting for these differences in prevalence by adding it as a covariate to the model. Table 4.1 demonstrates the accuracy of the different rules in a virtual population with a prevalence of PE of $15 \%$ (overall prevalence included studies $16 \%$ ). Because the actual prevalence in gestalt and Wells-studies is near $15 \%$ their accuracy hardly changed while sensitivity of the (revised) Geneva is considerably lower and specificity higher.

To study the influence of type of verification we classified studies into three groups. In group 1 all patients underwent pulmonary vascular imaging. In group 2 PE was excluded based on a negative decision rule or gestalt combined with a negative D-dimer test including follow-up. In group 3, PE was excluded solely on a negative Ddimer test including follow-up. Both sensitivity and specificity of gestalt, Wells-rules and Geneva-rules did not vary significantly across type of verification (data not shown).

To study the influence of type of study we excluded studies derivating a new rule from the meta-analysis and re-analyzed the remaining studies. Both sensitivity and specificity of gestalt, Wells-, and Geneva-rules did not change (data not shown).

\section{Adding D-dimer testing to the result of a clinical assessment}

A total of 20 studies reported data of combining the result of clinical assessment with D-dimer testing. Some studies reported on more than one rule or gestalt. One study failed to perform D-dimer testing on all patients with a low probability assessment ${ }^{28}$ and 4 studies used a high-cut-off and were excluded from analysis. ${ }^{21-24}$ Failure rate and efficiency of individual studies are shown in Figure 4.3 and 4.4. Rule or gestalt was 12 times combined with a quantitative D-dimer test, 11 times with a qualitative D-dimer test (Table 4.2). The failure rate for all studies was $0.7 \%$ (95\% $\mathrm{Cl} 0.5-1.0)$ with an overall efficiency of $35 \%$. Studies using a qualitative D-dimer test yielded a higher failure rate of $1.0 \%(95 \% \mathrm{Cl} 0.8-1.3)$ however with a higher efficiency of $45 \%$ as compared to a failure rate of $0.4 \%(95 \% \mathrm{Cl} 0.2-0.7)(p<0.01)$ and an efficiency of $27 \%$ $(p<0.01)$ for studies using a quantitative D-dimer test. Using a qualitative $D$-dimer test the failure rate of Wells 4 doubled in comparison with Wells2 (1.7\% versus $0.9 \%$ ). Using Wells4 in combination with a quantitative D-dimer test lowered the failure rate to $0.5 \%$. 


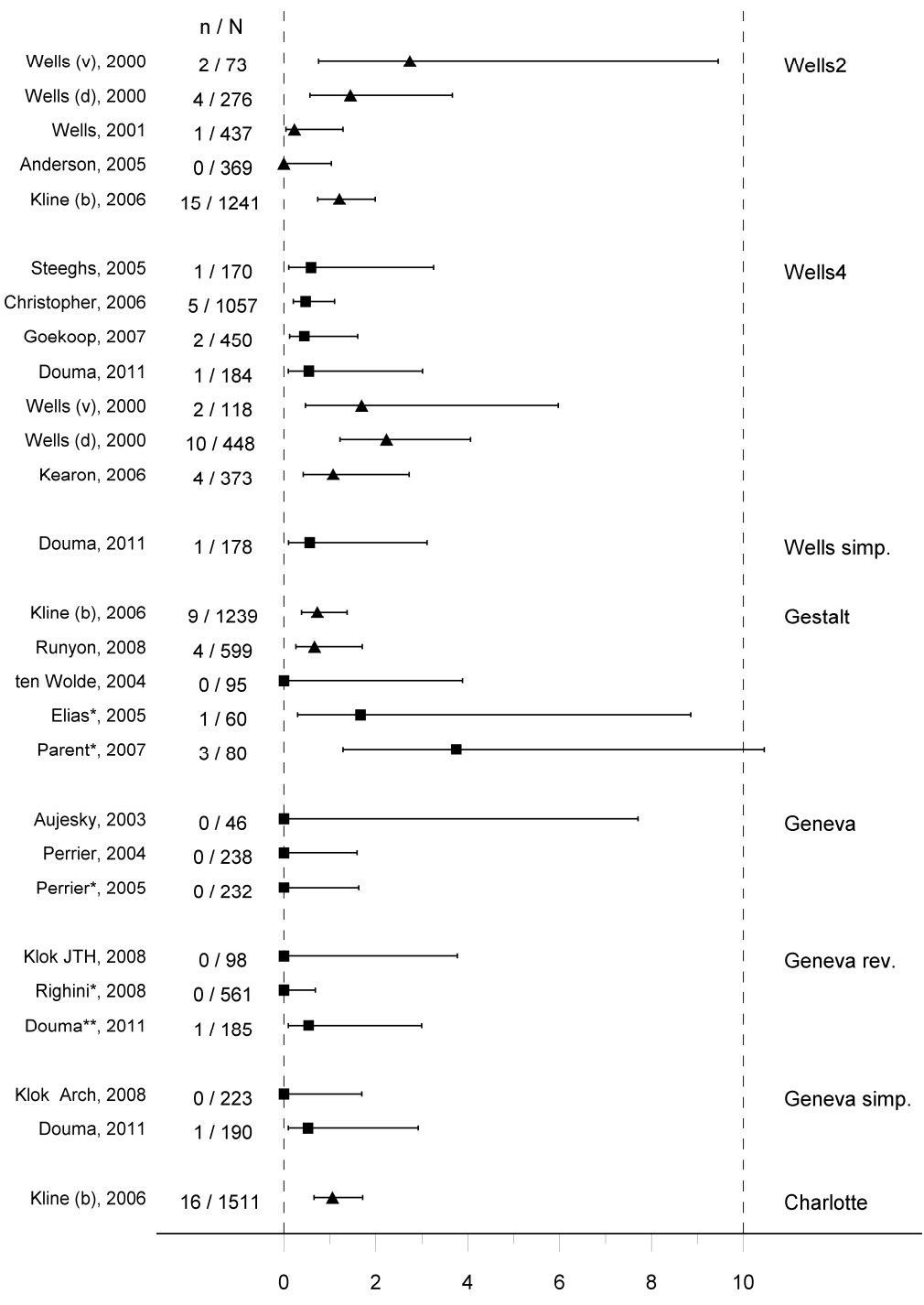

Failure rate in \%

Figure 4.3 Forest plot of the failure rate of gestalt and the different decision rules. $\mathbf{a}=$ Quantitative D-dimer test, $\boldsymbol{\Delta}=$ Qualitative D-dimer test, $\mathrm{n} / \mathrm{N}=$ patients with symptomatic and confirmed venous thrombo-embolism during follow-up ( $n$ ) divided by the total number of patients with negative results on both rule or gestalt and D-dimer test(N), Wells2= Wells with cut-off $<2$, Wells $4=$ Wells with cut-off $\leq 4$, Wells simp.=Wells simplified,Geneva rev.= revised Geneva with trichotomized cut-off, Geneva simp.=Geneva simplified, (d) derivation-study, (v) validationstudy, (b) author published two studies in same year, * study with high-cut-off excluded from analysis, ** study with revised Geneva dichotomized cut-off. 


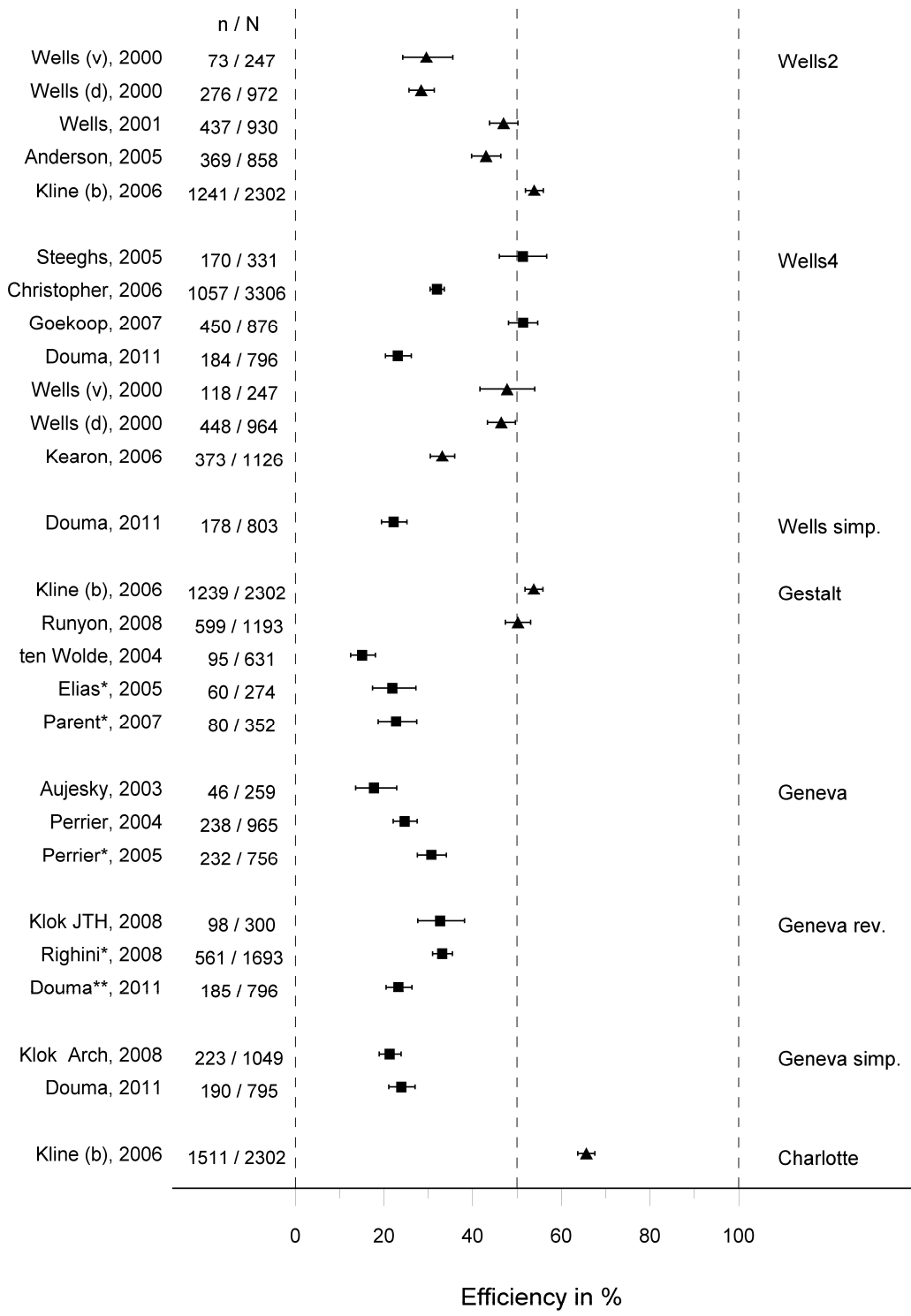

Figure 4.4 Forest plot of the efficiency of gestalt and different decision rules. $\mathbf{a}=$ Quantitative D-dimer test , $\boldsymbol{\Delta}=$ Qualitative D-dimer test, $n / N=$ number of patients with a negative result on both the rule or gestalt and the D-dimer test $(n)$ divided by all included patients $(N)$. Wells $2=$ Wells with cut-off $<2$, Wells $4=$ Wells with cut-off $\leq 4$, Wells simp.=Wells simplified, Geneva rev.= revised Geneva with trichotomized cut-off, Geneva simp.= Geneva simplified, (d) derivationstudy, (v) validation-study, (b) author published two studies in same year, * study with highcut-off excluded from analysis, ** study with revised Geneva dichotomized cut-off. 
Table 4.2 Failure rate and efficiency of gestalt and the different decision rules either combined with a quantitative or a qualitative D-dimer test.

\begin{tabular}{lccccc}
\hline Rule/gestalt & No. & No. pat. & Prevalence PE in \% & $\begin{array}{c}\text { Failure rate } \\
(95 \% \mathrm{Cl}) \text { in } \%\end{array}$ & $\begin{array}{c}\text { Efficiency } \\
(95 \% \mathrm{Cl}) \text { in } \%\end{array}$ \\
\hline All & 23 & $\begin{array}{c}24.384 \\
\text { Quantitative D-dimer }\end{array}$ & $0.7(0.5-1.0)$ & $35 \%(30-41)$ \\
All & 12 & 10.941 & 21.1 & $0.4(0.2-0.7)$ & $27 \%(22-34)$ \\
Wells4 & 4 & 5.320 & 19.2 & $0.5(0.2-0.9)$ & $39 \%(31-47)$ \\
Geneva & 2 & 1.224 & 24.4 & $0.0(0.0-1.3)$ & $21 \%(14-31)$ \\
Simpl.Geneva & 2 & 1.856 & 23.3 & $0.3(0.0-1.7)$ & $23 \%(15-33)$ \\
& & & Qualitative D-dimer & & \\
All & 11 & 13.443 & 8.3 & $1.0(0.8-1.3)$ & $45 \%(39-52)$ \\
Gestalt & 2 & 3.495 & 4.4 & $0.7(0.4 .-1.2)$ & $52 \%(40-64)$ \\
Wells4 & 3 & 2.337 & 16.0 & $1.7(1.0-2.8)$ & $42 \%(32-52)$ \\
Wells2 & 5 & 5.309 & 9.0 & $0.9(0.6-1.5)$ & $40 \%(33-48)$ \\
\hline
\end{tabular}

We only show separate results of a rule/ gestalt $+D$-dimer when minimal two studies are available. No: number of times a rule/ gestalt+ D-dimer was studied; No pat: number of patients included. Simpl. Geneva=simplified revised Geneva.

The two gestalt-studies using a qualitative D-dimer had an unexpectedly high efficiency, which is likely due to the low prevalence (4\% and $5 \%$ ) in both studies. ${ }^{29,30}$ Despite having a low cut-off $(<15 \%)$ both studies had significantly higher specificity than the summary estimate for specificity.

\section{Discussion}

We were able to perform a pooled bivariate analysis of gestalt, Wells2 and Wells4 (Wells-rule with cut-off $<2$ and $\leq 4$ ), Geneva and revised Geneva in their ability to exclude pulmonary embolism. Gestalt, Wells2 and the Geneva-rules had similar, high sensitivity for detecting pulmonary embolism. None of them however was sensitive enough to exclude pulmonary embolism on its own. The specificity of gestalt and the revised Geneva was considerably lower generating more false-positives and more unnecessary computerised tomography-scanning. Increasing prevalence of PE was associated with higher sensitivity and lower specificity, yielding fewer false negatives and more false positives.

A strategy to exclude PE using a combination of clinical probability assessment and a quantitative D-dimer test seemed safe for gestalt, the Wells-, and the Geneva-rules. When using a less sensitive qualitative D-dimer test the $95 \% \mathrm{Cl}$ exceeded our prespecified threshold of $2.7 \%$ failure-rate for Wells4. The more sensitive gestalt and Wells2 were safe in combination with a qualitative D-dimer.

Our findings are in line with a previous meta-analysis showing that different clinical decision rules had similar accuracy in assessing clinical probability. ${ }^{31}$ Our findings are also in line with a previous review and meta-analysis showing that PE can be safely 
excluded combining low-clinical probability and negative D-dimer test. ${ }^{32,33}$ However in these studies neither gestalt nor the importance of specificity of rules and prevalence of PE were reported.

Our meta-analysis has potential limitations. Firstly, we found substantial heterogeneity in sensitivity and specificity within gestalt-, Wells-, and Geneva-studies correlating with differences in PE-prevalence. Increasing prevalence was associated with higher sensitivity and lower specificity. Differences in prevalence can be an indirect reflection of differences in case-mix of included patients. In studies with lower disease prevalence more patients may be in an early stage of the condition which hampers detection. ${ }^{34-36}$ This can lead to more false negatives (lower sensitivity). PE-prevalence in included studies ranged from 5 to $44 \%$. Studies performed in the United States (prevalence $8 \%$ ) and Canada (13\%) had considerably lower PE-prevalence as compared to studies performed in Europe (26\%). In North-America a low threshold for testing for PE for medico-legal concerns results in low prevalence. ${ }^{37}$ In Europe, preselection by primary care physicians results in higher prevalence.

Another explanation for heterogeneity is remaining differences in threshold. In the gestalt-studies threshold-differences are clearly present as defining a low probability in the different gestalt-studies ranges from $<10 \%$ to $<40 \%$. These threshold differences are highly implicit. In the Wells-studies such implicit threshold-differences are also important as one of the seven items in the Wells-rule is rather subjective: 'PE is as likely as or more likely than an alternative diagnosis'. A positive score on this item counts three points, substantially influencing test-positivity (and thus both sensitivity and specificity).

Secondly, different reference standards to diagnose or exclude PE were used in the included studies. Adding different types of reference-methods used as a covariate to the bivariate model did not influence sensitivity or specificity of gestalt, Geneva-, and Wells-rules. The inclusion of studies that used methods of excluding PE without imaging but with uneventful follow-up could lead to a small overestimation of both sensitivity and specificity of gestalt or rule, as a patient with a negative test result but a small subsegmental embolus could be missed when managed with uneventful follow-up only. ${ }^{38}$

Thirdly, we included studies reporting data from both gestalt and rule, using the same study population. In these studies physicians might have been influenced using both gestalt and rule. Because of the limited number of studies available we were not able to perform a covariate-analysis.

Finally, our analysis is based only on published studies and publication bias may be a concern. We didn't look for publication bias.

In a high PE-prevalence population (i.e. a selected population as in a population referred by general practitioners) applying a high sensitive/low specific decision rule (Wells2, Geneva) is less desirable. The high prevalence decreases the already moderately or low specificity leading to an absolute increase of patients classified as false positive by the rule. As a consequence too many patients are referred for 
pulmonary vascular imaging. A less sensitive/more specific rule (Wells4) is recommended in this setting. The lower sensitivity of Wells4 urges combination with a high sensitive quantitative D-dimer test.

In a low prevalence unselected population (i.e. emergency department or in primary care) a highly sensitive rule such as Wells2 or Geneva is recommended as a lower PE prevalence lead to a further decrease of the sensitivity, yielding too many false negatives. In this setting it is possible to safely exclude PE using the more sensitive Wells2 and a less sensitive qualitative (point-of care) D-dimer test.

\section{Conclusion}

None of the rules nor gestalt is sensitive enough to exclude PE safely on its own. Combined with sensitive D-dimer tests all rules and gestalt are safe to exclude PE. However it is not just sensitivity of the rule that matters. A lower specificity (and thus more false-positives) of the rule increases the number of patients that are referred for pulmonary vascular imaging, without D-dimer testing. Compared to other rules gestalt and revised Geneva had lower specificity.

The clinician using gestalt tends to act as safe as possible by assigning the patient a higher probability in order not to miss a case of $P E$, causing more false-positives and causing more patients to be exposed to subsequent unnecessary pulmonary imaging. We advocate physicians to use a standardized decision rule instead of gestalt. Physicians should be aware that the sensitivity of a decision rule increases and specificity decreases with increasing prevalence. As prevalence of PE is an indirect reflection of the case-mix of their population, physicians should use the diagnostic strategy that fits the situation best. In high prevalence situations (a referred population) a rule with higher specificity is desirable, e.g. the Wells4 rule, while in a lower prevalence situation (emergency department or primary care) a more sensitive rule is desirable, e.g. the Wells2 rule or the Geneva rule. As all reviewed studies were performed in a hospital situation (emergency department, referred patients and inpatients), a diagnostic strategy to exclude pulmonary embolism in primary care without imaging must be evaluated before implementing such a strategy. 


\section{References of included studies}

1. Miniati M, Pistolesi M, Marini C, Di RG, Formichi B, Prediletto R et al. Value of perfusion lung scan in the diagnosis of pulmonary embolism: results of the Prospective Investigative Study of Acute Pulmonary Embolism Diagnosis (PISA-PED). Am J Respir Crit Care Med 1996;154:1387-1393.

2. Runyon MS, Webb WB, Jones $A E$, Kline JA. Comparison of the unstructured clinician estimate of pretest probability for pulmonary embolism to the Canadian score and the Charlotte rule: a prospective observational study. Acad Emerg Med 2005;12:587-593.

3. Kline JA, Hogg M. Measurement of expired carbon dioxide, oxygen and volume in conjunction with pretest probability estimation as a method to diagnose and exclude pulmonary venous thromboembolism. Clin Physiol Funct Imaging 2006;26:212-219.

4. Kline JA, Runyon MS, Webb WB, Jones AE, Mitchell AM. Prospective study of the diagnostic accuracy of the simplify D-dimer assay for pulmonary embolism in emergency department patients. Chest 2006;129:1417-1423.

5. Kline JA, Courtney DM, Kabrhel C, Moore CL, Smithline HA, Plewa MC et al. Prospective multicenter evaluation of the pulmonary embolism rule-out criteria. J Thromb Haemost 2008;6:772-780.

6. Runyon MS, Beam DM, King MC, Lipford EH, Kline JA. Comparison of the Simplify D-dimer assay performed at the bedside with a laboratory-based quantitative D-dimer assay for the diagnosis of pulmonary embolism in a low prevalence emergency department population. Emerg Med J 2008; 25:70-75.

7. Kabrhel C, Mark Court, Camargo CA, Jr., Moore CL, Richman PB, Plewa MC et al. Potential impact of adjusting the threshold of the quantitative D-dimer based on pretest probability of acute pulmonary embolism. Acad Emerg Med 2009;16:325-332.

8. Value of the ventilation/perfusion scan in acute pulmonary embolism. Results of the prospective investigation of pulmonary embolism diagnosis (PIOPED). The PIOPED Investigators. JAMA 1990; 263:2753-2759.

9. Miron MJ, Perrier A, Bounameaux H, De MP, Slosman DO, Didier D et al. Contribution of noninvasive evaluation to the diagnosis of pulmonary embolism in hospitalized patients. Eur Respir J 1999; 13:1365-1370.

10. Perrier A, Miron M-J, Desmarais S, De MP, Slosman D, Didier D et al. Using clinical evaluation and lung scan to rule out suspected pulmonary embolism: Is it a valid option in patients with normal results of lower-limb venous compression ultrasonography? Archives of Internal Medicine 2000;160:512-516.

11. Sanson BJ, Lijmer JG, Mac Gillavry MR, Turkstra F, Prins MH, Büller HR. Comparison of a clinical probability estimate and two clinical models in patients with suspected pulmonary embolism. ANTELOPE-Study Group. Thromb Haemost 2000;83:199-203

12. ten Wolde M, Hagen PJ, MacGillavry MR, Pollen IJ, Mairuhu AT, Koopman MM et al. Non-invasive diagnostic work-up of patients with clinically suspected pulmonary embolism; results of a management study. J Thromb Haemost 2004;2:1110-1117.

13. Nilsson T, Mare K, Carlsson A. Value of structured clinical and scintigraphic protocols in acute pulmonary embolism. J Intern Med 2001;250:213-218.

14. Cross JJL, Kemp PM, Walsh CG, Flower CDR, Dixon AK. A randomized trial of spiral CT and ventilation perfusion scintigraphy for the diagnosis of pulmonary embolism. Clinical Radiology 1998;53:177-182.

15. Musset D, Parent F, Meyer G, Maitre S, Girard P, Leroyer C et al. Diagnostic strategy for patients with suspected pulmonary embolism: a prospective multicentre outcome study. Lancet 2002; 360: 1914-1920.

16. Barghouth G, Yersin B, Boubaker A, Doenz F, Schnyder P, Delaloye AB. Combination of clinical and $\mathrm{V} / \mathrm{Q}$ scan assessment for the diagnosis of pulmonary embolism: a 2-year outcome prospective study. Eur J Nucl Med 2000;27:1280-1285.

17. Kabrhel C, Camargo CA, Jr., Goldhaber SZ. Clinical gestalt and the diagnosis of pulmonary embolism: does experience matter? Chest 2005;127:1627-1630.

18. Elias A, Cazanave A, Elias $M$, Chabbert V, Juchet $H$, Paradis $H$ et al. Diagnostic management of pulmonary embolism using clinical assessment, plasma D-dimer assay, complete lower limb venous ultrasound and helical computed tomography of pulmonary arteries. A multicentre clinical outcome study. Thromb Haemost 2005;93:982-988. 
19. Parent F, Maitre S, Meyer G, Raherison C, Mal H, Lancar R et al. Diagnostic value of D-dimer in patients with suspected pulmonary embolism: results from a multicentre outcome study. Thromb Res 2007;120:195-200.

20. Wells PS, Anderson DR, Rodger M, Ginsberg JS, Kearon C, Gent M et al. Derivation of a simple clinical model to categorize patients probability of pulmonary embolism: increasing the models utility with the SimpliRED D-dimer. Thromb Haemost 2000;83:416-420.

21. Wolf SJ, McCubbin TR, Feldhaus KM, Faragher JP, Adcock DM. Prospective validation of Wells Criteria in the evaluation of patients with suspected pulmonary embolism. Ann Emerg Med 2004;44:503-510.

22. Kabrhel C, McAfee AT, Goldhaber SZ. The contribution of the subjective component of the Canadian Pulmonary Embolism Score to the overall score in emergency department patients. Acad Emerg Med 2005;12:915-920.

23. Steeghs N, Goekoop RJ, Niessen RW, Jonkers GJ, Dik H, Huisman MV. C-reactive protein and D-dimer with clinical probability score in the exclusion of pulmonary embolism. Br J Haematol 2005; 130: 614-619.

24. Belle van A., Büller HR, Huisman MV, Huisman PM, Kaasjager K, Kamphuisen PW et al. Effectiveness of managing suspected pulmonary embolism using an algorithm combining clinical probability, D-dimer testing, and computed tomography. JAMA 2006;295:172-179.

25. Goekoop RJ, Steeghs N, Niessen RW, Jonkers GJ, Dik H, Castel A et al. Simple and safe exclusion of pulmonary embolism in outpatients using quantitative D-dimer and Wells' simplified decision rule. Thromb Haemost 2007;97:146-150.

26. Kearon C, Ginsberg JS, Douketis J, Turpie AG, Bates SM, Lee AY et al. An evaluation of D-dimer in the diagnosis of pulmonary embolism: a randomized trial. Ann Intern Med 2006;144:812-821.

27. Douma RA, Gibson NS, Gerdes VE, Büller HR, Wells PS, Perrier A et al. Validity and clinical utility of the simplified Wells rule for assessing clinical probability for the exclusion of pulmonary embolism. Thromb Haemost 2009;101:197-200.

28. Penaloza A, Melot C, Motte S. Comparison of the Wells score with the simplified revised Geneva score for assessing pretest probability of pulmonary embolism. Thrombosis Research 2011;127:81-84.

29. Douma RA, Mos IC, Erkens PM, Nizet TA, Durian MF, Hovens MM, van Houten AA, Hofstee HM, Klok FA, Ten Cate H, Ullmann EF, Büller HR, Kamphuisen PW, Huisman MV. Performance of 4 Clinical Decision Rules in the Diagnostic Management of Acute Pulmonary Embolism: A Prospective Cohort Study Ann Intern Med. 2011;154:709-718.

30. Wells PS, Anderson DR, Rodger M, Stiell I, Dreyer JF, Barnes D et al. Excluding pulmonary embolism at the bedside without diagnostic imaging: management of patients with suspected pulmonary embolism presenting to the emergency department by using a simple clinical model and d-dimer. Ann Intern Med 2001;135:98-107.

31. Chagnon I, Bounameaux H, Aujesky D, Roy PM, Gourdier AL, Cornuz J et al. Comparison of two clinical prediction rules and implicit assessment among patients with suspected pulmonary embolism. Am J Med 2002;113:269-275.

32. Anderson DR, Kovacs MJ, Dennie C, Kovacs G, Stiell I, Dreyer J et al. Use of spiral computed tomography contrast angiography and ultrasonography to exclude the diagnosis of pulmonary embolism in the emergency department. J Emerg Med 2005;29:399-404.

33. Miniati $M$, Bottai $M$, Monti S. Comparison of 3 clinical models for predicting the probability of pulmonary embolism. Medicine (Baltimore) 2005;84:107-114.

34. Stein PD, Fowler SE, Goodman LR, Gottschalk A, Hales CA, Hull RD et al. Multidetector computed tomography for acute pulmonary embolism. N Engl J Med 2006;354:2317-2327.

35. Siragusa S, Malato A, Falaschi F, Porro F, Anastasio R, Giarratano A et al. Deferral of assessment of pulmonary embolism. Haematologica 2007;92:410-413.

36. Yap KS, Kalff V, Turlakow A, Kelly MJ. A prospective reassessment of the utility of the Wells score in identifying pulmonary embolism. Med J Aust 2007;187:333-336.

37. Calisir C, Yavas US, Ozkan IR, Alatas F, Cevik A, Ergun N et al. Performance of the Wells and Revised Geneva scores for predicting pulmonary embolism. Eur J Emerg Med 2009;16:49-52.

38. Legnani C, Cini M, Scarvelis D, Toulon P, Wu JR, Palareti G. Multicenter evaluation of a new quantitative highly sensitive D-dimer assay, the Hemosil D-dimer HS 500, in patients with clinically suspected venous thromboembolism. Thrombosis Research 2010;125:398-401. 
39. Wicki J, Perneger TV, Junod AF, Bounameaux H, Perrier A. Assessing clinical probability of pulmonary embolism in the emergency ward: a simple score. Arch Intern Med 2001;161:92-97.

40. Aujesky D, Hayoz D, Yersin B, Perrier A, Barghouth G, Schnyder P et al. Exclusion of pulmonary embolism using C-reactive protein and D-dimer. A prospective comparison. Thromb Haemost 2003; 90:1198-1203.

41. Perrier A, Roy PM, Aujesky D, Chagnon I, Howarth N, Gourdier AL et al. Diagnosing pulmonary embolism in outpatients with clinical assessment, D-dimer measurement, venous ultrasound, and helical computed tomography: a multicenter management study. Am J Med 2004;116:291-299.

42. Perrier A, Roy PM, Sanchez O, Le GG, Meyer G, Gourdier AL et al. Multidetector-row computed tomography in suspected pulmonary embolism. N Engl J Med 2005;352:1760-1768.

43. Le Gal G, Righini M, Roy PM, Sanchez O, Aujesky D, Bounameaux $H$ et al. Prediction of pulmonary embolism in the emergency department: the revised Geneva score. Ann Intern Med 2006; 144: 165-171.

44. Klok FA, Kruisman E, Spaan J, Nijkeuter M, Righini M, Aujesky D et al. Comparison of the revised Geneva score with the Wells rule for assessing clinical probability of pulmonary embolism. Journal of Thrombosis and Haemostasis 2008;6:40-44.

45. Righini M, Le GG, Aujesky D, Roy PM, Sanchez O, Verschuren F et al. Diagnosis of pulmonary embolism by multidetector CT alone or combined with venous ultrasonography of the leg: a randomised non-inferiority trial. Lancet 2008;371:1343-1352.

46. Klok FA, Mos IC, Nijkeuter M, Righini M, Perrier A, Le GG et al. Simplification of the revised Geneva score for assessing clinical probability of pulmonary embolism. Arch Intern Med 2008;168:2131-2136.

47. Miniati M, Monti S, Bottai M. A structured clinical model for predicting the probability of pulmonary embolism. Am J Med 2003;114:173-179.

48. Miniati M, Monti S, Bauleo C, Scoscia E, Tonelli L, Dainelli A et al. A diagnostic strategy for pulmonary embolism based on standardised pretest probability and perfusion lung scanning: a management study. Eur J Nucl Med Mol Imaging 2003;30:1450-1456.

49. Miniati M, Bottai M, Monti S, Salvadori M, Serasini L, Passera M. Simple and accurate prediction of the clinical probability of pulmonary embolism. Am J Respir Crit Care Med 2008;178:290-294.

50. Kline JA, Nelson RD, Jackson RE, Courtney DM. Criteria for the safe use of D-dimer testing in emergency department patients with suspected pulmonary embolism: a multicenter US study. Ann Emerg Med 2002;39:144-152.

51. Wolf SJ, McCubbin TR, Nordenholz KE, Naviaux NW, Haukoos JS. Assessment of the pulmonary embolism rule-out criteria rule for evaluation of suspected pulmonary embolism in the emergency department. Am J Emerg Med 2008;26:181-185.

52. Hugli O, Righini M, Le GG, Roy P-M, Sanchez O, Verschuren F et al. The pulmonary embolism rule-out criteria (PERC) rule does not safely exclude pulmonary embolism. Journal of Thrombosis and Haemostasis 2011;9:300-304. 


\section{References}

1. Anderson FA Jr, Wheeler HB, Goldberg RJ, Hosmer DW, Patwardhan NA, Jovanovic B, Forcier A, Dalen JE. A population-based perspective of the hospital incidence and case-fatality rates of deep vein thrombosis and pulmonary embolism. The Worcester DVT Study. Arch Intern Med 1991;151:933-938.

2. Moser KM. Venous thromboembolism. Am Rev Respir Dis 1990;141:235-249.

3. Kruip MJ, Leclercq MG, van der HC, Prins $M H$, Büller HR. Diagnostic strategies for excluding pulmonary embolism in clinical outcome studies. A systematic review. Ann Intern Med 2003;138: 941-951.

4. van Belle A, Büller HR, Huisman MV, Huisman PM, Kaasjager K, Kamphuisen PW et al. Effectiveness of managing suspected pulmonary embolism using an algorithm combining clinical probability, D-dimer testing, and computed tomography. JAMA 2006;295:172-179.

5. Geersing GJ, Janssen KJ, Oudega R, Bax L, Hoes AW, Reitsma JB, Moons KG. Excluding venous thromboembolism using point of care D-dimer tests in outpatients: a diagnostic meta-analysis. BMJ 2009;339:b2990.

6. Reitsma JB, Glas AS, Rutjes AW, Scholten RJ, Bossuyt PM, Zwinderman AH. Bivariate analysis of sensitivity and specificity produces informative summary measures in diagnostic reviews. J Clin Epidemiol 2005;58:982-990.

7. Wasson JH, Sox HC, Neff RK, Goldman L. Clinical prediction rules. Applications and methodological standards. N Engl J Med 1985;313:793-799.

8. Anderson DR, Barnes D. The use of leg venous ultrasonography for the diagnosis of pulmonary embolism. Semin Nucl Med 2008;38:412-417.

9. Whiting P, Rutjes AW, Reitsma JB, Bossuyt PM, Kleijnen J. The development of QUADAS: a tool for the quality assessment of studies of diagnostic accuracy included in systematic reviews. BMC Med Res Methodol 2003;3:25.

10. Hamza TH, van Houwelingen HC, Stijnen T. The binomial distribution of meta-analysis was preferred to model within-study variability. J Clin Epidemiol. 2008;61:41-51

11. van Beek EJ, Brouwerst EM, Song B, Stein PD, Oudkerk M. Clinical validity of a normal pulmonary angiogram in patients with suspected pulmonary embolism--a critical review. Clin Radiol 2001; 56:838-842.

12. Wells PS, Anderson DR, Rodger M, Ginsberg JS, Kearon C, Gent M et al. Derivation of a simple clinical model to categorize patients probability of pulmonary embolism: increasing the models utility with the SimpliRED D-dimer. Thromb Haemost 2000;83:416-420.

13. Gibson NS, Sohne M, Kruip MJ, Tick LW, Gerdes VE, Bossuyt PM et al. Further validation and simplification of the Wells clinical decision rule in pulmonary embolism. Thromb Haemost 2008; 99:229-234.

14. Wicki J, Perneger TV, Junod AF, Bounameaux H, Perrier A. Assessing clinical probability of pulmonary embolism in the emergency ward: a simple score. Arch Intern Med 2001;161:92-97.

15. Le Gal G, Righini M, Roy PM, Sanchez O, Aujesky D, Bounameaux H et al. Prediction of pulmonary embolism in the emergency department: the revised Geneva score. Ann Intern Med 2006;144:165171.

16. Klok FA, Mos IC, Nijkeuter M, Righini M, Perrier A, Le GG et al. Simplification of the revised Geneva score for assessing clinical probability of pulmonary embolism. Arch Intern Med 2008;168:2131-2136.

17. Miniati M, Monti S, Bottai M. A structured clinical model for predicting the probability of pulmonary embolism. Am J Med 2003;114:173-179.

18. Miniati M, Bottai M, Monti S, Salvadori M, Serasini L, Passera M. Simple and accurate prediction of the clinical probability of pulmonary embolism. Am J Respir Crit Care Med 2008;178:290-294.

19. Kline JA, Nelson RD, Jackson RE, Courtney DM. Criteria for the safe use of D-dimer testing in emergency department patients with suspected pulmonary embolism: a multicenter US study. Ann Emerg Med 2002;39:144-152

20. Kline JA, Mitchell AM, Kabrhel C, Richman PB, Courtney DM. Clinical criteria to prevent unnecessary diagnostic testing in emergency department patients with suspected pulmonary embolism. J Thromb Haemost 2004;2:1247-1255. 
21. Perrier A, Roy PM, Sanchez O, Le GG, Meyer G, Gourdier AL et al. Multidetector-row computed tomography in suspected pulmonary embolism. N Engl J Med 2005;352:1760-1768.

22. Righini M, Le Gal G, Aujesky D, Roy PM, Sanchez O, Verschuren F et al. Diagnosis of pulmonary embolism by multidetector CT alone or combined with venous ultrasonography of the leg: a randomised non-inferiority trial. Lancet 2008;371:1343-1352.

23. Parent F, Maitre S, Meyer G, Raherison C, Mal H, Lancar R et al. Diagnostic value of D-dimer in patients with suspected pulmonary embolism: results from a multicentre outcome study. Thromb Res 2007;120:195-200.

24. Elias A, Cazanave A, Elias M, Chabbert V, Juchet $\mathrm{H}$, Paradis $\mathrm{H}$ et al. Diagnostic management of pulmonary embolism using clinical assessment, plasma D-dimer assay, complete lower limb venous ultrasound and helical computed tomography of pulmonary arteries. A multicentre clinical outcome study. Thromb Haemost 2005;93:982-988.

25. Douma RA, Mos IC, Erkens PM, Nizet TA, Durian MF, Hovens MM, van Houten AA, Hofstee HM, Klok FA, Ten Cate H, Ullmann EF, Büller HR, Kamphuisen PW, Huisman MV. Performance of 4 Clinical Decision Rules in the Diagnostic Management of Acute Pulmonary Embolism: A Prospective Cohort Study Ann Intern Med. 2011;154:709-718.

26. Kabrhel C, Camargo CA, Jr., Goldhaber SZ. Clinical gestalt and the diagnosis of pulmonary embolism: does experience matter? Chest 2005;127:1627-1630.

27. Barghouth G, Yersin B, Boubaker A, Doenz F, Schnyder P, Delaloye AB. Combination of clinical and $\mathrm{V} / \mathrm{Q}$ scan assessment for the diagnosis of pulmonary embolism: a 2-year outcome prospective study. Eur J Nucl Med 2000;27:1280-1285.

28. Kabrhel C, Mark Court, Camargo CA, Jr., Moore CL, Richman PB, Plewa MC et al. Potential impact of adjusting the threshold of the quantitative D-dimer based on pretest probability of acute pulmonary embolism. Acad Emerg Med 2009;16:325-332.

29. Runyon MS, Beam DM, King MC, Lipford EH, Kline JA. Comparison of the Simplify D-dimer assay performed at the bedside with a laboratory-based quantitative D-dimer assay for the diagnosis of pulmonary embolism in a low prevalence emergency department population. Emerg Med J 2008; 25:70-75.

30. Kline JA, Runyon MS, Webb WB, Jones AE, Mitchell AM. Prospective study of the diagnostic accuracy of the simplify D-dimer assay for pulmonary embolism in emergency department patients. Chest 2006;129:1417-1423.

31. Ceriani E, Combescure C, Le Gal G, Nendaz M, Perneger T, Bounameaux H, Perrier A, Righini M. Clinical prediction rules for pulmonary embolism: a systematic review and meta-analysis. J Thromb Haemost 2010;8:957-970

32. Pasha SM, Klok FA, Snoep JD, Mos IC, Goekoop RJ, Rodger MA, Huisman MV. Safety of excluding acute pulmonary embolism based on an unlikely clinical probability by the Wells rule and normal Ddimer concentration: a meta-analysis. Thromb Res 2010;125:e123-7.

33. Kruip MJ, Leclercq MG, van der HC, Prins MH, Büller HR. Diagnostic strategies for excluding pulmonary embolism in clinical outcome studies. A systematic review. Ann Intern Med 2003;138: 941-951.

34 Leeflang MM, Bossuyt PM, Irwig L. Diagnostic test accuracy may vary with prevalence: implications for evidence-based diagnosis. J Clin Epidemiol 2009;62:5-12.

35. Wolf SJ, McCubbin TR, Nordenholz KE, Naviaux NW, Haukoos JS. Assessment of the pulmonary embolism rule-out criteria rule for evaluation of suspected pulmonary embolism in the emergency department. Am J Emerg Med 2008;26:181-185.

36. Moons KG, van Es GA, Deckers JW, Habbema JD, Grobbee DE. Limitations of sensitivity, specificity, likelihood ratio, and bayes' theorem in assessing diagnostic probabilities: a clinical example. Epidemiology 1997;8:12-17.

37. Runyon MS, Webb WB, Jones AE, Kline JA. Comparison of the unstructured clinician estimate of pretest probability for pulmonary embolism to the Canadian score and the Charlotte rule: a prospective observational study. Acad Emerg Med 2005;12:587-593.

38. Carrier M, Righini M, Wells PS, Perrier A, Anderson DR, Rodger MA et al. Subsegmental pulmonary embolism diagnosed by computed tomography: incidence and clinical implications. A systematic review and meta-analysis of the management outcome studies. J Thromb Haemost 2010;8: 1716-1722. 



\section{Part II}

Treatment of Pulmonary Embolism in Secondary Care 



\section{Chapter 5}

Fixed dose subcutaneous low molecular weight heparins versus adjusted dose unfractionated

heparin for venous thromboembolism

PMG Erkens, MH Prins

Cochrane database systematic reviews, 2010;8:CD001100 


\section{Abstract}

\section{Background}

Low molecular weight heparins (LMWH) have been shown to be effective and safe in preventing venous thromboembolism (VTE), and may also be effective for the initial treatment of VTE. We aim to determine the effect of LMWH compared with unfractionated heparin (UFH) for the initial treatment of VTE.

\section{Methods}

Trials were identified by searching the Cochrane Peripheral Vascular Diseases Group's Specialised Register and CENTRAL. Colleagues and pharmaceutical companies were contacted for additional information. Randomised controlled trials comparing fixed dose subcutaneous LMWH with adjusted dose intravenous or subcutaneous UFH in people with VTE were included. At least two reviewers assessed trials for inclusion and quality, and extracted data independently.

\section{Results}

Twenty-three studies were included ( $n=9587)$. Thrombotic complications occurred in 165/4541 (3.6\%) participants treated with LMWH, compared with 226/4301 (5.3\%) treated with UFH (odds ratio (OR) 0.70; 95\% confidence intervals (CI) 0.57-0.85, 19 trials). Thrombus size was reduced in 53\% of participants treated with $\mathrm{LMWH}$ and $45 \%$ treated with UFH (OR 0.69; 95\% Cl 0.59-0.81, 12 trials). Major haemorrhages occurred in $44 / 3860$ (1.1\%) participants treated with LMWH, compared with $77 / 3984$ (1.9\%) treated with UFH (OR $0.58 ; 95 \% \mathrm{Cl} 0.40$ to $0.83,20$ trials). In nineteen trials, 199/4553 (4.3\%) participants treated with LMWH died, compared with 245/4221 (5.8\%) treated with UFH (OR $0.77 ; 95 \% \mathrm{Cl} 0.63-0.93$ ). Nine studies $(n=4451$ ) examined proximal thrombosis; 2192 participants treated with LMWH and 2259 with UFH. A subgroup analysis showed statistically significant reductions favouring $\mathrm{LMWH}$ in thrombotic complications and major haemorrhage. By end of follow up, 80 (3.6\%) participants treated with LMWH had thrombotic complications, compared with $143(6.3 \%)$ treated with UFH (OR 0.57; 95\% Cl 0.44-0.75). Major haemorrhage occurred in 18 (1.0\%) participants treated with LMWH, compared with 37 (2.1\%) treated with UFH (OR 0.50; $95 \% \mathrm{Cl}$ 0.29-0.85). Nine studies showed a statistically significant reduction favouring LMWH with respect to mortality. By the end of follow up, 3.3\% (70/2094) of participants treated with LMWH had died, compared with $5.3 \%(110 / 2063)$ treated with UFH (OR 0.62; 95\% Cl 0.46-0.84).

\section{Conclusion}

Fixed dose LMWH is more effective and safer than adjusted dose UFH for the initial treatment of VTE. LMWH, compared to UFH, significantly reduces the incidence of thrombotic complications, the occurrence of major haemorrhage during initial treatment and overall mortality at follow up. 


\section{Background}

\section{Description of the condition}

Venous thromboembolism (presence of a blood clot in the veins) has an incidence in the general population of approximately $0.1 \%$ per year. Its main manifestations are leg complaints, due to deep venous thrombosis in the lower limb (blood clot in the deep veins of the leg), and signs of dyspnea (shortness of breath) and pleuritic thoracic pain (chest pain) when a thrombus (clot) becomes dislodged and embolises in the pulmonary circulation. Recent evidence suggests that although people may only complain about either deep venous thrombosis or pulmonary embolism, in many cases the pathological manifestations are shared between these two clinically distinct conditions. $^{1,2}$ Therefore, they are referred to as one disease and are treated with comparable anticoagulant regimens.

\section{Description of the intervention}

Anticoagulant therapy is the treatment of choice for most patients with venous thromboembolism. ${ }^{3}$ Patients are usually treated with heparin for five to ten days and then with oral anticoagulants for a minimum of three months. Heparin is administered by either continuous intravenous infusion or twice daily subcutaneous injection. ${ }^{4-6}$ The evidence supporting initial treatment with heparin comes from a randomised placebocontrolled trial which demonstrated that a regimen of intravenous heparin plus oral anticoagulants was more effective in preventing recurrence than oral anticoagulants alone. ${ }^{7}$ It is standard practice to monitor heparin dosage by the activated partial thromboplastin time (APTT) and adjust the dose to maintain the anticoagulant effect within a defined therapeutic range. Laboratory monitoring is necessary because the anticoagulant response to heparin is highly variable among people with venous thromboembolism, as well as in an individual, and there is evidence that a minimum anticoagulant effect is required for optimum clinical efficacy. ${ }^{8,9}$

\section{Why it is important to do this review}

In the past decade a number of low molecular weight heparin preparations and heparinoids have been developed for clinical use. Compared with unfractionated heparin, low molecular weight heparin preparations have a longer plasma half-life, less inter-individual variability in anticoagulant response to fixed doses, and, in animal models, a more favourable antithrombotic to haemorrhagic ratio. ${ }^{10,11}$ As a result of their pharmacokinetic properties, a stable and sustained anticoagulant effect is achieved when low molecular weight heparins are administered subcutaneously, once or twice daily, without laboratory monitoring. Although most experience with low molecular weight heparins has been in the prevention of venous thromboembolism, where they have been shown to be safe and effective ${ }^{12}$, there is accumulating 
evidence that these new anticoagulants are also safe and effective for the treatment of venous thromboembolic events.

\section{Objectives}

The purpose of this critical review was to evaluate the efficacy and safety of fixed dose subcutaneous low molecular weight heparin compared to adjusted dose unfractionated heparin (intravenous (i.v.) or subcutaneous (s.c.)) for the initial treatment of people with acute deep venous thrombosis or pulmonary embolism.

\section{Methods}

\section{Criteria for considering studies for this review}

\section{Types of studies}

Randomised controlled clinical trials (RCTs) with prospective follow up.

\section{Types of participants}

People with venous thromboembolism (acute deep venous thrombosis or pulmonary embolism) confirmed by objective tests.

\section{Types of interventions}

Initial treatment (usually the first 5 to 14 days) with fixed dose subcutaneous low molecular weight heparin and adjusted dose unfractionated heparin (i.v. or s.c.).

\section{Types of outcome measures}

\section{Primary outcome}

(a) Incidence of symptomatic recurrent venous thromboembolism (deep venous thrombosis or pulmonary embolism) during the initial treatment and during follow up.

\section{Secondary outcomes}

(a) Change in thrombus size based on pre- and post-treatment venograms.

(b) Frequency of major haemorrhagic episodes during initial treatment or within 48 hours after treatment cessation.

(c) Overall mortality at the end of follow up. 


\section{Search methods for identification of studies}

\section{Electronic searches}

The Cochrane Peripheral Vascular Diseases Group searched their Specialised Register (last searched April 2010) and the Cochrane Central Register of Controlled Trials (CENTRAL) in The Cochrane Library (last searched Library Issue 2, 2010) for publications describing (or which might describe) RCTs that compared low molecular weight heparins against unfractionated heparin for the treatment of venous thromboembolism. Details of the search strategy used to search CENTRAL are available at www.cochrane.org. The Specialised Register is maintained by the Trials Search Co-ordinator and is constructed from weekly electronic searches of MEDLINE, EMBASE, CINAHL, AMED, and through handsearching relevant journals. The full list of the databases, journals and conference proceedings which have been searched, as well as the search strategies used are described in the Specialised Register section of the Cochrane Peripheral Vascular Diseases Group module in The Cochrane Library.

\section{Searching other resources}

The reference lists of papers resulting from these searches were reviewed. In addition, information about possible RCTs was sought through personal communication with colleagues and representatives of pharmaceutical companies. There were no language restrictions.

\section{Data collection and analysis}

\section{Selection of studies}

The evaluation of additional eligible studies for this updated review was performed by PE and checked by MP. There was $100 \%$ agreement about the classifications of the RCTs between the reviewers.

Studies were excluded if:

(1) they were dose-ranging studies using higher doses of low molecular weight heparin than are currently in use;

(2) they used low molecular weight heparin intravenously;

(3) they adjusted low molecular weight heparin dosages after initiation of treatment;

(4) the difference in initial treatment was confounded by differences in concomitant medication or long-term medication;

(5) they did not use a true low molecular weight heparin (by true low molecular weight heparin we mean that no compounds other than heparins are present);

(6) the administration of unfractionated heparin was suboptimal (i.e. not in adjusted dose);

(7) the report was an abstract with incomplete data. 


\section{Data extraction and management}

Data extracted included route of administration and intensity of heparin therapy, intensity of oral anticoagulant therapy, and the performance of independent assessment of study outcomes. Data on outcomes were only extracted if the assessment of the specific outcome was blinded.

In addition, the following data were extracted:

(1) The incidence of symptomatic recurrent deep venous thrombosis and pulmonary embolism during the initial treatment and during follow up (if active follow up was conducted prospectively at the study centres); whether this was assessed by persons unaware of treatment assignment; and if valid criteria for the diagnosis of recurrent venous thromboembolism were used.

The diagnosis of recurrent deep venous thrombosis was accepted if one of the following criteria was met:

(a) a new constant intraluminal filling defect not present on the last available venogram;

(b) if the venogram was not diagnostic, either an abnormal 125I-fibrinogen leg scan or abnormal impedance plethysmogram or ultrasound result that had been normal before the suspected recurrent episode. ${ }^{13}$

The diagnosis of pulmonary embolism was accepted if one of the following criteria was met:

(a) a segmental defect on the perfusion lung scan that was unmatched on the ventilation scan or chest röntgenogram;

(b) positive pulmonary angiography;

(c) pulmonary embolism at autopsy.

(2) The number of participants in each group with improved venographic score, if pre- and post-treatment venograms were obtained and were assessed by persons unaware of treatment assignment.

(3) The frequency of major haemorrhagic episodes during initial treatment. Haemorrhages were classified as major if they were intracranial, retroperitoneal, led directly to death, necessitated transfusion or they led to the interruption of antithrombotic treatment or (re)operation. All other haemorrhages were classified as minor.

(4) The overall mortality at the end of follow up specified for participants with or without malignant disease, if active follow up was prospectively conducted at the study centres.

\section{Assessment of risk of bias in included studies}

\section{Methodological quality}

For this updated review, a risk of bias table was completed by two authors (PE and $\mathrm{MP})$. The risk of bias was assessed for all new and previously included studies 
according to the guidelines given in the Cochrane Handbook for Systematic Reviews of Interventions, version 5.0.0 (The Cochrane Collaboration, 2008). The following domains were assessed by a score of 'Yes' (i.e. low risk of bias), 'No' (i.e. high risk of bias) or 'Unclear' (uncertain risk of bias):

1. Sequence generation: was the allocation sequence adequately generated?

2. Allocation treatment: was allocation adequately concealed?

3. Blinding: was knowledge of the allocated interventions adequately prevented during the study?

4. Incomplete data: were incomplete outcome data adequately addressed?

5. Selective outcome reporting: are reports of the study free of suggestion of selective outcome reporting?

6. Other potential threats to validity: was the study apparently free of other studies that could put it at risk of bias?

Disagreements were resolved by discussion and consensus.

\section{Measures of treatment effect}

The change in thrombus size between pre- and post-treatment venograms was classified as improved or not, based on the criteria used to measure thrombus size in each study. The incidence of venographic improvement and of each of the other outcomes for the different treatments was used to calculate an odds ratio separately for each trial. These odds ratios were then combined across studies, giving due weight to the number of events in each of the two treatment groups in each separate study using the Peto procedure, which assumes a fixed treatment effect. ${ }^{14,15}$

All these analyses were performed for the individual low molecular weight heparin preparations for venous thromboembolism (i.e. deep venous thrombosis and pulmonary embolism combined), and some were performed for proximal deep venous thrombosis and pulmonary embolism separately.

An analysis for all low molecular weight heparin preparations combined was performed if the treatment effects of the individual low molecular weight heparin preparations were compatible with each other, in view of the biochemical heterogeneity as well as the heterogeneity in animal experiments.

The validity of combining the trials was addressed with a statistical test of homogeneity, which considers whether differences in treatment effect over individual trials are consistent with natural variation around a constant effect. ${ }^{14}$

\section{Subgroup analysis and investigation of heterogeneity}

The following subgroup analyses were performed: an analysis in participants with pulmonary embolism, an analysis in participants with venous thromboembolism with or without malignant disease, an analysis of studies with subcutaneous UFH versus LMWH and studies with intravenous UFH versus $\mathrm{LMWH}$, an analysis with adequate 
concealment or allocation prior to randomisation and finally a separate analysis to explore trend over time.

In all analyses, the validity of combining the trials was addressed with a statistical test of homogeneity.

\section{Results}

\section{Description of studies}

\section{Results of the search}

For this update the search of the Specialised Register yielded 107 additional reports to trials and 1463 additional citations were retrieved from the search of CENTRAL. The CENTRAL results were screened by reading titles and abstracts.

\section{Included studies}

In this updated review, one study ${ }^{16}$ was added to the original meta-analyses. In total, twenty-three studies were truly randomised trials, published between 1988 and the end of 2004, with a total of 9587 participants. Thirteen of the twenty-three studies included participants with symptomatic deep venous thrombosis of the leg without symptoms of pulmonary embolism. In five of these thirteen studies people with distal deep venous thrombosis were included as well as people with proximal deep venous thrombosis. In seven studies participants were included if they had symptomatic deep venous thrombosis of the leg, with or without symptomatic pulmonary embolism or asymptomatic deep venous thrombosis of the leg with symptomatic pulmonary embolism or symptomatic deep venous thrombosis or pulmonary embolism. In two studies participants with pulmonary embolism only were included. All studies used objective diagnostic tests to confirm the diagnosis. All of the included studies considered fixed dose subcutaneous low molecular weight heparin once daily ${ }^{17-21}$ ), twice daily ${ }^{16,22-37}$ or both ${ }^{38}$ compared with adjusted dose intravenous unfractionated heparin $^{17-21,23,24,26-31,33,34,36-38}$ or subcutaneous unfractionated heparin ${ }^{16,25,32}$ or both $^{22}$. Eight different preparations of low molecular weight heparin were identified (nadroparin, tinzaparin, enoxaparin, dalteparin, CY 222, certoparin, ardeparin and reviparin). Ten trials did not have any post-randomisation exclusions or losses to follow up. Eleven trials reported the number of participants lost to follow up which ranged from $1.0 \%$ to $12.7 \%$. One trial did not report the dropouts 'Characteristics of included studies are available at www.cochrane.org'). 


\section{Excluded studies}

Twenty one trials were excluded for the following reasons: dosage of unfractionated heparin was not adjusted (four trials ${ }^{39-42}$; dose-ranging study (three trials ${ }^{43-45}$; low molecular weight heparin dosage was adjusted (four trials ${ }^{46-49}$ ); intravenous administration of low molecular weight heparin (four trials ${ }^{50-53}$ ); results from participants treated for venous thrombosis of the upper limb and for pulmonary embolism could not be distinguished from those of participants with leg vein thrombosis and the outcome was incompletely evaluated (four trials ${ }^{54-57}$ ); and difference in long-term treatment between the two treatment regimens (two trials $\left.{ }^{58,59}\right)$.

\section{Risk of bias in included studies}

\section{Allocation (selection bias)}

In twelve of the twenty-three included studies, the assigned treatment was adequately concealed prior to allocation, while in the other eleven trials concealment of allocation was unclear, based on the information given in the publication (Characteristics of the included studies are available at www.cochrane.org).

\section{Blinding (performance bias and detection bias)}

In the majority of the included studies treatment allocation was not blinded due to the difference in route of administration between subcutaneous low molecular weight heparin and intravenous unfractionated heparin. Even the three studies ${ }^{16,25,32}$ about subcutaneous unfractionated heparin versus subcutaneous low molecular weight heparin were not blinded for treatment allocation due to an initial intravenous bolus in the unfractionated heparin group. There is only one ${ }^{18}$ double blinded clinical trial in which patients received either intravenous unfractionated heparin with subcutaneous placebo or subcutaneous low molecular weight heparin with intravenous placebo. However, twenty-one studies were blinded for outcome assessment. In two studies $^{26,27}$ the blinding was unclear.

\section{Effects of intervention}

None of the trials individually demonstrated statistically significant protection from recurrent symptomatic venous thromboembolic complications during the initial treatment period. One trial ${ }^{23}$ showed that low molecular weight heparin conferred statistically significant protection from recurrent symptomatic venous thromboembolic complications at the end of follow up; only one study ${ }^{18}$ demonstrated a statistically significant reduction in major haemorrhage and mortality after treatment with low molecular weight heparin. Three studies ${ }^{23,32,34}$ showed a 
statistically significant reduction in thrombus size between pre-treatment and posttreatment venograms in favour of low molecular weight heparin.

\section{Recurrent venous thromboembolism (Graph 1.1-1.5)}

The occurrence of symptomatic recurrent venous thromboembolism was evaluated during the initial treatment period ${ }^{17,19,21,24,26,28-37}$, at three months follow up ${ }^{16,18,21-}$ 24,26,30-32,34,36-38 and at six months follow up. ${ }^{19,28-30,34,35}$ Combining all trials with longterm follow up gave a comparison of recurrent thromboembolism at the end of follow up. Analysis of the pooled data from these studies demonstrated a statistically significant reduction in recurrent venous thromboembolic events with low molecular weight heparin during the initial treatment period (OR $0.68 ; 95 \% \mathrm{Cl} 0.48-0.97$ ), at three and six months follow up (OR $0.71 ; 95 \% \mathrm{Cl} 0.56-0.90$ and $\mathrm{OR} 0.68 ; 95 \% \mathrm{Cl} 0.48$ to 0.96 , respectively) and at the end of follow up (OR $0.70 ; 95 \% \mathrm{Cl} 0.57-0.85$ ). During the initial treatment $51(1.7 \%)$ of the 3030 participants allocated to low molecular weight heparin had thrombotic complications versus $74(2.4 \%)$ of the 3030 of the participants allocated to unfractionated heparin. After a follow up of three months, the period in most of the studies for which oral anticoagulant therapy was given, 122 (3.6\%) of the 3382 participants treated with low molecular weight heparin had a recurrent thrombotic event versus 164 (5.2\%) of the 3169 participants treated with unfractionated heparin. The results of all individual trials include the observed common odds ratio and their individual 95\% confidence interval. Hence, there was no indication of heterogeneity and the statistical test for heterogeneity was negative.

\section{Major haemorrhage during the initial treatment (Graph 1.6)}

Twenty of the included trials evaluated the occurrence of major haemorrhage during the initial treatment. ${ }^{16-22,24-26,28-37}$ Analysis of the pooled data showed a statistically significant reduction in major haemorrhagic complications in favour of low molecular weight heparin (OR $0.58 ; 95 \% \mathrm{Cl} 0.40-0.83$ ). Of the individual trials, only one trial using tinzaparin demonstrated a statistically significant reduction in major haemorrhage (OR 0.19; 95\% Cl 0.06-0.59), whereas two studies using enoxaparin and reviparin showed a statistically non-significant increase in major haemorrhage favouring unfractionated heparin (OR 1.70; 95\% $\mathrm{Cl} 0.42-6.87$ and $\mathrm{OR} 1.26 ; 95 \% \mathrm{Cl} 0.49-3.19$, respectively). At the end of the initial treatment period, $44(1.1 \%)$ of the 3860 participants in the low molecular weight heparin group versus $77(1.9 \%)$ of the 3984 participants in the unfractionated heparin group suffered a major haemorrhage.

\section{Overall mortality at the end of follow up (Graph 1.7)}

Nineteen studies prospectively evaluated the overall mortality at the end of follow up. $^{16,18-21,23,24,26-32,34-38,55}$ Overall mortality at the end of follow up was significantly lower in participants treated with low molecular weight heparin (OR 0.77; $95 \% \mathrm{Cl}$ 0.63-0.93). In the low molecular weight heparin group 199 (4.4\%) of the 4553 
participants died versus $245(5.8 \%)$ of the 4221 participants in the unfractionated heparin group.

\section{Venographic assessment (Graph 1.8)}

Venograms were obtained before and after heparin treatment in twelve studies. $^{17,19,20,23,25,27-29,32-34,36}$ In all studies, these venograms were adjudicated by inverstigaors unaware of treatment allocation. The combined results of the twelve studies demonstrated a reduction of thrombus size in $53 \%$ of the participants treated with low molecular weight heparin and in $44 \%$ of participants treated with unfractionated heparin. Low molecular weight heparin was associated with a better venographic outcome (OR $0.69 ; 95 \% \mathrm{Cl} 0.59-0.81)$, compared with unfractionated heparin. Of the individual low molecular weight heparin preparations, a statistically significant better venographic outcome was observed for nadroparin (OR $0.54 ; 95 \% \mathrm{Cl}$ $0.37-0.79$ ), reviparin (OR $0.59 ; 95 \% \mathrm{Cl} 0.43-0.80$ ) and ardeparin (OR $0.37 ; 95 \% \mathrm{Cl} 0.14-$ $0.99)$.

\section{Analysis in participants with proximal deep venous thrombosis (Graph 2.1-2.5)}

Of the 4451 participants with proximal deep venous thrombosis enrolled in nine studies $^{18,22,23,28,30,31,34-36}, 2192$ were assigned to receive low molecular weight heparin and 2259 to receive unfractionated heparin. Five preparations of low molecular weight heparin were used: nadroparin (three trials, 864 participants), tinzaparin (one trial, 432 participants), enoxaparin (two trials, 634 participants), reviparin (one trial, 763 participants) and certoparin (two trials, 1758 participants).

At the end of follow up 80 (3.6\%) of the 2192 participants treated with low molecular weight heparin had a symptomatic recurrent venous thromboembolic event versus $143(6.3 \%)$ of the 2259 participants treated with unfractionated heparin. This reduction was statistically significant in favour of low molecular weight heparin (OR $0.57 ; 95 \% \mathrm{Cl} 0.44-0.75)$. The reduction in the incidence of symptomatic recurrent deep venous thrombosis as well as the reduction in the incidence of pulmonary embolism with low molecular weight heparin treatment was also statistically significant (OR 0.63; 95\% $\mathrm{Cl} 0.42-0.95$ and OR 0.42; 95\% Cl 0.26-0.70, respectively).

Analysis of the pooled data showed a statistically significant reduction in major haemorrhagic complications in favour of low molecular weight heparin (OR 0.50; 95\% $\mathrm{Cl}$ 0.29-0.85). At the end of the initial treatment period, $18(1.0 \%)$ of the 1804 participants in the low molecular weight heparin group versus $37(2.1 \%)$ of the 1785 participants in the unfractionated heparin group suffered a major haemorrhage.

Overall mortality at the end of follow up demonstrated a statistically significant reduction in favour of low molecular weight heparin (OR $0.62 ; 95 \% \mathrm{Cl} 0.46-0.84$ ). In the low molecular weight heparin group 70 (3.3\%) of the 2094 participants died versus 110 (5.3\%) of the 2063 participants in the unfractionated heparin group. 


\section{Analysis in participants with pulmonary embolism (Graph 3.1)}

The reduction of venous thromboembolic events in participants with pulmonary embolism was not statistically significant (OR 0.88; 95\% $\mathrm{Cl} 0.48-1.63$ ).

\section{Analysis in participants with venous thromboembolism with or without malignant disease (Graph 4.1-5.1)}

Six studies evaluated mortality at the end of follow up in participants with malignant disease. $^{18,19,21,32,34,37}$ One of these studies ${ }^{34}$ showed a statistically significant reduction in deaths at the end of follow up with low molecular weight heparin (OR 0.16; $95 \% \mathrm{CI}$ 0.03-0.72). Combining the six studies also demonstrated a statistically significant reduction in overall mortality in participants with cancer who were treated with low molecular weight heparin (OR 0.53; 95\% Cl 0.33-0.85). In participants without cancer who received low molecular weight heparin, the reduction in overall mortality of approximately $3 \%$ was not statistically significant (OR 0.97; 95\% Cl 0.61-1.56).

\section{Analysis of studies subcutaneous UFH versus $L M W H$ and studies of intravenous UFH versus LMWH (Graph 6.1-7.1)}

In three studies the UHF in the control group was administered subcutaneously. ${ }^{16,25,32}$ The analysis of the pooled data from these studies demonstrated a reduction in recurrent venous thromboembolism at the end of follow up in favour of low molecular weight heparin (OR $0.82 ; 95 \% \mathrm{Cl} 0.40-1.67$ ), although this was not statistically significant. Neither the reduction in major haemorrhagic episodes during initial treatment (OR $0.40 ; 95 \% \mathrm{Cl} 0.42-1.33$ ), nor the overall mortality at the end of follow-up (OR $0.92 ; 95 \% \mathrm{Cl} 0.41-2.04$ ) was statistically significant after treatment with low molecular weight heparin. In the studies which compared LMWH with intravenous UFH, we found a reduction in recurrent venous thromboembolism (OR $0.69 ; 95 \% \mathrm{Cl} 0.56-0.85$ ) as well as in major haemorrhages (OR $0.60 ; 95 \% \mathrm{Cl} 0.41-0.88$ ) as wells as in overall mortality (OR $0.76 ; 95 \% \mathrm{Cl} 0.62-0.93)$ with significant confidence intervals.

\section{Analysis of studies with adequate concealment of allocation prior to randomisation (Graph 8.1-8.6)}

Twelve studies had clear concealment of allocation prior to randomisation, based on the information given in the publication. ${ }^{16-18,21,24,27,29-31,35,37,38}$ The analysis of the pooled data from these studies demonstrated a reduction in recurrent venous thromboembolism during the initial treatment period as well as at the end of followup in favour of low molecular weight heparin (OR 0.80; 95\% $\mathrm{Cl} 0.55-1.16$ and OR 0.81; $95 \% \mathrm{Cl}$ 0.64-1.03, respectively), although this was not statistically significant. Neither the reduction in major haemorrhage (OR $0.61 ; 95 \% \mathrm{Cl} 0.46-1.05)$ nor the reduction in the overall mortality at the end of follow up (OR $0.82 ; 95 \% \mathrm{Cl} 0.66-1.02$ ) was 
statistically significant after treatment with low molecular weight heparin. The reduction in the thrombus size, however, was statistically significant in favour of low molecular weight heparin (OR 0.62; 95\% $\mathrm{Cl} 0.43-0.90$ ).

\section{Trends over time (Graph 9.1-9.4)}

In order to investigate trend over time, we performed analyses in which all studies were ordered by their date of publication. The forest plots of these analyses do not show an obvious trend over time.

\section{Discussion}

Our review on low molecular weight heparin for the initial treatment of venous thromboembolism includes more than 9000 participants and indicates that this drug is not only more efficacious than unfractionated heparin, but is also safer with regard to major bleeding episodes and mortality. Many of the included papers reported on the other advantages of low molecular weight heparin over unfractionated heparin. Firstly, the route of administration (subcutaneous once or twice daily) is more convenient, which increases the mobility of participants with venous thromboembolism. Secondly, the pharmacokinetics are more predictable, which abolishes the need for laboratory monitoring and subsequent dose adjustments. Hence, low molecular weight heparin can be advocated as the standard therapy for patients with confirmed venous thromboembolism. Treatment in an outpatient setting has been demonstrated to be feasible, safe and cost-effective for patients with deep venous thrombosis. $^{30,31,60}$

We believe that our efficacy data are robust the $99 \% \mathrm{Cl}$ for the main outcome of recurrent venous thromboembolism, at end of follow up and at three months, was less than one (OR 0.70; 99\% Cl 0.53-0.91) and (OR 0.71; 99\% $\mathrm{Cl} 0.52-0.97$ ). This was true for all of the other outcomes except recurrent venous thromboembolism at one month.

The tendency to improved efficacy with low molecular weight heparin treatment was not at the cost of a higher rate of major haemorrhage. On the contrary, a statistically significant reduction in major haemorrhage was demonstrated during the initial treatment period with low molecular weight heparin. In addition, overall mortality was reduced with low molecular weight heparin, compared with unfractionated heparin. However, the mechanism underlying this observation is unclear.

In the studies with adequate concealment of treatment allocation before randomisation, reductions in recurrent venous thromboembolism, major haemorrhages and overall mortality were also observed, albeit these were smaller than the overall reductions and were not statistically significant. An explanation for these differences in effect size could be that the overall reductions are possibly biased by including less adequate performed studies without adequate concealment. 
Although these results are promising, there are a number of unresolved issues. Firstly, since only approximately $25 \%$ of the participants included in this critical review had a diagnosis of primary pulmonary embolism, it can be argued that more data are required before low molecular weight heparins can be recommended as the standard treatment for primary pulmonary embolism. Secondly, the combination of all preparations of low molecular weight heparin seems logical, and heterogeneity could not be identified. Current data do not discriminate between different LMWH preparations. However, studies with large sample sizes which include comparisons of different preparations are needed to determine whether the efficacy and safety of the individual low molecular weight heparins is actually comparable. Thirdly, Prandoni et. al noted that the route of administration might be relevant to heparin efficacy. ${ }^{16}$ When we limited a subgroup analysis to studies that used intravenous UFH, similar results as in the main analyses were observed. When the analysis was confined to those studies that use subcutaneous UFH, we still find a reduction in the incidence of recurrent venous thromboembolism and major haemorrhages, albeit these were not statistically significant. The lack of significance could be due to the smaller patient groups in this subgroup analysis.

We conclude that low molecular weight heparin can safely be adopted as the standard therapy in patients with deep venous thrombosis. In patients with

pulmonary embolism, it would be prudent to await further results of new studies. If adequate support is available, low molecular weight heparin treatment can be administered at home in certain cases. In future, as low molecular weight heparin therapy becomes the standard treatment in patients with deep venous thrombosis, new drugs should be compared with low molecular weight heparin.

\section{Authors' conclusions}

\section{Implications for practice}

This systematic review suggests that low molecular weight heparin treatment can safely be adopted as the standard therapy in people with deep venous thrombosis.

\section{Implications for research}

Further studies are required to compare low molecular weight heparin with unfractionated heparin in the treatment of patients with pulmonary embolism. In addition, a large RCT of at least two years' duration should be performed to determine the effects of dosing frequency on long-term sequelae of venous thromboembolism, such as the development of the post-thrombotic syndrome. Individual low molecular weight heparins could be compared with each other, and new drugs should now be compared with low molecular weight heparin. 
Graph 1.1 Comparison 1: LMWH versus UFH in patients with thromboembolism. Outcome 1: Incidence of recurrent venous thromboembolism during initial treatment.

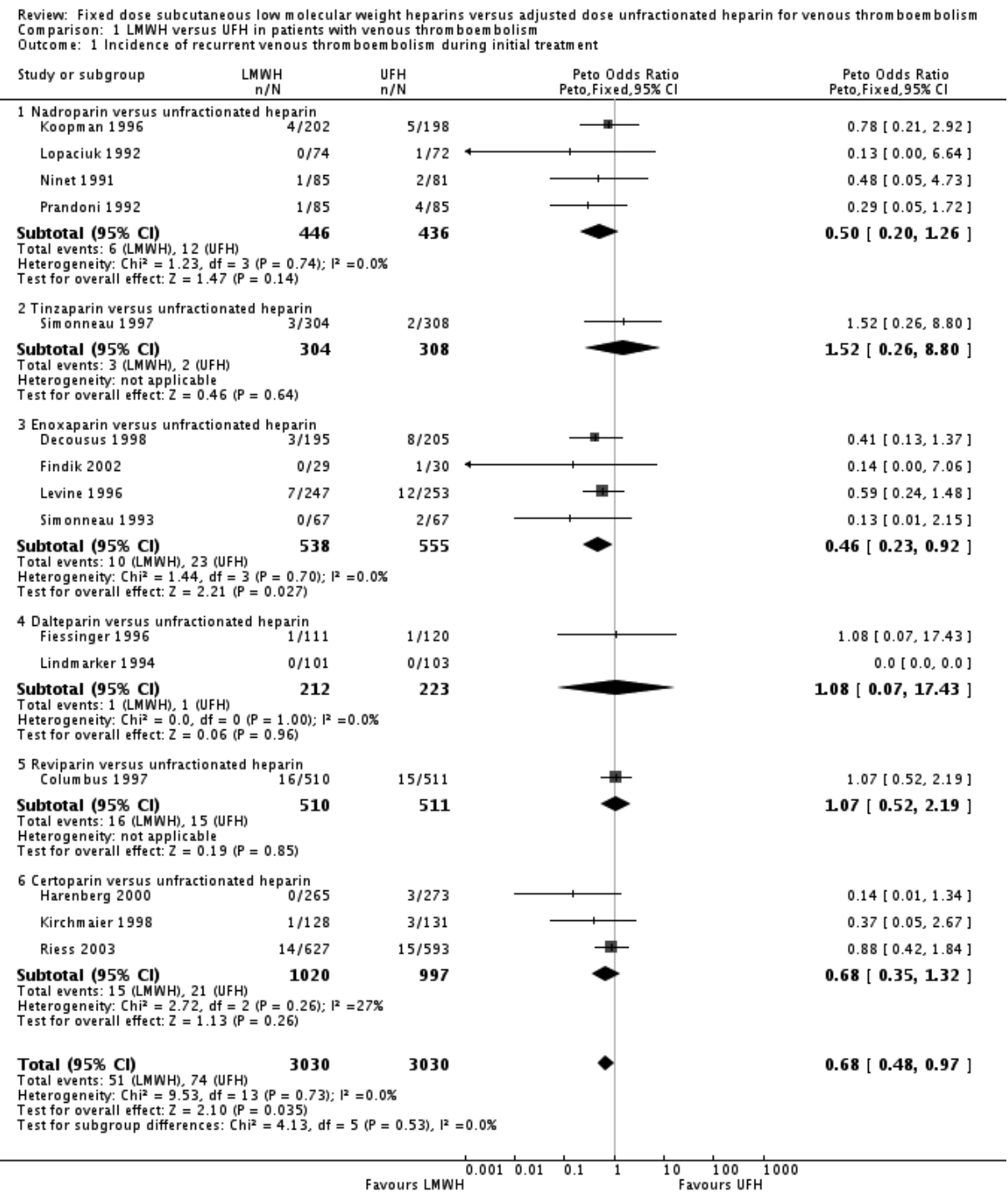


Graph 1.2 Comparison 1: LMWH versus UFH in patients with thromboembolism. Outcome 2: Incidence of recurrent venous thromboembolism at the end of follow up.

Review: Fixed dose subcutaneous low molecular weight heparins versus adjusted dose unfractionated heparin for venous throm boem bolism Comparison: 1 LMWH versus UFH in patients with venous throm boem bolism
Outcome: 2 Incidence of recurrent venous thromboembolism at the end of follow up

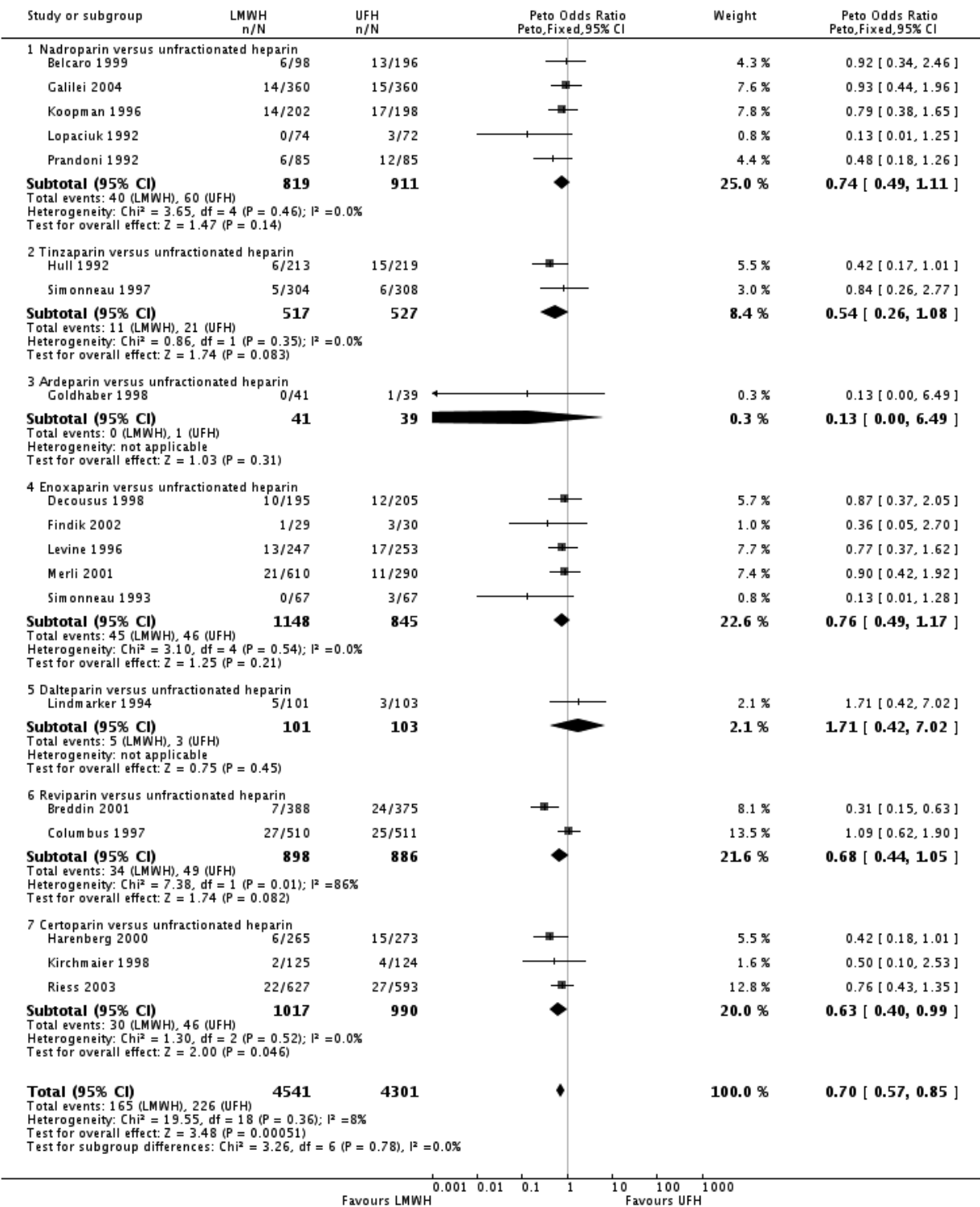


Graph 1.3 Comparison 1: LMWH versus UFH in patients with thromboembolism. Outcome 3: Incidence of recurrent venous thromboembolism at 1 month follow up.

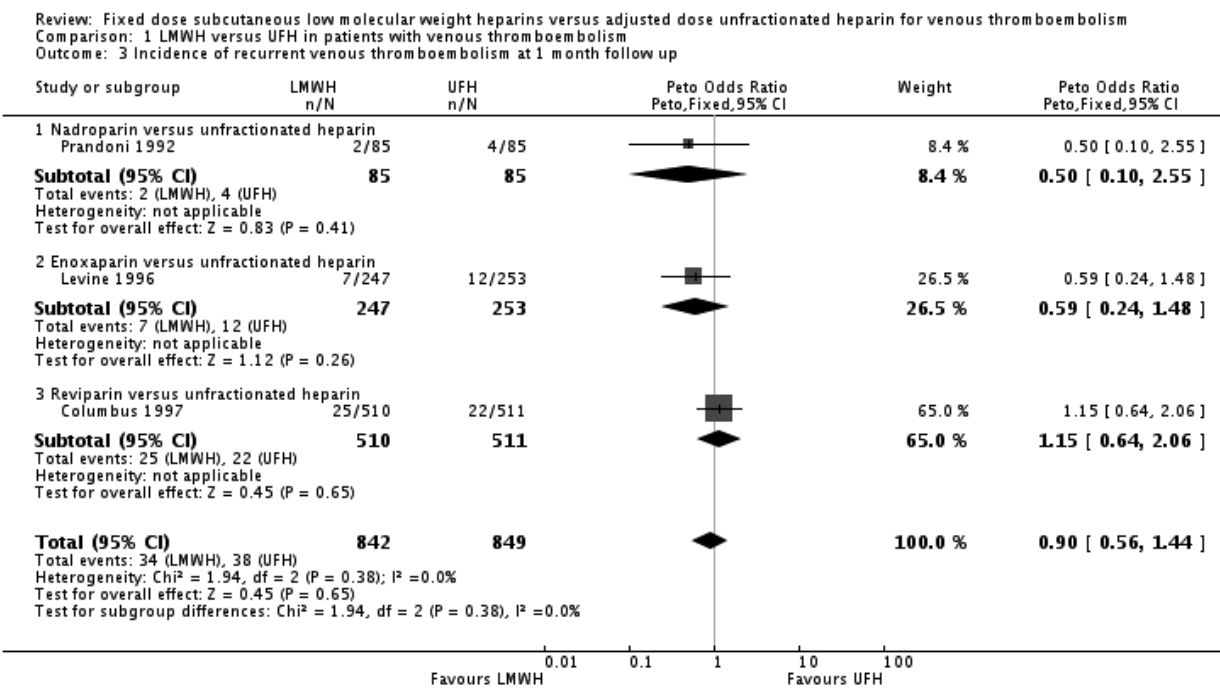


Graph 1.4 Comparison 1: LMWH versus UFH in patients with thromboembolism. Outcome 4: Incidence of recurrent venous thromboembolism at 2 months follow up.

Review: Fixed dose subcutaneous low molecular weight heparins versus adjusted dose unfractionated heparin for venous throm boem bolism Comparison: $1 \mathrm{LMWH}$ versus UFH in patients with venous throm boem bolism Outcom e: 4 Incidence of recurrent venous throm boembolism at 3 months follow up

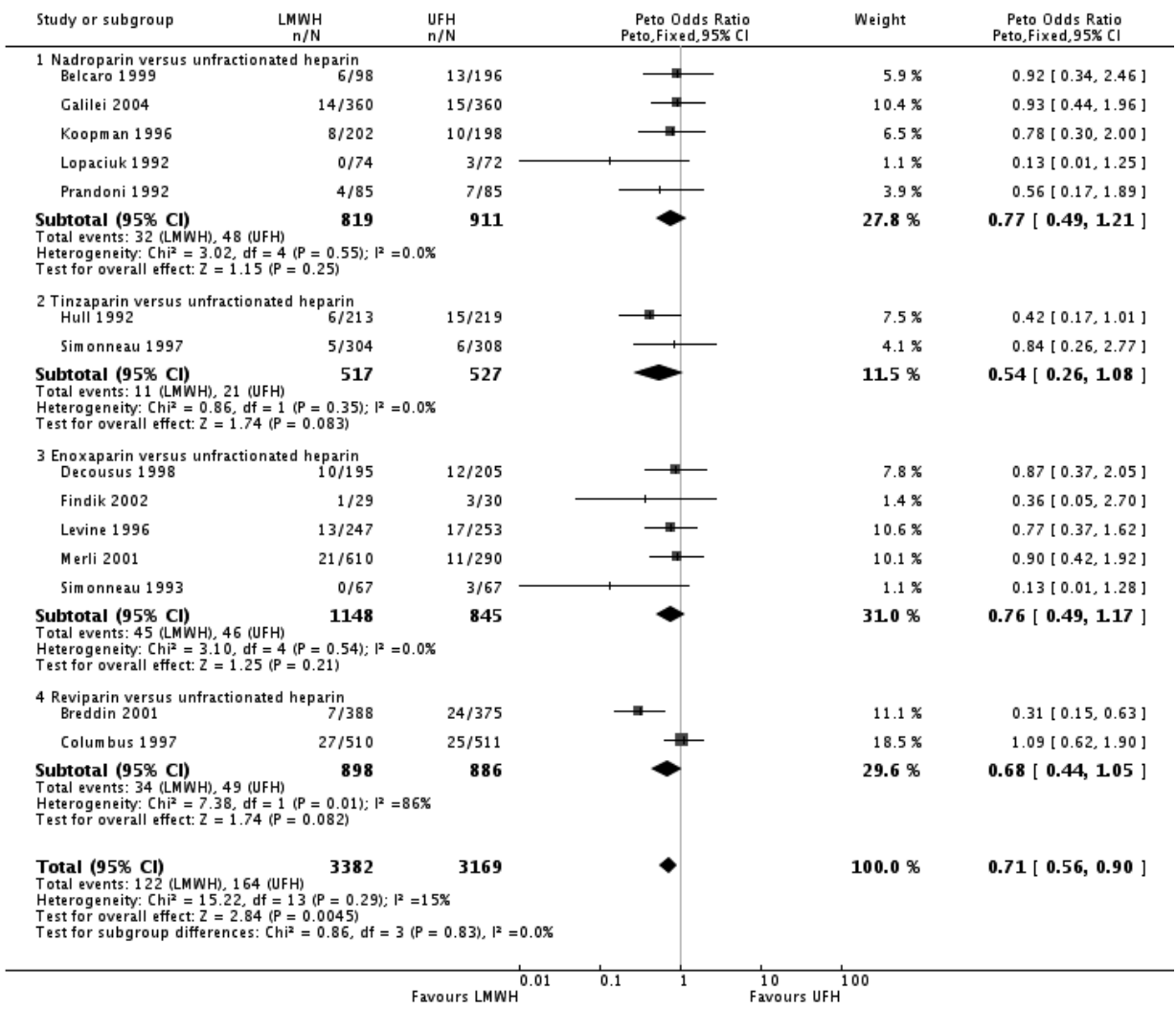


Graph 1.5 Comparison 1: LMWH versus UFH in patients with thromboembolism. Outcome 5: Incidence of recurrent venous thromboembolism at 6 months follow up.

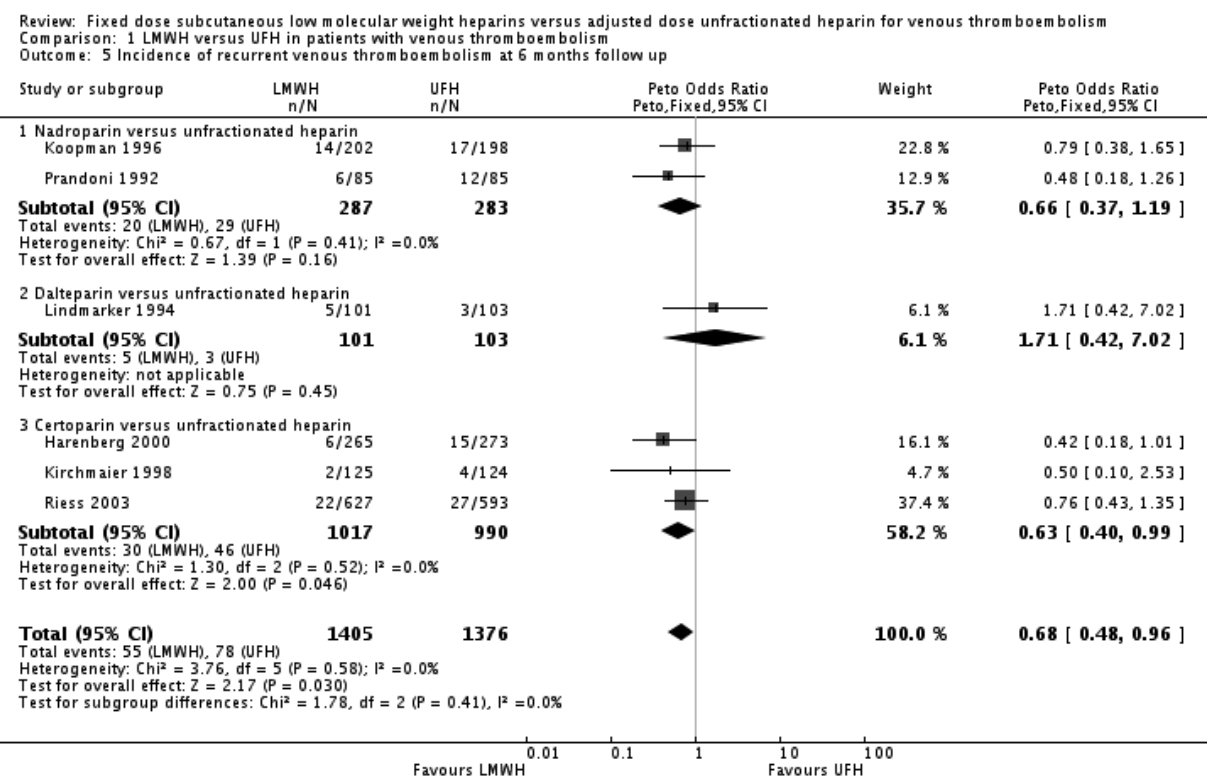


Graph 1.6 Comparison 1: LMWH versus UFH in patients with thromboembolism. Outcome 6: Incidence of major haemorrhagic episodes (during initial treatment).

Review: Fixed dose subcutaneous low molecular weight heparins versus adjusted dose unfractionated heparin for venous throm boem bolism Comparison: 1 LMWH versus UFH in patients with venous throm boem bolism Outcome: 6 Incidence of major haem orrhagic episodes (during initial treatment)

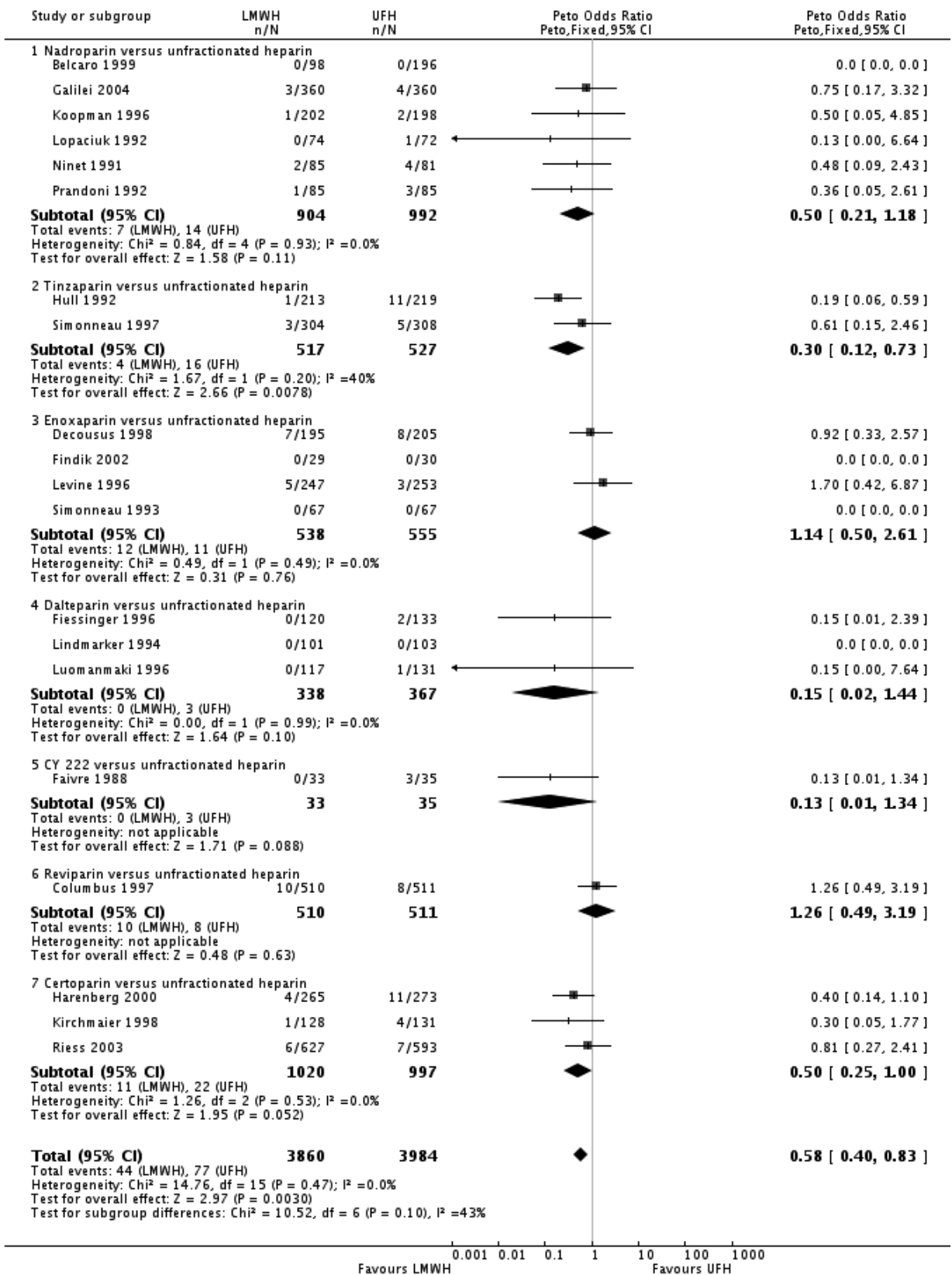


Graph 1.7 Comparison 1: LMWH versus UFH in patients with thromboembolism. Outcome 7: Overall mortality at the end of follow up.

Review: Fixed dose subcutaneous low molecular weight heparins versus adjusted dose unfractionated heparin for venous throm boem bolism Comparison: 1 LMWH versus UFH in patients with venous thromboembolism Outcome: 7 Overall mortality at the end of follow up

\begin{tabular}{|c|c|c|c|}
\hline Study or subgroup & $\begin{array}{l}\text { UFH } \\
\mathrm{n} / \mathrm{N}\end{array}$ & $\begin{array}{l}\text { Peto Odds Ratio } \\
\text { Peto,Fixed,95\% Cl }\end{array}$ & $\begin{array}{l}\text { Peto Odds Ratio } \\
\text { Peto,Fixed,95\% Cl }\end{array}$ \\
\hline \multicolumn{2}{|l|}{1 Nadroparin versus unfractionated heparin } & & $1.00[0.44,2.26]$ \\
\hline Koopm an 1996 & $16 / 198$ & $\Rightarrow$ & $0.85[0.40,1.78]$ \\
\hline Lopaciuk 1992 & $1 / 72$ & & $0.13[0.00,6.64]$ \\
\hline Prandoni 1992 & $12 / 85$ & — & $0.48[0.18,1.26]$ \\
\hline $\begin{array}{l}\text { Subtotal (95\% CI) } \\
\text { Total events: } 32(\mathrm{LMWH}), 41 \text { (UFH) } \\
\text { Heterogeneity: }\left(\mathrm{hi}^{2}=2.17 \mathrm{df}=3(\mathrm{P}=0.54) ; \mathrm{I}^{2}\right. \\
\text { Test for overall effect: } Z=1.13(\mathrm{P}=0.26)\end{array}$ & 715 & & $0.76[0.47,1.22]$ \\
\hline 2 Tinzaparin versus unfractionated heparin & $21 / 219$ & $\rightarrow$ & $0.48[0.23,1.00]$ \\
\hline Sim onneau 1997 & $14 / 308$ & $\rightarrow-$ & $0.86[0.39,1.89]$ \\
\hline $\begin{array}{l}\text { Subtotal }(95 \% \mathrm{Cl}) \\
\text { Total events: } 22(\mathrm{LMWH}), 35(\mathrm{UFH}) \\
\text { Heterogeneity: }\left(\mathrm{hi}^{2}=1.15, \mathrm{df}=1(\mathrm{P}=0.28) ; \mathrm{I}^{2}\right. \\
\text { Test for overall effect: } Z=1.69(\mathrm{P}=0.091)\end{array}$ & 527 & & $0.63[0.37,1.08]$ \\
\hline 3 Ardeparin versus unfractionated heparin & $0 / 39$ & & $0.0[0.0,0.0]$ \\
\hline $\begin{array}{l}\text { Subtotal }(95 \% \mathrm{CI}) \\
\text { Total events: } 0(\mathrm{LMWH}), 0(\mathrm{UFH}) \\
\text { Heterogeneity: not applicable } \\
\text { Test for overall effect: } Z=0.0(P<0.00001)\end{array}$ & 39 & & $0.0[0.0,0.0]$ \\
\hline $\begin{array}{l}4 \text { Enoxaparin versus unfractionated heparin } \\
\text { Decousus } 1998\end{array}$ & $43 / 205$ & & $0.97[0.60,1.58]$ \\
\hline Findik 2002 & $0 / 30$ & & $0.0[0.0,0.0]$ \\
\hline Levine 1996 & $17 / 253$ & $\rightarrow$ & $0.65[0.30,1.40]$ \\
\hline Merli 2001 & $9 / 290$ & $\rightarrow-$ & $0.95[0.42,2.15]$ \\
\hline Sim onneau 1993 & $2 / 67$ & & $1.51[0.25,8.96]$ \\
\hline $\begin{array}{l}\text { Subtotal }(95 \% \mathrm{Cl}) \\
\text { Total events: } 72(\mathrm{LMWH}), 71 \text { (UFH) } \\
\text { Heterogeneity: } C \mathrm{i}^{2}=1.13, \mathrm{df}=3(\mathrm{P}=0.77) ; \mathrm{I}^{2} \\
\text { Test for overall effect: } Z=0.56(\mathrm{P}=0.57)\end{array}$ & 845 & & $0.90[0.63,1.29]$ \\
\hline \multicolumn{4}{|l|}{5 Dalteparin versus unfractionated heparin } \\
\hline Luom anm aki 1996 & $4 / 116$ & & $0.31[0.05,1.82]$ \\
\hline $\begin{array}{l}\text { Subtotal }(95 \% \mathrm{Cl}) \\
\text { Total events: } 3(\mathrm{LMWH}), 7(\mathrm{UFH}) \\
\text { Heterogeneity: }\left(\mathrm{Ch}^{2}=0.37, \mathrm{df}=1(\mathrm{P}=0.54) ; \mathrm{I}^{2}\right. \\
\text { Test for overall effect: } Z=1.22(\mathrm{P}=0.22)\end{array}$ & 219 & & $0.46[0.13,1.60]$ \\
\hline \multicolumn{3}{|l|}{6 Reviparin versus unfractionated heparin } & $0.79[0.32,1.91]$ \\
\hline Columbus 1997 & $39 / 511$ & & $0.92[0.57,1.47]$ \\
\hline $\begin{array}{l}\text { Subtotal }(95 \% \mathrm{Cl}) \\
\text { Total events: } 45(\mathrm{LMWH}), 50(\mathrm{UFH}) \\
\text { Heterogeneity: }\left(\mathrm{h}^{2}=0.09, \mathrm{df}=1(\mathrm{P}=0.76) ; \mathrm{I}^{2}\right. \\
\text { Test for overall effect: } Z=0.56(\mathrm{P}=0.58)\end{array}$ & 886 & & $0.89[0.59,1.35]$ \\
\hline $\begin{array}{l}7 \text { Certoparin versus unfractionated heparin } \\
\text { Harenberg } 2000 \\
6 / 265\end{array}$ & $15 / 273$ & + & $0.42[0.18,1.01]$ \\
\hline Kirchm aier 1998 & $10 / 124$ & $\longrightarrow$ & $0.78[0.30,2.03]$ \\
\hline Riess 2003 & $16 / 593$ & $\rightarrow$ & $0.65[0.30,1.39]$ \\
\hline $\begin{array}{l}\text { Subtotal }(95 \% \mathrm{Cl}) \\
\text { Total events: } 25(\mathrm{LMWH}), 41(\mathrm{UFH}) \\
\text { Heterogeneity: }\left(\mathrm{Ch} \mathrm{i}^{2}=0.94, \mathrm{df}=2(\mathrm{P}=0.62) ; \mathrm{I}^{2}\right. \\
\text { Test for overall effect: } Z=2.07(\mathrm{P}=0.038)\end{array}$ & 990 & 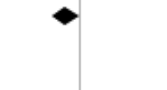 & $0.59[0.36,0.97]$ \\
\hline $\begin{array}{l}\text { Total (95\% CI) } \\
\text { Total events: } 199(\mathrm{LMWH}), 245 \text { (UFH) } \\
\text { Heterogeneity: } \mathrm{Chi} \mathrm{i}^{2}=9.33, \mathrm{df}=16(\mathrm{P}=0.90) \text {; } \\
\text { Test for overall effect: } \mathrm{Z}=2.66(\mathrm{P}=0.0078) \\
\text { Test for subgroup differences: } \mathrm{Chi}^{2}=3.47 \text {, df }\end{array}$ & $\begin{array}{l}4221 \\
.0 \% \\
=0.63), 1^{2}\end{array}$ & $\bullet$ & $0.77[0.63,0.93]$ \\
\hline
\end{tabular}


Graph 1.8 Comparison 1: LMWH versus UFH in patients with thromboembolism. Outcome 8: Change in thrombus size.

Review: Fixed dose subcutaneous low molecular weight heparins versus adjusted dose unfractionated heparin for venous throm boem bolism Comparison: 1 LMWH versus UFH in patients with venous thromboembolism

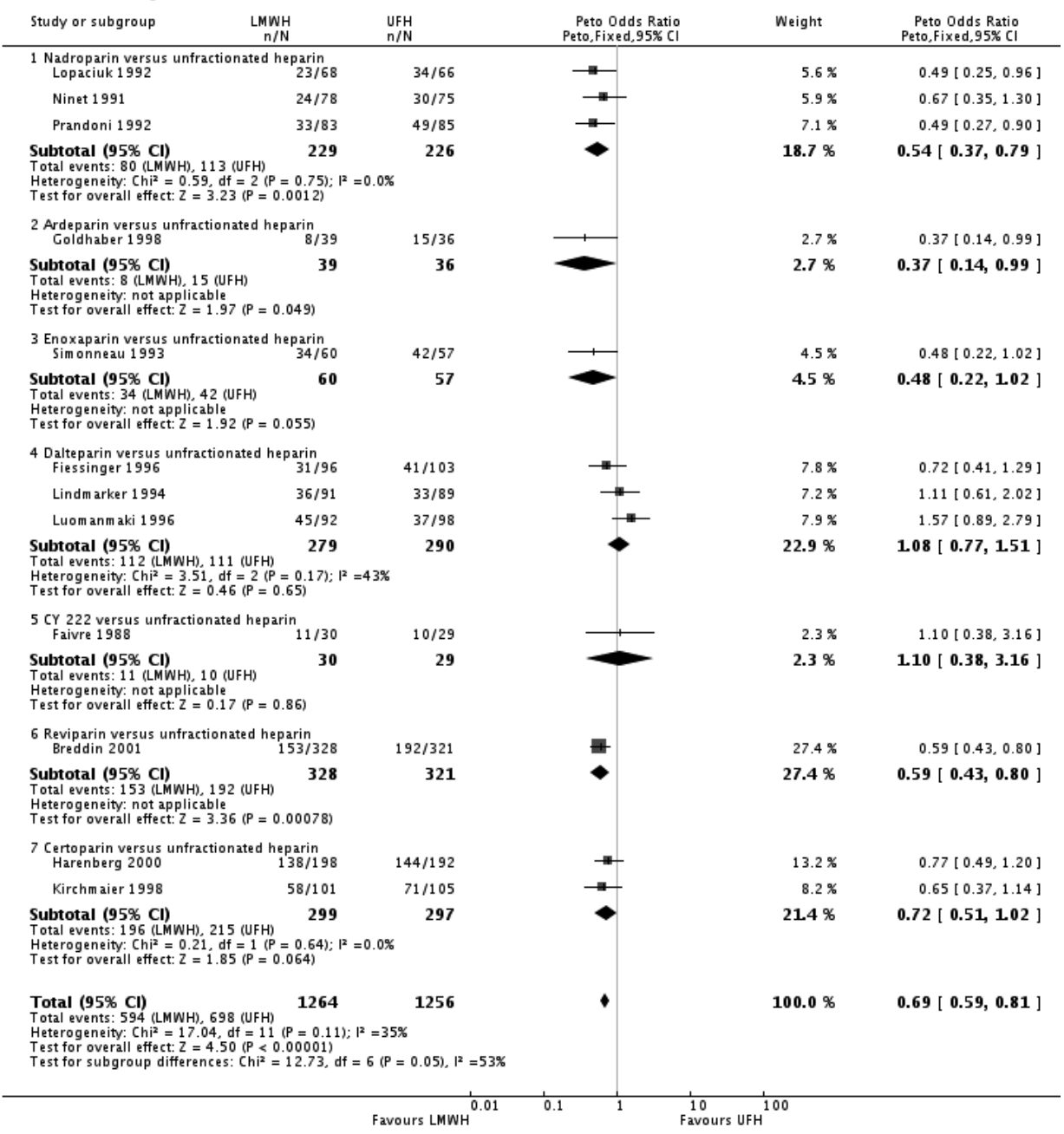


Graph 2.1 Comparison 2: LMWH versus UFH in patients with proximal deep venous thrombosis. Outcome 1: Incidence of recurrent venous thromboembolism at the end of follow up.

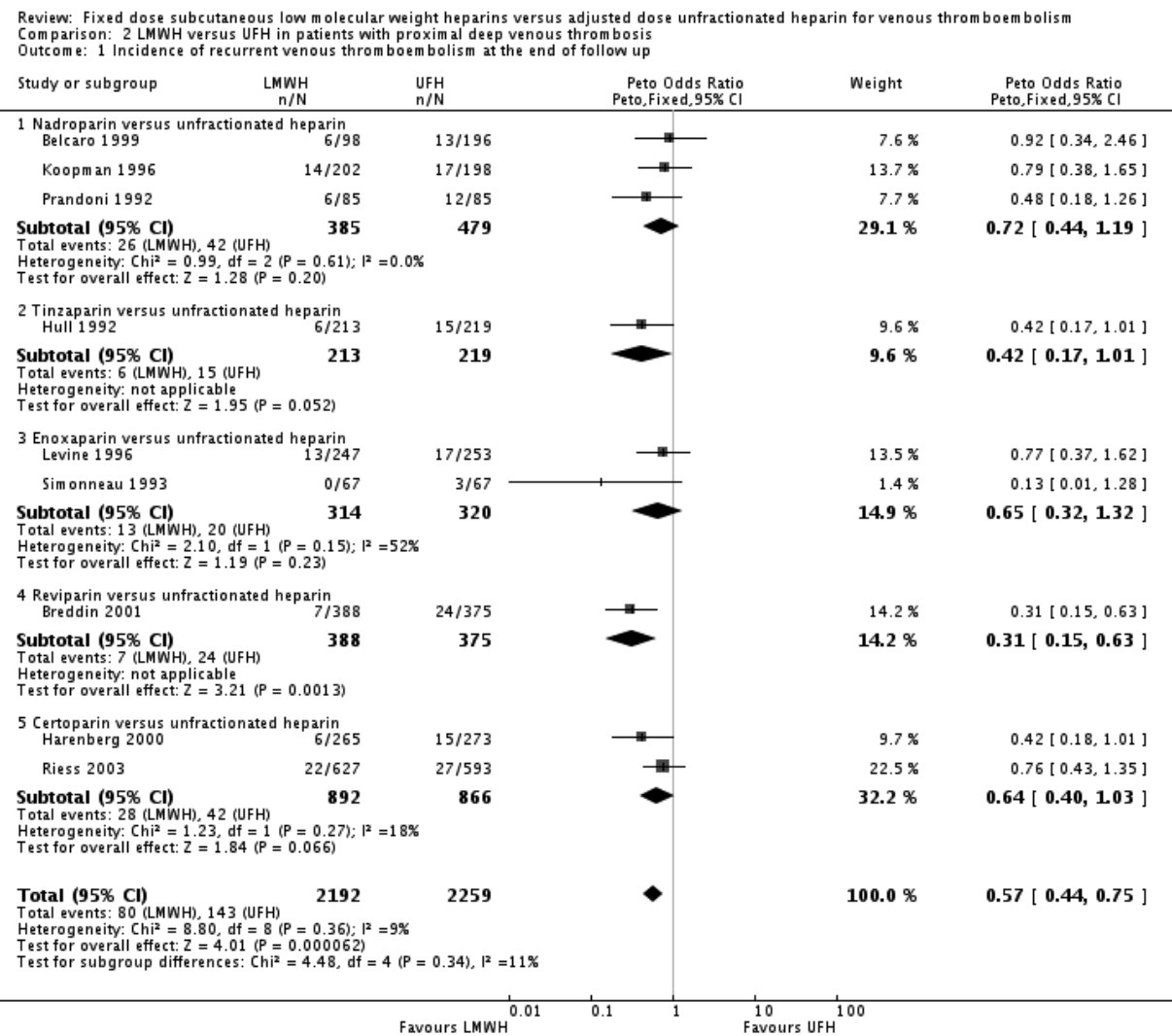


Graph 2.2 Comparison 2: LMWH versus UFH in patients with proximal deep venous thrombosis. Outcome 2: Incidence of deep venous thrombosis at the end of follow up.

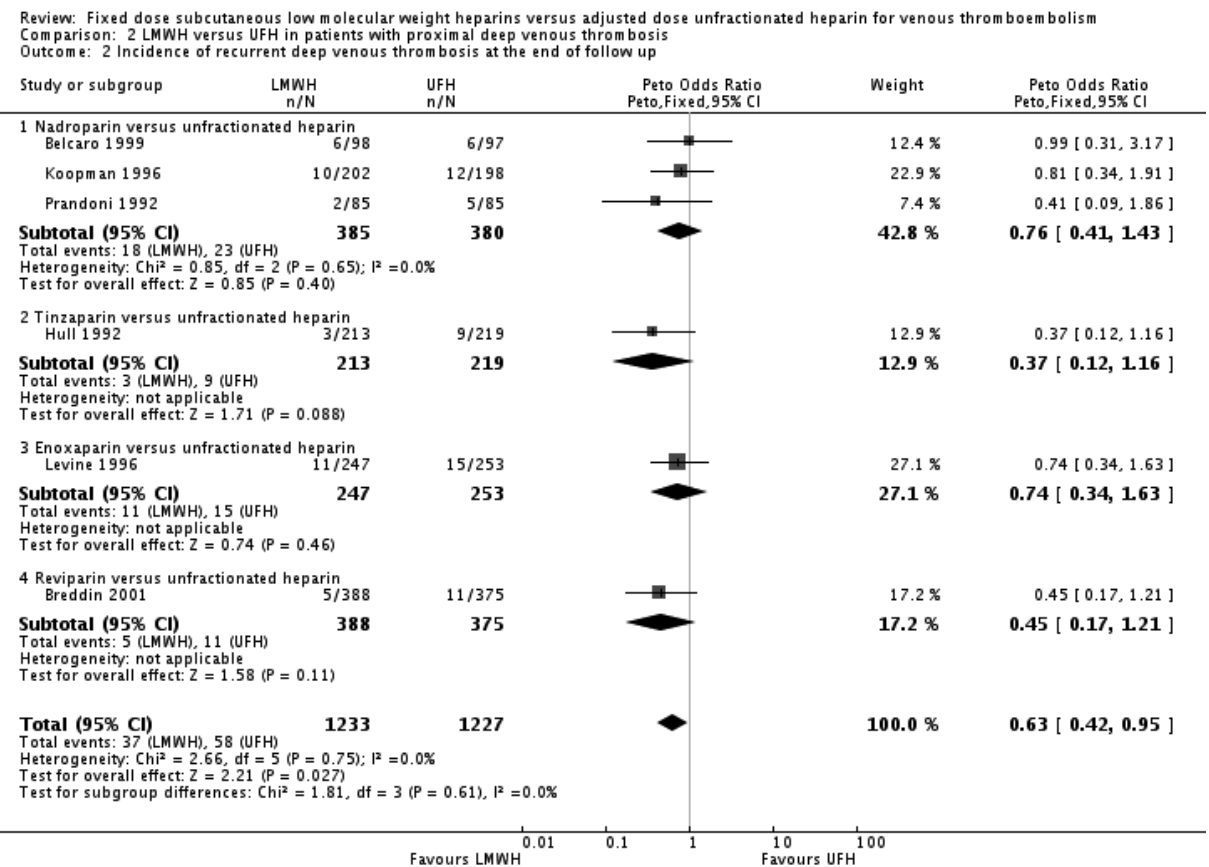


Graph 2.3 Comparison 2: LMWH versus UFH in patients with proximal deep venous thrombosis. Outcome 3: Incidence of pulmonary embolism at the end of follow up.

Review: Fixed dose subcutaneous low molecular weight heparins versus adjusted dose unfractionated heparin for venous throm boem bolism Comparison: 2 LMWH versus UFH in patients with proxim al deep venous throm bosi

\begin{tabular}{|c|c|c|c|c|}
\hline Study or subgroup & $\begin{array}{l}\text { UFH } \\
\mathrm{n} / \mathrm{N}\end{array}$ & $\begin{array}{r}\text { Peto Odds Ratio } \\
\text { Peto, Fixed, } 95 \% \mathrm{Cl}\end{array}$ & Weight & $\begin{array}{r}\text { Peto Odds Ratio } \\
\text { Peto, Fixed, } 95 \% \mathrm{Cl}\end{array}$ \\
\hline $\begin{array}{l}1 \text { Nadroparin versus unfractionated heparin } \\
\text { Koopman } 1996\end{array}$ & $5 / 198$ & 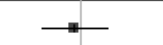 & $14.6 \%$ & $0.78[0.21,2.92]$ \\
\hline Prandoni 1992 & $7 / 85$ & & $17.2 \%$ & $0.56[0.17,1.89]$ \\
\hline $\begin{array}{l}\text { Subtotal }(95 \% \mathrm{Cl}) \\
\text { Total events: } 8(\mathrm{LMWH}), 12(\mathrm{UFH}) \\
\text { Heterogeneity: } \mathrm{Chi^{2 }}=0.13, \mathrm{df}=1(\mathrm{P}=0.72) \\
\text { Test for overall effect: } \mathrm{Z}=0.93(\mathrm{P}=0.35)\end{array}$ & 283 & & $31.8 \%$ & $0.65[0.27,1.60]$ \\
\hline $\begin{array}{l}2 \text { Tinzaparin versus unfractionated heparin } \\
\text { Hull } 1992\end{array}$ & $6 / 219$ & & $14.6 \%$ & $0.52[0.14,1.95]$ \\
\hline $\begin{array}{l}\text { Subtotal }(95 \% \text { Cl) } \\
\text { Total events: } 3(\mathrm{LMWH}), 6(\mathrm{UFH}) \\
\text { Heterogeneity: not applicable } \\
\text { Test for overall effect: } Z=0.97(\mathrm{P}=0.33)\end{array}$ & 219 & & $14.6 \%$ & $0.52[0.14,1.95]$ \\
\hline $\begin{array}{l}3 \text { Enoxaparin versus unfractionated heparin } \\
\text { Levine } 1996\end{array}$ & $2 / 253$ & & $5.0 \%$ & $0.52[0.05,5.07]$ \\
\hline $\begin{array}{l}\text { Subtotal }(95 \% \text { CI) } \\
\text { Total events: } 1 \text { (LMWH), } 2 \text { (UFH) } \\
\text { Heterogeneity: not applicable } \\
\text { Test for overall effect: } Z=0.56(P=0.58)\end{array}$ & 253 & & $5.0 \%$ & $0.52[0.05,5.07]$ \\
\hline $\begin{array}{l}4 \text { Reviparin versus unfractionated heparin } \\
\text { Breddin } 2001\end{array}$ & $13 / 375$ & & $26.0 \%$ & $0.27[0.10,0.73]$ \\
\hline $\begin{array}{l}\text { Subtotal }(95 \% \text { Cl) } \\
\text { Total events: } 3(\mathrm{LMWH}), 13(\mathrm{UFH}) \\
\text { Heterogeneity: not applicable } \\
\text { Test for overall effect: } Z=2.59(\mathrm{P}=0.0095)\end{array}$ & 375 & & $26.0 \%$ & $0.27[0.10,0.73]$ \\
\hline $\begin{array}{l}5 \text { Certoparin versus unfractionated heparin } \\
\text { Harenberg } 2000\end{array}$ & $11 / 273$ & $\pi$ & $22.6 \%$ & $0.32[0.11,0.92]$ \\
\hline $\begin{array}{l}\text { Subtotal }(95 \% \text { Cl) } \\
\text { Total events: } 3 \text { (LMWH), } 11 \text { (UFH) } \\
\text { Heterogeneity: not applicable } \\
\text { Test for overall effect: } Z=2.11(P=0.035)\end{array}$ & 273 & & $22.6 \%$ & $0.32[0.11,0.92]$ \\
\hline $\begin{array}{l}\text { Total (95\% CI) } \\
\text { Total events: } 18(\text { (LMWH), } 44(\mathrm{UFH}) \\
\text { Heterogeneity: } \mathrm{Chi}^{2}=2.23, \mathrm{df}=5(\mathrm{P}=0.82) \\
\text { Test for overall effect: } \mathrm{Z}=3.35(\mathrm{P}=0.00082) \\
\text { Test for subgroup differences: } \mathrm{Chi}^{2}=2.09, \mathrm{~d}\end{array}$ & $\begin{array}{l}1403 \\
=0.72),\left.\right|^{2}=0.0 \%\end{array}$ & $>$ & $100.0 \%$ & $0.42[0.26,0.70]$ \\
\hline
\end{tabular}


Graph 2.4 Comparison 2: LMWH versus UFH in patients with proximal deep venous thrombosis. Outcome 4: Incidence of major haemorrhagic episodes (during initial treatment).

Review: Fixed dose subcutaneous low molecular weight heparins versus adjusted dose unfractionated heparin for venous throm boembolism Comparison: 2 LMWH versus UFH in patients with proximal deep venous throm bosis Outcome: 4 Incidence of major haem orrhagic episodes (during initial treatm ent)

\begin{tabular}{|c|c|c|c|}
\hline Study or subgroup & $\begin{array}{l}\text { UFH } \\
\mathrm{n} / \mathrm{N}\end{array}$ & $\begin{array}{r}\text { Peto Odds Ratio } \\
\text { Peto,Fixed, } 95 \% \mathrm{Cl}\end{array}$ & $\begin{array}{l}\text { Peto Odds Ratio } \\
\text { Peto,Fixed,95\% Cl }\end{array}$ \\
\hline \multicolumn{3}{|l|}{1 Nadroparin versus unfractionated heparin } & $0.0[0.0,0.0]$ \\
\hline Koopm an 1996 & $2 / 198$ & & $0.50[0.05,4.85]$ \\
\hline Prandoni 1992 & $3 / 85$ & 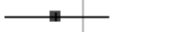 & $0.36[0.05,2.61]$ \\
\hline $\begin{array}{l}\text { Subtotal (95\% Cl) } \\
\text { Total events: } 2(\mathrm{LWMH}), 5(\mathrm{UFH}) \\
\text { Heterogeneity: }\left(\mathrm{Chi} \mathrm{i}^{2}=0.05, \mathrm{df}=1(\mathrm{P}=0.83) ; \mathrm{I}^{2}\right. \\
\text { Test for overall effect: } \mathrm{Z}=1.15(\mathrm{P}=0.25)\end{array}$ & 380 & & $0.42[0.09,1.85]$ \\
\hline 2 Tinzaparin versus unfractionated heparin & $11 / 219$ & & $0.19[0.06,0.59]$ \\
\hline $\begin{array}{l}\text { Subtotal }(95 \% \mathrm{CI}) \\
\text { Total events: } 1(\mathrm{LWMH}), 11(\mathrm{UFH}) \\
\text { Heterogeneity: not applicable } \\
\text { Test for overall effect: } Z=2.88(\mathrm{P}=0.0040)\end{array}$ & 219 & & $0.19[0.06,0.59]$ \\
\hline 3 Enoxaparin versus unfractionated heparin & $3 / 253$ & & $1.70[0.42,6.87]$ \\
\hline Simonneau 1993 & $0 / 67$ & & $0.0[0.0,0.0]$ \\
\hline $\begin{array}{l}\text { Subtotal (95\% Cl) } \\
\text { Total events: } 5(\mathrm{LWMH}), 3(\mathrm{UFH}) \\
\text { Heterogeneity: } \mathrm{Chi}^{2}=0.0, \mathrm{df}=0(\mathrm{P}=1.00) ;\left.\right|^{2} \\
\text { Test for overall effect: } \mathrm{Z}=0.75(\mathrm{P}=0.46)\end{array}$ & 320 & & $1.70[0.42,6.87$ ] \\
\hline \multicolumn{2}{|l|}{$\begin{array}{l}4 \text { Certoparin versus unfractionated heparin } \\
\text { Harenberg } 2000\end{array}$} & & $0.40[0.14,1.10]$ \\
\hline Riess 2003 & $7 / 593$ & _t & $0.81[0.27,2.41]$ \\
\hline $\begin{array}{l}\text { Subtotal }(95 \% \mathrm{CI}) \\
\text { Total events: } 10(\mathrm{LWM} H), 18(\mathrm{UFH}) \\
\text { Heterogeneity: }\left(\mathrm{Ch}^{2}=0.88, \mathrm{df}=1(\mathrm{P}=0.35) ; \mathrm{I}^{2}\right. \\
\text { Test for overall effect: } Z=1.55(\mathrm{P}=0.12)\end{array}$ & 866 & & $0.55[0.26,1.17$ ] \\
\hline $\begin{array}{l}\text { Total (95\% CI) } \\
\text { Total events: } 18 \text { (LWM H), } 37 \text { (UFH) } \\
\text { Heterogeneity: }\left(\mathrm{Ch} \mathrm{i}^{2}=6.87, \mathrm{df}=5(\mathrm{P}=0.23) ; \mathrm{I}^{2}\right. \\
\text { Test for overall effect: } Z=2.57(\mathrm{P}=0.010) \\
\text { Test for subgroup differences: } \mathrm{Chi}^{2}=5.94, \mathrm{df}\end{array}$ & $\begin{array}{l}1785 \\
=0.11), 1^{2}=50 \%\end{array}$ & & $0.50[0.29,0.85]$ \\
\hline
\end{tabular}


Graph 2.5 Comparison 2: LMWH versus UFH in patients with proximal deep venous thrombosis. Outcome 5: Overall mortality at the end of follow up.

\begin{tabular}{|c|c|c|c|c|}
\hline Study or subgroup & $\begin{array}{l}\text { UFH } \\
\mathrm{n} / \mathrm{N}\end{array}$ & $\begin{array}{r}\text { Peto Odds Ratio } \\
\text { Peto, Fixed, } 95 \% \mathrm{Cl}\end{array}$ & Weight & $\begin{array}{r}\text { Peto Odds Ratio } \\
\text { Peto,Fixed,95\% Cl }\end{array}$ \\
\hline $\begin{array}{l}\text { Nadroparin versus unfractionated heparin } \\
\text { Koopman } 1996 \\
14 / 202\end{array}$ & $16 / 198$ & $\mp-$ & $16.3 \%$ & $0.85[0.40,1.78]$ \\
\hline Prandoni 1992 & $12 / 85$ & $\longrightarrow$ & $9.5 \%$ & $0.48[0.18,1.26]$ \\
\hline $\begin{array}{l}\text { Subtotal (95\% Cl) } \\
\text { Total events: } 20(\mathrm{LWM}), 28 \text { (UFH) } \\
\text { Heterogeneity: }\left(\mathrm{Ch} \mathrm{i}^{2}=0.85, \mathrm{df}=1(\mathrm{P}=0.36) ; \mathrm{I}^{2}\right. \\
\text { Test for overall effect: } Z=1.25(\mathrm{P}=0.21)\end{array}$ & 283 & & $25.8 \%$ & $0.69[0.38,1.24]$ \\
\hline $\begin{array}{l}2 \text { Tinzaparin versus unfractionated heparin } \\
\text { Hull } 1992 \\
10 / 213\end{array}$ & $21 / 219$ & $一$ & $16.9 \%$ & $0.48[0.23,1.00]$ \\
\hline $\begin{array}{l}\text { Subtotal (95\% Cl) } \\
\text { Total events: } 10 \text { (LWM H), } 21 \text { (UFH) } \\
\text { Heterogeneity: not applicable } \\
\text { Test for overall effect: } Z=1.97(P=0.049)\end{array}$ & 219 & & $16.9 \%$ & $0.48[0.23,1.00]$ \\
\hline $\begin{array}{l}3 \text { Enoxaparin versus unfractionated heparin } \\
\text { Levine } 1996 \\
11 / 247\end{array}$ & $17 / 253$ & $v^{2}$ & $15.6 \%$ & $0.65[0.30,1.40]$ \\
\hline Sim onneau 1993 & $2 / 67$ & & $2.8 \%$ & $1.51[0.25,8.96]$ \\
\hline $\begin{array}{l}\text { Subtotal (95\% Cl) } \\
\text { Total events: } 14(\mathrm{LWMH}), 19(\mathrm{UFH}) \\
\text { Heterogeneity: Chi }{ }^{2}=0.72, \mathrm{df}=1(\mathrm{P}=0.40) ; \mathrm{I}^{2} \\
\text { Test for overall effect: } Z=0.83(\mathrm{P}=0.40)\end{array}$ & 320 & & $18.4 \%$ & $0.74[0.37,150]$ \\
\hline $\begin{array}{l}4 \text { Reviparin versus unfractionated heparin } \\
\text { Breddin } 2001\end{array}$ & $11 / 375$ & & $11.4 \%$ & $0.79[0.32,1.91]$ \\
\hline $\begin{array}{l}\text { Subtotal }(95 \% \mathrm{Cl}) \\
\text { Total events: } 9 \text { (LWMH), } 11 \text { (UFH) } \\
\text { Heterogeneity: not applicable } \\
\text { Test for overall effect: } Z=0.53(P=0.60)\end{array}$ & 375 & & $114 \%$ & $0.79[0.32,1.91]$ \\
\hline $\begin{array}{l}5 \text { Certoparin versus unfractionated heparin } \\
\text { Harenberg } 2000 \\
6 / 265\end{array}$ & $15 / 273$ & \pm & $11.9 \%$ & $0.42[0.18,1.01]$ \\
\hline Riess 2003 & $16 / 593$ & $\rightarrow-$ & $15.5 \%$ & $0.65[0.30,1.39]$ \\
\hline $\begin{array}{l}\text { Subtotal (95\% Cl) } \\
\text { Total events: } 17(\mathrm{LWM} H), 31(\mathrm{UFH}) \\
\text { Heterogeneity: } \mathrm{Chi}^{2}=0.51, \mathrm{df}=1(\mathrm{P}=0.47) ; \mathrm{I}^{2} \\
\text { Test for overall effect: } Z=2.11(\mathrm{P}=0.034)\end{array}$ & 866 & & $27.4 \%$ & $0.54[0.30,0.96]$ \\
\hline $\begin{array}{l}\text { Total (95\% CI) } \\
\text { Total events: } 70(\mathrm{LWMH}), 110(\mathrm{UFH}) \\
\text { Heterogeneity: } \mathrm{Chi}^{2}=3.43, \mathrm{df}=7(\mathrm{P}=0.84) ; \mathrm{I}^{2} \\
\text { Test for overall effect: } Z=3.09(\mathrm{P}=0.0020) \\
\text { Test for subgroup differences: Chi }{ }^{2}=1.34, \mathrm{df}\end{array}$ & $\begin{array}{l}2063 \\
.0 \%=0.85), 1^{2}=0.0 \%\end{array}$ & $\bullet$ & $100.0 \%$ & $0.62[0.46,0.84]$ \\
\hline
\end{tabular}


Graph 3.1 Comparison 3: LMWH versus UFH in patients with pulmonary embolism. Outcome 1: Incidence of recurrent venous thromboembolism at the end of follow up.

Review: Fixed dose subcutaneous low molecular weight heparins versus adjusted dose unfractionated heparin for venous thromboem bolism Comparison: 3 LMWH versus UFH in patients with pulm onary embolism

Outcom e: 1 Incidence of recurrent venous throm boembolism at the end of follow up

\begin{tabular}{|c|c|c|c|c|}
\hline Study or subgroup & $\begin{array}{l}\text { UFH } \\
\mathrm{n} / \mathrm{N}\end{array}$ & $\begin{array}{r}\text { Peto Odds Ratio } \\
\text { Peto, Fixed, } 95 \% \mathrm{Cl}\end{array}$ & Weight & $\begin{array}{r}\text { Peto Odds Ratio } \\
\text { Peto,Fixed, } 95 \% \mathrm{Cl}\end{array}$ \\
\hline $\begin{array}{l}1 \text { Tinzaparin versus unfractionated heparin } \\
\text { Sim onneau } 1997\end{array}$ & $6 / 308$ & & $26.3 \%$ & $0.84[0.26,2.77]$ \\
\hline $\begin{array}{l}\text { Subtotal }(95 \% \text { Cl) } \\
\text { Total events: } 5(\mathrm{LMWH}), 6(\mathrm{UFH}) \\
\text { Heterogeneity: not applicable } \\
\text { Test for overall effect: } Z=0.28(P=0.78)\end{array}$ & 308 & & $26.3 \%$ & $0.84[0.26,2.77]$ \\
\hline $\begin{array}{l}2 \text { Enoxaparin versus unfractionated heparin } \\
\text { Findik } 2002 \\
1 / 29\end{array}$ & $3 / 30$ & 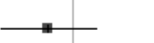 & $9.2 \%$ & $0.36[0.05,2.70]$ \\
\hline Merli 2001 & $4 / 88$ & & $27.7 \%$ & $1.11[0.35,3.55]$ \\
\hline $\begin{array}{l}\text { Subtotal (95\% Cl) } \\
\text { Total events: } 11(\mathrm{LMWH}), 7(\mathrm{UFH}) \\
\text { Heterogeneity: }\left(\mathrm{Ch} \mathrm{i}^{2}=0.90, \mathrm{df}=1(\mathrm{P}=0.34) ; \mathrm{I}^{2}\right. \\
\text { Test for overall effect: } Z=0.35(\mathrm{P}=0.73)\end{array}$ & 118 & & $36.9 \%$ & $0.84[0.31,2.29]$ \\
\hline $\begin{array}{l}3 \text { Reviparin versus unfractionated heparin } \\
\text { Columbus } 1997 \\
8 / 138\end{array}$ & $8 / 133$ & & $36.8 \%$ & $0.96[0.35,2.64]$ \\
\hline $\begin{array}{l}\text { Subtotal }(95 \% \text { Cl) } \\
\text { Total events: } 8 \text { (LMWH), } 8 \text { (UFH) } \\
\text { Heterogeneity: not applicable } \\
\text { Test for overall effect: } Z=0.08(P=0.94)\end{array}$ & 133 & & $36.8 \%$ & $0.96[0.35,2.64]$ \\
\hline $\begin{array}{l}\text { Total (95\% Cl) } \\
\text { Total events: } 24(\mathrm{LMWH}), 21(\mathrm{UFH}) \\
\text { Heterogeneity: } C \mathrm{Ch}^{2}=0.94, \mathrm{df}=3(\mathrm{P}=0.82) ; \mathrm{I}^{2} \\
\text { Test for overall effect: } Z=0.40(\mathrm{P}=0.69) \\
\text { Test for subgroup differences: } C \mathrm{Ch}^{2}=0.04 \mathrm{df}\end{array}$ & \% 0.98$), 1^{2}=0.0 \%$ & & $100.0 \%$ & $0.88[0.48,1.63]$ \\
\hline
\end{tabular}

Graph 4.1 Comparison 3: LMWH versus UFH in patients with proximal deep venous thrombosis and malignant disease. Outcome 1: Mortality at the end of follow up.

Review: Fixed dose subcutaneous low molecular weight heparins versus adjusted dose unfractionated heparin for venous thromboem bolism Comparison: 4 LMWH versus UFH in patients with venous thromboembolism and malignant disease
Outcome: 1 Mortality at the end of follow up

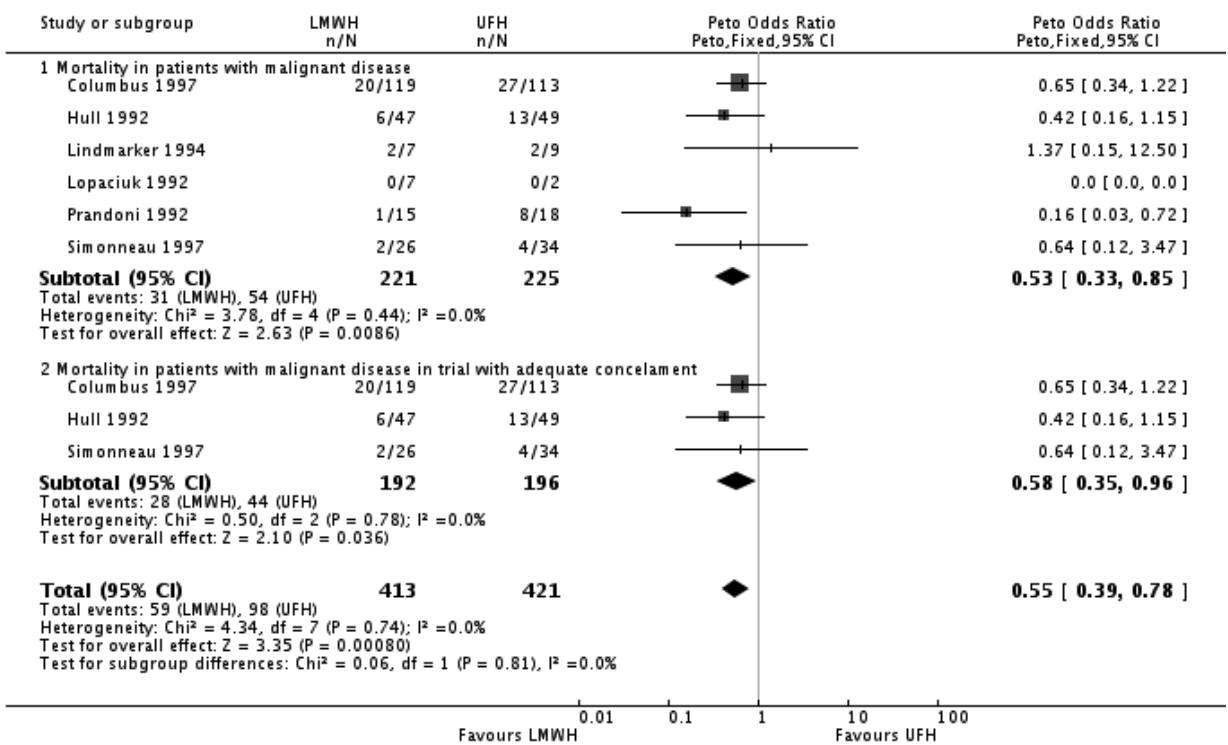


Graph 5.1 Comparison 5: LMWH versus UFH in patients with proximal deep venous thrombosis without malignant disease. Outcome 1: Mortality at the end of follow up.

Review: Fixed dose subcutaneous low m olecular weight heparins versus adjusted dose unfractionated heparin for venous throm boem bolism Comparison: 5 LMWH versus UFH in patients with venous thromboembolism without $m$ alignant disease Outcome: 1 Mortality at the end of follow up

\begin{tabular}{|c|c|c|c|c|c|}
\hline Study or subgroup & $\underset{\mathrm{n} / \mathrm{N}}{\mathrm{LMWH}}$ & $\begin{array}{l}\text { UFH } \\
\mathrm{n} / \mathrm{N}\end{array}$ & $\begin{array}{r}\text { Peto Odds Ratio } \\
\text { Peto, Fixed, } 95 \% \text { Cl } \\
\end{array}$ & Weight & $\begin{array}{r}\text { Peto Odds Ratio } \\
\text { Peto,Fixed, } 95 \% \mathrm{Cl} \\
\end{array}$ \\
\hline \multicolumn{6}{|c|}{$\begin{array}{l}1 \text { Mortality in patients without m alignant disease } \\
\text { Columbus } 1997 \\
16 / 391\end{array}$} \\
\hline Hull 1992 & $4 / 166$ & $8 / 170$ & $\longrightarrow$ & $9.2 \%$ & $0.51[0.16,1.63]$ \\
\hline Lindm arker 1994 & $0 / 94$ & $1 / 94$ & & $0.8 \%$ & $0.14[0.00,6.82]$ \\
\hline Lopaciuk 1992 & $0 / 67$ & $1 / 70$ & & $0.8 \%$ & $0.14[0.00,7.13]$ \\
\hline Prandoni 1992 & $5 / 70$ & $4 / 67$ & & $6.7 \%$ & $1.21[0.31,4.65]$ \\
\hline Simonneau 1997 & $10 / 278$ & $10 / 274$ & & $15.3 \%$ & $0.99[0.40,2.40]$ \\
\hline $\begin{array}{l}\text { Subtotal }(95 \% \mathrm{Cl}) \\
\text { Total events: } 35(\mathrm{LMW} \\
\text { Heterogeneity: } \mathrm{Chi}^{2}= \\
\text { Test for overall effect: }\end{array}$ & $\begin{array}{l}\text { H) } \\
=5(P=0.55) ;\left.\right|^{2}= \\
=(P=0.91)\end{array}$ & 1073 & & $54.1 \%$ & $0.97[0.61,1.56]$ \\
\hline \multicolumn{3}{|c|}{2 Mortality in patients without malignant disease in trials with adequate concealm ent } & ealm ent & $21.4 \%$ & $1.37[0.64,2.91]$ \\
\hline Hull 1992 & $4 / 166$ & $8 / 170$ & $\longrightarrow$ & $9.2 \%$ & $0.51[0.16,1.63]$ \\
\hline Simonneau 1997 & $10 / 278$ & $10 / 274$ & $\rightarrow-$ & $15.3 \%$ & $0.99[0.40,2.40]$ \\
\hline $\begin{array}{l}\text { Subtotal (95\% Cl) } \\
\text { Total events: } 30(\mathrm{LMW} \\
\text { Heterogeneity: } \mathrm{Chi}^{2}= \\
\text { Test for overall effect: }\end{array}$ & $\begin{array}{l}\text { H) } \\
=235=0.38) ;\left.\right|^{2}= \\
=2(P=0.97)\end{array}$ & 842 & & $45.9 \%$ & $1.01[0.60,1.69]$ \\
\hline $\begin{array}{l}\text { Total (95\% Cl) } \\
\text { Total events: } 65(\mathrm{LMn} \\
\text { Heterogeneity: } \mathrm{Chi}^{2}= \\
\text { Test for overall effect } \\
\text { Test for subgroup dif }\end{array}$ & $\begin{array}{l}1901 \\
=H) \quad 8(P=0.65) ;\left.\right|^{2} \\
=8(P=0.95) \\
C h i^{2}=0.01, d f=\end{array}$ & $\begin{aligned} & 1915 \\
0 \% & 0.92), 1^{2}=\end{aligned}$ & $\bullet$ & $100.0 \%$ & $0.99[0.70,1.40]$ \\
\hline
\end{tabular}


Graph 6.1 Comparison 6: LMWH versus subcutaneous UFH in patients with venous thromboembolism. Outcome 1: Incidence of recurrent venous thromboembolism at the end of follow up.

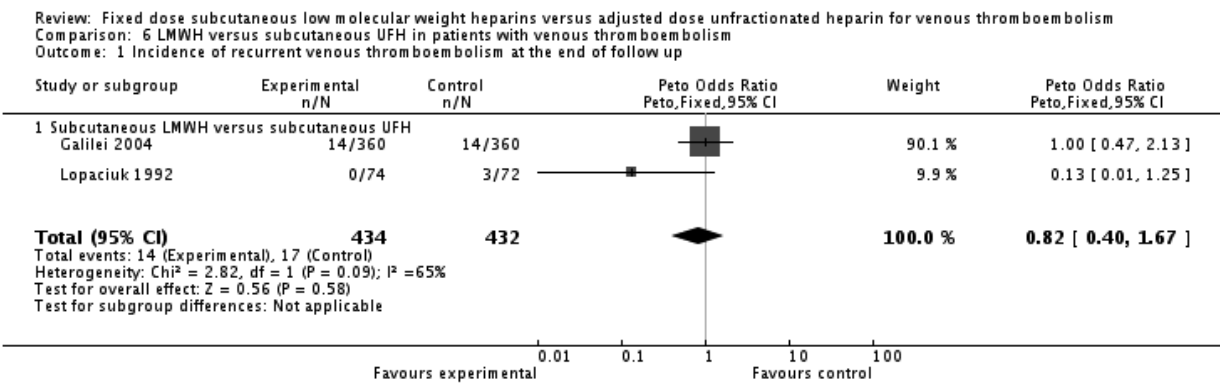

Graph 6.2 Comparison 6: LMWH versus subcutaneous UFH in patients with venous thromboembolism. Outcome 2: Incidence of major haemorrhagic episodes (during initial treatment).

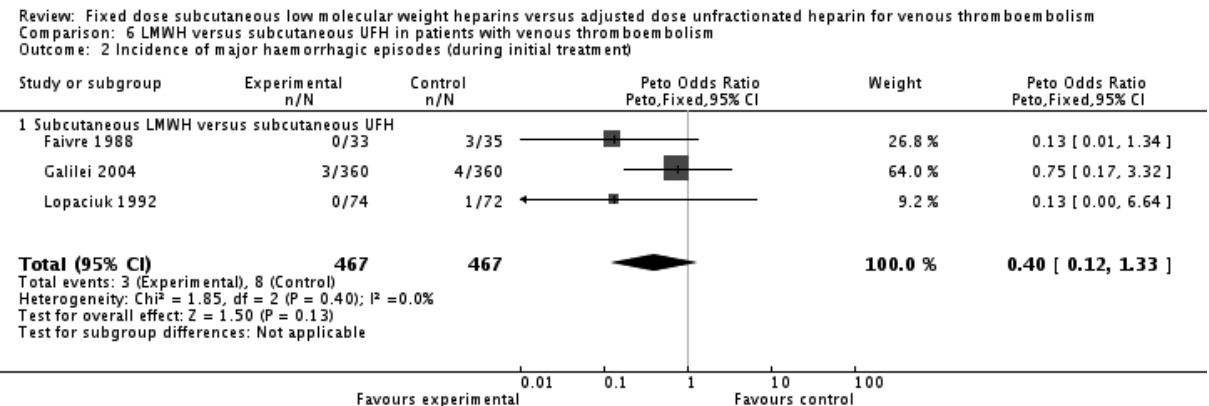

Graph 6.3 Comparison 6: LMWH versus subcutaneous UFH in patients with venous thromboembolism. Outcome 3: Overall mortality at the end of follow up.

Review: Fixed dose subcutaneous low molecular weight heparins versus adjusted dose unfractionated heparin for venous throm boem bolism Comparison: 6 LMWH versus subcutaneous UFH in patients with venous throm boem bolism Outcome: 3

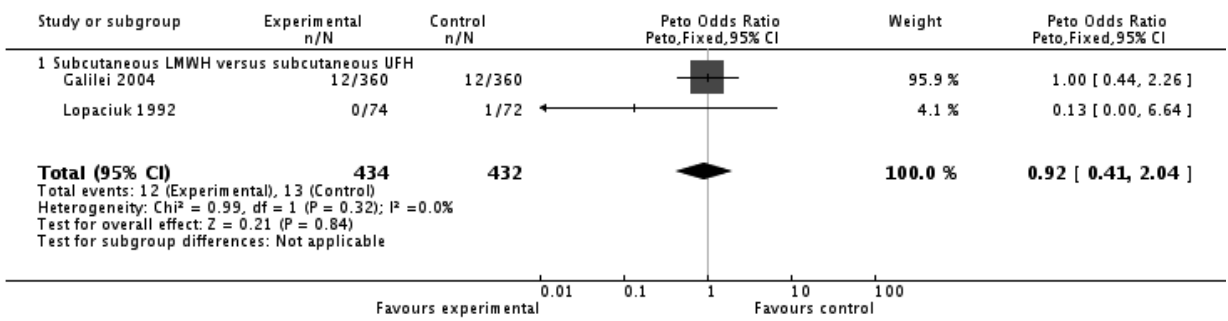


Graph 7.1 Comparison 7: LMWH versus intravenous UFH in patients with venous thromboembolism. Outcome 1: Incidence of recurrent venous thromboembolism at the end of follow up.

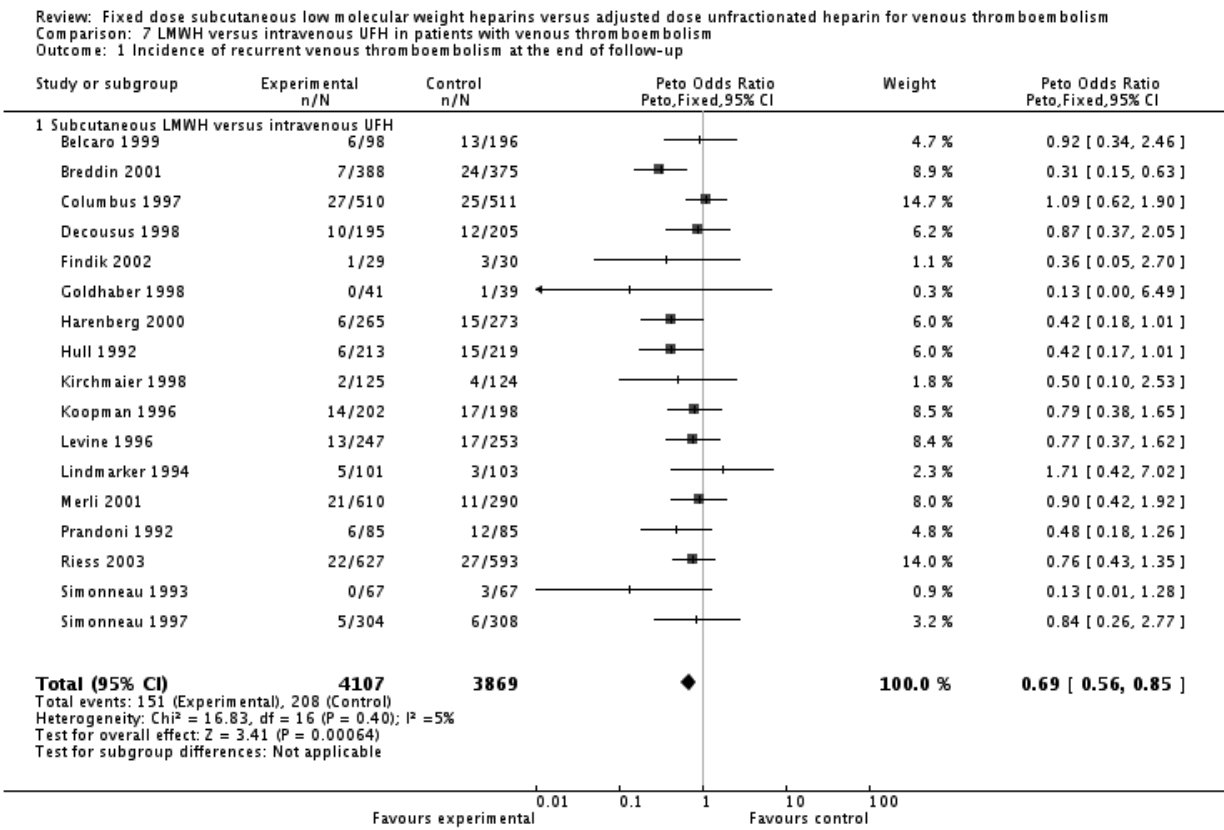


Graph 7.2 Comparison 7: LMWH versus intravenous UFH in patients with venous thromboembolism. Outcome 2: Incidence of major haemorrhigic episodes (during initial treatment).

Review: Fixed dose subcutaneous low molecular weight heparins versus adjusted dose unfractionated heparin for venous thromboem bolism Comparison: 7 LMWH versus intravenous UFH in patients with venous throm boem bolis Outcome: 2 Incidence of major haem orrhagic episodes (during initial treatm ent)

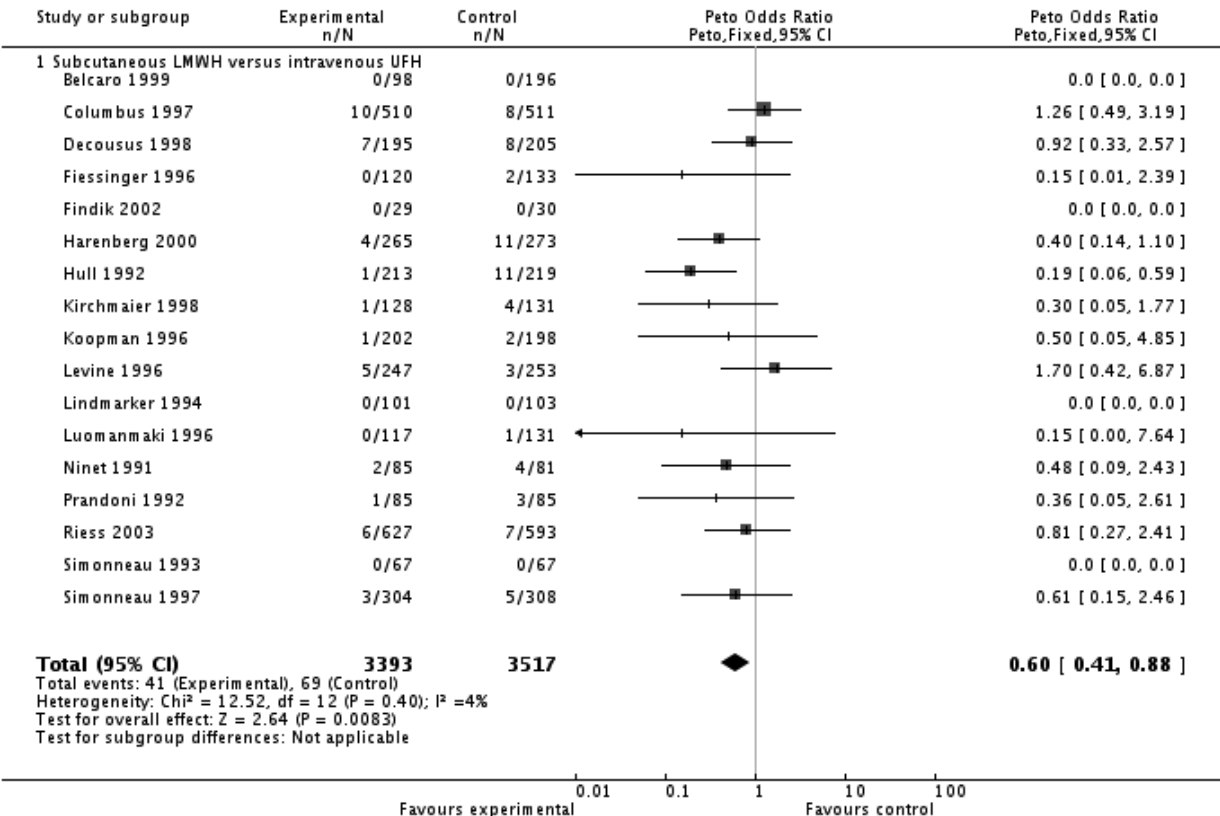


Graph 7.3 Comparison 7: LMWH versus intravenous UFH in patients with venous thromboembolism. Outcome 3: Overall mortality at the end of follow up.

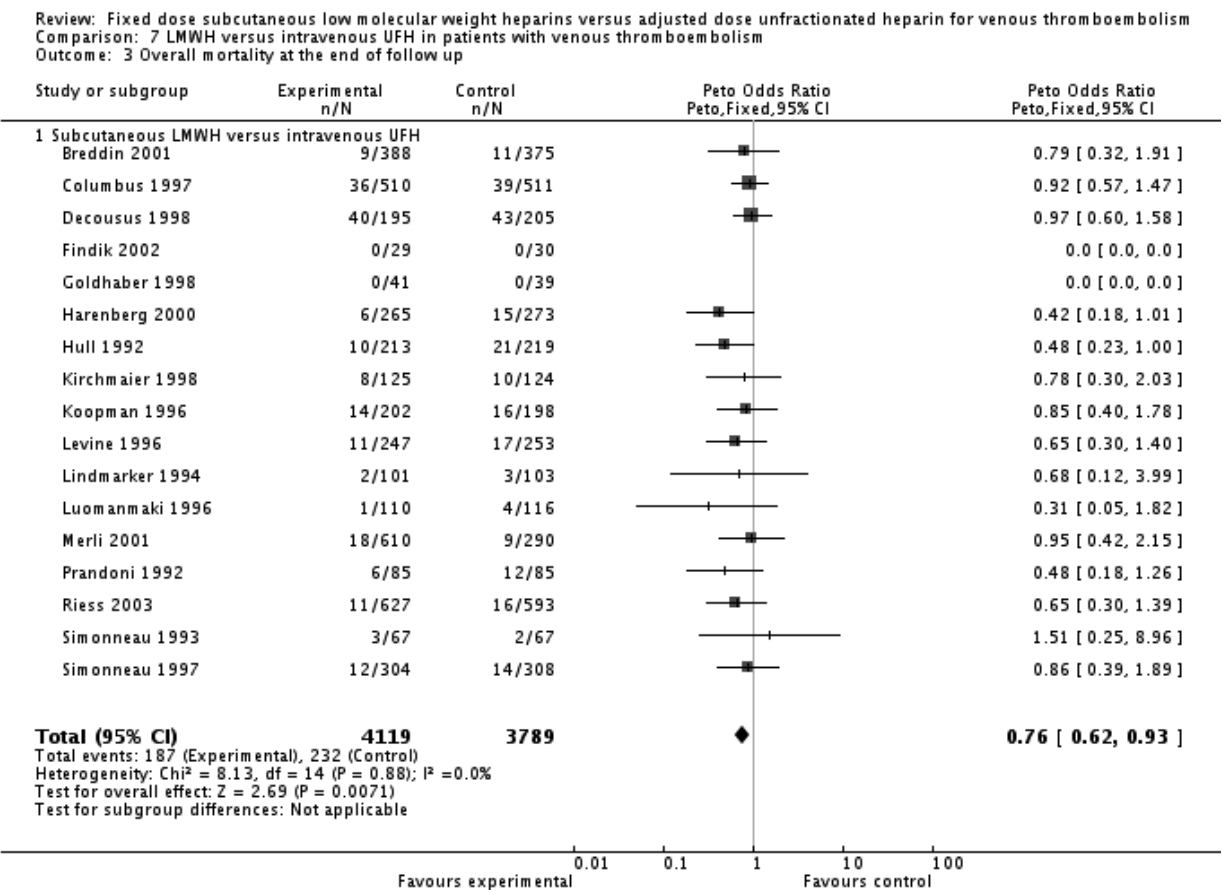


Graph 8.1 Comparison 8: LMWH versus UFH: all randomised controlled trials with adequate concealment of allocation. Outcome 1: Incidence of recurrent venous thromboembolism during initial treatment.

Review: Fixed dose subcutaneous low molecular weight heparins versus adjusted dose unfractionated heparin for venous thromboem bolism Comparison: 8 LMWH versus UFH: all random ised controlled trials with adequate concealment of allocation

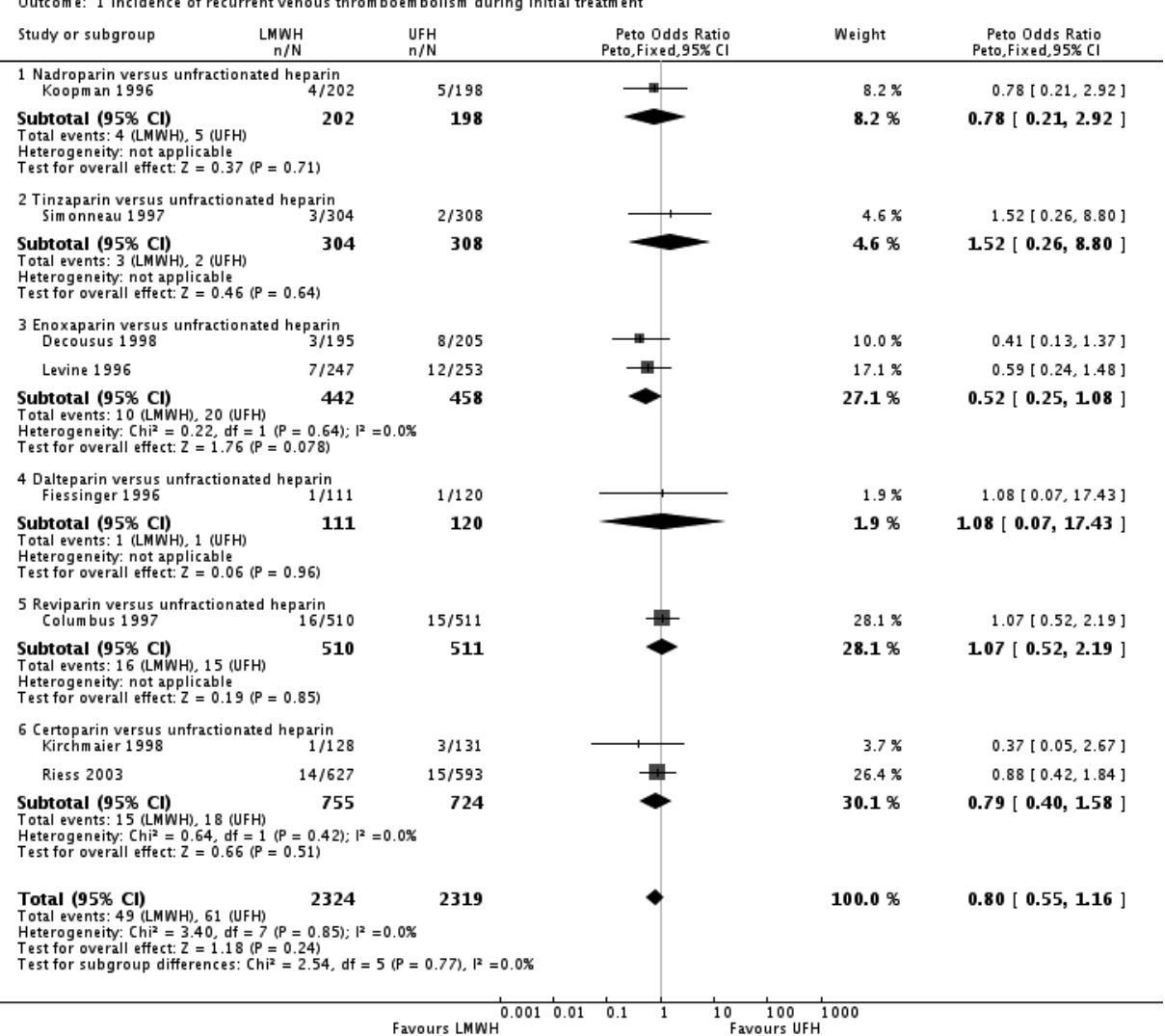


Graph 8.2 Comparison 8: LMWH versus UFH: all randomised controlled trials with adequate concealment of allocation. Outcome 2 : Incidence of recurrent venous thromboembolism at the end of follow up.

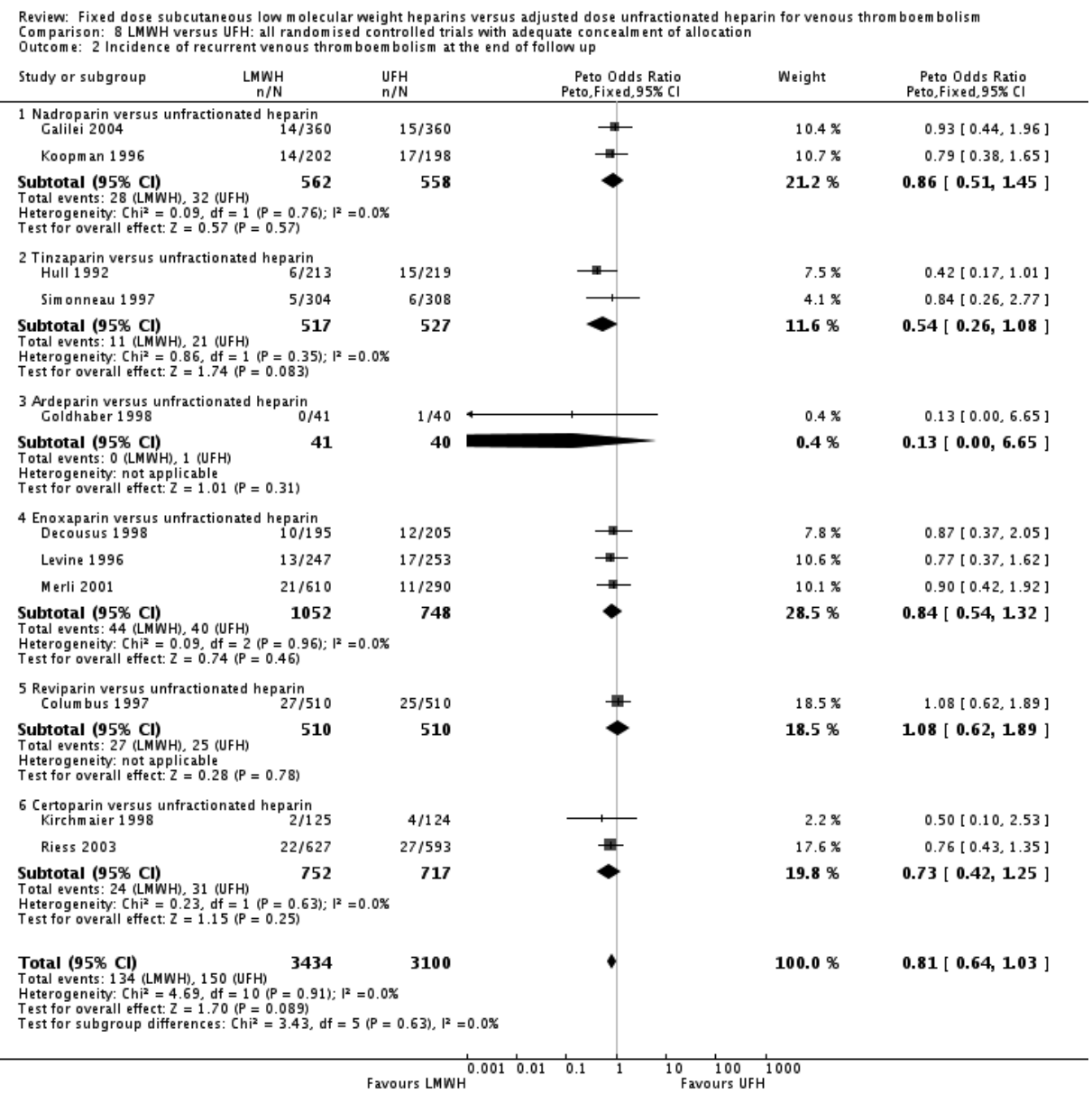


Graph 8.3 Comparison 8: LMWH versus UFH: all randomised controlled trials with adequate concealment of allocation. Outcome 3 : Incidence of recurrent venous thromboembolism at 3 months follow up.

Review: Fixed dose subcutaneous low molecular weight heparins versus adjusted dose unfractionated heparin for venous throm boem bolism Comparison: 8 LMWH versus UFH: all random ised controlled trials with adequate concealm ent of allocation

\begin{tabular}{|c|c|c|c|c|}
\hline Study or subgroup & $\begin{array}{l}\text { UFH } \\
\mathrm{n} / \mathrm{N}\end{array}$ & $\begin{array}{r}\text { Peto Odds Ratio } \\
\text { Peto, Fixed, } 95 \% \mathrm{Cl} \\
\end{array}$ & Weight & $\begin{array}{r}\text { Peto Odds Ratio } \\
\text { Peto,Fixed, } 95 \% \mathrm{Cl} \\
\end{array}$ \\
\hline $\begin{array}{c}1 \text { Tinzaparin versus unfractionated heparin } \\
\text { Galilei } 2004 \\
14 / 360\end{array}$ & $15 / 360$ & $\rightarrow-$ & $20.5 \%$ & $0.93[0.44,1.96]$ \\
\hline Sim onneau 1997 & $6 / 308$ & $\mp$ & $8.0 \%$ & $0.84[0.26,2.77]$ \\
\hline $\begin{array}{l}\text { Subtotal (95\% Cl) } \\
\text { Total events: } 19(\mathrm{LMWH}), 21(\mathrm{UFH}) \\
\text { Heterogeneity: }\left(\mathrm{Ch} \mathrm{i}^{2}=0.02, \mathrm{df}=1(\mathrm{P}=0.89) ; 1\right. \\
\text { Test for overall effect: } Z=0.31(\mathrm{P}=0.76)\end{array}$ & 668 & & $28.5 \%$ & $0.91[0.48,1.70]$ \\
\hline $\begin{array}{l}2 \text { Enoxaparin versus unfractionated heparin } \\
\text { Decousus } 1998 \\
10 / 195\end{array}$ & $12 / 205$ & 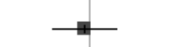 & $15.3 \%$ & $0.87[0.37,2.05]$ \\
\hline Merli 2001 & $11 / 290$ & $\rightarrow-$ & $19.9 \%$ & $0.90[0.42,1.92]$ \\
\hline $\begin{array}{l}\text { Subtotal (95\% Cl) } \\
\text { Total events: } 31(\mathrm{LMWH}), 23(\mathrm{UFH}) \\
\text { Heterogeneity: }\left(\mathrm{hi} \mathrm{i}^{2}=0.00, \mathrm{df}=1(\mathrm{P}=0.95) ; \mathrm{I}^{2}\right. \\
\text { Test for overall effect: } Z=0.41(\mathrm{P}=0.68)\end{array}$ & 495 & & $35.2 \%$ & $0.89[0.50,157]$ \\
\hline $\begin{array}{l}3 \text { Reviparin versus unfractionated heparin } \\
\text { Columbus } 1997 \\
27 / 510\end{array}$ & $25 / 511$ & & $36.3 \%$ & $1.09[0.62,1.90]$ \\
\hline $\begin{array}{l}\text { Subtotal (95\% Cl) } \\
\text { Total events: } 27 \text { (LMWH), } 25 \text { (UFH) } \\
\text { Heterogeneity: not applicable } \\
\text { Test for overall effect: } Z=0.29(\mathrm{P}=0.77)\end{array}$ & 511 & & $36.3 \%$ & $1.09[0.62,1.90]$ \\
\hline $\begin{array}{l}\text { Total (95\% Cl) } \\
\text { Total events: } 77 \text { (LMWH), } 69(\mathrm{UFH}) \\
\text { Heterogeneity: } \mathrm{Ch} \mathrm{i}^{2}=0.32, \mathrm{df}=4(\mathrm{P}=0.99) ; \mathrm{I}^{2} \\
\text { Test for overall effect: } \mathrm{Z}=0.23(\mathrm{P}=0.82) \\
\text { Test for subgroup differences: } \mathrm{Chi}^{2}=0.29 \text {, df }\end{array}$ & $\begin{array}{l}1674 \\
P=0.86), I^{2}=0.0 \%\end{array}$ & & $100.0 \%$ & $0.96[0.69,1.35]$ \\
\hline
\end{tabular}


Graph 8.4 Comparison 8: LMWH versus UFH: all randomised controlled trials with adequate concealment of allocation. Outcome 4: Incidence major haemorrhagic episodes (during initial treatment).

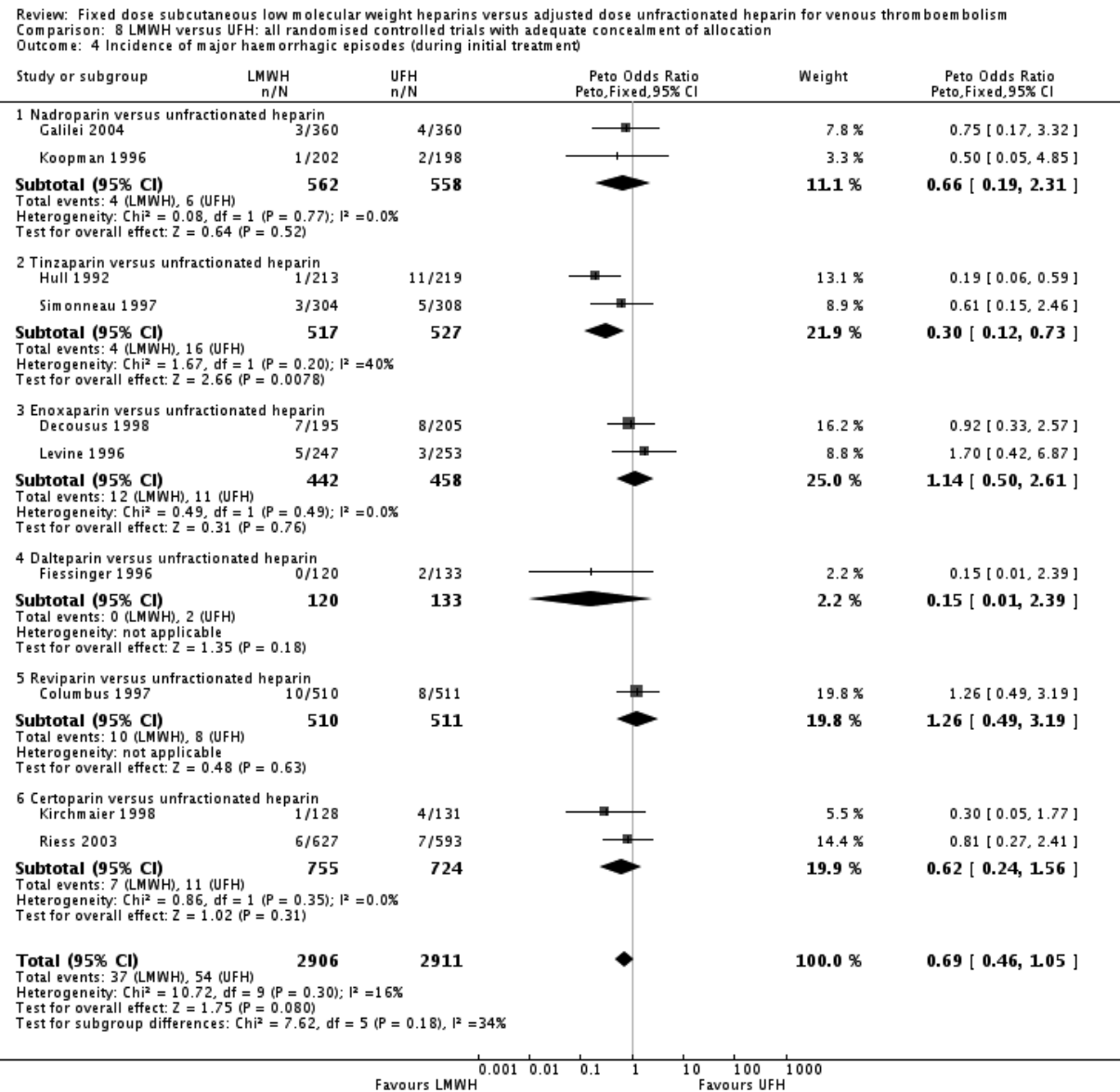


Graph 8.5 Comparison 8: LMWH versus UFH: all randomised controlled trials with adequate concealment of allocation. Outcome 5: Overall mortality at the end of follow up.

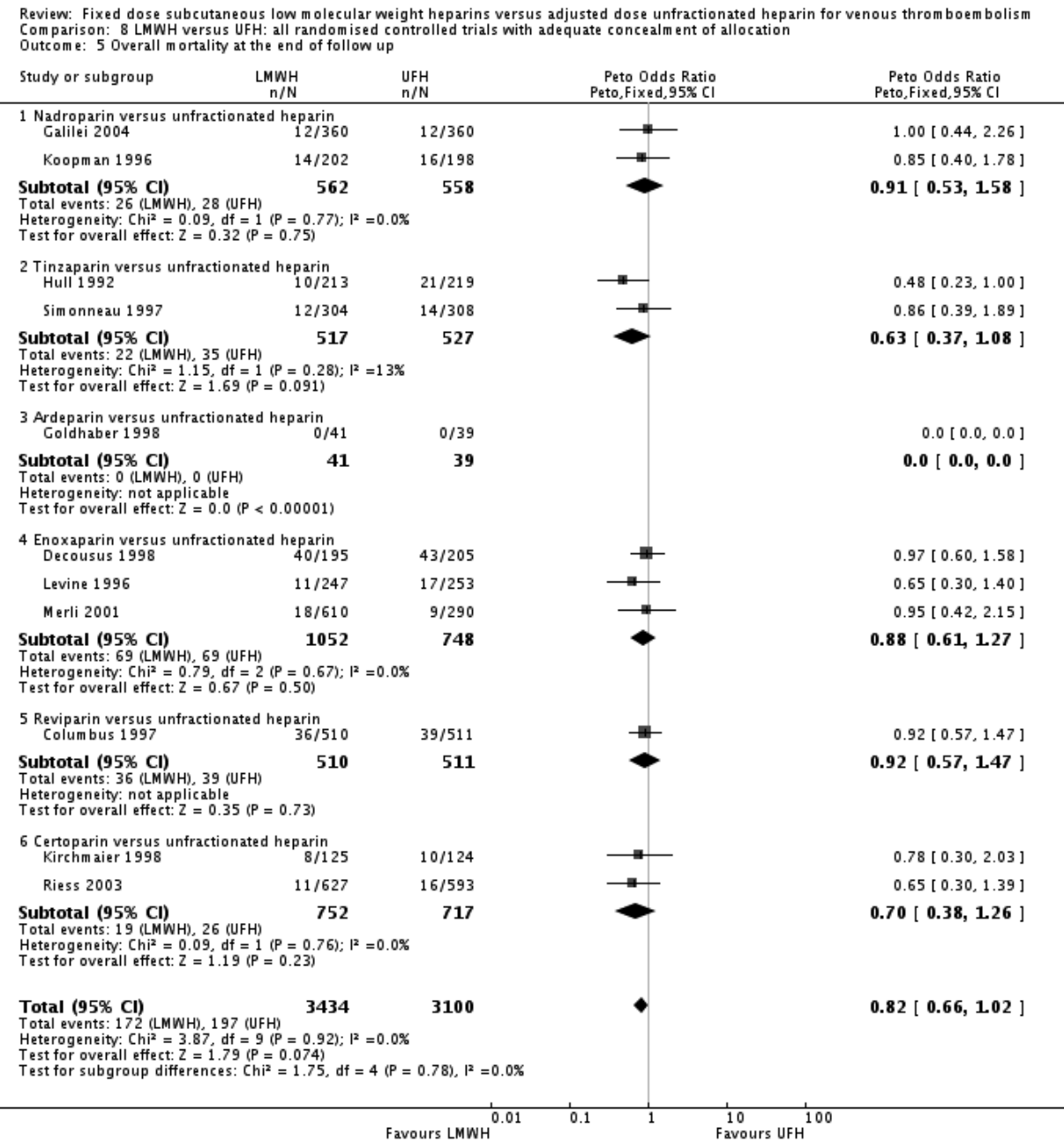


Graph 8.6 Comparison 8: LMWH versus UFH: all randomised controlled trials with adequate concealment of allocation. Outcome 6: Change in thrombus size.

Review: Fixed dose subcutaneous low molecular weight heparins versus adjusted dose unfractionated heparin for venous throm boem bolism Comparison: 8 LMWH versus UFH: all random ised controlled trials with adequate concealment of allocation

\begin{tabular}{|c|c|c|c|c|}
\hline Study or subgroup & $\begin{array}{l}\text { UFH } \\
\mathrm{n} / \mathrm{N}\end{array}$ & $\begin{array}{r}\text { Peto Odds Ratio } \\
\text { Peto, Fixed, } 95 \% \mathrm{Cl}\end{array}$ & Weight & $\begin{array}{r}\text { Peto Odds Ratio } \\
\text { Peto, Fixed, } 95 \% \mathrm{Cl}\end{array}$ \\
\hline $\begin{array}{l}1 \text { Ardeparin versus unfractionated heparin } \\
\text { Goldhaber } 1998 \\
8 / 41\end{array}$ & $15 / 36$ & $\longrightarrow$ & $14.7 \%$ & $0.35[0.13,0.93]$ \\
\hline $\begin{array}{l}\text { Subtotal }(95 \% \mathrm{Cl}) \\
\text { Total events: } 8(\mathrm{LMWH}), 15(\mathrm{UFH}) \\
\text { Heterogeneity: not applicable } \\
\text { Test for overall effect: } Z=2.11(\mathrm{P}=0.035)\end{array}$ & 36 & & $14.7 \%$ & $0.35[0.13,0.93]$ \\
\hline $\begin{array}{l}2 \text { Dalteparin versus unfractionated heparin } \\
\text { Fiessinger } 1996 \\
31 / 96\end{array}$ & $41 / 103$ & & $41.6 \%$ & $0.72[0.41,1.29]$ \\
\hline $\begin{array}{l}\text { Subtotal (95\% Cl) } \\
\text { Total events: } 31(\mathrm{LMWH}), 41 \text { (UFH) } \\
\text { Heterogeneity: not applicable } \\
\text { Test for overall effect: } Z=1.10(\mathrm{P}=0.27)\end{array}$ & 103 & & $41.6 \%$ & $0.72[0.41,1.29]$ \\
\hline $\begin{array}{l}3 \text { Certoparin versus unfractionated heparin } \\
\text { Kirchmaier } 1998\end{array}$ & $71 / 105$ & & $43.7 \%$ & $0.65[0.37,1.14]$ \\
\hline $\begin{array}{l}\text { Subtotal }(95 \% \mathrm{Cl}) \\
\text { Total events: } 58 \text { (LMWH), } 71 \text { (UFH) } \\
\text { Heterogeneity: not applicable } \\
\text { Test for overall effect: } Z=1.51(\mathrm{P}=0.13)\end{array}$ & 105 & & $43.7 \%$ & $0.65[0.37,1.14]$ \\
\hline $\begin{array}{l}\text { Total }(95 \% \mathrm{Cl}) \\
\text { Total events: } 97(\mathrm{LMWH}), 127 \text { (UFH) } \\
\text { Heterogeneity: } \mathrm{Ch}^{2}=1.60, \mathrm{df}=2(\mathrm{P}=0.45) \text {; } \\
\text { Test for overall effect: } \mathrm{Z}=2.51(\mathrm{P}=0.012) \\
\text { Test for subgroup differences: } \mathrm{Chi}^{2}=1.60 \text {, df }\end{array}$ & $\begin{array}{l}244 \\
P=0.45), I^{2}=0.0 \%\end{array}$ & & $100.0 \%$ & $0.62[0.43,0.90]$ \\
\hline
\end{tabular}


Graph 9.1 Comparison 9: LMWH versus UFH by year of publication. Outcome 1: Incidence of recurrent venous thromboembolism during initial treatment.

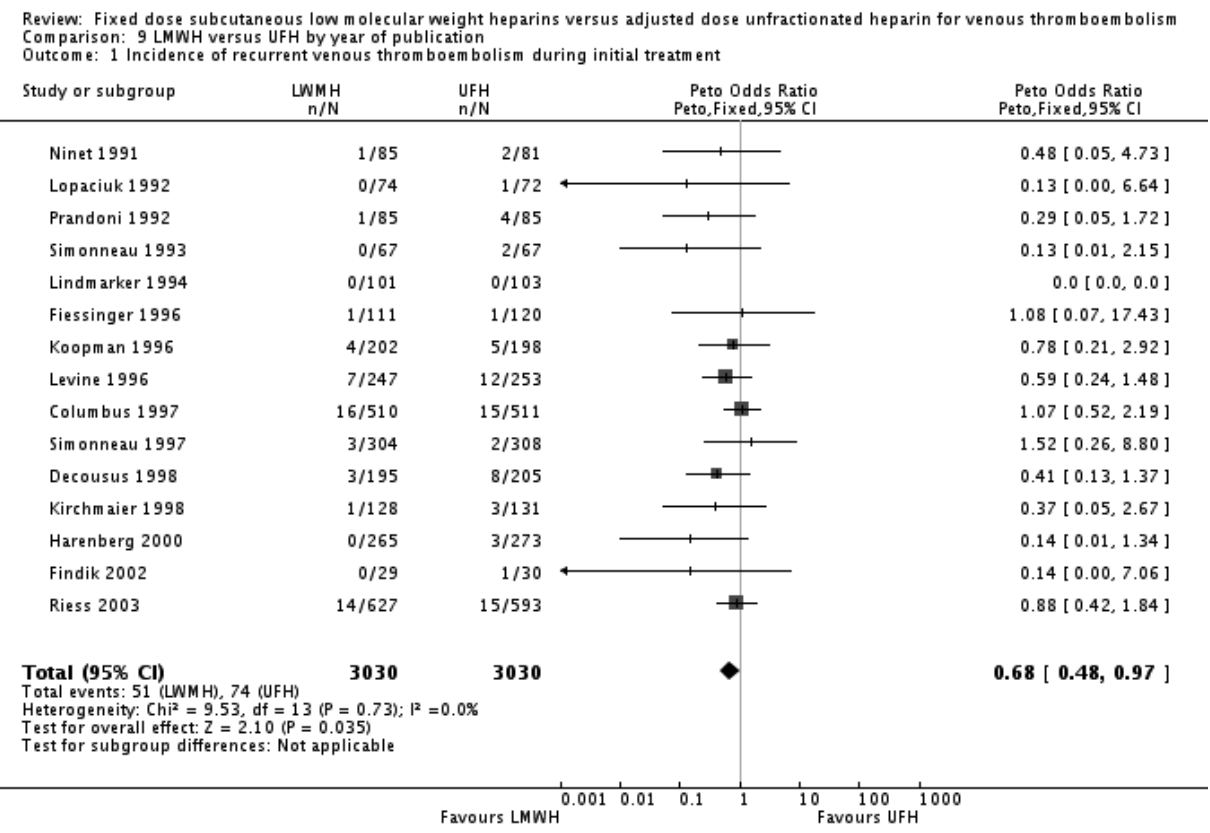


Graph 9.2 Comparison 9: LMWH versus UFH by year of publication. Outcome 2: Incidence of recurrent venous thromboembolism at the end of follow up.

Review: Fixed dose subcutaneous low molecular weight heparins versus adjusted dose unfractionated heparin for venous throm boem bolism Outcome: 2 Incidence of recurrent venous thromboembolism at the end of follow up

\begin{tabular}{|c|c|c|c|c|c|}
\hline \multirow{2}{*}{$\begin{array}{c}\text { Study or subgroup } \\
\text { Lopaciuk } 1992\end{array}$} & \multirow{2}{*}{$\underset{n / N}{\stackrel{\operatorname{LWMH}}{\mathrm{n} / \mathrm{N}}}$} & \multirow{2}{*}{$\begin{array}{l}\text { UFH } \\
\mathrm{n} / \mathrm{N} \\
\\
3 / 72\end{array}$} & $\begin{array}{r}\text { Peto Odds Ratio } \\
\text { Peto, Fixed,95\% CI } \\
\end{array}$ & \multirow{2}{*}{$\begin{array}{r}\text { Weight } \\
0.8 \%\end{array}$} & \multirow{2}{*}{$\begin{array}{r}\begin{array}{r}\text { Peto Odds Ratio } \\
\text { Peto,Fixed,95\% Cl }\end{array} \\
0.13[0.01,1.25]\end{array}$} \\
\hline & & & 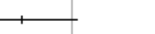 & & \\
\hline Hull 1992 & $6 / 213$ & $15 / 219$ & $\because-$ & $5.5 \%$ & $0.42[0.17,1.01]$ \\
\hline Prandoni 1992 & $6 / 85$ & $12 / 85$ & $\longrightarrow$ & $4.4 \%$ & $0.48[0.18,1.26]$ \\
\hline Simonneau 1993 & $0 / 67$ & $3 / 67$ & $\longleftarrow$ & $0.8 \%$ & $0.13[0.01,1.28]$ \\
\hline Lindm arker 1994 & $5 / 101$ & $3 / 103$ & -1 & $2.1 \%$ & $1.71[0.42,7.02]$ \\
\hline Levine 1996 & $13 / 247$ & $17 / 253$ & - & $7.7 \%$ & $0.77[0.37,1.62]$ \\
\hline Columbus 1997 & $27 / 510$ & $25 / 511$ & $\rightarrow$ & $13.5 \%$ & $1.09[0.62,1.90]$ \\
\hline Simonneau 1997 & $5 / 304$ & $6 / 308$ & 1 & $3.0 \%$ & $0.84[0.26,2.77]$ \\
\hline Decousus 1998 & $10 / 195$ & $12 / 205$ & $\rightarrow-$ & $5.7 \%$ & $0.87[0.37,2.05]$ \\
\hline Goldhaber 1998 & $0 / 41$ & $1 / 39$ & & $0.3 \%$ & $0.13[0.00,6.49]$ \\
\hline Breddin 2001 & $7 / 388$ & $24 / 375$ & $\mp-$ & $8.1 \%$ & $0.31[0.15,0.63]$ \\
\hline Findik 2002 & $1 / 29$ & $3 / 30$ & +1 & $1.0 \%$ & $0.36[0.05,2.70]$ \\
\hline Riess 2003 & $22 / 627$ & $27 / 593$ & $\#$ & $12.8 \%$ & $0.76[0.43,1.35]$ \\
\hline Galilei 2004 & $14 / 360$ & $15 / 360$ & $\rightarrow$ & $7.6 \%$ & $0.93[0.44,1.96]$ \\
\hline $\begin{array}{l}\text { Total }(95 \% \mathrm{Cl}) \\
\text { Total events: } 165 \text { (LWI } \\
\text { Heterogeneity: Chi }{ }^{2}= \\
\text { Test for overall effect: } \\
\text { Test for sub group diff }\end{array}$ & $\begin{array}{l}\quad 4541 \\
\text { UFH }) \quad \\
=18(P=0.36 \\
(P=0.00051) \\
\text { Not applicable }\end{array}$ & $\begin{array}{ll} & 4301 \\
8 \% & \end{array}$ & $\bullet$ & $100.0 \%$ & $0.70[0.57,0.85]$ \\
\hline
\end{tabular}


Graph 9.3 Comparison 9: LMWH versus UFH by year of publication. Outcome 3: Incidence of major haemorrhagic episodes (during initial treatment).

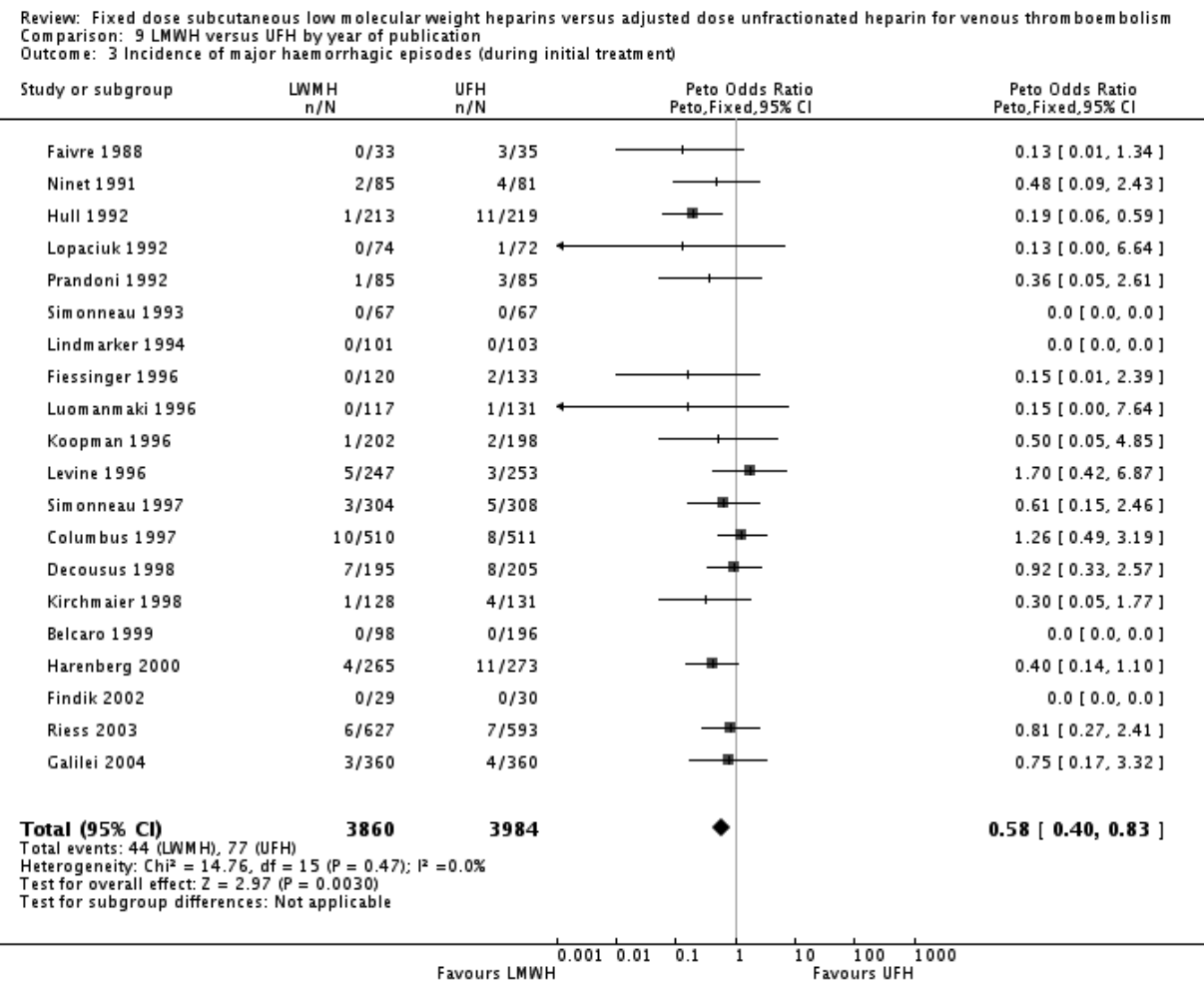


Graph 9.4 Comparison 9: LMWH versus UFH by year of publication. Outcome 4: Overall mortality at the end of follow up.

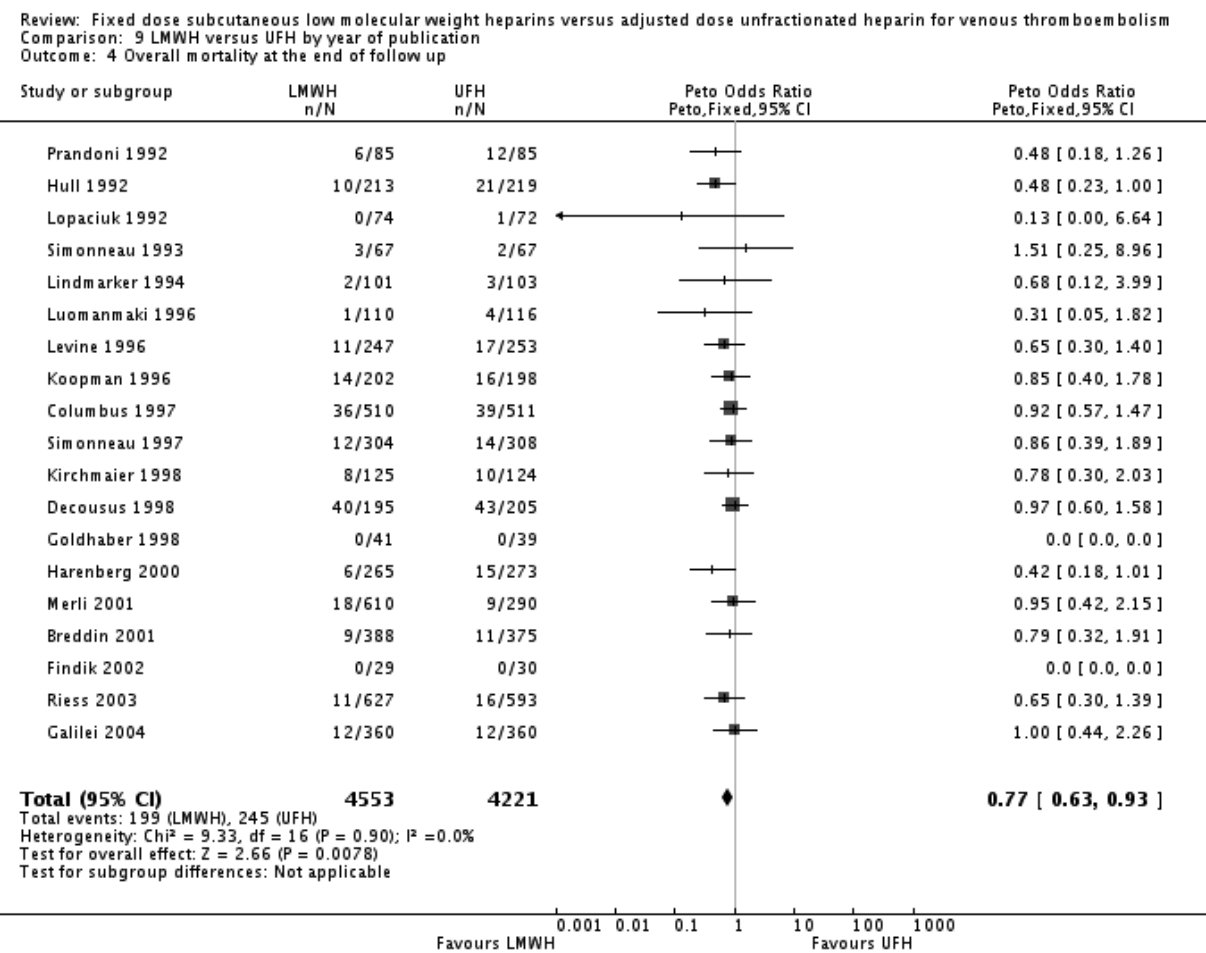




\section{References}

1. Huisman MV, Büller HR, ten Cate JW, van Royen EA, Vreeken J, Kersten MJ, et al. Unexpected high prevalence of silent pulmonary embolism in patients with deep venous thrombosis. Chest 1989;95:498-502.

2. Hull RD, Hirsh J, Carter CJ, Jay RM, Dodd PE, Ockelford PA, et al. Pulmonary angiography, ventilation lung scanning, and venography for clinically suspected pulmonary embolism with abnormal perfusion lung scan. Ann Intern Med 1983;98:891-899.

3. Hirsh J. Heparin. N Engl J Med 1991;324:1565-1574.

4. Gallus A, Jackaman J, Tillett J, Mills W, Wycherley A. Safety and efficacy of warfarin started early after submassive venous thrombosis or pulmonary embolism. Lancet 1986;2:1293-1296.

5. Hull RD, Raskob GE, Hirsh J, Jay RM, Leclerc JR, Geerts WH, et al. Continuous intravenous heparin compared with intermittent subcutaneous heparin in the initial treatment of proximal-vein thrombosis. N Engl J Med 1986;315:1109-1114.

6. Hull RD, Raskob GE, Rosenbloom D, Panju AA, Brill-Edwards P, Ginsberg JS, et al. Heparin for 5 days as compared with 10 days in the initial treatment of proximal venous thrombosis. N Engl J Med 1990;322:1260-1264.

7. Brandjes DP, Heijboer $H$, Büller HR, de Rijk M, Jagt $H$, ten Cate JW. Acenocoumarol and heparin compared with acenocoumarol alone in the initial treatment of proximal-vein thrombosis. $\mathrm{N}$ Engl J Med 1992;327:1485-1489.

8. Basu D, Gallus A, Hirsh J, Cade J. A prospective study of the value of monitoring heparin treatment with the activated partial thromboplastin time. N Engl J Med 1972;287:324-327.

9. Young $E$, prins $M$, Levine $M$, Hirsch J. Heparin binding to plasma proteins. An important mechanism for heparin resistance. . Thrombosis and Haemostasis 1992;67:639-643.

10. Hirsh J. From unfractionated heparins to low molecular weight heparins. Acta Chir Scand Suppl 1990;556:42-50.

11. Hirsh J, Levine MN. Low molecular weight heparin. Blood 1992;79:1-17.

12. Nurmohamed MT, Rosendaal FR, Büller HR, Dekker E, Hommes DW, Vandenbroucke JP, et al. Lowmolecular-weight heparin versus standard heparin in general and orthopaedic surgery: a metaanalysis. Lancet. 1992;340:152-156.

13. Büller HR, Lensing AW, Hirsh J, ten Cate JW. Deep vein thrombosis: new non-invasive diagnostic tests. Thromb Haemost 1991;66:133-137.

14. Collins R, Gray R, Godwin J, Peto R. Avoidance of large biases and large random errors in the assessment of moderate treatment effects: the need for systematic overviews. Stat Med 1987;6: 245-254.

15. Mantel N, Haenszel W. Statistical aspects of the analysis of data from retrospective studies of disease. J Natl Cancer Inst 1959;22:719-748.

16. Prandoni $P$, Carnovali M, Marchiori A. Subcutaneous adjusted-dose unfractionated heparin vs fixeddose low-molecular-weight heparin in the initial treatment of venous thromboembolism. Arch Intern Med 2004;164:1077-1083.

17. Fiessinger JN, Lopez-Fernandez M, Gatterer E, Granqvist S, Kher A, Olsson CG, et al. Once-daily subcutaneous dalteparin, a low molecular weight heparin, for the initial treatment of acute deep vein thrombosis. Thromb Haemost 1996;76:195-199.

18. Hull RD, Raskob GE, Pineo GF, Green D, Trowbridge AA, Elliott CG, et al. Subcutaneous low-molecularweight heparin compared with continuous intravenous heparin in the treatment of proximal-vein thrombosis. N Engl J Med 1992;326:975-982.

19. Lindmarker P, Holmstrom M, Granqvist S, Johnsson H, Lockner D. Comparison of once-daily subcutaneous Fragmin with continuous intravenous unfractionated heparin in the treatment of deep vein thrombosis. Thromb Haemost 1994;72:186-190.

20. Luomanmaki K, Grankvist S, Hallert C, Jauro I, Ketola K, Kim HC, et al. A multicentre comparison of once-daily subcutaneous dalteparin (low molecular weight heparin) and continuous intravenous heparin in the treatment of deep vein thrombosis. J Intern Med 1996;240:85-92. 
21. Simonneau G, Sors H, Charbonnier B, Page Y, Laaban JP, Azarian R, et al. A comparison of lowmolecular-weight heparin with unfractionated heparin for acute pulmonary embolism. The THESEE Study Group. Tinzaparine ou Heparine Standard: Evaluations dans l'Embolie Pulmonaire. N Engl J Med 1997;337:663-669.

22. Belcaro G, Nicolaides AN, Cesarone MR, Laurora G, De Sanctis MT, Incandela L, et al. Comparison of low-molecular-weight heparin, administered primarily at home, with unfractionated heparin, administered in hospital, and subcutaneous heparin, administered at home for deep-vein thrombosis. Angiology 1999;50:781-787.

23. Breddin HK, Hach-Wunderle V, Nakov R, Kakkar VV. Effects of a low-molecular-weight heparin on thrombus regression and recurrent thromboembolism in patients with deep-vein thrombosis. $\mathrm{N}$ Engl J Med 2001;344:626-631.

24. Decousus H, Leizorovicz A, Parent F, Page Y, Tardy B, Girard P, et al. A clinical trial of vena caval filters in the prevention of pulmonary embolism in patients with proximal deep-vein thrombosis. Prevention du Risque d'Embolie Pulmonaire par Interruption Cave Study Group. N Engl J Med 1998;338:409-415.

25. Faivre R, Neuhart Y, Kieffer Y, Apfel F, Magnin D, Didier D, et al. [A new treatment of deep venous thrombosis: low molecular weight heparin fractions. Randomized study]. Presse Med 1988;17: 197-200.

26. Findik S, Erkan ML, Selcuk MB, Albayrak S, Atici AG, Doru F. Low-molecular-weight heparin versus unfractionated heparin in the treatment of patients with acute pulmonary thromboembolism. Respiration 2002;69:440-444.

27. Goldhaber SZ, Morrison RB, Diran LL, Creager MA, Lee TH, Jr. Abbreviated hospitalization for deep venous thrombosis with the use of ardeparin. Arch Intern Med 1998;158:2325-2328.

28. Harenberg J, Schmidt JA, Koppenhagen K, Tolle A, Huisman MV, Büller HR. Fixed-dose, body weightindependent subcutaneous LMW heparin versus adjusted dose unfractionated intravenous heparin in the initial treatment of proximal venous thrombosis. EASTERN Investigators. Thromb Haemost 2000;83:652-656.

29. Kirchmaier CM, Wolf H, Schafer H, Ehlers B, Breddin HK. Efficacy of a low molecular weight heparin administered intravenously or subcutaneously in comparison with intravenous unfractionated heparin in the treatment of deep venous thrombosis. Certoparin-Study Group. Int Angiol 1998;17:135-145.

30. Koopman MM, Prandoni P, Piovella F, Ockelford PA, Brandjes DP, van der Meer J, et al. Treatment of venous thrombosis with intravenous unfractionated heparin administered in the hospital as compared with subcutaneous low-molecular-weight heparin administered at home. The Tasman Study Group. N Engl J Med 1996;334:682-687.

31. Levine M, Gent M, Hirsh J, Leclerc J, Anderson D, Weitz J, et al. A comparison of low-molecular-weight heparin administered primarily at home with unfractionated heparin administered in the hospital for proximal deep-vein thrombosis. N Engl J Med 1996;334:677-681.

32. Lopaciuk S, Meissner AJ, Filipecki S, Zawilska K, Sowier J, Ciesielski L, et al. Subcutaneous low molecular weight heparin versus subcutaneous unfractionated heparin in the treatment of deep vein thrombosis: a Polish multicenter trial. Thromb Haemost 1992;68:14-18.

33. Ninet J, Bachet $P$, Prandoni $P$, Ruol A, Vigo M, Barret A, et al. A randomised trial of subcutaneous low molecular weight heparin ( $C Y$ 216) compared with intravenous unfractionated heparin in the treatment of deep vein thrombosis. A collaborative European multicentre study. Thromb Haemost 1991;65:251-6.

34. Prandoni $P$, Lensing AW, Büller HR, Carta M, Cogo A, Vigo M, et al. Comparison of subcutaneous lowmolecular-weight heparin with intravenous standard heparin in proximal deep-vein thrombosis. Lancet 1992;339:441-445.

35. Riess H, Koppenhagen K, Tolle A, Kemkes-Matthes B, Grave M, Patek F, et al. Fixed-dose, body weightindependent subcutaneous low molecular weight heparin Certoparin compared with adjusted-dose intravenous unfractionated heparin in patients with proximal deep venous thrombosis. Thromb Haemost 2003;90:252-259.

36. Simonneau G, Charbonnier B, Decousus H, Planchon B, Ninet J, Sie P, et al. Subcutaneous lowmolecular-weight heparin compared with continuous intravenous unfractionated heparin in the treatment of proximal deep vein thrombosis. Arch Intern Med 1993;153:1541-1546. 
37. The-Columbus-Investigators. Low-molecular-weight heparin in the treatment of patients with venous thromboembolism. The Columbus Investigators. N Engl J Med 1997;337:657-662.

38. Merli G, Spiro TE, Olsson CG, Abildgaard U, Davidson BL, Eldor A, et al. Subcutaneous enoxaparin once or twice daily compared with intravenous unfractionated heparin for treatment of venous thromboembolic disease. Ann Intern Med 2001;134:191-202.

39. Kearon C, Ginsberg JS, Julian JA, Douketis J, Solymoss S, Ockelford P, et al. Comparison of fixed-dose weight-adjusted unfractionated heparin and low-molecular-weight heparin for acute treatment of venous thromboembolism. JAMA 2006;296:935-942.

40. Notarbartolo A, Salanitri G, Davi G, Averna M, Barbagallo C, I. C. Low molecular weight heparin in the short and long-term treatment of deep vein thrombosis in diabetic subjects. Praxis Med 1988;9: 393-405.

41. Tedoldi A, Botticella F, MR. M. Antithrombophilic effect of low molecular weight heparins in patients with deep vein thrombosis. Clinical Trials and Meta-analysis 1993;28:215-225.

42. Zanghi M, Morici V, Costanzo M, Astuto L, Salanitri G. Deep vein thrombosis of the legs: new therapy by means of low molecular weight heparins. J Int Med Res 1988;16:474-484.

43. Banga J, de Valk H, Wester J, Brouwer C, van Hessen M, Meuwissen O, et al. A dose finding study of subcutaneous heparinoid Oragaran (ORG 10172) twice daily compared to continuous intravenous unfractionated heparin in the treatment of venous thromboembolism. Thrombosis and Haemostasis 1993;69(545):Abstract 20.

44. de Valk HW, Banga JD, Wester JW, Brouwer CB, van Hessen MW, Meuwissen OJ, et al. Comparing subcutaneous danaparoid with intravenous unfractionated heparin for the treatment of venous thromboembolism. A randomized controlled trial. Ann Intern Med 1995;123:1-9.

45. Handeland GF, Abildgaard U, Holm HA, Arnesen KE. Dose adjusted heparin treatment of deep venous thrombosis: a comparison of unfractionated and low molecular weight heparin. Eur J Clin Pharmacol. 1990;39:107-112.

46. Aiach M, Fiessinger J, Vitoux J, Le Querrec A, Gouault-Heilmann M, et al. e. Deep vein thrombosis treatment. A comparative study: subcutaneous Fragmin versus unfractionated heparin administered by continuous infusion. Multicentre trial. [Traitement des thromboses veineuses profondes constituees. Etude comparative d'un fragment d'heparine de bas poids moleculaire (Fragmine) administree par voie sous-cutanee et de I'heparine standard administree par voie intraveineuse continue. Etude multicentrique. [French]]. Revue de Medecine Interne 1989;10:375-381.

47. Bratt G, Aberg W, Johansson M, Tornebohm E, Granqvist S, Lockner D. Two daily subcutaneous injections of fragmin as compared with intravenous standard heparin in the treatment of deep venous thrombosis (DVT). Thromb Haemost 1990;64:506-510.

48. Holm HA, Ly B, Handeland GF, Abildgaard U, Arnesen KE, Gottschalk P, et al. Subcutaneous heparin treatment of deep venous thrombosis: a comparison of unfractionated and low molecular weight heparin. Haemostasis. 1986;16 Suppl 2:30-7.

49. Ly B, Arnesen K, Holm H, Handeland G, U. A. Subcutaneous LMW or unfractionated heparin in DVT: A randomized, double blind study with dose adjustments according to heparin concentration in plasma. Thrombosis and Haemostasis 1985;54(1):Abstract No. 91.

50. Bratt G, Tornebohm E, Granqvist S, Aberg W, Lockner D. A comparison between low molecular weight heparin (KABI 2165) and standard heparin in the intravenous treatment of deep venous thrombosis. Thromb Haemost 1985;54:813-817.

51. Lockner D, Bratt G, Tornebohm E, Aberg W, Granqvist S. Intravenous and subcutaneous administration of Fragmin in deep venous thrombosis. Haemostasis 1986;16 Suppl 2:25-9.

52. Lockner D, Bratt G, Tornebohm E, Aberg W, S. G. A comparison between low molecular weight heparin (LMWH, KABI 2165) and standard heparin in the intravenous treatment of deep vein thrombosis (DVT). Thrombosis and Haemostasis 1985;54:813-7.

53. Vogel G, Machulik M. Efficacy and safety of a low molecular weight heparin (LMW-heparin Sandoz) in patients with deep vein thrombosis. Thrombosis and Haemostasis 1987;58(Suppl):Abstract No. 427.

54. Albada J, Nieuwenhuis HK, Sixma JJ. Treatment of acute venous thromboembolism with low molecular weight heparin (Fragmin). Results of a double-blind randomized study. Circulation 1989;80:935-940. 
55. Harenberg J, Breddin H, Kirchmaier C, A. T. Does fixed dose body weight independent subcutaneous low-molecular-weight heparin imporve the Marder score compared to adjusted dose unfractionated heparin in the treatment of venous thrombosis. . Annals of Hematology 2000;79(Suppl 1):A84.

56. Harenberg J, Huck K, Bratsch H, Stehle G, Dempfle CE, Mall K, et al. Therapeutic application of subcutaneous low-molecular-weight heparin in acute venous thrombosis. Haemostasis 1990;20 Suppl 1:205-219.

57. Harenberg J, Huck K, Stehle G, Mall K, Schwarz A, DL. H. Prospective randomized, controlled study on the treatment of deep venous thrombosis using low molecular weight heparin compared with unfractionated heparin. Thrombosis and Haemostasis 1989;62(356):Abstract No. 1106.

58. Monreal M, Lafoz E, Olive A, del Rio L, Vedia C. Comparison of subcutaneous unfractionated heparin with a low molecular weight heparin (Fragmin) in patients with venous thromboembolism and contraindications to coumarin. Thromb Haemost 1994;71:7-11.

59. Monreal M, Lafoz E, Vedia C, J. R. Comparison of subcutaneous unfractioned heparin with a low molecular weight heparin (Fragmin) in patients with venous thromboembolism and contraindications to coumarin. Thrombosis and Haemostasis 1993;69(649):Abstract No. 383.

60. van den Belt AG, Bossuyt PM, Prins MH, Gallus AS, Büller HR. Replacing inpatient care by outpatient care in the treatment of deep venous thrombosis--an economic evaluation. TASMAN Study Group. Thromb Haemost 1998;79:259-263. 



\section{Chapter 6}

\section{Safety of outpatient treatment in acute pulmonary embolism}

PMG Erkens, E Gandara, PH Wells, AYH Shen, G Bose, G le Gal, M Rodger, MH Prins, M Carrier Journal of Thrombosis and Haemostasis, 2010;8: 2412-2417 


\section{Abstract}

\section{Background}

Data regarding outpatient treatment of pulmonary embolism (PE) is scarce. This study evaluates the safety of outpatient management of acute PE.

\section{Methods}

This is a retrospective cohort study of consecutive patients presenting at the Ottawa Hospital with acute PE diagnosed between January 1, 2007 and December 31, 2008. PE was defined as an arterial filling defect on CTPA or a high probability V/Q scan. Patients were managed as outpatients if they were hemodynamically stable, did not require supplemental oxygenation and did not have contraindications to low molecular weight heparin therapy.

\section{Results}

In this cohort of 473 patients with acute PE, 260 (55.0\%) were treated as outpatients and 213 (45.0\%) were admitted to the hospital. The majority of the patients were admitted because of severe co-morbidities (45.5\%) or hypoxia (22.1\%). No outpatient died of fatal PE during the 3 month follow-up period. At the end of follow-up, the overall mortality was $5.0 \%(95 \% \mathrm{Cl}: 2.7-8.4)$. The rates of recurrent venous thromboembolism (VTE) in outpatients were $0.4 \%(95 \% \mathrm{Cl}: 0.0-2.1)$ and $3.8 \%(95 \% \mathrm{Cl}$ : 1.9-7.0) within 14 days and 3 months, respectively. The rates of major bleeding episodes were $0 \%(95 \% \mathrm{Cl}: 0-1.4)$ and $1.5 \%(95 \% \mathrm{Cl}: 0.4-3.9)$ within 14 days and 3 months, respectively. Four (1.5\%) outpatients were admitted to the hospital within 14 days.

\section{Conclusion}

A majority of patients with acute PE can be managed as outpatients with a low risk of mortality, recurrent VTE and major bleeding episodes. 


\section{Introduction}

Patients with deep vein thrombosis (DVT) can be safely managed and treated as outpatients using subcutaneous low molecular weight heparins (LMWH). ${ }^{1,2}$ However, the role of outpatient therapy in patients with pulmonary embolism (PE) is unclear and has been a matter of debate in literature.

A large majority of patients with PE are still systematically admitted to the hospital to avoid potential complications such as death, progressive right ventricular (RV) failure and major bleeding. Although the risk of fatal recurrent PE is higher in patients treated for $\mathrm{PE}$ than the risk of fatal $\mathrm{PE}$ in patients treated for DVT, ${ }^{3,4}$ literature suggests that only $4.5 \%$ of PE-patients develop serious complications during the first 10 days of treatment. ${ }^{5}$

Small cohort studies and subgroup analyses of randomized controlled trials have investigated the outcomes of outpatient treatment for PE. Two systematic reviews, which include observational studies of patients diagnosed with symptomatic PE who were treated completely as outpatients or early discharge (within 3 days), concluded that outpatient therapy is safe in hemodynamically stable patients without hypoxia. ${ }^{6,7}$ More recently, a randomized controlled trial was stopped early due to an increased mortality in the group of patients treated as outpatients. ${ }^{8}$

Outpatient treatment in patients with PE may be important to reduce hospitalizations and medical costs and hence save scarce health care resources. In order to counsel hemodynamically stable PE patients on the risks and benefits of outpatient treatment, clinicians require estimates of the rates for overall mortality, fatal $P E$, recurrent venous thromboembolism (VTE) and major bleeding at 14-days and 3 months. To address these knowledge gaps and assess the safety and feasibility of outpatient treatment of $P E$, we performed a retrospective study of patients diagnosed with $P E$ and treated as outpatients at the Ottawa Hospital.

\section{Methods}

\section{Study population}

A retrospective cohort study of consecutive patients with suspected acute PE that underwent computed tomographic pulmonary angriography (CTPA) or lung ventilation/perfusion (V/Q) scan was conducted at the Ottawa Hospital Thrombosis Program, Ottawa, Canada. All reports of CTPA or V/Q scans conducted from January $1^{\text {st }}, 2007$ to December $31^{\text {st }}, 2008$ at The Ottawa Hospital, a large tertiary care center serving a catchment area greater than 1 million population, were reviewed. PE was defined as a pulmonary artery filling defect on CTPA or as a high probability V/Q scan. Patients diagnosed with PE during hospitalization, patients with chronic PE and patients in whom anticoagulation treatment was not initiated (e.g. palliative care 
patients, small clinical non-significant PE) were excluded from the analyses. Patients were also excluded if they received treatment at another hospital or were followedup by a health care professional out of the Ottawa Hospital. All included patients were followed for three months.

At our institution, the following patients are managed, as per hospital protocol, as outpatients: patients who do not have a systolic blood pressure of $100 \mathrm{mmHg}$ or less, who have an oxygen saturation of $92 \%$ or more and do not require supplemental oxygen, who do not have contraindications for the use of LMWH (such as a high bleeding risk or renal failure) and who do not need hospitalization for other comorbidities (such as severe cancer, heart failure, chronic obstructive pulmonary disease, coronary artery disease, cerebrovascular events etc.). Outpatients with PE are treated with daily injections of LMWH for a minimum of 5 days with concomitant oral vitamin $\mathrm{K}$ antagonist (VKA). LWMH is discontinued if the International Normalized Ratio (INR) is above 2.0 on two consecutive readings. Outpatients are discharged home from the emergency department and are followed in the Outpatient Thrombosis Assessment and Treatment Unit within 24-48 hours of diagnosis, then again at 7 days and 3 months.

\section{Outcomes}

The following variables were specified prior to data collection: 1) patient demographics; 2) reasons for hospitalization; 3) recurrent VTE and bleeding episodes; 4) death (date and cause). Data was extracted from hospital discharge reports and consultation notes from the Thrombosis Assessment and Treatment Unit. All outcomes were reviewed independently by two investigators (EG, PE). Disagreements on information were resolved by consensus or retrieving further information from other medical records.

The primary outcomes of this study were overall mortality and fatal recurrent PE. The cause of death was identified by a review of hospital records including death summaries. Secondary outcomes included recurrent VTE, major bleeding and VTErelated hospitalization at 14 days and 3 months of follow-up. Recurrent PE was defined as a new arterial filling defect on CTPA or a new mismatched area on a high probability V/Q-scan and recurrent DVT was defined as a new non-compressible venous segment on an ultrasound of the extremities. Major bleeding events were defined as: 1) fatal bleeding; 2) symptomatic bleeding in a critical area or organ such as intracranial, intraspinal, intraocular, retroperitoneal, intra-articular or pericardial, or intramuscular with compartment syndrome; and/or 3) Bleeding causing a fall in hemoglobin level of $20 \mathrm{~g} \mathrm{~L}^{-1}\left(1.24 \mathrm{mmol} \mathrm{L}^{-1}\right)$ or more, or leading to transfusion of two or more units of whole blood or red cells. ${ }^{9}$ 


\section{Statistical analysis}

Descriptive statistics were used to describe the patient characteristics and outcomes. Ninety-five percent confidence intervals $(95 \% \mathrm{Cl})$ and $p$-values were calculated for each event rate by using Fisher's exact test. A subgroup analysis was performed for patients without active cancer. The statistical analyses were performed using the Statistical Package for the Social Sciences software (version 16; SPSS; Chicago, IL, USA).

\section{Results}

Over a two-year period, 4410 CTPA and $740 \mathrm{~V} / \mathrm{Q}$ scans were carried out for suspected PE at The Ottawa Hospital. A total of 724 patients had a positive CTPA for PE and 115 patients had a high probability V/Q scan. A flow diagram including the reasons for patient's exclusion is depicted in Figure 6.1. A total of 473 patients presenting at the Ottawa Hospital with confirmed PE were included in the study. Two hundred and sixty (55.0\%; 95\% Cl: 50.4-59.5) patients were managed entirely as outpatients and 213 (45.0\%; 95\% Cl: 40.5-49.6) patients were admitted to the hospital.

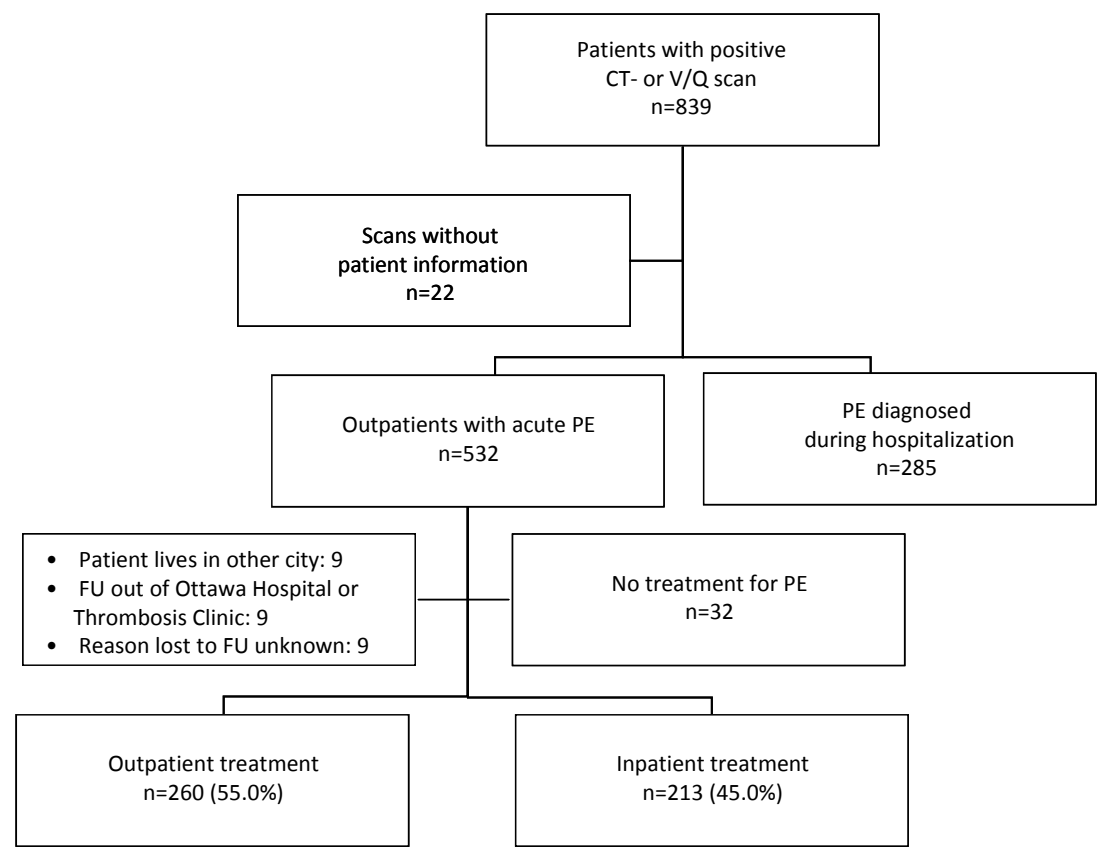

Figure 6.1 Flow diagram of the study. $\mathrm{CT}=$ computed tomography pulmonary angiography; $\mathrm{V} / \mathrm{Q}=$ ventilation / perfusion; $\mathrm{PE}=$ pulmonary embolism; $\mathrm{FU}=$ follow-up. 
Baseline characteristics of patients treated as outpatients and of those admitted to the hospital (inpatients) are shown in Table 1. Admitted patients were more likely to have had a previous diagnosis of heart failure whereas outpatients were more likely to have presented with chest pain. All outpatients were initially treated with LMWH. Most (70.4\%) of the inpatients were also treated with LMWH while $25.8 \%$ received UFH (Table 6.1).

Table 6.1 Baseline characteristics of the cohort

\begin{tabular}{|c|c|c|c|}
\hline & $\begin{array}{l}\text { Outpatient treatment } \\
\qquad(n=260)\end{array}$ & $\begin{array}{l}\text { Inpatient treatment } \\
\qquad(n=213)\end{array}$ & \\
\hline \multicolumn{4}{|l|}{ Demographics } \\
\hline Female, n (\%) & $128(49.2 \%)$ & $106(49.8 \%)$ & \\
\hline \multirow[t]{2}{*}{ Age, mean years $(\mathrm{sd})$} & $54.7(17.1)$ & $62.0(17.5)$ & \\
\hline & $\begin{array}{l}\text { Outpatient treatment } \\
\qquad \begin{array}{c}(n=260) \\
N(\% ; 95 \% \mathrm{Cl})\end{array}\end{array}$ & $\begin{array}{l}\text { Inpatient treatment } \\
\qquad(\mathrm{n}=213) \\
\mathrm{N}(\% ; 95 \% \mathrm{Cl})\end{array}$ & $P$-value \\
\hline \multicolumn{4}{|l|}{ Risk factors for VTE } \\
\hline Immobilization at least 3 days & 40 (15.4\%; $11.2-20.4)$ & 35 (16.4\%; $11.7-22.1)$ & 0.801 \\
\hline Surgery in the previous 4 weeks & $41(15.8 \% ; 11.6-20.6)$ & $28(13.1 \% ; 8.9-18.4)$ & 0.436 \\
\hline Previously objective diagnosed VTE & $53(20.4 \% ; 15.9-25.8)$ & $27(12.7 \% ; 8.5-17.9)$ & 0.027 \\
\hline \multicolumn{4}{|l|}{ Comorbidity } \\
\hline Active Cancer & 83 (31.9\%; $26.3-38.0)$ & 86 (40.4\%; $33.7-47.3)$ & 0.067 \\
\hline Heart failure & $4(1.5 \% ; 0.4-3.9)$ & $15(7.0 \% ; 4.0-11.4)$ & 0.004 \\
\hline COPD & $9(3.5 \% ; 1.6-6.5)$ & $18(8.5 \% ; 5.1-13.0)$ & 0.027 \\
\hline CAD & $22(8.5 \% ; 5.4-12.5)$ & $27(12.0 \% ; 8.5-17.9)$ & 0.172 \\
\hline Stroke & $8(3.1 \% ; 1.3-6.0)$ & $14(6.6 \% ; 3.6-10.8)$ & 0.082 \\
\hline \multicolumn{4}{|l|}{ Clinical presentation } \\
\hline Dyspnea & $191(73.5 \% ; 67.7-78.7)$ & $176(82.6 \% ; 76.9-87.5)$ & 0.020 \\
\hline Chest pain & $167(64.2 \% ; 58.1-70.1)$ & 95 (44.6\%; $37.8-51.6)$ & 0.000 \\
\hline Hemoptysis & $11(4.2 \% ; 2.1-7.4)$ & $16(7.5 \% ; 4.4-11.9)$ & 0.163 \\
\hline Syncope & $2(0.8 \% ; 0.1-2.8)$ & $13(6.1 \% ; 3.3-10.2)$ & 0.001 \\
\hline Clinical symptoms of DVT & $82(31.5 \% ; 25.9-37.6)$ & $48(22.5 \% ; 17.1-28.8)$ & 0.030 \\
\hline Heart rate $>100 \mathrm{bpm}$ & $33(12.7 \% ; 8.9-17.4)$ & $61(28.6 \% ; 22.7-35.2)$ & 0.000 \\
\hline SBP $<100 \mathrm{mmHg}$ & $0(0 \% ; 0-1.4)$ & $15(7.0 \% ; 4.0-11.5)$ & 0.000 \\
\hline Arterial oxygen saturation $<90 \% *$ & $3(1.2 \% ; 0.2-3.3)$ & $45(21.1 \% ; 15.9-27.3)$ & 0.000 \\
\hline \multicolumn{4}{|l|}{ Initial treatment } \\
\hline LWMH & 260 (100\%; $98.6-100.0)$ & $150(70.4 \% ; 63.8-76.4)$ & 0.000 \\
\hline UFH & $0(0 \% ; 0.0-1.4)$ & $55(25.8 \% ; 20.1-32.3)$ & 0.000 \\
\hline Other initial treatment ${ }^{\dagger}$ & $0(0 \% ; 0.0-1.4)$ & $8(3.8 \% ; 1.6-7.3)$ & 0.002 \\
\hline
\end{tabular}

$\mathrm{VTE}=$ Venous ThromboEmbolism; COPD= Chronic Obstructive Pulmonary Disease; CAD= Coronary Artery Disease; DVT= Deep Vein Thrombosis; SBP= Systolic Blood Pressure; LMWH= Low Molecular Weight Heparin; UFH= Unfractionated Heparin. *Saturation assessed with and without the administration of supplemental oxygen. ${ }^{\dagger}$ Other initial treatment: five patients received an IVC-filter, two patients received thrombolysis, one patient was treated with argatroban because of Heparin Induced Thrombocytopenia.

For the patients admitted to the hospital, the median length of admission was 6 days (range 1 to 209 days). Almost seventy-five percent of the inpatients were admitted for 10 days or less. The majority of these patients were admitted because of severe co- 
morbidities (45.5\%), hypoxia (22.1\%), extensive PE (8.5\%), hypotension (7.0\%), renal dysfunction $(6.6 \%)$, pain management $(4.7 \%)$ or syncope $(2.3 \%)$. The reason for admission was unclear in 7 (3.3\%) patients.

\section{Overall Mortality and Fatal PE}

Only one outpatient $(0.4 \% ; 95 \% \mathrm{Cl}: 0.0-2.1 \%)$ died within the first few weeks after the index PE (Table 6.2). This patient was initially sent home from the emergency room to be treated as an outpatient but was admitted within 24 hours of discharge. The patient was transferred to a palliative care facility after 10 days of hospitalization and died from progression of her metastatic cancer. After 3 months of follow-up, the overall mortality in the outpatient group was 5.0\% (95\% $\mathrm{Cl} 2.7-8.4)$. No patient died of recurrent fatal PE (Table 6.2).

Table 6.2 Main outcomes.

\begin{tabular}{|c|c|c|c|}
\hline & $\begin{array}{l}\text { Outpatients treatment } \\
\qquad(n=260) \\
n(\% ; 95 \% \mathrm{Cl})\end{array}$ & $\begin{array}{c}\text { Inpatient treatment } \\
(\mathrm{n}=213) \\
n(\% ; 95 \% \mathrm{Cl})\end{array}$ & $p$-value \\
\hline \multicolumn{4}{|l|}{14 days follow-up } \\
\hline Overall mortality & $1(0.4 \% ; 0.0-2.1)^{\dagger}$ & $27(12.7 \% ; 8.5-17.9)^{\ddagger}$ & 0.000 \\
\hline PE-specific mortality & $0(0 \% ; 0-1.4)$ & $5(2.3 \% ; 0.8-5.4)$ & 0.018 \\
\hline Recurrence VTE & $1(0.4 \% ; 0.0-2.1)$ & $4(1.9 \% ; 0.5-4.7)$ & 0.180 \\
\hline Major haemorrhages* & $0(0 \% ; 0.0-1.4)$ & $13(6.1 \% ; 3.3-10.2)$ & 0.000 \\
\hline Re-admissions & $4(1.5 \% ; 0.4-3.9)$ & $4(1.9 \% ; 0.5-4.7)$ & 1.000 \\
\hline \multicolumn{4}{|l|}{ VTE / treatment related } \\
\hline \multicolumn{4}{|l|}{3 months follow-up } \\
\hline Overall mortality & $13(5 \% ; 2.7-8.4)^{\S}$ & $57(26.7 \% ; 20.9-33.2)^{\pi}$ & 0.000 \\
\hline PE-specific mortality & $0(0 \% ; 0-1.4)$ & $5(2.3 \% ; 0.8-5.4)$ & 0.018 \\
\hline Recurrence VTE & $10(3.8 \% ; 1.9-7.0)$ & $10(4.7 \% ; 2.3-8.5)$ & 0.654 \\
\hline Major haemorrhages ${ }^{*}$ & $4(1.5 \% ; 0.4-3.9)$ & $17(8.0 \% ; 4.7-12.5)$ & 0.001 \\
\hline Re-admissions & $6(2.3 \% ; 0.9-5.0)$ & $11(5.2 \% ; 2.6-9.1)^{* *}$ & 0.135 \\
\hline VTE / treatment related & & & \\
\hline
\end{tabular}

$\mathrm{PE}=$ Pulmonary Embolism; VTE= Venous ThromboEmbolism. * Major haemorrhage defined according to the Control of Anticoagulation Subcommitte (ISTH SSC 2004):

Fatal bleeding, and/or

Symptomatic bleeding in a critical area or organ, such as intracranial, intraspinal, intraocular, retroperitoneal, intra-articular or pericardial, or intramuscular with compartment syndrome, and/or Bleeding causing a fall in hemoglobin level of $20 \mathrm{~g} \mathrm{~L}^{-1}\left(1.24 \mathrm{mmol} \mathrm{L}^{-1}\right)$ or more, or leading to transfusion of two or more units of whole blood or red cells.

${ }^{+}$This outpatient received palliative care 10 days after PE; ${ }^{\ddagger}$ Five of these inpatients received palliative care at 14 days follow-up; ${ }^{\S}$ Three of these outpatients received palliative care at 3 months follow-up; "No patients with palliative care; ${ }^{* *}$ Nine patients with 1 re-admission and 2 patients with 2 readmissions.

In the inpatient group, $5(2.3 \% ; 95 \% \mathrm{Cl} 0.8-5.4)$ patients died because of fatal PE. All of these patients died within 7 days of the index PE diagnosis. The overall mortality was $12.7 \%(95 \% \mathrm{Cl} 8.5-17.9)$ within 14 days and $26.7 \%(95 \% \mathrm{Cl} 20.9-33.2)$ within 3 months. 
The majority (76.4\%) of patients died from cancer. In a subgroup analysis excluding patients with active cancer, the 3 months overall mortality in the outpatient and inpatient group was $0 \%(95 \% \mathrm{Cl} 0-2.1)$ and $9.4 \%$ (95\% $\mathrm{Cl} 5.0-15.9)$, respectively.

\section{Recurrent VTE and major bleeding episodes}

One (0.4\%; 95\% $\mathrm{Cl} 0.0-2.1$ ) outpatient had recurrent PE within 14 days. At 3 months follow-up 10 outpatients (3.8\%; $95 \% \mathrm{Cl} 1.9-7.0)$ developed recurrent VTE (Table 2). Four patients had DVT and 6 patients had recurrent PE. The incidence of recurrent VTE in hospitalized patients was similar at 14 days and 3 months $(p=0.180$ and 0.654 , respectively).

None of the outpatients suffered from major bleeding during the first two weeks. Four (1.5\%; 95\% Cl 0.4-3.9) outpatients, however, had a major bleeding during the 3 months follow-up (Table 6.2). The percentage of major bleeding episodes was higher in the inpatient group. Thirteen $(6.1 \%$; $95 \% \mathrm{Cl} 3.3-10.2)$ inpatients suffered from major bleeding episodes within 14 days after the index $\mathrm{PE}$, and at 3 months follow-up 17 (8.0\%; 95\% Cl 4.7-12.5) inpatients had a major bleeding episode (Table 6.2).

\section{Hospitalization during follow-up}

Four (1.5\%; 95\% Cl 0.4-3.9) outpatients were admitted to the hospital within 14 days of their index PE diagnosis. Outpatients were admitted either because of progressive shortness of breath $(n=2)$, presyncopal episode $(n=1)$ or heparin induced thrombocytopenia $(n=1)$. During the 3 months follow-up two more patients were admitted (one recurrent VTE; one major bleeding episode). Therefore, the VTE-related admission rate of outpatients at 3 months follow-up was $2.3 \%(95 \% \mathrm{Cl} 0.9-5.0)$ (Table 6.2). No differences were seen in the readmission rates between patients originally admitted and outpatients at the end of follow up ( $p=0.135)$.

\section{Discussion}

Our study suggests that outpatient PE treatment is feasible and safe in a majority of patients. To our knowledge, this is one of the largest cohort studies to evaluate the safety of outpatient treatment in low-risk patients with acute PE. More than $50 \%$ of the patients were treated as outpatient with a low subsequent risk of death, recurrent VTE and major bleeding episodes in the first 14 days. None of the outpatients died from PE and there is only one $(0.4 \%)$ death from metastatic cancer within the first few weeks.

Our results are consistent with previously published smaller studies assessing outpatient management or an early discharge strategy (less than 3 days of 
hospitalization) in patients with hemodynamically stable acute PE. ${ }^{8,10-20}$ No PE-related deaths and only one death due to a major bleeding were reported in these studies. The overall short-term mortality in our study was $0.4 \%(95 \% \mathrm{Cl} 0-2.1 \%)$. Although this is consistent with previously reported cohort studies ${ }^{10,12,13,15-18}$, a recent randomized controlled trial reported an overall mortality of $2.8 \%$ within the first 10 days after the index PE. This study was stopped early due to this increased mortality in the outpatient group. ${ }^{8}$ The reasons behind this discrepancy are unclear but might be explained by the difference in follow-up management between studies (in-person versus telephone follow-up). Short-term recurrent VTE in literature ranged from $0 \%$ to $3.2 \%$ and major bleeding from $0 \%$ to $2.3 \%{ }^{8,10,12,13,15-18}$ Similarly, our results are consistent with prior studies assessing long-term outcomes in patients with PE treated as outpatients. The three months overall mortality in these studies ranged from $0 \%$ to $43.5 \%$. The percentage of recurrent VTE and major bleeding ranged from $0 \%$ to $9.3 \%$ and $0 \%$ to $3.7 \%$, respectively. ${ }^{8,10-20}$

In our cohort study, the decision whether patients with PE could be managed as outpatients or required hospitalization was based on the clinical judgment of the doctor at the emergency department. All hemodynamically stable patients that did not require supplemental oxygenation and had no contraindications to LMWH or significant co-morbidities were considered for outpatient management. Our rate of serious adverse events is higher in patients who were admitted to the hospital immediately after their index PE (Table 2) suggesting that these simple criteria are able to discriminate between low and high-risk patients.

Several studies investigated risk stratification in PE and developed risk-prediction models to identify patients with acute PE who are at low risk for adverse outcomes and could be treated as outpatients. ${ }^{21}$ The most extensively validated models are the Geneva Prognostic Score (GPS) and the Pulmonary Embolism Severity Index (PESI). ${ }^{21-23}$ Other studies have shown that patients with acute PE who have elevated cardiac enzymes (such as troponin, brain natriuretic peptide (BNP) and creatinine kinase), or evidence of right-heart dysfunction on either echocardiography or CTPA, have a worse short-term survival rate than those without these findings. ${ }^{21,23-26}$ There are also studies pointing to the role of plasmin degradation products, such as D-Dimer concentration, in the risk stratification of patients with PE. ${ }^{10,27}$ More recently, a prospective management study showed that out of hospital treatment is safe in hemodynamically stable PE-patients with low NT-proBNP level $(<500 \mathrm{pg} / \mathrm{ml}) .{ }^{10}$ Future prospective management studies are required to assess if the use of biomarkers can improve stratification of patients with $\mathrm{PE}$ and optimize the number of patients with $\mathrm{PE}$ that can be safely treated as outpatients.

In a recent publication, Aujeskey et al. showed that emergency physicians in the United States are reluctant to discharge patients with PE for outpatient treatment due to insufficient data supporting the effectiveness and safety of the outpatient management of PE. ${ }^{27}$ However, safe outpatient management of patients with PE may lead to: 1 ) a decrease in unnecessary hospitalizations; 2 ) decrease in hospital acquired 
infections and death; 3) improvement in health-related quality of life; and 4) reduction in health care costs. ${ }^{27-30}$ Our results suggest that outpatient treatment is feasible and safe in selected patients with PE.

It is important to note the limitations of our study. First, this is a retrospective cohort study and as such, our findings may be subject to bias, incomplete information or misdiagnosis. We tried to minimize selection bias by including all consecutive patients with confirmed PE on CTPA or V/Q scan over a defined time period and by adjudicating all outcome events (two independent reviewers). Complete information about follow up was only missing in $5.1 \%$ of the sample. We performed a worse-casescenario analysis for all patients who were lost to follow-up. Assuming that all of these patients died at their end of follow-up, the overall mortality for the outpatients would have been 8 (2.9\%) within the first 14 days and 25 (9.1\%) at 3 months follow-up. Second, as previously stated, the decision to admit or discharge the patient was left to the discretion of the treating physician. Hence, it is possible that some admitted patients could have been safely managed as outpatients. Nonetheless, our results are conservative as they suggest already that a majority of the patients can be treated as outpatient with low risk of adverse events. Future prospective management studies are required to validate this approach. Finally, all patients with PE treated as outpatients were seen within 24 to 48 hours in our thrombosis clinic and followed up after 7 days. Close follow-up of patients managed as outpatients in a specialized thrombosis clinic might not be possible in all settings and therefore rates of major bleeding episodes and recurrent VTE may differ if patients are followed by other health care professionals.

In conclusion, a majority of patients with acute PE at the Ottawa Hospital were treated as outpatient with a low risk of mortality, recurrent VTE and major bleeding episodes. Out of hospital treatment for PE should be considered as a feasible and safe treatment in uncomplicated patients and can contribute to a substantial reduction in health care costs. 


\section{References}

1. Quinlan DJ, McQuillan A, Eikelboom JW. Low-molecular-weight heparin compared with intravenous unfractionated heparin for treatment of pulmonary embolism: a meta-analysis of randomized, controlled trials. Ann Intern Med 2004;140:175-183.

2. Segal JB, Streiff MB, Hofmann LV, Thornton K, Bass EB. Management of venous thromboembolism: a systematic review for a practice guideline. Ann Intern Med 2007;146:211-222.

3. Carrier M, Le Gal G, Wells PS, Rodger MA. Systematic review: case-fatality rates of recurrent venous thromboembolism and major bleeding events among patients treated for venous thromboembolism. Ann Intern Med 2010;152:578-589.

4. Douketis JD, Kearon C, Bates S, Duku EK, Ginsberg JS. Risk of fatal pulmonary embolism in patients with treated venous thromboembolism. JAMA 1998;279:458-462.

5. Agterof MJ, van Bladel ER, Schutgens RE, Snijder RJ, Tromp EA, Prins MH, et al. Risk stratification of patients with pulmonary embolism based on pulse rate and D-dimer concentration. Thromb Haemost 2009;102:683-687.

6. Janjua M, Badshah A, Matta F, Danescu LG, Yaekoub AY, Stein PD. Treatment of acute pulmonary embolism as outpatients or following early discharge. A systematic review. Thromb Haemost 2008; 100:756-761.

7. Squizzato A, Galli M, Dentali F, Ageno W. Outpatient treatment and early discharge of symptomatic pulmonary embolism: a systematic review. Eur Respir J 2009;33:1148-1155.

8. Otero R, Uresandi F, Jimenez D, Cabezudo MA, Oribe M, Nauffal D, et al. Home treatment in pulmonary embolism. Thromb Res 2010;126:e1-5.

9. Schulman S, Kearon C. Definition of major bleeding in clinical investigations of antihemostatic medicinal products in non-surgical patients. J Thromb Haemost 2005;3:692-694.

10. Agterof MJ, Schutgens RE, Snijder RJ, Epping G, Peltenburg HG, Posthuma EF, et al. Out of hospital treatment of acute pulmonary embolism in patients with a low NT-proBNP level. J Thromb Haemost 2010;3:1235-1241.

11. Beer JH, Burger M, Gretener S, Bernard-Bagattini S, Bounameaux H. Outpatient treatment of pulmonary embolism is feasible and safe in a substantial proportion of patients. J Thromb Haemost 2003;1:186-187.

12. Büller HR, Davidson BL, Decousus H, Gallus A, Gent M, Piovella F, et al. Subcutaneous fondaparinux versus intravenous unfractionated heparin in the initial treatment of pulmonary embolism. $\mathrm{N}$ Engl J Med 2003;349:1695-1702.

13. Davies CW, Wimperis J, Green ES, Pendry K, Killen J, Mehdi I, et al. Early discharge of patients with pulmonary embolism: a two-phase observational study. Eur Respir J 2007;30:708-714.

14. Kovacs MJ, Anderson D, Morrow B, Gray L, Touchie D, Wells PS. Outpatient treatment of pulmonary embolism with dalteparin. Thromb Haemost 2000;83:209-211.

15. Lim AY, Parr DG, Stableforth DE, Fellows M, Fontaine R, Fegan CD. Early discharge and home supervision of patients with pulmonary embolism treated with low-molecular weight heparin. Eur J Intern Med. 2003;14:89-93.

16. Lui B, Tran A, Montalto M. Treatment of patients with pulmonary embolism entirely in Hospital in the Home. Aust Fam Physician 2007;36:381-384.

17. Olsson CG, Bitzen U, Olsson B, Magnusson P, Carlsson MS, Jonson B, et al. Outpatient tinzaparin therapy in pulmonary embolism quantified with ventilation/perfusion scintigraphy. Med Sci Monit 2006;12:PI9-13.

18. Ong BS, Karr MA, Chan DK, Frankel A, Shen Q. Management of pulmonary embolism in the home. Med J Aust 2005;183:239-242.

19. Siragusa S, Arcara C, Malato A, Anastasio R, Valerio MR, Fulfaro F, et al. Home therapy for deep vein thrombosis and pulmonary embolism in cancer patients. Ann Oncol 2005; 16:iv136-139.

20. Wells PS, Anderson DR, Rodger MA, Forgie MA, Florack P, Touchie D, et al. A randomized trial comparing 2 low-molecular-weight heparins for the outpatient treatment of deep vein thrombosis and pulmonary embolism. Arch Intern Med 2005;165:733-738.

21. Almahameed A, Carman TL. Outpatient management of stable acute pulmonary embolism: proposed accelerated pathway for risk stratification. Am J Med 2007;120:S18-25. 
22. Donze J, Le Gal G, Fine MJ, Roy PM, Sanchez O, Verschuren F, et al. Prospective validation of the Pulmonary Embolism Severity Index. A clinical prognostic model for pulmonary embolism. Thromb Haemost 2008;100:943-948.

23. Kucher N, Goldhaber SZ. Risk stratification of acute pulmonary embolism. Semin Thromb Hemost 2006;32:838-847.

24. Becattini C, Vedovati MC, Agnelli G. Prognostic value of troponins in acute pulmonary embolism: a meta-analysis. Circulation 2007;116:427-433.

25. Klok FA, Mos IC, Huisman MV. Brain-type natriuretic peptide levels in the prediction of adverse outcome in patients with pulmonary embolism: a systematic review and meta-analysis. Am J Respir Crit Care Med 2008;178:425-430.

26. Moores LK, Holley AB. Computed tomography pulmonary angiography and venography: diagnostic and prognostic properties. Semin Respir Crit Care Med 2008;29:3-14.

27. Aujesky D, Mazzolai L, Hugli O, Perrier A. Outpatient treatment of pulmonary embolism. Swiss Med Wkly 2009;139:685-690.

28. Aujesky D, Smith KJ, Cornuz J, Roberts MS. Cost-effectiveness of low-molecular-weight heparin for treatment of pulmonary embolism. Chest 2005;128:1601-1610.

29. Shepperd S, Doll H, Angus RM, Clarke MJ, lliffe S, Kalra L, et al. Admission avoidance hospital at home. Cochrane Database Syst Rev. 2010. Ref Type: Electronic Citation.

30. WHO. World Health Organization guidelines on Hand Hygiene in Health Care: a Summary. First Global Patient Safety Challenge. Clean Care is Safe Care. World Health Organization. Geneva. 2009. Ref Type: Report. 


\section{Chapter}

\section{Does the Pulmonary Embolism Severity Index accurately identify low risk patients eligible for outpatient treatment?}

PMG Erkens, E Gandara, PH Wells, AYH Shen, G Bose, G le Gal, M Rodger, MH Prins, M Carrier 


\section{Abstract}

\section{Background}

The pulmonary embolism severity index (PESI) and the recently derived simplified PESI prognostic model have been developed to estimate the risk of 30-day mortality in patients with acute PE. We sought to assess if the PESI and simplified PESI prognostic models can accurately identify adverse events and to determine the rates of events in patients treated as outpatients.

\section{Methods}

A retrospective cohort study of patients with acute pulmonary embolism (PE) presenting at the Ottawa Hospital (Canada) was conducted between 1 January 2007 and 31 December 2008.

\section{Results}

Two hundred and forty three patients were included. A total of 118 (48.6\%) and 81 (33.3\%) were classified as low risk patients using the original and simplified PESI prognostic models respectively. None of the low risk patients died within the 3 months of follow-up. One hundred and fifteen (47.3\%) patients were safely treated as outpatients with no deaths or bleeding episodes and only 1 recurrent event within the first 14 days or after 30 days of follow-up. Thirty four (29.6\%) of these outpatients were classified as high risk patients according to the original PESI and $54(47.0 \%)$ to the simplified PESI prognostic model.

\section{Conclusion}

Both PESI strategies accurately identify patients with acute PE who are at low risk and high risk for short-term adverse events. However, 30 to $47 \%$ of patients with acute PE and a high risk PESI score were safely managed as outpatients. Future research should be directed at developing tools that predict which patients would benefit from inpatient management. 


\section{Introduction}

The mortality and morbidity of pulmonary embolism (PE) may vary considerably depending on the severity of the event and co-morbidities. Predicting patient outcomes may enable different management strategies and may inform the clinician which patients can be treated as outpatients. ${ }^{1,2}$

Over the last decade, several studies have suggested that outpatient treatment in a selected group of hemodynamically stable patients with acute PE is safe ${ }^{3-7}$. Benefits include: 1) cost savings from a decrease in hospitalizations; 2) fewer patients at risk for hospital acquired infections; and 3) an improvement in quality of life, increased physical activity and social functioning. ${ }^{3,8-11}$ However, physicians are reluctant to treat patients with PE at home due to uncertainty on how to safely identify patients who are at low risk for short-term adverse events ${ }^{8}$, irrespective of whether the adverse events could be averted by hospitalization.

Prognostic models that will accurately predict short-term adverse outcomes may help identify patients with acute PE at low-risk of adverse events that can be safely treated as outpatients. Several prognostic models have been developed to assess the risk of death, recurrent venous thromboembolism (VTE) or major bleeding in patients with acute PE. ${ }^{12}$ The most extensively validated prognostic models are the Geneva Prognostic Score (GPS) and the Pulmonary Embolism Severity Index (PESI). ${ }^{12}$ The GPS predicts the combined adverse outcomes of death, recurrent VTE and major bleeding episodes during the first three months following the index PE. However, the GPS prognostic model is not frequently used since it requires the use of ultrasound variables and arterial blood gas which decrease feasibility. Moreover, a comparison of GPS low-risk patients with PESI low-risk patients in a cohort of 599 consecutive patients with acute symptomatic PE showed that the PESI low-risk patients had a significantly lower mortality. ${ }^{13}$

The PESI prognostic model stratifies patients in five risk classes with increasing risk of all cause short term mortality without any need for ultrasonography or laboratory studies. ${ }^{14}$ The use of the PESI prognostic model requires computation of a score based on 11 variables each with a different weight (Table 7.1). Recently, a PESI-derived simplified model with a less complex scoring system has been proposed and seems to have a similar prognostic accuracy as the original PESI (Table7.1). ${ }^{15}$

We sought to evaluate if the original and the simplified PESI prognostic models could identify patients with acute PE at low risk of short term adverse outcome who can be safely managed as outpatients. 
Table 7.1 Pulmonary Embolism Severity Index (PESI). ${ }^{15}$

\begin{tabular}{|c|c|c|}
\hline Predictors & Original score* & Simplified score \\
\hline \multicolumn{3}{|l|}{ Demographic characteristics } \\
\hline Age $>80$ years & Age, in years & 1 \\
\hline Male sex & +10 & \\
\hline \multicolumn{3}{|l|}{ Comorbid illnesses } \\
\hline Cancer $^{+}$ & +30 & 1 \\
\hline Heart failure & +10 & $-\mid 1 * *$ \\
\hline Chronic lung disease & +10 & $-\left.\right|^{1}$ \\
\hline \multicolumn{3}{|l|}{ Clinical findings } \\
\hline Pulse $\geq 110 / \mathrm{min}$ & +20 & 1 \\
\hline Systolic blood pressure $<100 \mathrm{mmHg}$ & +30 & 1 \\
\hline Respiratory rate $\geq 30 / \mathrm{min}$ & +20 & \\
\hline Temperature $<36^{\circ} \mathrm{C}$ & +20 & \\
\hline Altered mental status ${ }^{\ddagger}$ & +60 & \\
\hline Arterial oxygen saturation $<90 \%{ }^{\S}$ & +20 & 1 \\
\hline
\end{tabular}

* A total point score for a given patient is obtained by summing the patient's age in years and the points for each predictor when present. The score corresponds with the following risk classes: <65, class I; 66-85, class II; 86-105, class III; 106-125, class IV; and $\geq 125$, class V. Patients in risk class I and II are defined as being at low risk. ${ }^{+}$Cancer defined as a history of cancer or active cancer; ${ }^{\ddagger}$ Defined as disorientation, lethargy, stupor or coma; ${ }^{\S}$ With and without the administration of supplemental oxygen. " A total point score for a given patient is obtained by summing the points. The score corresponds with the following risk classes: 0 , low risk; $\geq 1$, high risk. Empty cells indicate that the variable was not included. ${ }^{* *}$ The variables were combined into a single category of chronic cardiopulmonary disease.

\section{Methods}

\section{Study population}

We performed a retrospective cohort study including consecutive patients with high risk and non-high risk acute $\mathrm{PE}^{16,17}$ presenting at the Ottawa Hospital between 1 January 2007 and 31 December 2008. ${ }^{4}$ PE was defined as an intraluminal filling defect on CTPA or a high probability V/Q scan. Patients diagnosed with PE during hospitalization, patients with chronic PE and patients in whom anticoagulation was not initiated (e.g. palliative care patients, small clinical non-significant PE) were excluded from the analyses. Patients were also excluded if they were followed-up by a health care professional out of the Ottawa Hospital. ${ }^{4}$ Patients were considered for outpatient management if they were hemodynamically stable, did not require supplemental oxygenation and had no contraindications to Low Molecular Weight Heparin (LMWH) or significant comorbidities. The decision to manage the patients as an outpatient or an inpatient was ultimately left to the discretion of the emergency room physician. Outpatients were followed in the Outpatient Thrombosis Assessment and Treatment Unit within 24-48 hours of diagnosis, then again at 7 days and 3 months. Admitted patients were followed in the Thrombosis Unit after discharge. 


\section{Risk-prognostic models}

The original PESI prognostic model stratifies patients into five severity classes of increasing risk of mortality within 30 days after the diagnosis PE [16]. The model includes 11 routinely available clinical parameters at the time of presentation: age, male sex, cancer, heart failure, chronic lung disease, pulse $\geq 110$ beats/min, systolic blood pressure less than $100 \mathrm{mmHg}$, respiratory rate $30 \geq$ breaths/min, temperature $<36^{\circ} \mathrm{C}$, altered mental status and arterial oxygen saturation $<90 \%$. The model assigns points for each applicable characteristic and calculates a total point score by summing these points and the patient's age in years (Table 7.1). Point assignments correspond with the following risk classes: 65 or less, class I, very low risk; 66-85, class II, low risk; 86-105, class III, intermediate risk; $106-125$, class IV, high risk; greater than 125 , class $\mathrm{V}$, very high risk. ${ }^{18}$

The simplified PESI prognostic model consists of 6 variables: one demographic variable (age >80 years), two comorbid conditions (cancer, chronic pulmonary disease), and three physical examination findings (pulse $\geq 110$ beats/min, systolic blood pressure $<100 \mathrm{mmHg}$ and arterial oxygen saturation <90\%) (Table 7.1). Patients with none of these factors were defined as being at low risk. ${ }^{15}$

\section{Outcomes}

Charts of all included patients were reviewed to extract the data necessary for computation of the original PESI and the simplified PESI prognostic models. All included patients were followed for 3 months.

The following variables were also specified prior to data collection: i) patient demographics; ii) reasons for hospitalization; iii) recurrent VTE and bleeding episodes; and iv) death (date and cause). Data were extracted from paper charts at the emergency department, hospital discharge reports and consultation notes from the Thrombosis Assessment and Treatment Unit. All outcomes were reviewed independently by two reviewers. Disagreements on the variables were resolved by consensus or retrieving further information from other medical records.

The primary outcomes used to validate the risk-prediction models were overall mortality and fatal PE. The cause of death was identified by discharge summaries or other medical records. Secondary outcomes included recurrent VTE and major hemorrhage. Recurrent PE was defined as a new arterial filling defect on CTPA or high probability V/Q-scan and recurrent DVT was defined as a new non-compressible venous segment on an ultrasound of the extremities. Major hemorrhage was defined according to the definition of the Control of Anticoagulation Subcommittees (ISTH SSC 2004). ${ }^{19}$ 


\section{Statistical analysis}

Descriptive statistics were used to describe the patient characteristics and outcomes. Ninety-five percent confidence intervals $(95 \% \mathrm{Cl}$ ) and $\mathrm{p}$-values were calculated for each event rate by using Fisher's exact test. The statistical analyses were performed using the Statistical Package for the Social Sciences software (version 17; SPSS; Chicago, IL, USA).

\section{Results}

A total of 243 patients presenting at the Ottawa Hospital with confirmed PE were included in this study. One hundred and fifteen (47.3\%) patients were directly discharged from the Emergency Department and were treated out of the hospital, while $128(52.7 \%)$ patients were admitted. According to the original PESI prognostic model, 118 (48.6\%; 95\% Cl 42.1-55.0) patients were classified as low risk (class I and II) and 125 (51.4\%; 95\% Cl 45.0-58.0) were classified as high risk (class III to V). According to the simplified PESI prognostic model, 81 (33.3\%; 27.4-39.6) patients were classified as low risk patients and 162 (66.7\%; 60.4-72.6) were classified as high risk patients.

Baseline characteristics of patients in different PESI risk groups are shown in Table 7.2. High risk patients were older than low risk patients. High risk patients were more likely to have had a previous diagnosis of cancer, heart failure or chronic obstructive pulmonary disease (COPD) whereas low risk patients were more likely to have presented with chest pain and hemoptysis. Most low risk patients were treated with LMWH, while $16 \%$ to $22 \%$ of the high risk patients were treated with unfractionated heparin (UFH). Two $(0.8 \% ; 95 \% \mathrm{Cl} 0.1-2.9)$ patients were treated with thrombolysis.

\section{Overall mortality and fatal PE}

No low risk patients, in either group, died within 14 days, 30 days or 3 months (Table 7.3). In the original PESI high risk group, 7 (5.6\%; $95 \% \mathrm{Cl} 2.3-11.2)$ patients died within 14 days, 10 (8\%; 95\% Cl 3.9-14.2) within 30 days and 32 (25.6\%; 95\% Cl 18.2-34.2) patients died within 3 months. The overall mortality in the simplified PESI high risk group was 7 (4.3\%; 95\% Cl 1.8-8.7) within 14 days, 10 (5.5\%; 95\% Cl 2.7-9.9) within 30 days and 32 (19.8\%; 95\% Cl 13.9-26.8) within 3 months (Table 7.3). None of the patients died from PE. The majority $(84.4 \%$; $95 \% \mathrm{Cl} 67.2-94.7)$ of the patients died from disease progression of an underlying cancer. 


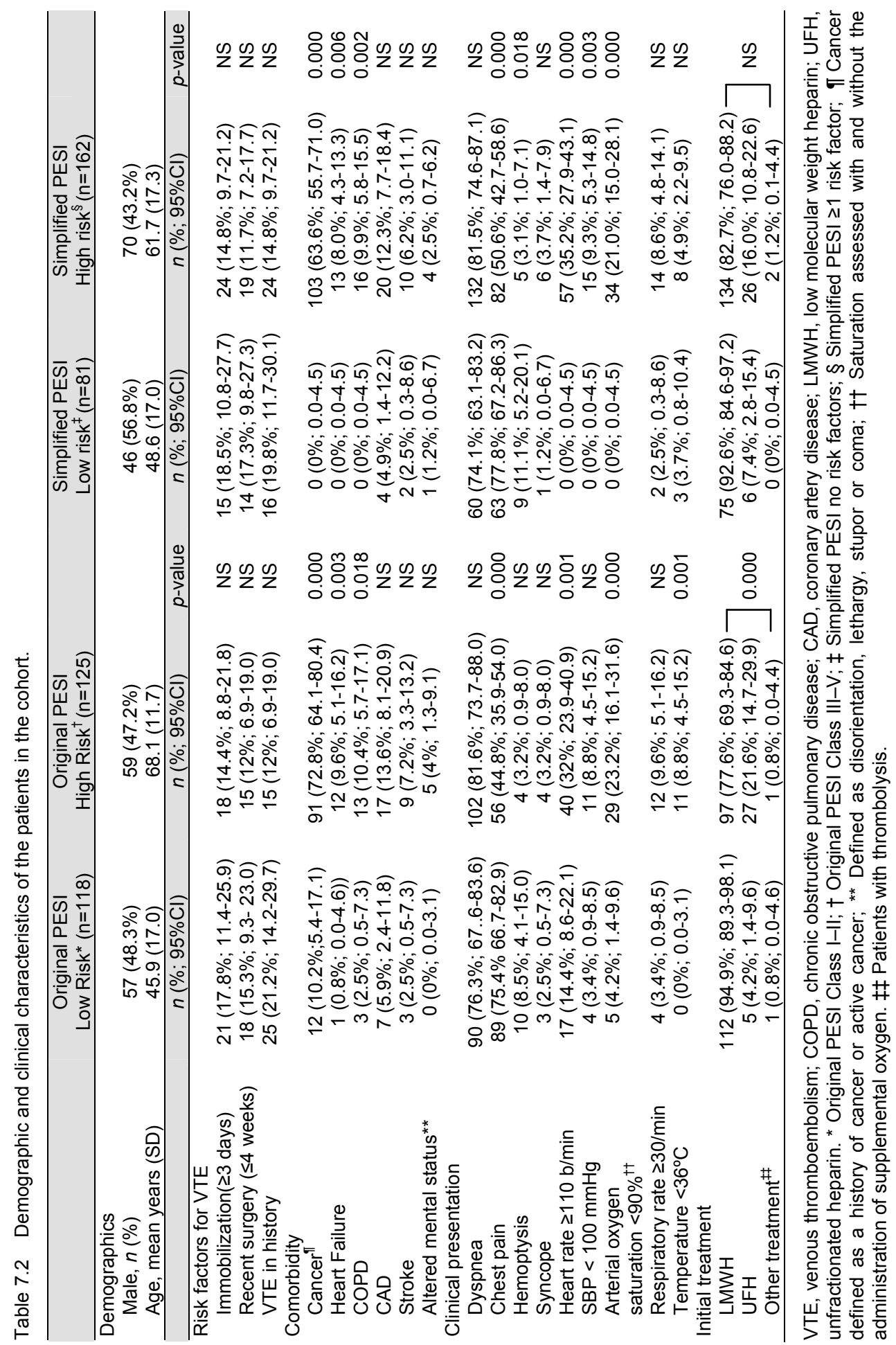




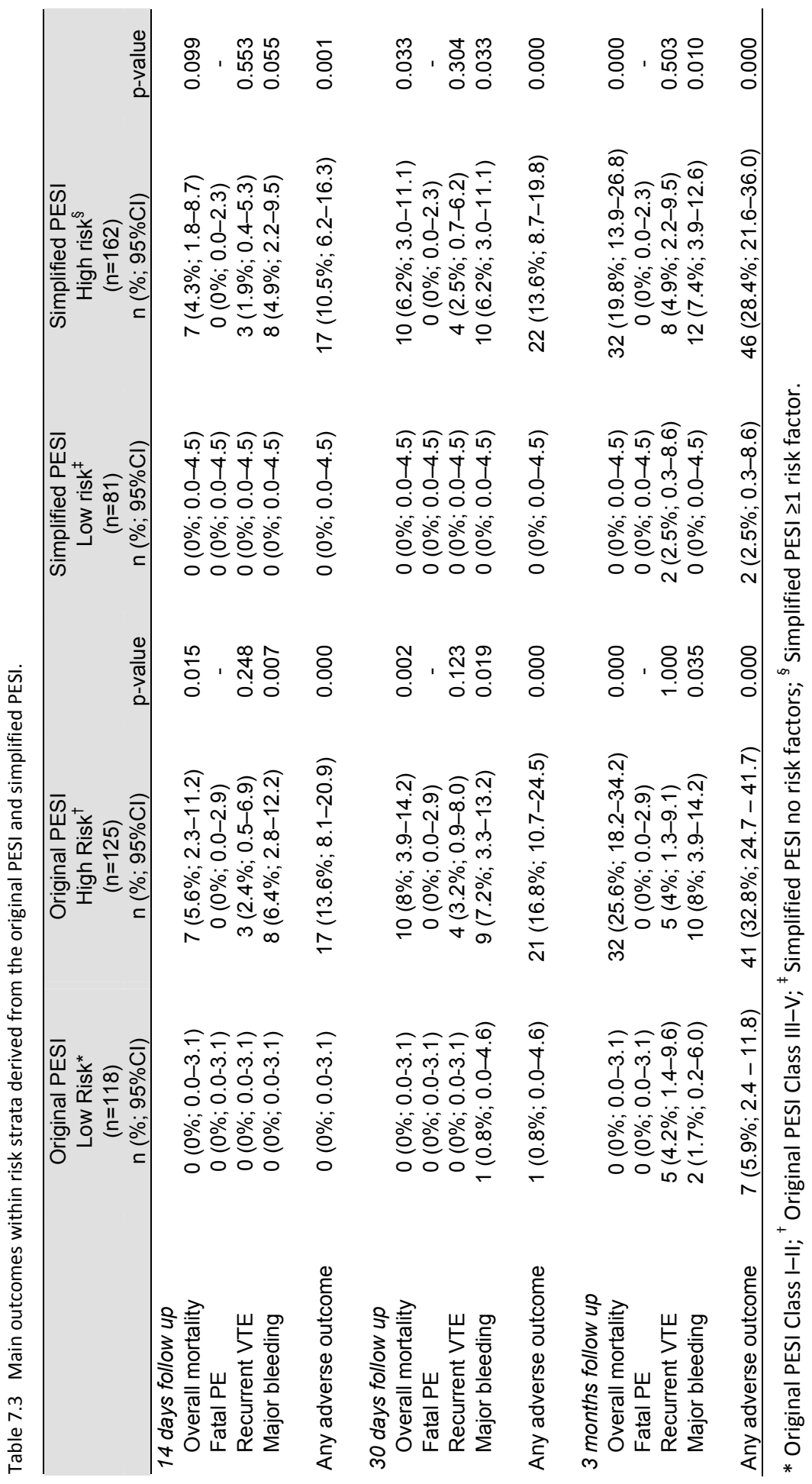




\section{Recurrent VTE and major bleeding episodes}

None of the low risk patients, in either group, had a recurrent event within 14 days (Table 7.3). At 3 months follow-up, 5 (4.2\%; 95\% Cl 1.4-9.6) and 2 (2.5\%; 95\% Cl 0.3-8.6) low risk patients from the original PESI and simplified PESI prognostic models developed recurrent VTE respectively. The rates of recurrent VTE in the high risk groups at 14 days and 3 months follow-up were 3 (2.4\%; 95\% Cl 0.5-6.9) and 5 (4\%; $95 \% \mathrm{Cl} 1.3-9.1)$ in the original PESI and $3(1.9 \% ; 0.4-5.3)$ and $8(4.9 \% ; 2.2-9.5)$ in the simplified PESI prognostic model (Table 7.3). The incidence of recurrent events did not differ significantly between the low and high risk groups at 14 days and 3 months (original PESI $P=0.248$ and 1.000 , simplified PESI $P=0.553$ and 0.503 ).

There were no major hemorrhages in the low risk groups within 14 days (Table 7.3). At 3 months follow-up $2(1.7 \% ; 95 \% \mathrm{Cl} 0.2-6.0)$ patients in the original PESI low risk group had a major hemorrhage, while no $(0 \% ; 95 \% \mathrm{Cl} 0.0-4.5)$ patients in the simplified PESI low risk group had a major bleed. The rates of major bleeding in the high risk groups were $8(6.4 \% ; 95 \% \mathrm{Cl} 2.8-12.2)$ at 14 days and $10(8 \% ; 95 \% \mathrm{Cl}$ $3.9-14.2)$ at 3 months follow-up using the original PESI prognostic model and 8 (4.9\%; $95 \% \mathrm{Cl} 2.2-9.5)$ at 14 days and 12 (7.4\%; 95\% $\mathrm{Cl} 3.9-12.6)$ at 3 month follow-up within the simplified PESI prognostic group (Table 7.3).

\section{Any adverse outcome}

None of the low risk patients had any adverse outcome within the first 14 days after the index PE (Table 7.3). The difference in adverse events between the low risk and high risk patients at 14 days and 3 months follow-up were statistically significant (original PESI $P=0.000$ and 0.000 , simplified PESI $P=0.001$ and 0.000 )

\section{Outpatients versus inpatients}

In our sample of 243 patients, 115 (47.3\%; 95\% Cl 40.9-53.8) patients were safely treated out of the hospital with no deaths or bleeding episodes and only 1 recurrent event within the first 14 days or 30 days of follow-up. Thirty four (29.6\%) of these outpatients were classified as high risk patients according to the original PESI (19 patients in class III, 13 in class IV and 2 patients in class V) and 54 (47.0\%) were classified as high risk patients according to the simplified PESI prognostic model. In the majority of these patients (74.5\%) a malignancy contributed to the high PESI scores. On the contrary, thirty seven (28.9\%) out of the 128 admitted patients were classified as low risk patients according to the original PESI (19 patients in class I and 18 in class II) and 20 (15.6\%) were classified as low risk patients according to the simplified PESI prognostic model. The most frequent reasons for admission of these 37 low risk patients were: extensive PE (22.0\%) such as saddle PE, hypoxia $(22.0 \%)$ and severe comorbidities $(22.0 \%)$ such as pneumonia, transaminitis, advanced cancer, stroke and 
coronary artery disease. Other reasons for admission were pain management, renal dysfunction, syncope and hypotension. Eight of these patients were treated with intravenous unfractionated heparin and 1 patient received thrombolysis. None of these 37 patients suffered from any adverse event during the first 14 days. There is 1 (2.7\%; 95\% Cl 0.1-14.2) recurrent event and 1 (2.7\%; 95\% Cl 0.1-14.2) major bleeding during the 3 months follow-up.

\section{Discussion}

The results of our study suggest that both PESI prognostic models accurately identify patients with acute PE who are at low risk for short-term adverse events, including death, recurrent venous thromboembolism and major hemorrhage. None of the low risk patients died or had any adverse event within the first 14 days. Both PESI prognostic models also seem to identify patients with acute PE at low risk of adverse outcome who can be safely managed as outpatients.

Our results are consistent with previously published studies validating the original and simplified PESI. ${ }^{14,15,20-22}$ The 3 months overall mortality in the low risk groups according to the original PESI model has been reported to be between $0 \%$ and $1.2 \%{ }^{14,20,21}$ The overall mortality in the low risk group of our study was $0 \%(95 \% \mathrm{Cl}$ $0.0-3.1)$. The overall mortality in our high risk group was $25.6 \%$ (95\% Cl 18.2-34.2). Although this is consistent with two large validation studies ${ }^{14,20}$, a recent cohort reported an overall mortality of $9 \%$ in the risk classes IV and V in the first 3 months. This discrepancy might be explained by the exclusion of patients with terminal illness, such as metastatic cancer, in that particular study. ${ }^{21}$ There is only one derivation and one validation study using the simplified PESI. ${ }^{15,23}$ Their 30 -day overall mortality of approximately $1 \%$ in the low risk groups correspond to our 30-day overall mortality of $0 \%(95 \% \mathrm{Cl} 0-4.5)$. To our knowledge, our study is the first external validation study reporting a shorter term follow-up of 14 days. Besides overall and PE-related mortality we also report recurrent VTE and major bleeding episodes. In order to select patients for outpatient treatment, clinicians require risk estimates of any adverse event in a short-term follow-up.

The overall proportion of patients classified into the low-risk category according to both PESI-scores and our own criteria for outpatient treatment was similar. However, in the current study $53 \%$ of patients were hospitalized following the diagnosis of the acute PE. Sixteen to $29 \%$ of these patients had a low risk PESI score. None of these admitted patients developed an adverse event during the first 14 days. However, some of these patients needed to be admitted to the hospital because of large PE (one patient with a saddle $\mathrm{PE}$, severe tachycardia and tachypnea required thrombolysis), hypoxia or other severe comorbidities (e.g. advanced cancer). These features likely influenced the clinical judgment of the treating physician to hospitalize these patients. This emphasizes that the clinical judgment of the treating physician 
may overrule a suggested decision by the PESI. On the contrary, 30 to $47 \%$ of patients with acute PE and a high risk PESI score were safely treated as outpatients. An underlying malignancy contributed to the high PESI scores in $75 \%$ of these cases. This suggests that a proportion of patients with high risk PESI scores might be safely treated as outpatients. Although, cancer patients have a high risk of death, it does not seem to be associated with worse short term adverse events in these patients with acute PE who were treated out of the hospital ( $P=0.339$ for any adverse event during 14 and 30-days follow-up). Future research is needed to identify patients with a low risk of short term adverse events who do not need hospitalization especially in those with significant other comorbidities.

Our study is limited by the small number of patients. The confidence intervals are large as a consequence of the small sample size and therefore our results and conclusions should be further investigated in larger studies. Secondary, the study is also limited by its retrospective design. However, we tried to minimize bias by reviewing patients' paper charts completed at the emergency department and all other patient data in our hospital database in duplicates. Furthermore, it is important to acknowledge possible selection bias by the exclusion of patients not followed at the Ottawa Hospital $(n=21)$. None of the included patients were lost to follow-up and no patients with PE were missed since we reviewed all VQs and CTPAs during the study period.

In conclusion, the original PESI as well as the simplified PESI prognostic models accurately identify patients with acute PE who are at low risk for short-term adverse events, such as death, fatal PE, recurrent VTE and major bleeding episodes. However, many high risk patients according to the PESI prognostic model were safely treated as outpatients. Further research using different prognostic models is required to better stratify patients according to their risk of short term adverse event and optimize outpatient management of patients with acute PE. 


\section{References}

1. British Thoracic Society guidelines for the management of suspected acute pulmonary embolism. Thorax 2003;58:470-483.

2. Torbicki A, Perrier A, Konstantinides S, Agnelli G, Galie N, Pruszczyk P, et al. Guidelines on the diagnosis and management of acute pulmonary embolism: the Task Force for the Diagnosis and Management of Acute Pulmonary Embolism of the European Society of Cardiology (ESC). Eur Heart J 2008;29:2276-2315.

3. Agterof MJ, Schutgens RE, Snijder RJ, Epping G, Peltenburg HG, Posthuma EF, et al. Out of hospital treatment of acute pulmonary embolism in patients with a low NT-proBNP level. J Thromb Haemost 2010;8:1235-1241.

4. Erkens PM, Gandara E, Wells P, Shen AY, Bose G, Le Gal G, et al. Safety of outpatient treatment in acute pulmonary embolism. J Thromb Haemost 2010;8:2412-2417.

5. Janjua M, Badshah A, Matta F, Danescu LG, Yaekoub AY, Stein PD. Treatment of acute pulmonary embolism as outpatients or following early discharge. A systematic review. Thromb Haemost 2008;100:756-761.

6. Kovacs MJ, Hawel JD, Rekman JF, Lazo-Langner A. Ambulatory management of pulmonary embolism: a pragmatic evaluation. J Thromb Haemost 2010;8:2406-2411.

7. Squizzato A, Galli M, Dentali F, Ageno W. Outpatient treatment and early discharge of symptomatic pulmonary embolism: a systematic review. Eur Respir J 2009;33:1148-1155.

8. Aujesky D, Mazzolai L, Hugli O, Perrier A. Outpatient treatment of pulmonary embolism. Swiss Med Wkly 2009;139:685-690.

9. Aujesky D, Stone RA, Kim S, Crick EJ, Fine MJ. Length of hospital stay and postdischarge mortality in patients with pulmonary embolism: a statewide perspective. Arch Intern Med 2008;168:706-712.

10. Park B, Messina L, Dargon P, Huang W, Ciocca R, Anderson FA. Recent trends in clinical outcomes and resource utilization for pulmonary embolism in the United States: findings from the nationwide inpatient sample. Chest 2009;136:983-990.

11. Shepperd S, Doll H, Angus RM, Clarke MJ, Iliffe S, Kalra L, et al. Admission avoidance hospital at home. Cochrane Database Syst Rev 2010(4):CD007491.

12. Jimenez D, Yusen RD. Prognostic models for selecting patients with acute pulmonary embolism for initial outpatient therapy. Curr Opin Pulm Med 2008;14:414-421.

13. Jimenez D, Yusen RD, Otero R, Uresandi F, Nauffal D, Laserna E, et al. Prognostic models for selecting patients with acute pulmonary embolism for initial outpatient therapy. Chest 2007;132:24-30.

14. Aujesky D, Roy PM, Le Manach CP, Verschuren F, Meyer G, Obrosky DS, et al. Validation of a model to predict adverse outcomes in patients with pulmonary embolism. Eur Heart J 2006;27:476-481.

15. Jimenez D, Aujesky D, Moores L, Gomez V, Lobo JL, Uresandi F, et al. Simplification of the pulmonary embolism severity index for prognostication in patients with acute symptomatic pulmonary embolism. Arch Intern Med 2010;170:1383-1389.

16. Jaff MR, McMurtry MS, Archer SL, Cushman M, Goldenberg N, Goldhaber SZ, et al. Management of massive and submassive pulmonary embolism, iliofemoral deep vein thrombosis, and chronic thromboembolic pulmonary hypertension: a scientific statement from the American Heart Association. Circulation 2011;123:1788-1830.

17. Torbicki A, Perrier A, Konstantinides S, Agnelli G, Galie N, Pruszczyk P, et al. Guidelines on the diagnosis and management of acute pulmonary embolism: the Task Force for the Diagnosis and Management of Acute Pulmonary Embolism of the European Society of Cardiology (ESC). Eur Heart J 2008;29:2276-2315.

18. Aujesky D, Obrosky DS, Stone RA, Auble TE, Perrier A, Cornuz J, et al. Derivation and validation of a prognostic model for pulmonary embolism. Am J Respir Crit Care Med 2005;172:1041-1046.

19. Schulman S, Kearon C. Definition of major bleeding in clinical investigations of antihemostatic medicinal products in non-surgical patients. J Thromb Haemost 2005;3:692-694.

20. Aujesky D, Perrier A, Roy PM, Stone RA, Cornuz J, Meyer G, et al. Validation of a clinical prognostic model to identify low-risk patients with pulmonary embolism. J Intern Med 2007;261:597-604.

21. Chan CM, Woods C, Shorr AF. The validation and reproducibility of the pulmonary embolism severity index. J Thromb Haemost 2010;8:1509-1514. 
22. Hariharan $\mathrm{P}$, Takayesu JK, Kabrhel C. Association between the Pulmonary Embolism Severity Index (PESI) and short-term clinical deterioration. Thromb Haemost 2011;105:706-711.

23. Sam A, Sanchez D, Gomez V, Wagner C, Kopecna D, Zamarro C, et al. The shock index and the simplified PESI for identification of low-risk patients with acute pulmonary embolism. Eur Respir J 2011;37:762-766. 



\section{Chapter 8

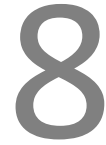

Benchmark for time in therapeutic range in venous thromboembolism: a systematic review and meta-analysis

PMG Erkens, $\mathrm{H}$ ten Cate, HR Büller, MH Prins Plos One 2012;7:e42269 


\section{Abstract}

\section{Background}

The percentage of time within the target INR range 2.0 to 3.0 (TTR) in patients treated with vitamin $\mathrm{K}$ antagonists varies considerably among efficacy-studies of novel anticoagulants. In order to properly asses the quality of anticoagulant control in upcoming cost-effectiveness studies and real life registries this systematic review reports a benchmark of TTR for different treatment durations in patients with venous thromboembolism and discusses ways to calculate TTR. This review aims to inform clinicians on the benchmark of TTR and to discuss properly TTR assessments

\section{Methods}

Medline and Embase were searched for studies published between January 1990 and May 2012. Randomized controlled trials and cohort studies reporting the TTR in patients with objectively confirmed venous thromboembolism treated with vitamin $\mathrm{K}$ antagonists (VKA) were eligible. Duplicate reports, studies only reporting INR during initial treatment or with VKA treatment less than 3 months were excluded. Three authors assessed trials for inclusion and extracted data independently. Discrepancies were resolved by discussion between the reviewers. A meta-analysis was performed by calculating a weighted mean, based on the number of participants in each included study, for each time-period in which the TTR was measured since the confirmation of the diagnosis of VTE.

\section{Results}

Forty studies were included (26064 patients). The weighted means of TTR were $54.0 \%$ in the first month since the start of treatment, $55.6 \%$ in months 1 to 3,60.0\% in months 2 to $3,60.0 \%$ in the months 1 to $6+$ and $75.2 \%$ in months 4 to $12+$. Five studies reported TTR in classes. The INR in these studies was $\geq 67 \%$ of time in therapeutic range in $72.0 \%$ of the patients.

\section{Conclusion}

Reported quality of VKA treatment is highly dependent on the time-period since the start of treatment, with TTR ranging from approximately $56 \%$ in studies including the $1^{\text {st }}$ month to $75 \%$ in studies excluding the first 3 months. 


\section{Introduction}

Traditionally, patients with venous thromboembolism (VTE) are treated with low molecular weight heparins (LMWH) and vitamin K antagonists (VKA) such as warfarin, acenocoumarol or phenprocoumon. ${ }^{1,2}$ As with any medical treatment, the weighing of risks and benefits must be carefully balanced. The effect of VKA therapy depends on many factors including variation in dose response between patients, individual variation in pharmacokinetics and pharmacodynamic response, multiple interactions with food, co- medication and finally also by variation in adherence. ${ }^{3,4}$ VKA have a narrow therapeutic index, which needs to be monitored carefully in order to reduce the risk of tromboembolic events as well as bleeding complications. ${ }^{5}$ With the large scale clinical testing of novel, direct acting oral anticoagulants, including the thrombin and factor Xa inhibitors dabigatran and rivaroxaban, a new era has been heralded. The main advantage of these new anticoagulants is the lack of a need for laboratory monitoring and dose adjustment due to more stable pharmacokinetics. ${ }^{6}$ Several recent large randomized controlled trials have shown non-inferiority in effectiveness and safety of the new anticoagulants compared to VKA treatment. ${ }^{711}$ However, the percentage of time within therapeutic range in the VKA-group, representing the quality of the control group, appears to vary considerably among these studies.

The International Normalized Ratio (INR), the ratio of a patient's prothrombin time to a normal (control) sample, raised to the power of the International Sensitivity Index (ISI) value, is established by the World Health Organization (WHO) and the International Committee on Thrombosis and Hemostasis for monitoring the effects of VKA. A target INR range of 2.0 to 3.0 is recommended for the treatment of VTE. ${ }^{3}$ The most recognized way to measure the therapeutic effectiveness of VKA over time is to measure the percentage of time in the therapeutic range (TTR). TTR has been shown to strongly correlate with the clinical outcomes of hemorrhage or thrombosis and, thus, TTR is a reliable measure of the quality of anticoagulation management. ${ }^{12}$

Dabigatran and rivaroxaban have been recently approved in many countries including the USA, Canada and also in Europe. This development will cause major changes in thrombosis management in the near future. Cost-effectiveness studies and real life registries will be the next step in the implementation of new oral anticoagulants. In order to adequately compare all treatment options, including novel anticoagulants and VKA, and to interpret the relative efficacy and safety of these novel anticoagulants, it is important to properly assess the quality of anticoagulant control, i.e. TTR, in the VKA group. This systematic review tries to provide a benchmark of TTR in patients with VTE receiving VKA and discusses the pros and cons of various ways to calculate TTR. Finally, it emphasizes the need to standardize TTR reporting, thereby contributing to a meaningful comparison among treatment options in studies evaluating novel anticoagulants. 


\section{Materials and methods}

\section{Data sources and searches}

A systematic search was performed to identify randomized controlled trials and cohort studies reporting the TTR in patients treated with VKA for deep vein thrombosis (DVT) confirmed by a non-compressible venous segment on an ultrasound of the extremities, or pulmonary embolism (PE) confirmed by an arterial filling defect on Computed Tomographic Pulmonary Angiography (CTPA) or a high probability ventilation/perfusion (V/Q) scan, or both (VTE). We searched Medline and Embase for articles in English, French, German, Dutch, Polish, Swedish, Danish, Italian and Spanish. Since the World Health Organization introduced the INR in $1983^{13}$ and the first studies reporting TTR in VKA in patients with VTE were published in the nineties, we searched for publications between January 1990 and May 2012. See www.plosone.org for detailed information about the search strategy and key words.

\section{Study selection}

To be eligible for inclusion, studies had to fulfill the following criteria:

1. Study population consisted of consecutive adult patients with objectively confirmed DVT or PE.

2. Patients were treated with VKA for a minimum of three months.

Studies were excluded if they only reported the TTR in the initial treatment period while patients were still on parental medication such as low molecular weight heparin and unfractionated heparin.

\section{Data extraction and management}

Three reviewers (PE, HTC, MP) operating in pairs of two extracted independently the following characteristics from each included study: study design, type of study (e.g. evaluation of a new drug, dose-finding, evaluation of duration of anticoagulation), characteristics of the study population (e.g. number of patients treated with VKA, country, inclusion criteria, proportion of patients with a malignancy), initial treatment, type of VKA (e.g. warfarin, acenocoumarol, phenprocoumon or other), initial dose of VKA, treatment duration, INR-monitoring by thrombosis service or self-management, percentage of time below therapeutic range (INR <2), percentage of time within therapeutic range (INR 2.0-3.0), percentage of time above therapeutic range (INR $>3$ ), method of calculation TTR, adverse events (e.g. recurrent VTE, major bleeding and mortality), period of follow-up and percentage lost to follow-up. The quality of the included studies was assessed by addressing the following issues: a) were consecutive patients included in the study?, b) did the authors report reasons for exclusion?, c) were incomplete data adequately addressed?, d) did the authors address potential sources of bias?, e) what was the duration of follow-up?, f) how many patients 
(percentage) were lost to follow-up?. Discrepancies were resolved by discussion. If agreement could not be reached a third reviewer was consulted.

\section{Data synthesis and analysis}

A meta-analysis was performed by calculating a weighted mean, based on the number of participants in each included study, for each time-period in which the TTR was measured since the confirmation of the diagnosis of VTE.

\section{Results}

\section{Results of the search}

The systematic search yielded 3636 citations. The results were screened and after reading titles and abstracts 3154 articles were excluded. Of the remaining 482 publications the full text was assessed. (Figure 8.1)

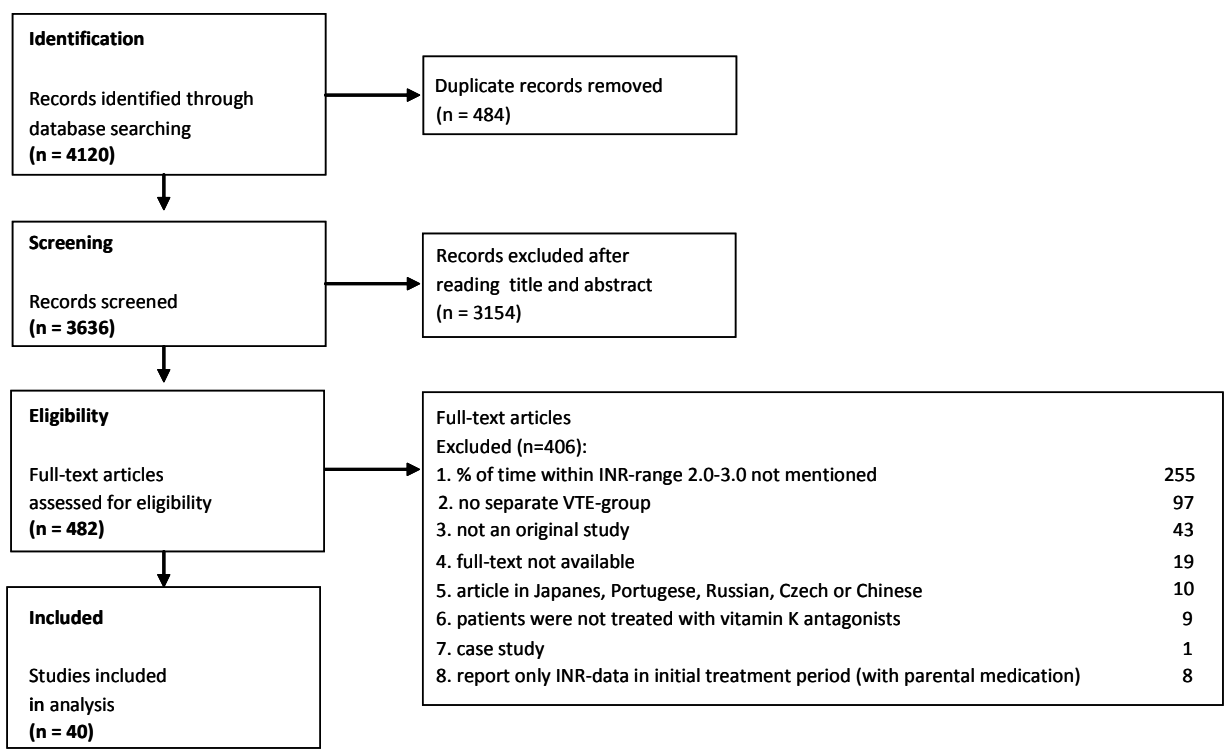

Figure 8.1 Flow diagram of literature search.

\section{Included studies}

In total, 40 studies $^{8,9,14-51}$ reporting the TTR in 26064 patients treated with VKA for VTE were included in the analyses. Most studies included patients with DVT as well as PE. 
Fifteen studies $9,14,16,19-22,25,31-33,36,39,42,47$ reported the results from patients with only DVT and eight studies ${ }^{15,18,38,47-51}$ reported the results from patients with only PE. The percentage of cancer ranged from $0 \%$ to $100 \%$. The study characteristics of the included studies are presented in Table 8.1a. The quality assessment of each study is available at www.plosone.org.

\section{Methods of calculating TTR}

Five studies ${ }^{24,39,42,43,45}$ reported TTR in classes ranging from $<33 \%$ to $\geq 75 \%$ of time spent within INR-range 2.0 to 3.0 . (e.g. $57 \%$ of all patients spent $70 \%$ of time within therapeutic range). All other TTRs were reported in percentages over time. Two studies ${ }^{9,20}$ reported the TTR in the first month since the start of treatment, thirteen studies $^{14,18,19,21,25,29,31,34,36,40,46,48,49}$ reported the TTR measured in months 1 to 3 , four studies $^{20,28,32,44}$ measured the TTR in months 2 to 3 , fifteen studies ${ }^{8,9,17,22,23,26,33,35,37,38}$ $41,45,47,50,51$ in months 1 to a minimum of 6 months and four studies ${ }^{15,16,27,3]}$ reported the TTR in months 4 to at least 12 months since the start of treatment. Twenty (50\%) studies $^{15-19,25,27-31,33,35,37,41,45,47-50}$ reported that they calculated the TTR by using linear interpolation. $^{52}$ The method used for calculating TTR was not mentioned in $12(30.0 \%)$ studies $^{8,14,20-23,32,34,36,38,44,46}$ (Table 8.1).

\section{Percentage of time in therapeutic range}

Table 8.2 presents the percentage of time below, within and above the therapeutic INR range of 2.0 to 3.0 of the individual studies. A histogram with the TTR in each individual study is given in Figure 8.2.

Table 8.3 details the weighted means for different time-periods since objective confirmation of the diagnosis VTE. The reported quality of VKA treatment is highly dependent on the time-period. In the first month the reported TTR is $54.0 \%$. The TTR is $55.6 \%$ during the months 1 to 3 and $60.0 \%$ during a treatment of at least 6 months including the INRs in the first month. In studies reporting TTR without INRs in the first month, the TTR was $60.0 \%$ in months 2 to 3 since the start of treatment and $75.2 \%$ in the months 4 to 12 or longer. 


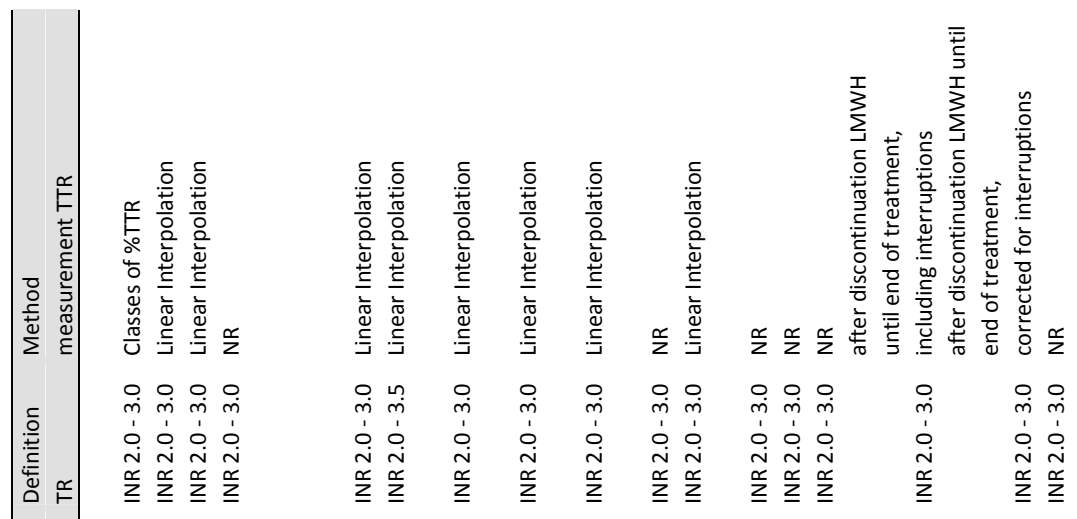

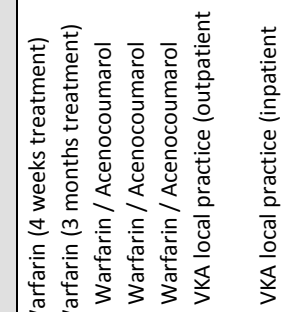

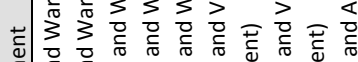

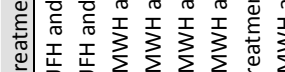

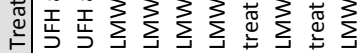

웅

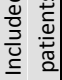

岳离

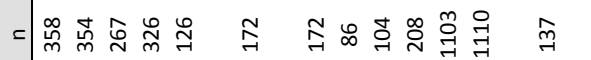

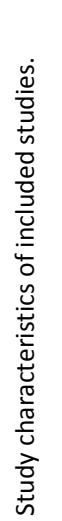

岁吉㟔吕

\section{뜸}

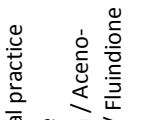

焉

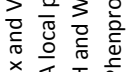

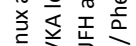

$\therefore$ 당

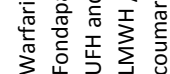

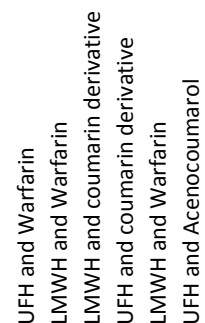

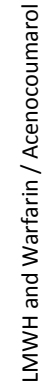

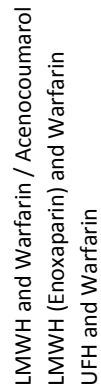

㟔幽岁占告

뜽

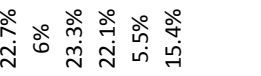

ஸे

m

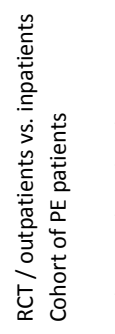

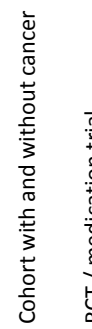

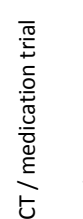

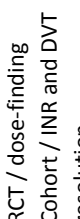

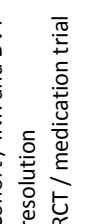

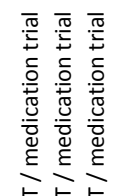

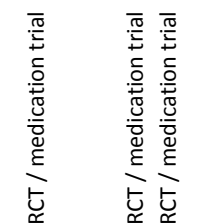

ริ

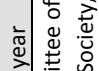

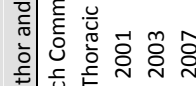

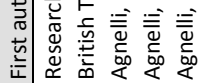

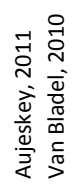

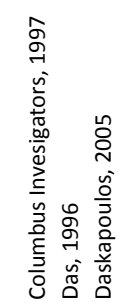

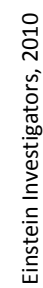

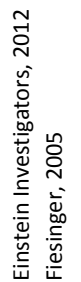




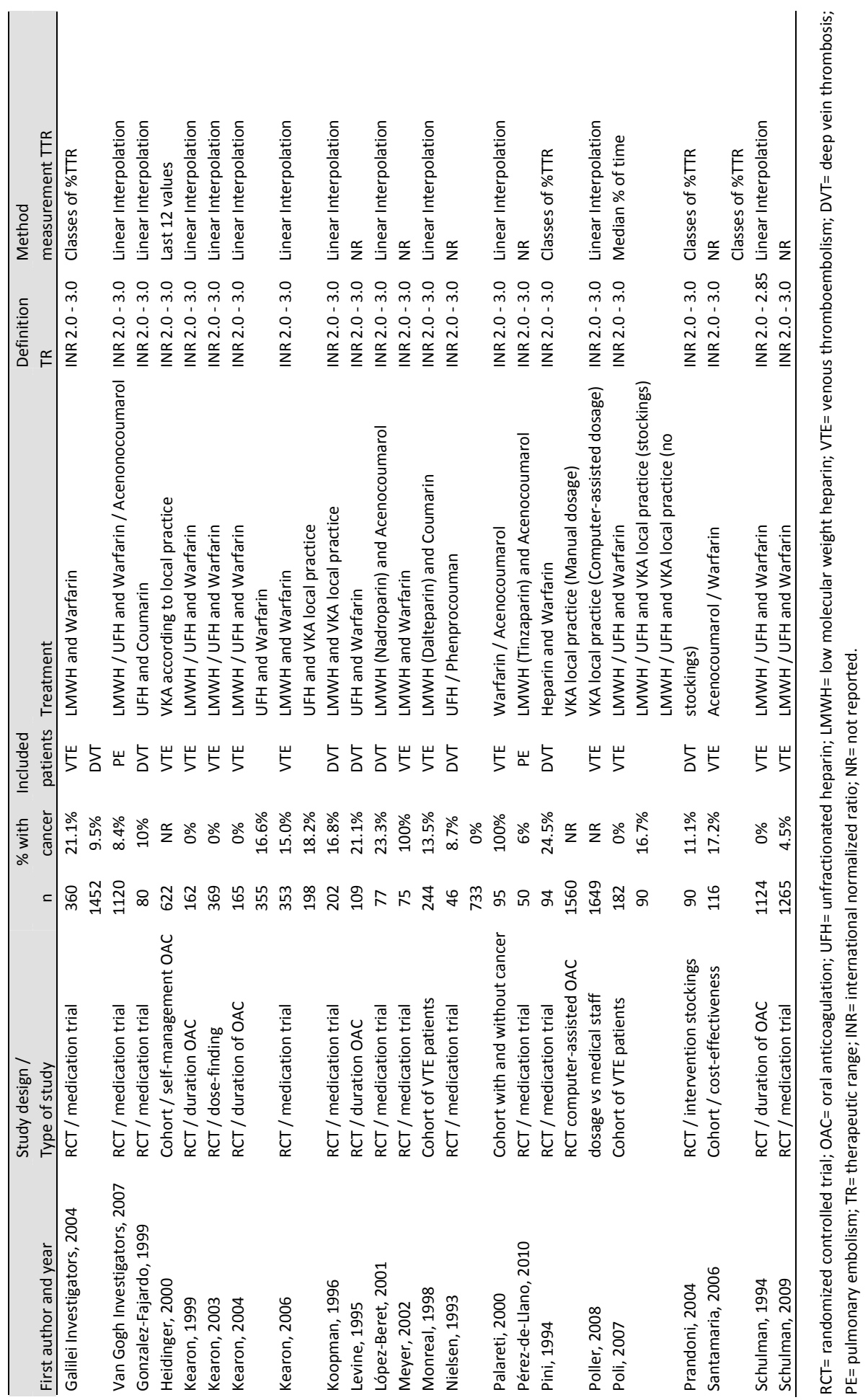




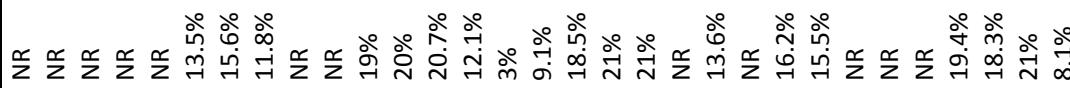

茈芷

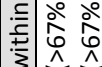

$\widehat{\widetilde{r}} \widetilde{\underline{r}}$

至

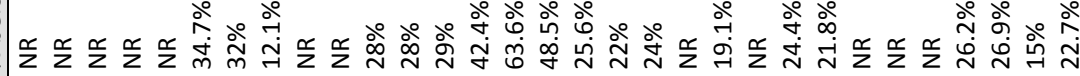

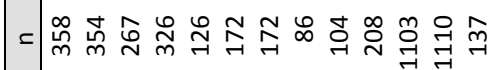

m

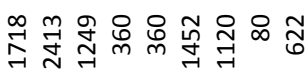

$\frac{1}{\pi}$

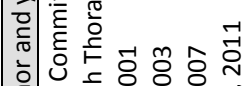

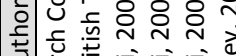

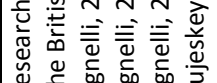

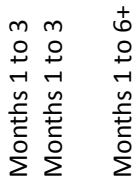

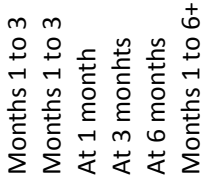

$m m \stackrel{t}{t}+t$

$m$ t $m \stackrel{\text { กั }}{+}$

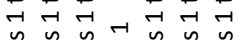

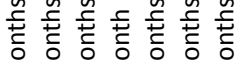

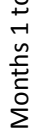

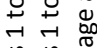

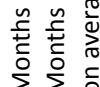

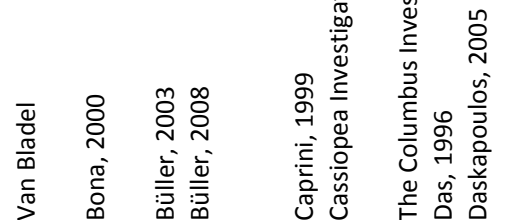

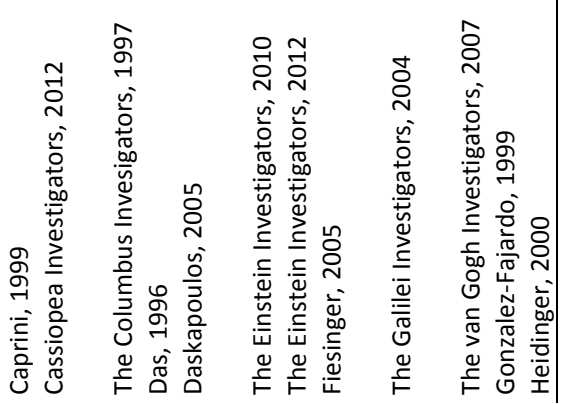




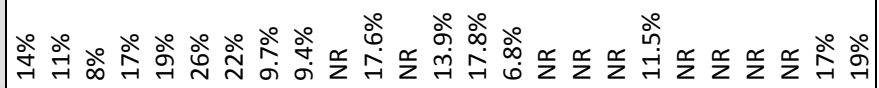

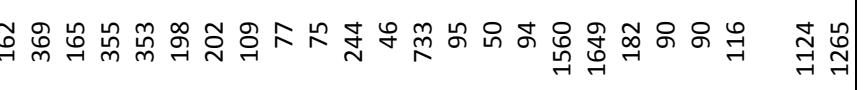




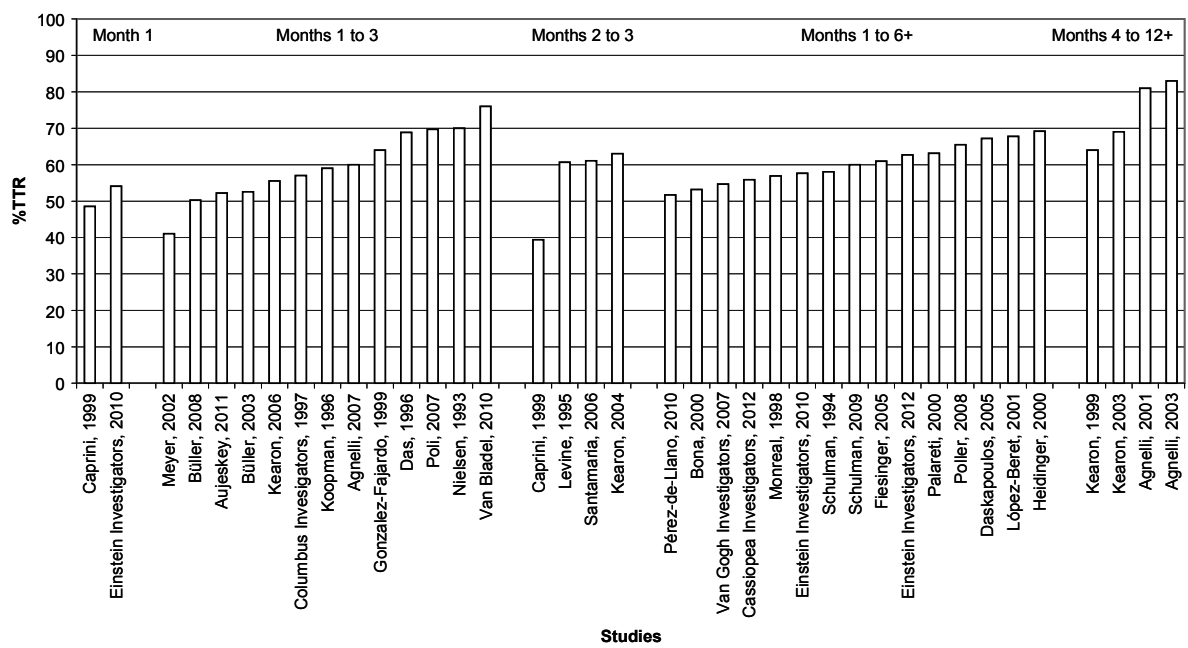

Figure 8.2 Time in therapeutic range in individual studies. (A weighted mean is calculated if a study reported more than 1 group; studies that only presented classes of \%TTR are not represented here).

Table 8.3 Weighted mean \% of time below, within and above Therapeutic Range INR 2.0-3.0.

\begin{tabular}{|c|c|c|c|}
\hline $\begin{array}{r}\text { Time-period TTR } \\
\text { INR 2.0-3.0 } \\
\text { Since diagnosis }\end{array}$ & $\begin{array}{c}\% \text { below TR } \\
\text { Weighted mean }\end{array}$ & $\begin{array}{c}\text { \% TTR } \\
\text { Weighted mean }\end{array}$ & $\begin{array}{c}\% \text { above TR } \\
\text { Weighted mean }\end{array}$ \\
\hline \multicolumn{4}{|l|}{ Month 1} \\
\hline ( $\mathrm{n}$ studies $=2, \mathrm{n}$ patients $=1751$ ) & $42.4 \%$ & $54.0 \%$ & $12.1 \%$ \\
\hline Months 1 to 3 & & & \\
\hline (n studies $=13, \mathrm{n}$ patients $=5473$ ) & $35.0 \%$ & $55.6 \%$ & $19.2 \%$ \\
\hline Months 2 to 3 & & & \\
\hline (n studies $=4, n$ patients $=423$ ) & $32.9 \%$ & $60.0 \%$ & $8.1 \%$ \\
\hline $\begin{array}{r}\text { Months } 1 \text { to } 6+ \\
\text { (n studies }=13, \mathrm{n} \text { patients }=17338\end{array}$ & $24.1 \%$ & $60.0 \%$ & $16.7 \%$ \\
\hline $\begin{array}{r}\text { Months } 4 \text { to } 12+ \\
\text { (n studies }=4, \mathrm{n} \text { patients }=1124\end{array}$ & $20.6 \%$ & $75.2 \%$ & $11.9 \%$ \\
\hline
\end{tabular}

$\mathrm{TTR}=$ time in therapeutic range; INR= international normalized ratio; $T R=$ therapeutic rang.

\section{Discussion}

A strong relationship between TTR and bleeding or thromboembolic rates has been observed across a large number of studies with different patient populations. ${ }^{53}$ Since under-anticoagulation gives inadequate protection against thromboembolic events and over-anticoagulation increases the bleeding risk, it is important to report the quality of VKA treatment by using the TTR. ${ }^{54}$ The evidence for non-inferiority of new 
anticoagulants depends on the quality of the VKA control group. The present review provides a benchmark of TTR in patients with VTE receiving VKA and discusses the pros and cons of various ways to calculate TTR.

We included 40 studies with more than 26000 participants and the results indicate that the achieved TTR ranges from approximately $56 \%$ to $75 \%$.

The reported quality of VKA treatment was highly dependent on the time-period since the start of treatment. A statistically significant lower TTR was seen in studies reporting a TTR that covers all INRs, including the first month, compared to studies reporting the TTR without the first month. This difference is to be expected because of the difficulty to reach the therapeutic range in the initial treatment period and improvement in TTR during continuation of VKA treatment. Another explanation of the high TTR during longterm treatments is a selection-to-continue bias. Patients with stable INRs are more likely to continue their treatment with VKA than patients who experience problems in reaching the therapeutic range. ${ }^{55}$ However, even after 4 to 12 months of treatment with VKA, patients spent $25 \%$ of their time outside of the therapeutic range.

Our review has some limitations that have to be mentioned. First, methods used to calculate TTR differed across the included studies. Fifty percent of the studies used linear interpolation, a few studies reported the percentage of time in a certain TTR class and $30 \%$ of the studies did not report the method of TTR calculation at all. Due to missing information about the exact calculation of TTR, we were unable to compare the different methods in a meaningful way. In literature, several methods to assess therapeutic control are described: e.g. the assessment of the number of INR measurements within the target range expressed as a percentage of the total number of INRs obtained, the cross-section-of the-files technique (the fraction of patients in range at one point in time compared to the total number of patients who had an INR at that point in time), equidivision, linear interpolation and the hybrid method. ${ }^{52,56,57}$ Each approach has its advantages and disadvantages. A disadvantage of the first two methods is that they do not incorporate time and therefore cannot be used to calculate incidence rates of recurrences at different INR levels. ${ }^{54}$ Time is incorporated in the method of equidivision, which assumes that the change between two consecutive INR measurements occurred halfway the interval. ${ }^{[56]}$ The time spent in INR ranges can also be estimated by linear interpolation, which assumes that the INR between two measurements varies linearly from the first INR to the second INR. ${ }^{52} \mathrm{~A}$ disadvantage of these last two methods is that extreme out of range INR values may bias overall results. ${ }^{58}$ The hybrid method, in addition, takes effects of dosage modifications into account. ${ }^{54}$ The results of all of these methods depend on whether an exact (INR 2.0-3.0) or an expanded therapeutic range is used, whether VKA-naïve patients (those just beginning therapy) are included or only patients already on established therapy, whether INRs obtained during invasive procedures when VKA therapy might be interrupted are excluded, and whether different oral anticoagulant preparations (e.g. warfarin or acenocoumarol) are allowed. ${ }^{53}$ In a comparison of the 
equidivision, linear interpolation and hybrid methods, linear interpolation has been suggested as the preferred method as it shows a high validity and reproducibility. ${ }^{54}$ We suggest that drug trials and real life registries with a VKA control group report the TTR in a uniform manner, to allow adequate comparison of data. Since linear interpolation has a high validity and was the most common method used to calculate TTR in the present review, we recommend to use linear interpolation in future studies covering the INRs from each patient from the discontinuation of heparin until the end of treatment. In order to avoid complex calculations, we believe that including timeperiods with interruptions in VKA treatment in the TTR are acceptable. However, for calculating the relationship between TTR and adverse events, such as major bleeding episodes and thromboembolic events, we would suggest to exclude bridging periods, since the TTR will not represent the quality of anticoagulant treatment during these periods when most patients receive LMWH (Figure 8.3.

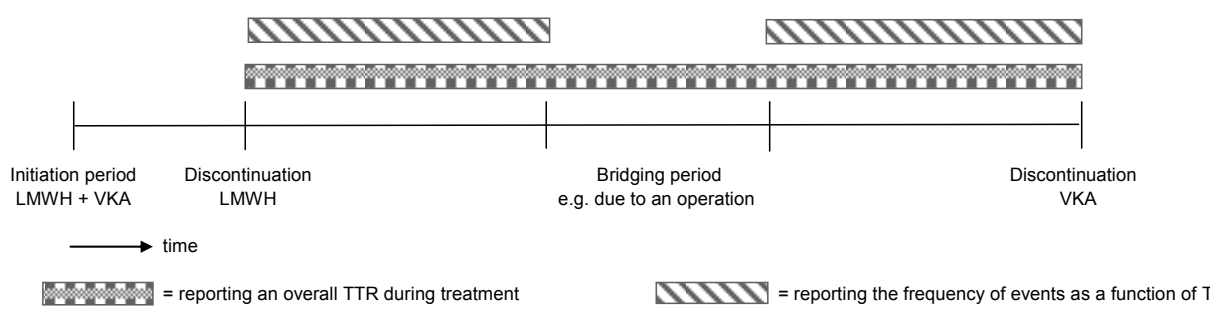

Figure 8.3 Suggestions for calculating TTR.

A second important limitation of the present review is that we were not able to investigate the association between TTR and clinical endpoints. Several studies in literature show a strong relationship between TTR and bleeding or thromboembolic events. ${ }^{53}$ Unfortunately, data on such clinical endpoints related to TTR was not provided in the included studies.

Additionally, some other interesting sub-analyses were difficult due to small subgroups and the absence of detailed data. Hutten et al. indicated that the therapeutic quality of treatment was decreased when patients were treated with acenocoumarol rather than with warfarin. ${ }^{59}$ This might implicate that the use of warfarin is preferable. However, since it is not clear whether these results might be influenced by factors such as frequency of monitoring and comorbidities, we need to be careful with drawing a conclusion. Furthermore, Hutten et al. showed that TTR was decreased in the presence of cancer and in the presence of a pulmonary embolism. ${ }^{59}$ The same subgroup analyses in the present review did not show statistically significant results (data not shown). This might be explained by the fact that we did not have individual patient data (IPD). An IPD meta-analysis may give more detailed 
information for investigating such associations and may be interesting. Hutten et al. also showed a decrease in the therapeutic quality of VKA treatment when more than four changes in co-medication occurred. ${ }^{59}$ Unfortunately such data was not available for our review.

The main conclusion of our systematic review is that the reported quality of VKA treatment is highly dependent on the time-period since the start of treatment, with the TTR ranging from approximately $56 \%$ in studies including the first month to $75 \%$ in studies excluding the first 3 months. The clinical consequences of our findings are not straightforward. However, it needs to be emphasized that the reported quality of VKA treatment should be taken into consideration while interpreting results from trials with new anticoagulants. Assuming an average treatment duration of 6 months, the mean TTR is approximately $60 \%$. We recommend to calculate the TTR by using linear interpolation covering the INRs from each patient from discontinuation of heparin until the end of treatment. Furthermore, TTR is predictive of thromboembolic and bleeding complications for patients on VKA ${ }^{53}$; therefore a proper calculation of TTR in the VKA group is of importance in assessing the adequacy and quality of novel anticoagulants.

Oral anticoagulants are also effective in preventing stroke ${ }^{60-64}$ and prolonging survival rates in patients with atrial fibrillation (AF). ${ }^{65}$ It may be interesting to investigate a benchmark of the TTR in patients treated with VKA in AF in the near future. However, since patients with AF are usually on long-term VKA treatment, selection-to-continue bias will be more evident than in patients with VTE and should be taken into consideration in an analysis in AF patients. ${ }^{55}$ 


\section{References}

1. Hull R, Delmore T, Carter C, Hirsh J, Genton E, Gent M, et al. Adjusted subcutaneous heparin versus warfarin sodium in the long-term treatment of venous thrombosis. N Engl J Med 1982;306:189-194.

2. Hull R, Delmore T, Genton E, Hirsh J, Gent M, Sackett D, et al. Warfarin sodium versus low-dose heparin in the long-term treatment of venous thrombosis. N Engl J Med 1979;301:855-858.

3. Büller HR, Agnelli G, Hull RD, Hyers TM, Prins MH, Raskob GE. Antithrombotic therapy for venous thromboembolic disease: the Seventh ACCP Conference on Antithrombotic and Thrombolytic Therapy. Chest 2004;126(3 Suppl):401S-428S.

4. Hirsh J, V. F. Guide to anticoagulant therapy. Part 2: Oral anticoagulants. American Heart. . Circulation 1994;89:1469-1480.

5. Hull R, Hirsh J, Jay R, Carter C, England C, Gent M, et al. Different intensities of oral anticoagulant therapy in the treatment of proximal-vein thrombosis. N Engl J Med 1982;307:1676-1681.

6. Eriksson BI, Quinlan DJ, Weitz JI. Comparative pharmacodynamics and pharmacokinetics of oral direct thrombin and factor xa inhibitors in development. Clin Pharmacokinet 2009;48:1-22.

7. Botticelli-Investigators, Büller H, Deitchman D, Prins M, Segers A. Efficacy and safety of the oral direct factor Xa inhibitor apixaban for symptomatic deep vein thrombosis. The Botticelli DVT dose-ranging study. J Thromb Haemost 2008;6:1313-1318.

8. Schulman S, Kearon C, Kakkar AK, Mismetti P, Schellong S, Eriksson H, et al. Dabigatran versus warfarin in the treatment of acute venous thromboembolism. N Engl J Med 2009;361:2342-2352.

9. The-Einstein-Investigators, Bauersachs R, Berkowitz SD, Brenner B, Büller HR, Decousus H, et al. Oral rivaroxaban for symptomatic venous thromboembolism. N Engl J Med 2010;363:2499-2510.

10. Connolly SJ, Ezekowitz MD, Yusuf S, Eikelboom J, Oldgren J, Parekh A, et al. Dabigatran versus warfarin in patients with atrial fibrillation. N Engl J Med 2009;361:1139-1151.

11. ROCKET-AF-Study-Investigators. Rivaroxaban-once daily, oral, direct factor Xa inhibition compared with vitamin $\mathrm{K}$ antagonism for prevention of stroke and Embolism Trial in Atrial Fibrillation: rationale and design of the ROCKET AF study. Am Heart J 2010;159:340-347 e1.

12. Phillips KW, Ansell J. Outpatient management of oral vitamin K antagonist therapy: defining and measuring high-quality management. Expert Rev Cardiovasc Ther 2008;6:57-70.

13. WHO Expert Committee on Biological Standardization. Thirty-third report. World Health Organ Tech Rep Ser 1983;687:1-184.

14. Agnelli G, Gallus A, Goldhaber SZ, Haas S, Huisman MV, Hull RD, et al. Treatment of proximal deepvein thrombosis with the oral direct factor Xa inhibitor rivaroxaban (BAY 59-7939): the ODIXa-DVT (Oral Direct Factor Xa Inhibitor BAY 59-7939 in Patients With Acute Symptomatic Deep-Vein Thrombosis) study. Circulation 2007;116:180-187.

15. Agnelli G, Prandoni P, Becattini C, Silingardi M, Taliani MR, Miccio M, et al. Extended oral anticoagulant therapy after a first episode of pulmonary embolism. Ann Intern Med 2003;139:19-25.

16. Agnelli G, Prandoni P, Santamaria MG, Bagatella P, lorio A, Bazzan M, et al. Three months versus one year of oral anticoagulant therapy for idiopathic deep venous thrombosis. Warfarin Optimal Duration Italian Trial Investigators. N Engl J Med 2001;345:165-169.

17. Bona RD, Hickey AD, Wallace DM. Warfarin is safe as secondary prophylaxis in patients with cancer and a previous episode of venous thrombosis. Am J Clin Oncol 2000;23:71-73.

18. Büller HR, Davidson BL, Decousus H, Gallus A, Gent M, Piovella F, et al. Subcutaneous fondaparinux versus intravenous unfractionated heparin in the initial treatment of pulmonary embolism. N Engl J Med 2003;349:1695-1702.

19. Büller HR, Lensing AW, Prins MH, Agnelli G, Cohen A, Gallus AS, et al. A dose-ranging study evaluating once-daily oral administration of the factor Xa inhibitor rivaroxaban in the treatment of patients with acute symptomatic deep vein thrombosis: the Einstein-DVT Dose-Ranging Study. Blood 2008;112: 2242-7.

20. Caprini JA, Arcelus JI, Reyna JJ, Motykie GD, Mohktee D, Zebala LP, et al. Deep vein thrombosis outcome and the level of oral anticoagulation therapy. J Vasc Surg 1999;30:805-811.

21. Das SK, Cohen AT, Edmondson RA, Melissari E, Kakkar VV. Low-molecular-weight heparin versus warfarin for prevention of recurrent venous thromboembolism: a randomized trial. World J Surg 1996;20:521-6. 
22. Daskalopoulos ME, Daskalopoulou SS, Tzortzis E, Sfiridis P, Nikolaou A, Dimitroulis D, et al. Long-term treatment of deep venous thrombosis with a low molecular weight heparin (tinzaparin): a prospective randomized trial. Eur J Vasc Endovasc Surg 2005;29:638-650.

23. Fiessinger JN, Huisman MV, Davidson BL, Bounameaux H, Francis CW, Eriksson H, et al. Ximelagatran vs low-molecular-weight heparin and warfarin for the treatment of deep vein thrombosis: a randomized trial. JAMA 2005;293:681-689.

24. Galilei-Investigators, Prandoni P, Carnovali M, Marchiori A. Subcutaneous adjusted-dose unfractionated heparin vs fixed-dose low-molecular weight heparin in the initial treatment of venous thromboembolism. Arch Intern Med 2004;164:1077-1083.

25. Gonzalez-Fajardo JA, Arreba E, Castrodeza J, Perez JL, Fernandez L, Agundez I, et al. Venographic comparison of subcutaneous low-molecular weight heparin with oral anticoagulant therapy in the long-term treatment of deep venous thrombosis. J Vasc Surg 1999;30:283-292.

26. Heidinger KS, Bernardo A, Taborski U, Muller-Berghaus G. Clinical outcome of self-management of oral anticoagulation in patients with atrial fibrillation or deep vein thrombosis. Thromb Res 2000;98:287-293.

27. Kearon C, Gent M, Hirsh J, Weitz J, Kovacs MJ, Anderson DR, et al. A comparison of three months of anticoagulation with extended anticoagulation for a first episode of idiopathic venous thromboembolism. N Engl J Med 1999;340:901-907.

28. Kearon C, Ginsberg JS, Anderson DR, Kovacs MJ, Wells P, Julian JA, et al. Comparison of 1 month with 3 months of anticoagulation for a first episode of venous thromboembolism associated with a transient risk factor. J Thromb Haemost 2004;2:743-749.

29. Kearon C, Ginsberg JS, Julian JA, Douketis J, Solymoss S, Ockelford P, et al. Comparison of fixed-dose weight-adjusted unfractionated heparin and low-molecular-weight heparin for acute treatment of venous thromboembolism. JAMA 2006;296:935-942.

30. Kearon C, Ginsberg JS, Kovacs MJ, Anderson DR, Wells P, Julian JA, et al. Comparison of low-intensity warfarin therapy with conventional-intensity warfarin therapy for long-term prevention of recurrent venous thromboembolism. N Engl J Med 2003;349:631-639.

31. Koopman MM, Prandoni P, Piovella F, Ockelford PA, Brandjes DP, van der Meer J, et al. Treatment of venous thrombosis with intravenous unfractionated heparin administered in the hospital as compared with subcutaneous low-molecular-weight heparin administered at home. The Tasman Study Group. N Engl J Med 1996;334:682-687.

32. Levine MN, Hirsh J, Gent M, Turpie AG, Weitz J, Ginsberg J, et al. Optimal duration of oral anticoagulant therapy: a randomized trial comparing four weeks with three months of warfarin in patients with proximal deep vein thrombosis. Thromb Haemost 1995;74:606-611.

33. Lopez-Beret P, Orgaz A, Fontcuberta J, Doblas M, Martinez A, Lozano G, et al. Low molecular weight heparin versus oral anticoagulants in the long-term treatment of deep venous thrombosis. Journal of Vascular Surgery 2001;33:77-90.

34. Meyer G, Marjanovic Z, Valcke J, Lorcerie B, Gruel Y, Solal-Celigny P, et al. Comparison of lowmolecular-weight heparin and warfarin for the secondary prevention of venous thromboembolism in patients with cancer: a randomized controlled study. Arch Intern Med 2002;162:1729-1735.

35. Monreal M, Roncales FJ, Ruiz J, Muchart J, Fraile M, Costa J, et al. Secondary prevention of venous thromboembolism: A role for low-molecular-weight heparin. Haemostasis 1998;28:236-243.

36. Nielsen HK, Husted SE, Krusell LR, Fasting $\mathrm{H}$, Charles $\mathrm{P}$, Hansen $\mathrm{HH}$, et al. Anticoagulant therapy in deep venous thrombosis. A randomized controlled study. Thromb Res 1993;73:215-226.

37. Palareti G, Legnani C, Lee A, Manotti C, Hirsh J, D'Angelo A, et al. A comparison of the safety and efficacy of oral anticoagulation for the treatment of venous thromboembolic disease in patients with or without malignancy. Thromb Haemost 2000;84:805-810.

38. Perez-De-Llano LA, Leiro-Fernandez V, Golpe R, Nunez-Delgado JM, Palacios-Bartolome A, MendezMarote $L$, et al. Comparison of tinzaparin and acenocoumarol for the secondary prevention of venous thromboembolism: A multicentre, randomized study. Blood Coagulation and Fibrinolysis 2010;21: 744-749.

39. Pini M, Aiello S, Manotti C, Pattacini C, Quintavalla R, Poli T, et al. Low molecular weight heparin versus warfarin in the prevention of recurrences after deep vein thrombosis. Thromb Haemost 1994; 72:191-197. 
40. Poli D, Antonucci E, Ciuti G, Abbate R, Prisco D. Anticoagulation quality and the risk of recurrence of venous thromboembolism. Thromb Haemost 2007;98:1148-1150.

41. Poller L, Keown M, Ibrahim S, Lowe G, Moia M, Turpie AG, et al. An international multicenter randomized study of computer-assisted oral anticoagulant dosage vs. medical staff dosage. J Thromb Haemost 2008;6:935-943.

42. Prandoni $P$, Lensing $A W$, Prins $M H$, Frulla $M$, Marchiori $A$, Bernardi $E$, et al. Below-knee elastic compression stockings to prevent the post-thrombotic syndrome: a randomized, controlled trial. Ann Intern Med 2004;141:249-256.

43. Research-Committee-of-the-British-Thoracic-Society. Optimum duration of anticoagulation for deepvein thrombosis and pulmonary embolism. Lancet 1992;340:873-876.

44. Santamaria A, Juarez S, Reche A, Gomez-Outes A, Martinez-Gonzalez J, Fontcuberta J. Low-molecularweight heparin, bemiparin, in the outpatient treatment and secondary prophylaxis of venous thromboembolism in standard clinical practice: the ESFERA Study. Int J Clin Pract 2006;60:518-525.

45. Schulman S. Quality of oral anticoagulant control and treatment in Sweden. Duration of Anticoagulation (DURAC) Trial Study Group. J Intern Med 1994;236:143-152.

46. The-Columbus-Investigators. Low-molecular-weight heparin in the treatment of patients with venous thromboembolism. . N Engl J Med 1997;337:657-662.

47. The-van-Gogh-Investigators, Büller HR, Cohen AT, Davidson B, Decousus H, Gallus AS, et al. Idraparinux versus standard therapy for venous thromboembolic disease. N Engl J Med 2007;357: 1094-1104.

48. Aujesky D, Roy PM, Verschuren F, Righini M, Osterwalder J, Egloff $M$, et al. Outpatient versus inpatient treatment for patients with acute pulmonary embolism: an international, open-label, randomised, non-inferiority trial. Lancet 2011;378:41-48.

49. van Bladel ER, Agterof MJ, Frijling BD, van der Griend R, Prins MH, Schutgens RE, et al. Out of hospital anticoagulant therapy in patients with acute pulmonary embolism is frequently practised but not perfect. Thromb Res 2010;126:481-485.

50. Cassiopea-Investigators, Büller HR, Gallus AS, Pillion G, Prins MH, Raskob GE. Enoxaparin followed by once-weekly idrabiotaparinux versus enoxaparin plus warfarin for patients with acute symptomatic pulmonary embolism: a randomised, double-blind, double-dummy, non-inferiority trial. Lancet. 2012;379:123-129.

51. The-Einstein-Investigators, Büller HR, Prins MH, Lensin AW, Decousus H, Jacobson BF, et al. Oral rivaroxaban for the treatment of symptomatic pulmonary embolism. N Engl J Med 2012;366: 1287-1297.

52. Rosendaal FR, Cannegieter SC, van der Meer FJ, Briet E. A method to determine the optimal intensity of oral anticoagulant therapy. Thromb Haemost 1993;69:236-239.

53. Ansell J, Hirsh J, Hylek E, Jacobson A, Crowther M, Palareti G. Pharmacology and management of the vitamin K antagonists: American College of Chest Physicians Evidence-Based Clinical Practice Guidelines (8th Edition). Chest 2008;133(6 Suppl):160S-198S.

54. Hutten BA, Prins MH, Redekop WK, Tijssen JG, Heisterkamp SH, Büller HR. Comparison of three methods to assess therapeutic quality control of treatment with vitamin $\mathrm{K}$ antagonists. Thromb Haemost 1999;82:1260-1263.

55. Kearon C, Kahn SR, Agnelli G, Goldhaber S, Raskob GE, Comerota AJ. Antithrombotic therapy for venous thromboembolic disease: American College of Chest Physicians Evidence-Based Clinical Practice Guidelines (8th Edition). Chest 2008;133(6 Suppl):454S-545S.

56. Duxbury BM. Therapeutic control of anticoagulant treatment. Br Med J (Clin Res Ed) 1982;284: 702-704.

57. Loeliger EA. Laboratory control, optimal therapeutic ranges and therapeutic quality control in oral anticoagulation. Acta Haematol 1985;74:125-131.

58. Veeger NJ, Piersma-Wichers M, Tijssen JG, Hillege HL, van der Meer J. Individual time within target range in patients treated with vitamin $\mathrm{K}$ antagonists: main determinant of quality of anticoagulation and predictor of clinical outcome. A retrospective study of 2300 consecutive patients with venous thromboembolism. Br J Haematol 2005;128:513-519. 
59. Hutten BA, Riel van I, Büller H, Prins M. Treatment with vitamin K antagonists for symptomatic venous thromboembolism: determinants of time spent in the therapeutic range. [In thesis: Treatment of Venous Thromboembolism with vitamin K antagonists]. Amsterdam: University of Amsterdam 2000: 29-39.

60. Stroke Prevention in Atrial Fibrillation Study. Final results. Circulation 1991;84:527-539.

61. EAFT-(European-Atrial-Fibrillation-Trial)-Study-Group. Secondary prevention in non-rheumatic atrial fibrillation after transient ischaemic attack or minor stroke. . Lancet 1993;342:1255-1262.

62. Ezekowitz MD, Bridgers SL, James KE, Carliner NH, Colling CL, Gornick CC, et al. Warfarin in the prevention of stroke associated with nonrheumatic atrial fibrillation. Veterans Affairs Stroke Prevention in Nonrheumatic Atrial Fibrillation Investigators. N Engl J Med 1992;327:1406-1412.

63. Petersen P, Boysen G, Godtfredsen J, Andersen ED, Andersen B. Placebo-controlled, randomised trial of warfarin and aspirin for prevention of thromboembolic complications in chronic atrial fibrillation. The Copenhagen AFASAK study. Lancet 1989;1:175-179.

64. The-Boston-Area-Anticoagulation-Trial-for-Atrial-Fibrillation-Investigators. The effect of low-dose warfarin on the risk of stroke in patients with nonrheumatic atrial fibrillation. $\mathrm{N}$ Engl J Med 1990;323:1505-1511.

65. Currie CJ, Jones M, Goodfellow J, McEwan P, Morgan CL, Emmas C, et al. Evaluation of survival and ischaemic and thromboembolic event rates in patients with non-valvar atrial fibrillation in the general population when treated and untreated with warfarin. Heart 2006;92:196-200. 


\section{Chapter 9}

General discussion 
Chapter 9 


\section{General discussion}

In this general discussion the overall methodological considerations of the studies in this dissertation will be discussed and practical implications of the results, new developments in the field and recommendations for further research will be outlined. In line with the structure of this thesis, these items will be addressed in two parts: 'diagnosing pulmonary embolism in primary care' and 'treatment of pulmonary embolism in secondary care'.

\section{Diagnosing pulmonary embolism in primary care}

\section{Methodological considerations}

The diagnostic part of this thesis comprises research findings obtained from 598 adult patients with suspected PE enrolled in a prospective multicenter diagnostic cohort by primary care physicians between July 2007 and December 2010 (AMUSE-2). In chapter 4 we show that none of the clinical decision rules in secondary care is sensitive enough to exclude PE on its own. ${ }^{1}$ Therefore, we validated the use of the Wells clinical decision rule for PE combined with D-dimer testing for excluding PE in primary care. In primary care, physicians are frequently confronted with situations where quantitative laboratory based D-dimer tests are not readily available. To ensure that the AMUSE-2 diagnostic strategy was accessible for all primary care physicians we chose to use a qualitative point-of-care D-dimer test.

Since this was a validation study to investigate the safety of excluding PE in primary care, we chose to refer all included patients to the hospital for further diagnostic work-up. In secondary care, the diagnostic strategy was based on current guidelines and routine care protocols. In the Netherlands, this commonly is a combination of probability estimation by a clinical decision rule and quantitative laboratory based Ddimer testing, followed by CT-scanning if indicated. To guarantee independence and thereby avoiding that physicians in secondary care would base their decision for imaging on the results of the Wells rule and point-of-care D-dimer test in primary care, secondary care physicians were not informed by the referring primary care physician that the particular patient was a study patient and thus they were not aware of the risk-score in primary care.

PE was confirmed or refuted based on a composite reference, including spiral CT and 3 months of follow-up. There is convincing evidence from large diagnostic studies that a low probability of PE according to a clinical decision rule combined with D-dimer testing safely excludes PE in secondary care. ${ }^{2,3}$ Therefore, spiral CT-scanning deemed to be unethical in patients with a low probability of PE in secondary care. In low-risk patients PE was excluded if an alternative diagnosis was found that completely explained the symptoms of the included patient and no thromboembolic event occurred during 3 months of follow-up. An independent adjudication committee 
evaluated all patients with a diagnosis of PE despite a negative Wells PE rule and a negative point-of-care D-dimer test in primary care.

Information about the investigations done in the hospital and the final diagnosis were retrieved from hospital discharge letters or from the 3 months follow-up form filled out by the primary care physician. In $30 \%$ of clinically serious alternative diagnoses of $\mathrm{PE}$, i.e. patients who needed immediate medical treatment, it was not clear if objective testing was performed to confirm these diagnoses. These alternative diagnoses may be mainly based on clinical features. Since this also occurs in daily clinical practice, we think that our study still is a good representation of daily practice. There was some missing data in a few patients. Missing data seldom occurs completely at random. We compared the values of several variables from the patients without to the patients with missing information. The missing data turned out to be rather selective. For example, missing values were less frequently observed in patients with a positive point-of-care D-dimer test. Deleting subjects with a missing value would therefore not only lead to a loss of statistical power but also to biased results. To minimize the effect of selective missing we chose to impute the missing values of the most important variables using multiple imputation techniques. The imputation technique was based on the correlation between each variable with missing values and all other variables as estimated from the set of complete subjects. ${ }^{4,5}$

\section{Practical implications}

AMUSE-2 demonstrated that a diagnostic approach of a Wells score $\leq 4$ combined with D-dimer testing would rule out PE in 4 to 5 out of 10 primary care patients with an acceptably low failure rate of less than $2 \%{ }^{6}$ This implies that probably more than $40 \%$ of the patients with suspected PE do not need to be referred to secondary care for further diagnostic work-up to exclude PE. These results are comparable to the efficiency and failure rate of clinical decision rules combined with D-dimer testing in secondary care as seen in chapter 4 , which justifies the use of the AMUSE-2 diagnostic strategy in a future management study.

The most common alternative diagnoses of $P E$ in primary care are thoracic pain/dyspnoea e.c.i., pneumonia and myalgia. We found that a low probability of PE according to the Wells rule and point-of-care D-dimer testing in primary care, may not only exclude PE but also other serious diseases. Patients with a high probability of PE often have a clinically serious diagnosis and need immediate medical treatment, while patients with a low probability of PE are often diagnosed with a less serious disease. This emphasizes the usefulness of the Wells rule and point-of-care D-dimer testing in the differentiation between high and low risk patients for clinically serious diseases in primary care and further justifies referral to secondary care in high risk patients. ${ }^{7}$

Do these findings imply that in case of suspected PE a primary care physician should have the Wells clinical decision rule and a point-of-care D-dimer test readily available at his office or in his briefcase? Before implementing this diagnostic strategy in daily practice it may be prudent first to evaluate the safety of withholding anticoagulant 
therapy in primary care patients with a low suspicion of PE in a management study. Further research will be discussed in the next paragraph.

\section{Developments and recommendations for further research}

Before moving on to management and implementation studies it might be informative to investigate whether the use of the Wells rule for PE combined with D-dimer testing in primary care will be cost-effective. In a cost-effectiveness study we can evaluate whether the Amuse-2 strategy will reduce health care costs while increasing the quality of life of patients suspected of PE.

In a health economics evaluation we are currently modeling different scenarios of the diagnostic strategy used in AMUSE-2. Modeling allows us to synthesize all relevant data and information from multiple sources of evidence, including the results of the AMUSE-2 study and results in literature. ${ }^{5,8}$

The following Markov model represents the complex process of health states and events following suspicion of PE (Figure 9.1).

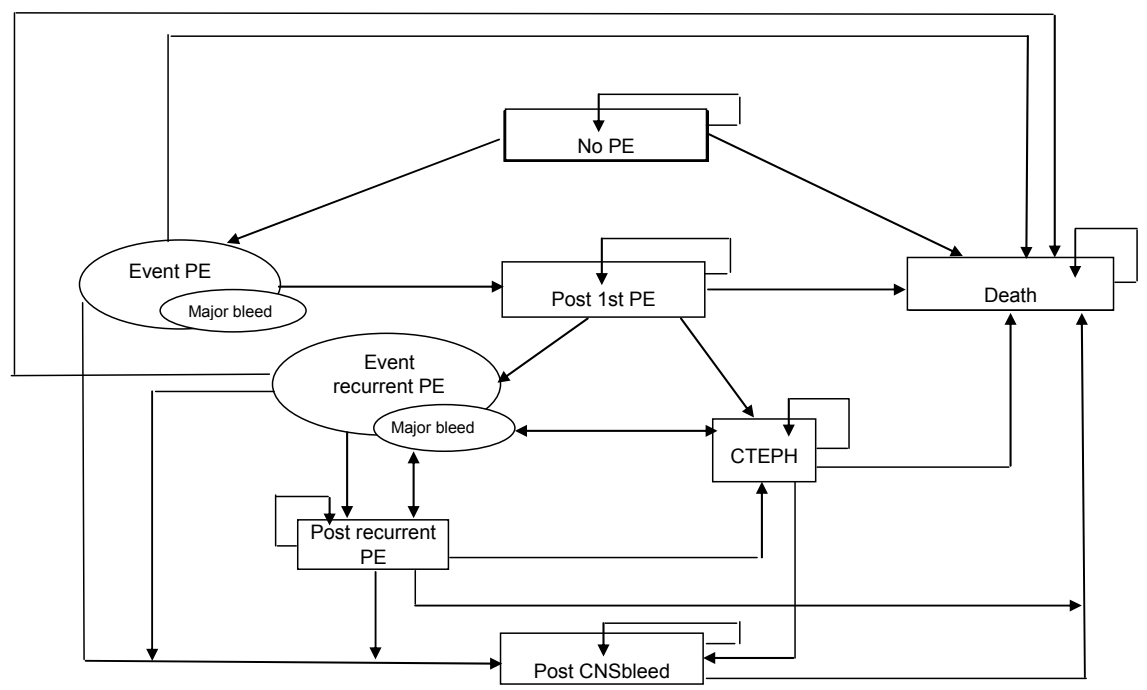

Figure 9.1 Markov model AMUSE-2.

$\mathrm{PE}=$ pulmonary embolism; $\mathrm{CTEPH}=$ chronic thromboembolic pulmonary hypertension; $\mathrm{CNS}=$ central nervous system.

This Markov model is divided into 6 mutually exclusive health states: no PE, post $1^{\text {st }}$ $\mathrm{PE}$, post recurrent $\mathrm{PE}$, chronic thromboembolic pulmonary hypertension, post central nervous system bleed and death. Use of the Wells clinical decision rule and D-Dimer 
test in primary care may have consequences for all health states and outcomes related to PE. Each health state has its own quality of life and costs. In order to investigate the cost-effectiveness of using the Wells rule and point-of-care D-dimer testing in primary care, the costs and health effects of each health state and event have to be taken into account.

A cost-effectiveness study can also help in deciding whether further research will be necessary. If the Amuse- 2 strategy is more cost-effective than care as usual, a management study should be the next step. Since implementation of a method on a larger scale remains difficult, a management study may be combined with implementation research to promote the uptake of our research findings and to close the gap between science and clinical practice.

If the Amuse-2 strategy turns out not to be cost-effective further research should be focused on optimizing the diagnostic strategy. In AMUSE-2 we used a qualitative point-of-care D-dimer test (Simplify, Clearview, Inverness Medical, Bedford, UK). ${ }^{9}$ A review of point-of-care $D$-dimer testing showed that the user-friendly quantitative tests Cardiac and Triage also have good diagnostic accuracy. ${ }^{10}$ This is important since it is known that the specificity of a D-dimer test decreases with age, whereas the risk of PE increases with aging. ${ }^{11-14}$ The lower specificity makes D-dimer testing less useful to exclude PE in older patients. It has recently been shown that an age-adjusted cutoff of the D-dimer (patient's age multiplied by 10 ) in combination with an unlikely clinical decision rule increases the number of patients above 50 years in whom PE could safely be excluded. ${ }^{15,16}$ It may be interesting to validate the use of the Wells rule combined with age-adjusted quantitative point-of-care D-dimer testing for excluding PE. A limitation of the available quantitative D-Dimer tests, however, is that, because of their size, the primary care physician will not be able to use them out of the office. Therefore, the qualitative point-of care test still will be needed for excluding PE during home visits.

\section{Treatment of pulmonary embolism in secondary care}

\section{Methodological considerations}

PE is usually treated with anticoagulant therapy. There is considerable evidence on the effectiveness of the traditional treatment of heparin and vitamin $\mathrm{K}$ antagonists (VKA). In a systematic clinical review we pooled all available data on the efficacy of the initial heparin treatment and compared intravenous unfractionated heparin to subcutaneous low molecular weight heparin (LMWH). ${ }^{17}$

The use of fixed-dose subcutaneous LMWH makes it possible to treat patients out of the hospital. In most countries in Europe, including the Netherlands, patients with DVT are managed as outpatients, whereas patients with PE are usually admitted to the hospital for at least a few days. This differs from the situation in Canada and the United States where a lot of patients with acute PE receive outpatient treatment. 
Therefore, Canada seemed to be the right place to investigate the safety of outpatient treatment in PE.

Generally, randomized controlled trials evaluate efficacy and may be the first and preferred choice to investigate an intervention such as outpatient treatment. We, however, aimed for a pragmatic approach with a retrospective cohort study, since outpatient treatment of PE is everyday clinical practice in Canada. To minimize selection bias we included all consecutive patients with confirmed PE on CTPA or V/Q scan over a predefined time period and adjudicated all outcome events by two independent reviewers.

In our study all patients who did not have a systolic blood pressure of $100 \mathrm{mmHg}$ or less, who had an oxygen saturation of $92 \%$ or more and did not require supplemental oxygen, who did not have contraindications for the use of LMWH and who did not need hospitalization for other co-morbidities, were managed as outpatients. However, the final decision to admit the patient or not was left to the discretion of the treating physician. Sharper inclusion criteria for outpatient treatment might help physicians to decide whether a patient can be treated out of the hospital. Therefore, we decided to perform an additional analysis in chapter 7 to investigate whether a widely validated prognostic model, the Pulmonary Embolism Severity Index, could help in identifying appropriate patients for outpatient treatment.

Recently, novel oral anticoagulants have been introduced and approved in many countries worldwide. To be able to properly asses the quality of anticoagulant control in the VKA control group in upcoming cost-effectiveness studies and real life registries of novel anticoagulants, we decided to conclude this dissertation with an evaluation of the international quality of VKA therapy and report a benchmark for time in therapeutic range in the meta-analysis in chapter 8.

\section{Practical implications}

Our review on the initial heparin treatment of venous thromboembolism (VTE) showed that subcutaneous LMWH is more effective and safer that intravenous unfractionated heparin. ${ }^{17}$ Adopting subcutaneous LMWH as the standard initial treatment enables outpatient treatment of patients with VTE.

The Canadian study suggests that outpatient treatment is safe and feasible in more than $50 \%$ of the patients with PE. ${ }^{18}$ All patients treated as outpatients were seen within 24 to 48 hours in a specialized thrombosis clinic where they learned to administer the LMWH and were followed up after 7 days. Close follow-up of patients managed as outpatients in specialized thrombosis clinics might not be possible in all settings and therefore event rates of recurrent VTE and major bleeding episodes may differ if patients are followed-up in other health care settings. In the Netherlands anticoagulant monitoring is usually done by one of the many Thrombosis Services. Since the Thrombosis Service already is involved in anticoagulant treatment it may also be the right institution for the coordination of outpatient treatment. 
Although several studies showed the safety of outpatient treatment, physicians are reluctant to treat patients with PE at home due to uncertainty on how to safely identify patients who are at low risk for short-term adverse events ${ }^{19}$, irrespective of whether the adverse events could be averted by hospitalization. In an additional analysis of the Canadian cohort we showed that the Pulmonary Embolism Severity Index accurately discriminates between patients who are at low versus patients who are high risk of adverse events. ${ }^{20}$ A randomized controlled trial in Europe confirmed our findings that in low-risk patients, selected by the Pulmonary Embolism Severity Index, outpatient care can be safe and effective. ${ }^{21}$ These results imply that outpatient treatment of PE should be considered in patients who are at low risk of adverse events.

The practical implications of our findings on the quality of anticoagulant treatment with VKA are not straightforward. The reported quality of VKA treatment, however, should be taken into consideration while interpreting results from trials with novel anticoagulants.

\section{Developments and recommendations for further research}

As addressed above PE is traditionally treated with LMWH and VKA. Although VKA are highly effective for the prevention and treatment of thrombosis, they carry a number of relevant limitations including the need for regular laboratory monitoring and dose adjustments. Recently a new era has been heralded with the large scale clinical testing and approval of novel, direct acting oral anticoagulants, including the thrombin and factor Xa inhibitors dabigatran and rivaroxaban, respectively. Several studies have shown that the efficacy of those new oral anticoagulants is non-inferior to VKA. ${ }^{22-25}$ These new agents have been recently approved in many countries including the USA, Canada and several countries in Europe, including the Netherlands. However, trials studying the efficacy of the novel anticoagulants had in- and exclusion criteria that limit their ability to be generalized or at least raise questions with regard to how well they will perform in the real world of non-selected patients. The efficacy was investigated in study settings with a carefully selected, motivated study population. The effectiveness in real life may differ from the efficacy in trials due to other patient populations and medication adherence. With a recently acquired postdoctoral grant we will investigate the effectiveness of novel anticoagulants in everyday clinical practice mainly focusing on medication non-adherence.

The main advantage of the new agents is that regular follow-up and dose-adjustments will not be necessary anymore, due to more stable pharmacokinetics. ${ }^{26}$ However, the frequent patient contacts served as a constant reminder of the necessity for medical treatment and allowed caregivers to observe problems that may hamper adequate medication intake at an early stage. It is known from experience with other chronic conditions, such as hypertension and hyperlipidemia, that medication use is not consistent over time and may be as low as 50\% if left unmonitored. ${ }^{27,28}$ This raises concerns with regard to medication adherence to the novel oral anticoagulants. 
Proper medication adherence is extremely important to attain good clinical outcomes $^{29,30}$, even more so because the new anticoagulants have a short half-life, necessitating daily intake to maintain an effective drug level. Lack of proper drug intake may also contribute to a higher bleeding risk; as antidotes are still lacking this poses an additional risk related to these novel anticoagulants. As a result of nonadherence it is expected that a substantial number of patients will not get the maximum benefit of anticoagulant treatment, resulting in thrombo-embolic events, major bleeding episodes, lower quality of life and increased health care costs. In our research project we will focus on predicting anticoagulant adherence by investigating associations between non-adherent behavior and patient, disease and treatment characteristics.

\section{Conclusion}

The main findings of this dissertation are that PE can be safely ruled out in primary care by using the Wells clinical decision rule for PE combined by point-of-care D-dimer testing and that the majority of hemodynamic stable patients with confirmed acute PE can be safely treated out of the hospital. These findings may cause changes in the role of primary and secondary care in the management of PE. Although specialized care in the hospital still will be needed for complex situations, primary care physicians could play a much larger role in the management of $P E$ in the near future. In case of suspected PE a primary care physician should have readily available the Wells clinical decision rule and a point-of-care D-dimer test. Furthermore, not all patients with confirmed PE need to be admitted to the hospital. Outpatient treatment should be considered in hemodynamic stable patients who do not need supplemental oxygenation. Treatment with novel anticoagulants may even facilitate treatment in primary care in the future. Further pragmatic research should follow the efficacy studies of novel anticoagulants in order to evaluate the safety and effectiveness of the new medication in daily clinical practice. 


\section{References}

1. Lucassen W, Geersing GJ, Erkens PM, Reitsma JB, Moons KG, et al. Clinical decision rules for excluding pulmonary embolism: a meta-analysis. Ann Intern Med 2011;155: 448-460.

2. Douma RA, Mos IC, Erkens PM, Nizet TA, Durian MF, et al. Performance of 4 Clinical Decision Rules in the Diagnostic Management of Acute Pulmonary Embolism: A Prospective Cohort Study. Ann Intern Med 2011;154: 709-718.

3. van Belle A, Buller HR, Huisman MV, Huisman PM, Kaasjager $K$, et al. Effectiveness of managing suspected pulmonary embolism using an algorithm combining clinical probability, D-dimer testing, and computed tomography. JAMA 2006;295:172-179.

4. Janssen KJ, Vergouwe $\mathrm{Y}$, Donders AR, Harrell FE, Jr., Chen Q, et al. Dealing with missing predictor values when applying clinical prediction models. Clin Chem 2009;55:994-1001.

5. Rubin DB, Schenker N. Multiple imputation in health-care databases: an overview and some applications. Stat Med 1991;10:585-598.

6. Geersing GJ EP, Lucassen WAM, Büller HR, ten Cate $H$, Hoes AW, Moons KGM, Prins MH, Oudega R, van Weert HCPM, Stoffers HEJH. (2012) Safe Exclusion of Pulmonary Embolism using the Wells rule and D-dimer testing in Primary Care. BMJ. 2012;345:e6564.

7. Erkens P, Lucassen W, Geersing G, Kuijs M, van Heugten $M$, et al. Alternative diagnoses of pulmonary embolism in primary care. Submitted.

8. Brennan A, Akehurst R. Modelling in health economic evaluation. What is its place? What is its value? Pharmacoeconomics 2000;17:445-459.

9. Geersing GJ, Janssen KJ, Oudega R, Bax L, Hoes AW, et al. Excluding venous thromboembolism using point of care D-dimer tests in outpatients: a diagnostic meta-analysis. BMJ 2009;339:b2990.

10. Geersing GJ, Toll DB, Janssen KJ, Oudega R, Blikman MJ, et al. Diagnostic accuracy and userfriendliness of 5 point-of-care D-dimer tests for the exclusion of deep vein thrombosis. Clin Chem 2010;56:1758-1766.

11. Dentali F, Crowther M. Venous thromboembolism, age and hospitalisation: A potentially deadly combination. Thromb Haemost 2010;104:655-656.

12. Engbers MJ, van Hylckama Vlieg A, Rosendaal FR. Venous thrombosis in the elderly: incidence, risk factors and risk groups. J Thromb Haemost 2010;8:2105-2112.

13. Righini M, Nendaz M, Le Gal G, Bounameaux H, Perrier A. Influence of age on the cost-effectiveness of diagnostic strategies for suspected pulmonary embolism. J Thromb Haemost 2007;5:1869-1877.

14. Rosendaal FR, A VANHV, Doggen CJ. Venous thrombosis in the elderly. J Thromb Haemost 2007;5 Suppl 1: 310-317.

15. Douma RA, le Gal G, Sohne M, Righini M, Kamphuisen PW, et al. Potential of an age adjusted D-dimer cut-off value to improve the exclusion of pulmonary embolism in older patients: a retrospective analysis of three large cohorts. BMJ 2010;340:c1475.

16. van Es J, Mos I, Douma R, Erkens P, Durian M, et al. The combination of four different clinical decision rules and an age-adjusted D-dimer cut-off increases the number of patients in whom acute pulmonary embolism can safely be excluded. Thromb Haemost 2012;107:167-171.

17. Erkens PM, Prins MH. Fixed dose subcutaneous low molecular weight heparins versus adjusted dose unfractionated heparin for venous thromboembolism. Cochrane Database Syst Rev: 2010;CD001100.

18. Erkens PM, Gandara E, Wells P, Shen AY, Bose G, et al. Safety of outpatient treatment in acute pulmonary embolism. J Thromb Haemost 2010;8:2412-2417.

19. Aujesky D, Mazzolai L, Hugli O, Perrier A. Outpatient treatment of pulmonary embolism. Swiss Med Wkly 2009;139:685-690.

20. Erkens PM, Gandara E, Wells PS, Shen AY, Bose G, et al. Does the Pulmonary Embolism Severity Index accurately identify low risk patients eligible for outpatient treatment? Thromb Res 2012;129:710-714.

21. Aujesky D, Roy PM, Verschuren F, Righini M, Osterwalder J, et al. Outpatient versus inpatient treatment for patients with acute pulmonary embolism: an international, open-label, randomised, non-inferiority trial. Lancet 2011;378:41-48.

22. ROCKET-AF-Study-Investigators. Rivaroxaban-once daily, oral, direct factor Xa inhibition compared with vitamin $\mathrm{K}$ antagonism for prevention of stroke and Embolism Trial in Atrial Fibrillation: rationale and design of the ROCKET AF study. Am Heart J 2010;159:340-347 e341. 
23. Schulman S, Kearon C, Kakkar AK, Mismetti P, Schellong S, et al. Dabigatran versus warfarin in the treatment of acute venous thromboembolism. N Engl J Med 2009;361:2342-2352.

24. The-Einstein-Investigators, Bauersachs R, Berkowitz SD, Brenner B, Buller HR, et al. Oral rivaroxaban for symptomatic venous thromboembolism. N Engl J Med 2010;363:2499-2510.

25. The-Einstein-Investigators, Buller HR, Prins $\mathrm{MH}$, Lensin AW, Decousus $\mathrm{H}$, et al. Oral rivaroxaban for the treatment of symptomatic pulmonary embolism. N Engl J Med 2012;366:1287-1297.

26. Eriksson BI, Quinlan DJ, Weitz JI. Comparative pharmacodynamics and pharmacokinetics of oral direct thrombin and factor xa inhibitors in development. Clin Pharmacokinet 2009;48:1-22.

27. Osterberg L, Blaschke T. Adherence to medication. N Engl J Med 2005;353:487-497.

28. Sanz G, Fuster V. Fixed-dose combination therapy and secondary cardiovascular prevention: rationale, selection of drugs and target population. Nat Clin Pract Cardiovasc Med 2009;6:101-110.

29. Ansell J, Hirsh J, Hylek E, Jacobson A, Crowther M, et al. Pharmacology and management of the vitamin K antagonists: American College of Chest Physicians Evidence-Based Clinical Practice Guidelines (8th Edition). Chest 2008;133:160S-198S.

30. Kimmel SE, Chen Z, Price M, Parker CS, Metlay JP, et al. The influence of patient adherence on anticoagulation control with warfarin: results from the International Normalized Ratio Adherence and Genetics (IN-RANGE) Study. Arch Intern Med 2007;167:229-235. 

Summary 


\section{Summary}

\section{Chapter 1}

Chapter 1 introduces the topic of the thesis. In this thesis we investigated the management of pulmonary embolism (PE) at the interface of community and hospital based health care.

The chapter first describes the definition and epidemiology of PE. PE is a blood clot that blocks the main artery of the lung or one of its branches. It is the third most common cause of death from cardiovascular disease and results from a combination of hereditary and acquired risk factors.

The chapter then discusses the historical developments in diagnosing PE. Diagnosis of $P E$ is a major challenge because patients often present with non-specific symptoms. The invasive and labor intensive cathether guided pulmonary angiography has been the gold stadard reference test for PE for many years. Nowadays, probability estimation by using a clinical decision rule and laboratory-based D-Dimer testing, followd by CT-scanning if indicated, is the routine protocol in patients suspected of PE in secondary care. The diagnostic strategy of assessing the probability of PE by a clinical decision rule and D-dimer testing seems also ideal for primary care to decide which patients suspected of PE need to be referred to secondary care for further diagnostic work-up. The chapter then goes on to report the rationale and aim of part I of this thesis 'Diagnosing pulmonary embolism in primary care'. In the Netherlands, the primary care physician is commonly the first to encounter outpatients suspected of PE. In the Amsterdam Maastricht Utrecht Study on thromboEmbolism (AMUSE-2) we investigated the accuracy and safety of the Wells clinical decision rule combined with point-of-care D-dimer testing for excluding PE in primary care.

The next section of the chapter starts with the historical developments in the treatment of PE. Pateints with PE are usually treated with low molecular weight heparin for 5 to 10 days simultaneously with vitamin $\mathrm{K}$ antagonists (VKA). However, recently novel anticoagulant medication with a similar effcicacy as VKA has been developed and approved in many countries worldwide. The guidelines of the American College of Chest Physicians recommend to treat patients with a first provoked PE for 3 months, patients with a first episode of idiopathic PE at least 6 to 12 monhts and patients with two or more objectively documented PE indefintely. The chapter then describes the rational and aim of the second part of this thesis 'Treatment of pulmonary embolism in secondary care'. The role of outpatient therapy in patients with PE is unclear and has been a matter of debate in literature. We investigated whether patients with hemodynamically stable PE could be safely treated out of the hospital and whether the Pulmonary Embolism Severity Index, a prognostic model for prediction of short-term adverse outcomes, could help in the identification of appropriate patients for outpatient management.

The chapter ends with an outline of the thesis. 


\section{Part I: Diagnosis pulmonary embolism in primary care}

\section{Chapter 2}

Chapter 2 describes the Amsterdam Maastricht Utrecht Study on thromboEmbolism (AMUSE-2) in which we investigated the safety of using the Wells clinical decision rule for PE combined with point-of-care D-Dimer testing to exclude PE in primary care. We included 598 adult patients with suspected PE. After medical history and physical examination, primary care physicians scored the seven variables of the Wells PE-rule, and performed a point-of-care D-dimer test. All patients were referred to secondary care and diagnosed according to local protocols. PE was confirmed or refuted based on a composite reference standard, including spiral CT and 3 months of follow-up. The proportion of 'low-risk' patients and the number of missed PE cases in the low-risk category were calculated. PE was present in 73 patients (prevalence 12\%). Using a threshold score $\leq 4$ on the Wells PE rule and a negative point-of-care D-dimer test, 272 of these patients were classified as 'low-risk' (efficiency $45 \%$ ). In these patients 4 PE cases were observed (false negative rate $1.5 \%$ ). The sensitivity and specificity of this diagnostic approach were $94.5 \%$ and $51.0 \%$.

\section{Chapter 3}

This chapter aims to report the most common alternative diagnoses of PE in primary care patients suspected of PE and investigates whether the Wells rule combined with a point-of-care D-dimer test not only excludes PE but also other serious diagnoses. The chapter presents a secondary analysis of AMUSE-2. The most frequent alternative diagnoses after excluding PE were: nonspecific thoracic pain / dyspnoea (42.6\%), pneumonia (13.0\%), myalgia (11.8\%), asthma / COPD (4.8\%), panic disorder / hyperventilation $(4.1 \%)$ and respiratory tract infection (2.3\%). Patients with a Wells score of $>4$ or a positive D-dimer test were significantly more often diagnosed with a clinically serious disease that needs immediate medical treatment. Therefore, a low probability of PE according to the Wells rule and point-of-care D-dimer testing may also help to exclude other serious diseases than PE.

\section{Chapter 4}

Chapter 4 provides a frame of reference to interpret the results of the AMUSE-2 study. We performed a systematic review and meta-analysis to compare the sensitivity and specificity of different clinical decision rules used to exclude PE in adult patients suspected of PE. We searched Medline and Embase for articles in English, French, German, Italian, Spanish and Dutch, published between 1966 and June 2011. Three reviewers operating in pairs of two selected prospective studies conducted in 
consecutive patients suspected of PE. The studies provided PE-probability estimate using gestalt or decision rule as compared to an appropriate reference standard. We extracted data on study characteristics, test performance and prevalence, constructed 2*2-tables and assessed methodological quality. Fifty-two studies, including 55268 patients were selected. A meta-analysis was performed on studies investigating gestalt $(n=15$; sensitivity $0.85 /$ specificity 0.51$)$, Wells-rule at cut-off $<2 \quad(n=19$; $0.84 / 0.58)$, Wells-rule at cut-off $\leq 4(n=11 ; 0.60 / 0.80)$, Geneva-rule ( $n=5 ; 0.84 / 0.50)$ and revised Geneva-rule ( $n=4 ; 0.91 / 0.37)$. Increasing prevalence of PE was associated with higher sensitivity and lower specificity. Combining a decision rule or gestalt with a D-dimer test seemed safe for all strategies except for combining the less sensitive Wells 4 with the less sensitive qualitative D-dimer.

\section{Part II: Treatment of pulmonary embolism in secondary care}

\section{Chapter 5}

In chapter 5 the literature is reviewed to determine the effect of LMWH compared with unfractionated heparin for the initial treatment of venous thromboembolism. Randomised controlled trials comparing fixed dose subcutaneous LMWH with adjusted dose intravenous or subcutaneous UFH in people with VTE were included. At least two reviewers assessed trials for inclusion and quality, and extracted data independently. Twenty-three studies were included ( $n=9587)$. Thrombotic complications occurred in $3.6 \%$ of the participants treated with LMWH, compared with $5.3 \%$ of the participants treated with UFH (odds ratio (OR) 0.70 ). Thrombus size was reduced in $53 \%$ of participants treated with $\mathrm{LMWH}$ and $45 \%$ treated with UFH (OR 0.69. Major haemorrhages occurred in $1.1 \%$ of the participants treated with LMWH, compared with $1.9 \%$ of the participants treated with UFH (OR 0.58). In nineteen trials, $4.3 \%$ of the participants treated with LMWH died, compared with $5.8 \%$ treated with UFH (OR 0.77). Nine studies $(n=4451)$ examined proximal thrombosis; 2192 participants treated with LMWH and 2259 with UFH. A subgroup analysis showed statistically significant reductions favouring $\mathrm{LMWH}$ in thrombotic complications and major haemorrhage. By end of follow up, $3.6 \%$ of the participants treated with LMWH had thrombotic complications, compared with $6.3 \%$ of the participants treated with UFH (OR 0.57). Major haemorrhage occurred in $1.0 \%$ of the participants treated with $\mathrm{LMWH}$, compared with $2.1 \%$ of the participants treated with UFH (OR 0.50). Nine studies showed a statistically significant reduction favouring LMWH with respect to mortality. By the end of follow up, $3.3 \%$ of the participants treated with LMWH had died, compared with 5.3\% treated with UFH (OR 0.62). Our conclusion is that fixed dose $\mathrm{LMWH}$ is more effective and safer than adjusted dose UFH for the initial treatment of VTE. LMWH, compared to UFH, significantly reduces 
the incidence of thrombotic complications, the occurrence of major haemorrhage during initial treatment and overall mortality at follow up.

\section{Chapter 6}

In chapter 6 the safety of outpatient treatment in hemodynamically stable patients with acute PE is investigated. This is a retrospective cohort study of consecutive patients presenting at the Ottawa Hospital with acute PE diagnosed between January 1, 2007 and December 31, 2008. Patients were managed as outpatients if they were hemodynamically stable, did not require supplemental oxygenation and did not have contraindications to low molecular weight heparin therapy. In the cohort of 473 patients with acute PE, 260 (55.0\%) were treated as outpatients and 213 (45.0\%) were admitted to the hospital. The majority of the patients were admitted because of severe co-morbidities (45.5\%) or hypoxia (22.1\%). No outpatient died of fatal PE during the 3 month follow-up period. At the end of follow-up, the overall mortality was $5.0 \%$. The rates of recurrent venous thromboembolism (VTE) in outpatients were $0.4 \%$ and $3.8 \%$ within 14 days and 3 months, respectively. The rates of major bleeding episodes were $0 \%$ and $1.5 \%$ within 14 days and 3 months, respectively. Four (1.5\%) outpatients were admitted to the hospital within 14 days.

\section{Chapter 7}

In chapter 7 we study whether the pulmonary embolism severity (PESI) index can help identifying patient with PE who are at low risk for short-term adverse events and can be treated out of the hospital. The PESI is a prognostic model that has been developed to estimate the risk of 30-day mortality in patients with acute PE. This chapter contains an additional analysis of the retrospective cohort study in chapter 6 . Two hundred and forty three patients were included. A total of 118 (48.6\%) and 81 (33.3\%) were classified as low risk patients using the original and simplified PESI prognostic models respectively. None of the low risk patients died within the 3 months of followup. One hundred and fifteen (47.3\%) patients were safely treated as outpatients with no deaths or bleeding episodes and only 1 recurrent event within the first 14 days or after 30 days of follow-up. Thirty four (29.6\%) of these outpatients were classified as high risk patients according to the original PESI and $54(47.0 \%)$ to the simplified PESI prognostic model. Both PESI strategies accurately identify patients with acute PE who are at low risk and high risk for short-term adverse events. However, 30 to $47 \%$ of patients with acute PE and a high risk PESI score were safely managed as outpatients.

\section{Chapter 8}

Chapter 8 presents a benchmark for time in therapeutic range in the treatment of venous thromboembolism. The percentage of time within the target INR range 2.0 to 3.0 (Time in Therapeutic Range (TTR)) in patients treated with vitamin K antagonists 
varies considerably among efficacy-studies of novel anticoagulants. In order to properly asses the quality of anticoagulant control in upcoming cost-effectiveness studies and real life registries this systematic review reports a benchmark of TTR for different treatment durations in patients with venous thromboembolism and discusses ways to calculate TTR. Medline and Embase were searched for studies published between January 1990 and May 2012. Randomized controlled trials and cohort studies reporting the TTR in patients with objectively confirmed venous thromboembolism treated with vitamin K antagonists (VKA) were eligible. Duplicate reports, studies only reporting INR during initial treatment or with VKA treatment less than 3 months were excluded. Three authors assessed trials for inclusion and extracted data independently. Discrepancies were resolved by discussion between the reviewers. A meta-analysis was performed by calculating a weighted mean, based on the number of participants in each included study, for each time-period in which the TTR was measured since the confirmation of the diagnosis of VTE. Reported quality of VKA treatment was highly dependent on the time-period since the start of treatment, with TTR ranging from approximately $56 \%$ in studies including the $1^{\text {st }}$ month to $75 \%$ in studies excluding the first 3 months.

\section{Chapter 9}

Chapter 9 discusses the overall methodological considerations of our studies and outlines practical implications of the results, new developments in the field and recommendations for further research. These items are addressed in two parts: 'diagnosing PE in primary care' and 'treatment of PE in secondary care'.

In the first part we discuss the composite reference standard in AMUSE-2 and the use of multiple imputation techniques to deal with missing data. The results of AMUSE-2 imply that a diagnostic approach of a Wells score $\leq 4$ combined with D-dimer testing would rule out PE in 4 to 5 out of 10 primary care patients suspected of PE with an acceptably low failure rate. However, before moving on to a management or implementation study it might be informative to investigate whether the use of the Wells rule for PE combined with D-dimer testing in primary care will be cost-effective. Furthermore, research to optimize the diagnostic strategy by using an age-adjusted quantitative point-of-care $D$-dimer test may be interesting.

The second part discusses the retrospective character of our cohort to investigate the safety of outpatient treatment. This study suggests that outpatient treatment is safe and feasible in more than $50 \%$ of the patients with acute PE. The Pulmonary Embolism Severity Index can be used to discriminate between patients with PE who are at low risk and patients who are at high risk of adverse events.

Since recently novel anticoagulant medication has been developed and approved in many countries worldwide, furture research investigating the treatment of PE should be focussed on the effectiveness of those novel anticoagulants. The efficacy of the new medication was investigated in a study stetting with a carefully selected, 
motivated study population. The effectiveness in real life, however, may differ from the efficacy in trials due to other patient populations and medication adherence. With a recently acquired postdoctoral grant we will investigate the effectiveness of novel anticoagulants in everyday clinical practice focussing on medication non-adherence. The chapter ends with our overall conclusion. The main findings of this dissertation are that PE can be safely ruled out in primary care by using the Wells clinical decision rule for PE combined by point-of-care D-dimer testing and that the majority of hemodynamic stable patients with confirmed acute PE can be safely treated out of the hospital. These findings stimulate a much larger role for primary care physicians in the management of PE in the near future. 
Samenvatting

185 


\section{Samenvatting}

\section{Hoofstuk 1}

Hoofdstuk 1 introduceert het onderwerp van de dissertatie. In deze dissertatie onderzoeken we het management van longembolie op het snijvlak van de huisarts en het ziekenhuis.

Het hoofdstuk beschrijft eerst de definitie en epidemiologie van longembolie. Een longembolie is een bloedstolsel dat de slagader of een vertakking daarvan blokkeert. Het is de derde meest voorkomende doodsoorzaak door hart- en vaatziekten en komt voort uit een combinatie van erfelijke en verworven risicofactoren.

Het hoofdstuk bespreekt vervolgens de historische ontwikkelingen in de diagnostiek van longembolie. Het stellen van de diagnose longembolie is een grote uitdaging, omdat patiënten zich vaak presenteren met aspecifieke symptomen. De invasieve en arbeidsintensieve methode waarbij via een catheter een pulmonalis angiografie wordt uitgevoerd, werd lang gezien als de gouden standaard. Tegenwoordig echter is de standaard procedure in het ziekenhuis dat de klinische waarschijnlijkheid van een longembolie wordt vastgesteld aan de hand van uitslagen van een klinische beslisregel en een D-dimeer bloedtest, eventueel gevolgd door een CT-scan. De diagnostische strategie om de waarschijnlijkheid van een longembolie vast te stellen door middel van een klinische beslisregel en een D-dimeer test lijkt ideaal voor gebruik in de eerste lijn en kan een huisarts helpen bij de beslissing om een patiënt met verdenking longembolie wel of niet te verwijzen naar het ziekenhuis. Vervolgens vermeldt het hoofdstuk de beweegredenen en het doel van het eerste deel van het proefschrift 'Diagnostiek van longembolie in de $1^{\mathrm{e}}$ lijn'. In Nederland is, buiten het ziekenhuis, de huisarts over het algemeen de eerste medicus met wie patiënten, die mogelijk longembolie hebben, contact hebben. In de Amsterdam Maastricht Utrecht studie naar trombo-embolie (Amuse-2) onderzochten we de nauwkeurigheid en veiligheid van het gebruik van de klinische beslisregel van Wells in combinatie met een point-ofcare D-dimeer test voor het uitsluiten van longembolie in de eerste lijn.

De volgende paragraaf van het hoofstuk begint met de historische ontwikkelingen in de behandeling van longembolie. Patiënten met een longembolie worden over het algemeen gedurende 5 tot 10 dagen behandeld met laag moleculair gewicht heparine waarna de behandeling wordt voortgezet met vitamine K-antagonisten (VKA). Onlangs zijn er echter een nieuwe antistollingsmiddelen ontwikkeld en goedgekeurd in vele landen wereldwijd, die even werkzaam zijn als de traditionele VKA. De richtlijn van het American College of Chest Physicians adviseert om een longembolie met een duidelijke oorzaak 3 maanden te behandelen, patienten met een eerste episode van idiopatische longembolie minstens 6 tot 12 maanden te behandelen en patiënten met twee of meer objectief gedocumenteerde longembolieën levenslang te behandelen. Het hoofdstuk vemeldt vervolgens de beweegredenen en het doel van het tweede deel van het proefschrift 'Behandeling van longembolie in de tweede lijn'. De rol van 
mogelijke poliklinische behandeling van patiënten met een longembolie is onduidelijk en een discussiepunt in de literatuur. In dit proefschrift is onderzocht of patiënten met een hemodynamisch stabiele longembolie veilig poliklinisch kunnen worden behandeld. Ook is onderzocht of de 'Pulmonary Embolism Severity Index', een prognostisch model voor het inschatten van de kans op korte termijn complicaties, zou kunnen helpen bij de bepaling welke patiënten met een longembolie geschikt zijn voor een poliklinische behandeling.

Het hoofdstuk eindigt met een overzicht van het proefschrift.

\section{Deel I: Diagnostiek van longembolie in de eerste lijn}

\section{Hoofdstuk 2}

Hoofdstuk 2 beschrijft de Amsterdam Maastricht Utrecht Studie naar trombo-embolie (Amuse-2) waarin de veiligheid van het gebruik van de klinische beslisregel van Wells voor longembolie in combinatie met een point-of-care D-dimeer test onderzocht is om veilig longembolie uit te sluiten in de eerste lijn. We hebben 598 volwassen patiënten met verdenking longembolie geïncludeerd in de studie. Na het afnemen van de medische voorgeschiedenis en het doen van een lichamelijk onderzoek, scoorde de huisarts de 7 items van de klinische beslisregel van Wells en voerde een point-of-care D-dimeer test uit. Alle patiënten werden daarna verwezen naar een ziekenhuis in de buurt, alwaar volgens de daar geldende protocollen een diagnose werd gesteld. $\mathrm{Na}$ 3 maanden werd beoordeeld of de patiënt een longembolie had of niet, door een onafhankelijke commissie. Bij 73 patiënten is een longembolie gediagnosticeerd (prevalentie 12\%). Tweehonderdtweeënzeventig van de 598 patiënten (45\%) hadden een lage klinische waarschijnlijkheid, dat wil zeggen een Wells-score van 4 of lager en een negatieve point-of-care D-dimeer test. Bij 4 van deze patiënten (1.5\%) werd toch een longembolie gediagnosticeerd. De sensitiviteit en specificiteit van deze diagnostische strategie was $94,5 \%$ en $51,0 \%$.

\section{Hoofdstuk 3}

Dit hoofdstuk heeft tot doel het rapporteren van de meest voorkomende alternatieve diagnosen van longembolie in de eerste lijn bij patiënten bij wie eerst gedacht werd aan een longembolie. Ook onderzoeken we of de klinische beslisregel van Wells gecombineerd met een point-of-care D-dimeer test niet alleen longembolie, maar ook andere ernstige diagnosen kan uitsluiten. Het hoofdstuk is een secundaire analyse van Amuse-2. De meest voorkomende alternatieve diagnosen, na het uitsluiten van een longembolie, waren: aspecifieke thoracale pijnklachten / dyspnoe $(42,6 \%)$, pneumonie $(13,0 \%)$, myalgie $(11,8 \%)$, astma / COPD $(4,8 \%)$, paniekstoornis / hyperventilatie $(4,1 \%)$ en een luchtweginfectie (2,3\%). Patiënten met een Wells-score van meer dan 4 
punten of een positieve D-dimeer test werden significant vaker gediagnosticeerd met een klinisch relevante diagnose waarbij onmiddellijke medische behandeling nodig is. Het lijkt erop dat een lage klinische waarschijnlijkheid op longembolie op basis van de klinische beslisregel van Wells en een point-of-care D-dimeer test niet alleen longembolie, maar ook andere klinisch relevante diagnosen kan uitsluiten.

\section{Hoofdstuk 4}

Hoofdstuk 4 geeft een referentiekader om de resultaten van de Amuse-2 studie te interpreteren. In een systematische literatuurstudie en meta-analyse hebben we de sensitiviteit en specificiteit vergeleken van verschillende klinische beslisregels die gebruikt worden voor het uitsluiten van longembolie bij patiënten met verdenking longembolie in de tweede lijn. Medline en Embase zijn doorzocht voor wetenschappelijke artikelen in het Engels, Frans, Duits, Italiaans, Spaans en Nederlands, die gepubliceerd zijn tussen 1966 en juni 2011. Drie beoordelaars hebben prospectieve studies geselecteerd waarin de klinische waarschijnlijkheid van longembolie werd bepaald met behulp van Gestalt of een klinische beslisregel bij patiënten met verdenking longembolie. De studies dienden een geschikte referentiestandaard te gebruiken. De volgende gegevens werden genoteerd: de studie-karakteristieken, de accuraatheid van de test, de prevalentie van longembolie en de methodologische kwaliteit van het artikel. Tweeënvijftig studies met in totaal 55.268 patiënten werden geïncludeerd in de analyses. In de meta-analyse werden de volgende resultaten met betrekking tot de sensitiviteit en specificiteit van de beslisregels gevonden: Gestalt ( $n=15$; sens 0,85 / spec 0,51), Wells-regel met afkappunt $<2$ ( $n=190 ;$ sens 0,84 / spec $0,58)$, Wells-regel met afkappunt $\leq 4(n=11$; sens $0,60 /$ spec 0,80$)$, Geneva-regel $(n=5$; sens 0,84 / spec 0,50) en de gereviseerde Geneva-regel ( $n=4$; sens 0,91 / spec 0,37). Een toenemende prevalentie van longembolie werd geassocieerd met een hogere sensitiviteit en lagere specificiteit. De combinatie van een beslisregel of Gestalt met een D-dimeer test leek bij alle strategieën veilig longembolie uit te sluiten, met uitzondering van de combinatie van de minder sensitieve Wells-regel met afkappunt 4 en de minder sensitieve kwalitatieve D-dimeer test.

\section{Deel II: Behandeling van longembolie in de tweede lijn}

\section{Hoofdstuk 5}

In hoofdstuk 5 is er een literatuuronderzoek gedaan om in de initiële behandeling van veneuze trombo-embolie de effectiviteit van laag moleculair gewicht heparine te vergelijken met niet-gefractioneerde heparine. In de analyses werden gerandomiseerde studies geïncludeerd die een vaste dosis subcutane laag moleculaire gewicht heparine (LMWH) vergeleken met een aangepaste dosis intraveneuze gefractioneerde 
heparine (UFH) in de behandeling van patiënten met veneuze trombo-embolie. Tenminste 2 beoordelaars hebben onafhankelijk de geïncludeerde studies beoordeeld op kwaliteit en de benodigde gegevens geregistreerd. Drieëntwintig studies werden geïncludeerd ( $n=9587$ ). Trombotische complicaties kwamen voor bij 3,6\% van de patiënten behandeld met $\mathrm{LMWH}$, in vegelijking met $5.3 \%$ van de patiënten behandeld met UFH (odds ratio (OR) 0,70 ). De grootte van de trombus was afgenomen in $53 \%$ van de patiënten behandeld met LMWH en in $45 \%$ van de patiënten behandeld met UFH (OR 0,69). Grote levensbedreigende bloedingen kwamen voor bij 1,1\% van de patiënten behandeld met $\mathrm{LMWH}$, in vergelijking met $1,9 \%$ van de patiënten behandeld met UFH (OR 0,58). In 19 studies werd de mortaliteit beschreven: 4,3\% van de patiënten behandeld met LMWH stierf en 5,8\% van de patiënten behandeld met UFH (OR 0,77). Negen studies hebben patiënten met proximale trombose geïncludeerd: 2192 deelnemers hiervan werden behandeld met LMWH en 2259 met UFH. Een subgroep analyse toonde bij deze patiënten een significante vermindering aan in trombotische complicaties en ernstige bloedingen ten gunste van LMWHbehandeling. Aan het einde van de follow-up had 3,6\% van de patiënten behandeld met $\mathrm{LMWH}$ een trombotische complicatie in vergelijking met $6,3 \%$ van de patiënten behandeld met UFH (OR 0,57). Grote bloedingen traden op bij 1,0\% van de patiënten behandeld met $L M W H$ en bij $2,1 \%$ van de patiënten behandeld met UFH $(O R 0,50)$. In negen studies werd aangetoond dat de mortatliteit significant lager was in de groep met LMWH. Aan het einde van de follow-up was 3,3\% van de deelnemers met LMWH overleden, terwijl in groep met UFH 5,3\% was overleden (OR 0,62). Uit deze bevindingen concluderen we dat LMWH effectiever en veiliger is voor initiële behandeling van veneuze trombo-embolie dan UFH. De incidentie van trombotische complicaties als ook van ernstige bloedingen tijdens de initiële behandeling en de totale sterfte bij follow-up zijn lager bij behandeling met LMWH dan met UFH.

\section{Hoofdstuk 6}

In hoofdstuk 6 wordt de veiligheid van een poliklinische behandeling bij hemodynamisch stabiele patiënten met een longembolie onderzocht. Dit is een retrospectieve cohort studie met patiënten die tussen 1 januari 2007 en 31 december 2008 in het ziekenhuis in Ottawa, Canada, gediagnosticeerd zijn met een acute longembolie. Patiënten werden poliklinisch behandeld indien ze hemodynamisch stabiel waren, geen extra zuurstof nodig hadden, er geen contra-indicaties waren voor behandeling met laag moleculair gewicht heparine en er geen ernstige comorbiditeit was. Het cohort bestond uit 473 patiënten met een acute longembolie: 260 (55\%) mensen werden poliklinisch behandeld en 213 (45,0\%) werd opgenomen in het ziekenhuis. De meerderheid van de patiënten werd opgenomen vanwege een ernstige comorbiditeit $(45,5 \%)$ of hypoxie $(22,1 \%)$. Tijdens de 3 maanden follow-up is geen van de poliklinische patiënten overleden aan een fatale longembolie. Aan het einde van de follow-up was de totale mortaliteit 5,0\%. Het percentage recidieven bij de 
poliklinsiche behandeling was $0,4 \%$ en $3,8 \%$ binnen 14 dagen en 3 maanden, respectievelijk. Het percentage ernstige bloedingen was $0.0 \%$ en $1,5 \%$ binnen 14 en 3 maanden, respectievelijk. Vier (1,5\%) poliklinische patiënten werden binnen 14 dagen alsnog opgenomen in het ziekenhuis.

\section{Hoofdstuk 7}

In hoofdstuk 7 wordt bestudeerd of de Pulmonary Embolism Severity Index (PESI) gebruikt kan worden voor identificatie van patiënten met een longembolie met een laag risico voor complicaties op de korte termijn die veilig poliklinisch behandeld zouden kunnen worden. De PESI is een prognostisch model dat oorspronkelijk ontwikkeld is voor het voorspellen van de 30-dagen mortaliteit bij patiënten met een acute longembolie. Dit hoofdstuk beschrijft een secundaire analyse van het retrospectieve cohort uit hoofdstuk 6 . Tweehonderdendrieënveertig patiënten werden in deze secundaire analyse geïncludeerd. Het originele PESI model classificeerde $118(48,6 \%)$ van deze patiënten in de laag risico groep, terwijl het vereenvoudigde PESI model $81(33,3 \%)$ van de patiënten in de laag risico groep classificeerde. Geen van de laag risico patiënten stierf gedurende de 3 maanden follow-up. Honderdenvijftien (47,3\%) patiënten werden veilig poliklinisch behandeld zonder overlijden en slechts 1 recidief binnen de 14 en 30 dagen follow-up. De originele PESI classificeerde $34(29,6 \%)$ van deze poklinische patiënten in de hoog risico groep en het vereenvoudigde PESI model classificeerde $54(47,0 \%)$ van deze patiënten in de de hoog risico groep. Beide PESI-strategieën identificeren nauwkeurig longembolie-patiënten met een laag en hoog risico op korte termijn complicaties. Dertig tot $47 \%$ van de longembolie-patiënten in de hoog-risico groep werd echter veilig poliklinisch behandeld.

\section{Hoofdstuk 8}

Hoofdstuk 8 geeft een benchmark voor de tijd doorgebracht in de therapeutische range bij de behandeling van veneuze-tromboembolie. Het percentage van de tijd dat de patiënten in de controlegroep behandeld met vitamine K-antagonisten (VKA) doorbrengt binnen de gewenste INR-range van 2,0 tot 3,0 (TTR) verschilt aanzienlijk tussen studies met nieuwe antistollingsmiddelen. Om goed de effecitiviteit van de nieuwe antistollingsmiddelen te kunnen beoordelen in toekomstig onderzoek rapporteert dit hoofdstuk een benchmark van de TTR en worden manieren om de TTR te berekenen besproken. Medline en Embase werden onderzocht voor studies gepubliceerd tussen januari 1990 en mei 2012. In aanmerking voor inclusie kwamen gerandomiseerde trials en cohort studies die de TTR rapporteerden bij patiënten met veneuze trombo-embolie die behandeld werden met VKA. Geëxcludeerd werden duplicaten, studies die alleen de INR tijdens de initiële behandelperiode rapporteerden en studies met een VKA-behandeling van minder dan 3 maanden. Drie auteurs selecteerden onafhankelijk van elkaar studies voor inclusie en extraheerden 
de data voor de analyses. Verschillen werden opgelost door overleg tussen de beoordelaars. In een meta-analyse werd een gewogen gemiddelde berekend gebaseerd op het aantal deelnemers per studie. De TTR werd berekend voor de verschillende lengten van de behandeling. De gerapporteerde kwaliteit van de VKAbehandeling was sterk afhankelijk van de duur van de behandeling. De TTR varieerde van ongeveer $56 \%$ in de $1^{\mathrm{e}}$ maand van de behandeling tot $72 \%$ vanaf 4 maanden behandeling.

\section{Hoofdstuk 9}

Hoofdstuk 9 gaat in op de methodologische overwegingen van de studies en schetst de praktische implicaties van de resultaten, nieuwe ontwikkelingen in het vakgebied en aanbevelingen voor verder onderzoek. Dit wordt geadresseerd in twee delen: 'diagnostiek van longembolie in de eerste lijn' en 'behandeling van longembolie in de tweede lijn'.

In het eerste deel bespreken we de samengestelde referentiestandaard in de Amuse-2 studie. Ook wordt het gebruik van multipele imputatie als techniek voor het omgaan met missende variabelen besproken. De resultaten van Amuse-2 impliceren dat de klinische beslisregel van Wells voor longembolie met een afkappunt van $\leq 4$ gecombineerd met een point-of-care D-dimeer test veilig longembolie kan uitsluiten in 4 tot 5 van de 10 patiënten in de eerste lijn met verdenking longembolie. Voor het uitvoeren van een management studie kan het echter informatief zijn om eerst een kosteneffectiviteitsstudie te doen naar het gebruik van de Wells-regel en D-dimeer test in de eerste lijn. Bovendien zou het interessant kunnen zijn om te onderzoeken of de diagnostische strategie geoptimaliseerd kan worden door gebruik te maken van een kwantitatieve point-of-care D-dimeer test met een leeftijdsafhankelijk afkappunt. Het tweede deel gaat in op het retrospectieve karakter van de cohort studie naar de veiligheid van een poliklinische behandeling bij longembolie. Deze studie laat zien dat een poliklinische behandeling veilig en haalbaar is in meer dan $50 \%$ van de patiënten met een acute longembolie. De Pulmonary Embolism Severity Index kan gebruikt worden om onderscheid te maken tussen patiënten met een laag risico en patiënten met een hoog risico op complicaties.

Sinds kort zijn er nieuwe antistollingsmiddelen ontwikkeld en goedgekeurd over de hele wereld. Verder onderzoek naar deze nieuwe middelen dient vooral de effectiviteit van deze nieuwe antistollingsmiddelen in de dagelijkse klinische praktijk te onderzoeken. De werkzaamheid van deze nieuwe middelen werd tot nu toe onderzocht in een zorgvuldig geselecteerde en gemotiveerde studiepopulatie. De werkzaamheid in de dagelijkse klinische praktijk kan echter anders zijn vanwege een andere samenstelling van de patiëntenpopulatie en vanwege die therapietrouw van patiënten. Met een onlangs verworven postdoctorale beurs zullen we de effectiviteit van de nieuwe antistollingsmiddelen onderzoeken en ons hierbij vooral richten op therapie-ontrouw. 
Het hoofdstuk eindigt met een algemene conclusie. De belangrijkste bevindingen van dit proefschrift zijn dat longembolie op een veilige manier door de huisarts uitgesloten kan worden met behulp van de klinische beslisregel van Wells voor longembolie gecombineerd met een point-of-care $\mathrm{D}$-dimeer test en dat de meerderheid van de hemodynamisch stabiele patiënten met een acute longembolie veilig poliklinisch behandeld kunnen worden. Deze bevindingen stimuleren een grotere rol voor huisartsen in de diagnostiek en behandeling van longembolie in de nabije toekomst. 



\section{Appendix}

Different clinical decision rules for pulmonary embolism 
Appendix I 


\section{Different clinical decision rules for PE}

- Wells rule: Wells et al. ${ }^{1}$ obtained data from a prospective cohort of 1239 patients suspected of PE to derive this clinical decision rule. Using logistic regression, seven variables from the patient history and physical examination were selected for inclusion in the final rule (Figure 1). Cut-off points were identified to classify patients as low (score <2), moderate (score 2-6) and high (score >6) probability for pulmonary embolism. Alternatively, the total score can be dichotomized into a pulmonary-embolism-unlikely (score $\leq 4$ ) or a pulmonary embolism-likely (score $>4$ ) clinical probability. The rule was simplified ${ }^{2}$ by assigning the same weight (one point) to each of the seven variables. The score was dichotomized in PE-unlikely (score $\leq 1$ ) and PE-likely (score $>1$ ).

Figure 1 Wells rule.

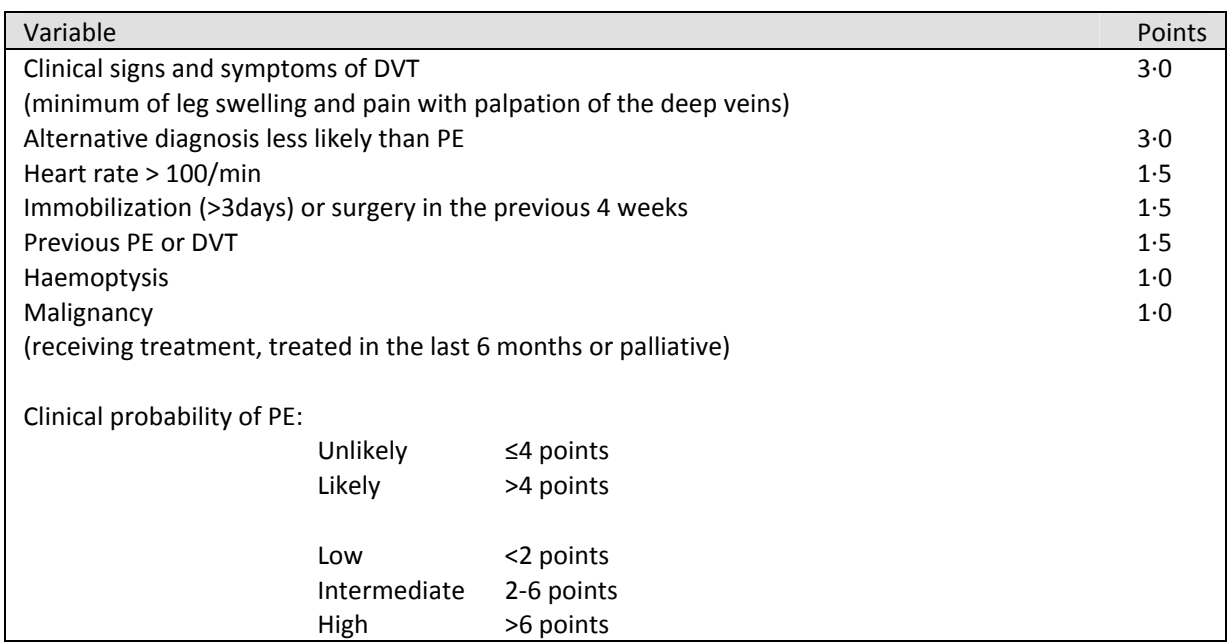

DVT= deep venous thrombosis; $\mathrm{PE}=$ pulmonary embolism.

- Geneva rule: Wicki et al. ${ }^{3}$ combined clinical variables from the patient history and physical examination together with results of a chest $x$-ray, electro-cardiogram and arterial blood gas analysis in a cohort of 986 consecutive patients suspected of PE. Using logistic regression eight variables were selected (Figure 2). Subsequently a score was introduced to classify patients into groups of a low (score $<5$ ), moderate (score 5-8) or high (score >8) clinical probability. 
Figure 2 Geneva rule.

\begin{tabular}{|c|c|c|}
\hline \multicolumn{2}{|l|}{ Variable } & Score* \\
\hline \multicolumn{2}{|c|}{ 1. Previous pulmonary embolism or deep venous thrombosis } & 2 \\
\hline \multicolumn{2}{|c|}{ 2. Heart rate $>100$ beats per minute } & 1 \\
\hline \multicolumn{2}{|l|}{ 3. Recent surgery } & 3 \\
\hline \multirow[t]{2}{*}{ 4. Age (years): } & $60-79$ & 1 \\
\hline & $\geq 80$ & 2 \\
\hline \multirow[t]{2}{*}{ 5. PaCO2: } & $<4.8 \mathrm{kPa}(36 \mathrm{mmHg})$ & 2 \\
\hline & $4 \cdot 8-5 \cdot 19 \mathrm{kPa}(36-38.9 \mathrm{mmHg})$ & 1 \\
\hline \multirow[t]{4}{*}{ 6. $\mathrm{PaO} 2$ : } & $<6.5 \mathrm{kPa}(<48.7 \mathrm{mmHg})$ & 4 \\
\hline & $6 \cdot 5-7.99 \mathrm{kPa}(48 \cdot 7-59.9 \mathrm{mmHg})$ & 3 \\
\hline & $8-9.49 \mathrm{kPa}(60-71.2 \mathrm{mmHg})$ & 2 \\
\hline & $9 \cdot 5-10 \cdot 99 \mathrm{kPa}(71 \cdot 3-82 \cdot 4 \mathrm{mmHg})$ & 1 \\
\hline \multicolumn{3}{|l|}{ Chest radiograph: } \\
\hline \multicolumn{2}{|l|}{ 7. Platelike atelectasis } & 1 \\
\hline \multicolumn{2}{|c|}{ 8. Elevated hemidiaphragm } & 1 \\
\hline \multicolumn{3}{|c|}{$\mathrm{PaCO} 2$ =partial pressure of carbon dioxide, arterial } \\
\hline \multicolumn{3}{|c|}{$\mathrm{PaO} 2$ = partial pressure of oxygen, arterial. } \\
\hline \multirow[t]{3}{*}{ * Clinical probability: } & $<5$ points: low & \\
\hline & 5-8 points: moderate & \\
\hline & $>8$ points: high & \\
\hline
\end{tabular}

In addition, a new rule, using only clinical variables, was derived by Le Gal et al. ${ }^{4}$ (Figure 3, the Revised Geneva rule). In this rule, patients were classified as low (score $<4$ ), intermediate (score 4-10) or high (score $>10$ ) pre-test probability of PE. The score was dichotomized in PE-unlikely (score $\leq 5$ ) and PE-likely (score $>5)^{5,6}$. The rule was simplified ${ }^{5}$ by assigning the same weight (one point) to each of the eight variables. Patients were classified into groups of low (score $\leq 1$ ), intermediate (score $2-4$ ) and high (score $\geq 5$ ) clinical probability. The score was dichotomized in PE-unlikely (score $\leq 2$ ) and PE-likely (score $>2$ ).

Figure 3 Revised Geneva.

\begin{tabular}{|c|c|c|c|}
\hline \multicolumn{3}{|l|}{ Variable } & Score \\
\hline \multicolumn{3}{|l|}{ 1. Age $>65 y$} & 1 \\
\hline \multicolumn{3}{|c|}{ 2. Previous DVT or PE } & 3 \\
\hline \multicolumn{3}{|c|}{ 3. Surgery (under general anaesthesia) or fracture (of the lower limbs) within 1 month } & 2 \\
\hline \multicolumn{3}{|c|}{$\begin{array}{l}\text { 4. Active malignant condition (solid or hematologic malignant condition, currently active } \\
\text { or considered cured }<1 \mathrm{y} \text { ) }\end{array}$} & 2 \\
\hline \multicolumn{3}{|c|}{ 5. Unilateral lower-limb pain } & 3 \\
\hline \multicolumn{3}{|l|}{ 6. Haemoptysis } & 2 \\
\hline \multirow[t]{2}{*}{ 7. Heart rate } & $75-94$ beats & & 3 \\
\hline & $\geq 95$ beats $/ \mathrm{m}$ & & 5 \\
\hline \multicolumn{3}{|c|}{ 8. Pain on lower-limb deep venous palpation and unilateral oedema } & 4 \\
\hline Clinical probability & $\begin{array}{l}\text { <4 points: } \\
\text { 4-10 points: } \\
>10 \text { : }\end{array}$ & $\begin{array}{l}\text { low } \\
\text { intermediate } \\
\text { high }\end{array}$ & \\
\hline
\end{tabular}


- Pisa rule: Miniati et al. ${ }^{7}$ used logistic regression to construct a model of independent predictors associated with pulmonary embolism using data from a cohort of 1100 consecutive patients admitted to hospital with suspected pulmonary embolism. The final model comprises 15 variables of which ten are positively associated and five are negatively associated with pulmonary embolism (Figure 4). Patients were categorized as low $(\leq 10 \%)$, intermediate $(>10 \%, \leq 50 \%)$, moderately high $(>50 \%, \leq 90 \%)$, or high $(>90 \%)$ probability of pulmonary embolism. Because this model depends heavily on the interpretation of the chest radiograph, Miniati et al. ${ }^{8}$ also developed a more simple model based only on variables from patient history, physical examination and the interpretation of the electrocardiogram (Figure 5, the Revised Pisa rule). Patients are categorized in the same way as in the original Pisa-rule.

Figure 4 Pisa-rule.

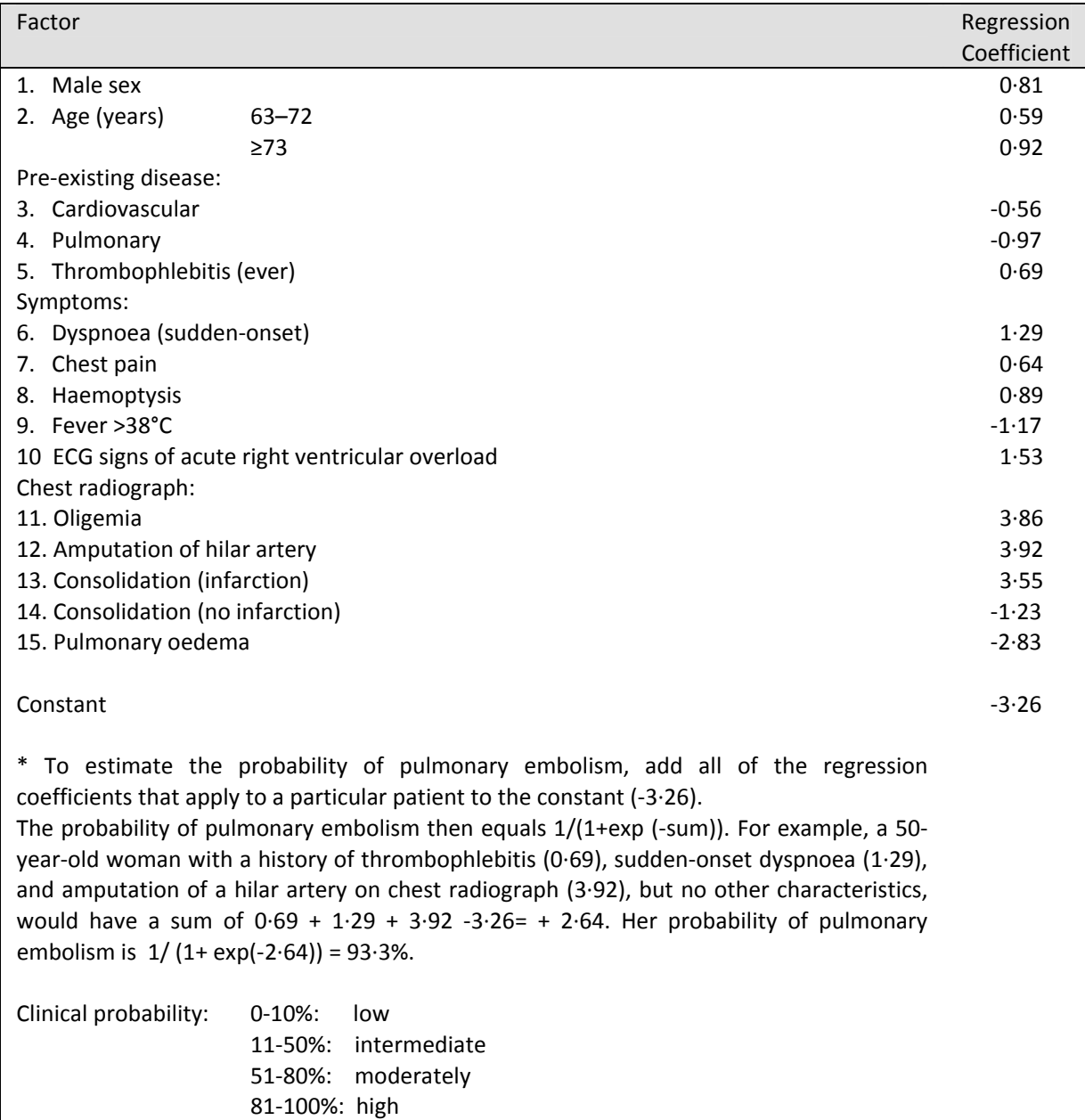


Figure 5 Revised Pisa.

\begin{tabular}{|c|c|c|}
\hline \multicolumn{2}{|l|}{ Predictor } & \multirow[t]{2}{*}{ Coefficient } \\
\hline 1. Age, $y r$ & $57-67$ & \\
\hline & $68-74$ & $0 \cdot 80$ \\
\hline & $\geq 75$ & $0 \cdot 87$ \\
\hline & & $1 \cdot 14$ \\
\hline \multicolumn{2}{|l|}{ 2. Male sex } & $0 \cdot 60$ \\
\hline \multicolumn{2}{|l|}{ 3. Immobilization } & $0 \cdot 42$ \\
\hline \multicolumn{2}{|c|}{ 4. Deep venous thrombosis (ever) } & $0 \cdot 64$ \\
\hline \multicolumn{3}{|l|}{ Pre-existing diseases: } \\
\hline \multicolumn{2}{|l|}{ 5. Cardiovascular } & $-0 \cdot 51$ \\
\hline \multicolumn{2}{|l|}{ 6. Pulmonary } & $-0 \cdot 89$ \\
\hline \multicolumn{2}{|c|}{ 7. Dyspnoea (sudden onset) } & $2 \cdot 00$ \\
\hline \multicolumn{2}{|l|}{ 8. Orthopnea } & $-1 \cdot 51$ \\
\hline \multicolumn{2}{|l|}{ 9. Chest pain } & $1 \cdot 01$ \\
\hline \multicolumn{2}{|c|}{ 10. Fainting or syncope } & 0.66 \\
\hline \multicolumn{2}{|l|}{ 11. Haemoptysis } & 0.93 \\
\hline \multicolumn{2}{|c|}{ 12. Leg swelling (unilateral) } & $0 \cdot 80$ \\
\hline \multicolumn{2}{|l|}{ 13. Fever $>38 \mathrm{C}$} & $-1 \cdot 47$ \\
\hline \multicolumn{2}{|l|}{ 14. Wheezes } & $-1 \cdot 20$ \\
\hline \multicolumn{2}{|l|}{ 15. Crackles } & -0.61 \\
\hline \multirow{2}{*}{\multicolumn{2}{|c|}{ 16. Acute cor pulmonale on ECG* }} & 1.96 \\
\hline & & $-3 \cdot 43$ \\
\hline \multicolumn{3}{|l|}{$\begin{array}{l}\text { Constant } \\
\text { * One or more of the } \\
\text { precordial leads, tran }\end{array}$} \\
\hline \multicolumn{3}{|c|}{$\begin{array}{l}\text { Calculation of the clinical probability of pulmonary embolism: (1) Add all the coefficients } \\
\text { that apply to a given patients and the constant (sum); (2) the probability of pulmonary } \\
\text { embolism equals } 1 /[1+\exp (- \text { sum) }]\end{array}$} \\
\hline \multirow[t]{4}{*}{ Clinical probability: } & 0-10\%: low & \\
\hline & 11-50\%: intermediate & \\
\hline & 51-80\%: moderately high & \\
\hline & 81-100\%: high & \\
\hline
\end{tabular}

- $\quad$ PERC (Pulmonary Embolism Rule-out Criteria): Kline et al. ${ }^{9}$ derived this eightfactor decision rule from logistic regression analysis of 21 variables collected in 3148 emergency department patients evaluated for PE. The rule was developed to support the decision not to order subsequent diagnostic tests for PE in patients in whom the clinician had a low suspicion for PE. To be negative the PERC rule requires the clinician to answer 'no' to eight questions. (Figure 6) 
Figure 6 PERC.

PERC negative requires the clinician to answer 'no' to the following eight questions:

1. Is the patient older than 49 years of age?

2 . Is the pulse rate above 99 beats/ $\mathrm{min}$ ?

3 . Is the pulse oximetry reading $<95 \%$ while the patient breathes room air?

4. Is there a present history of haemoptysis?

5. Is the patient taking exogenous oestrogen?

6. Does the patient have a prior diagnosis of venous thromboembolism (VTE)?

7. Has the patient had recent surgery or trauma? (Requiring endotracheal intubation or hospitalization in the previous four weeks.)

8. Does the patient have unilateral leg swelling? (Visual observation of asymmetry of the calves.)

- Charlotte-rule: Kline et al. ${ }^{10}$ derived a six variable model using logistic regression from a database consisting of 934 emergency-department patients suspected of PE. This model combines two screening variables: patients younger than 50 years of age and with a shock-index (heart rate divided by systolic blood pressure) less than one are deemed "safe". The remaining patients are then further assessed using four variables. The rule classifies patients as safe (this is, eligible for D-dimer testing) and unsafe (requiring imaging). (Figure 7)

Figure 7 Charlotte rule.

This rule divides patients in safe (eligible for D-dimertesting) and unsafe.

A. If the patient is 50 years of age or younger and the heart rate is less than or equal to the systolic blood pressure (ie, shock index $\leq 1 \cdot 0$ ), the patient is safe.

B. If the patient is either older than 50 years or has a shock index of more than $1 \cdot 0$, the clinician should ask four sequential questions:

1. Does the patient have unexplained hypoxemia?

2. Does the patient have unilateral leg swelling?

3. Has the patient had surgery requiring general anaesthesia in the past 4 weeks?

4. Does the patient have haemoptysis?

If the answer to all four questions is "no," then the patient is safe. 


\section{References}

1. Wells PS, Anderson DR, Rodger M, Ginsberg JS, Kearon C, Gent M et al. Derivation of a simple clinical model to categorize patients probability of pulmonary embolism: increasing the models utility with the SimpliRED D-dimer. Thromb Haemost 2000;83:416-420.

2. Gibson NS, Sohne M, Kruip MJ, Tick LW, Gerdes VE, Bossuyt PM et al. Further validation and simplification of the Wells clinical decision rule in pulmonary embolism. Thromb Haemost 2008; 99:229-234.

3. Wicki J, Perneger TV, Junod AF, Bounameaux H, Perrier A. Assessing clinical probability of pulmonary embolism in the emergency ward: a simple score. Arch Intern Med 2001;161:92-97.

4. Le Gal G, Righini M, Roy PM, Sanchez O, Aujesky D, Bounameaux H et al. Prediction of pulmonary embolism in the emergency department: the revised Geneva score. Ann Intern Med 2006;144: 165-171.

5. Klok FA, Mos IC, Nijkeuter M, Righini M, Perrier A, Le GG et al. Simplification of the revised Geneva score for assessing clinical probability of pulmonary embolism. Arch Intern Med 2008;168:2131-2136.

6. Douma RA, Mos IC, Erkens PM, Nizet TA, Durian MF, Hovens MM, van Houten AA, Hofstee HM, Klok FA, Ten Cate H, Ullmann EF, Büller HR, Kamphuisen PW, Huisman MV. Performance of 4 Clinical Decision Rules in the Diagnostic Management of Acute Pulmonary Embolism: A Prospective Cohort Study Ann Intern Med. 2011;154:709-718.

7. Miniati M, Monti S, Bottai M. A structured clinical model for predicting the probability of pulmonary embolism. Am J Med 2003;114:173-179.

8. Miniati M, Bottai M, Monti S, Salvadori M, Serasini L, Passera M. Simple and accurate prediction of the clinical probability of pulmonary embolism. Am J Respir Crit Care Med 2008;178:290-294.

9. Kline JA, Courtney DM, Kabrhel C, Moore CL, Smithline HA, Plewa MC et al. Prospective multicenter evaluation of the pulmonary embolism rule-out criteria. J Thromb Haemost 2008;6:772-780.

10. Kline JA, Nelson RD, Jackson RE, Courtney DM. Criteria for the safe use of D-dimer testing in emergency department patients with suspected pulmonary embolism: a multicenter US study. Ann Emerg Med 2002; 39:144-152. 
Dankwoord 


\section{Dankwoord}

Het is misschien cliché, maar een promotieonderzoek doe je niet alleen. Er zijn veel mensen die belangrijk zijn geweest voor het tot stand komen van dit proefschrift, die ik hier graag wil bedanken.

Allereerst wil ik alle deelnemers, zowel huisartsen als patiënten, van het Amuse-2 project bedanken. Zonder deelnemers, geen onderzoek. Ondanks de drukte van de gemiddelde huisartsenpraktijk, hebben toch vele huisartsen de tijd genomen om patiënten te vragen voor deelname aan het Amuse-2 onderzoek.

Ten tweede mijn speciale dank aan het promotieteam. Van het sollicitatiegesprek kan ik me nog goed herinneren dat ik meteen een goed gevoel had. Mijn masterthesis bij epidemiologie moest nog afgerond worden, maar ik was al vastbesloten om verder te gaan in het wetenschappelijk onderzoek. Ik wilde graag werken aan praktisch onderzoek met een duidelijke klinische relevantie, het liefst in de cardiovasculaire richting gezien mijn ervaring als research-verpleegkundige op de afdeling cardiologie in het azM. Onderzoek naar de diagnostiek en behandeling van longembolie pastte hier helemaal bij.

Beste dr. Stoffers, beste Jelle, jij was mijn dagelijks begeleider. Ik wil je ontzettend bedanken voor de vele gezamenlijke uurtjes overleg. Wij zijn allebei praktisch ingesteld en konden vaak redelijk snel een oplossing vinden voor de praktische problemen in de Amuse-2 studie. Ik heb jou leren kennen als iemand die hard werkt, veel op zich neemt en ook nog alles heel goed wil doen. Elke nieuwsbrief, flyer, artikel, presentatie en poster die ik jou liet zien voor feedback werd grondig van commentaar voorzien. Hier heb ik enorm veel van geleerd. Ik waardeer je directheid en betrokkenheid.

Beste Prof. dr. ten Cate, beste Hugo, met je warme persoonlijkheid en rustige uitstraling heb jij de rust weten te bewaren als ik wel eens zat te stressen over wat er nog allemaal moest gebeuren en of het allemaal wel goed ging. Je agenda zit overvol, maar toch kon ik altijd bij je terecht en reageer je snel op mails met vragen. Je hebt me veel ruimte gegeven en hebt altijd blijk gegeven van je vertrouwen in mijn kunnen. Dit heb ik als heel prettig ervaren. Via jou werd ik opgenomen in de groep van het laboratorium voor klinische trombose en hemostase. Hier heb ik me altijd heel welkom gevoeld en veel geleerd van de dinsdagochtend-besprekingen. Dank ook dat ik via jouw netwerk heb mogen meewerken aan landelijke multicenter studies zoals de Prometheus studie.

Beste Prof. dr. Prins, beste Martin, jij verstaat de kunst om zo even uit je hoofd te brainstormen. Kennis over wat, wanneer, waar en door wie gepubliceerd is, heb jij altijd meteen paraat en de benodigde steekproefgrootte voor een studie reken je gewoon even op de achterkant van een kladje uit. Menigmaal heeft een brainstormsessie met jou ervoor gezorgd dat ik weer verder kon werken aan een artikel of onderzoeksvoorstel. Ook dank voor het delen van het internationale netwerk van jou en Hugo en dat jullie het mogelijk hebben gemaakt dat ik tijdens mijn 
promotiestudie vele nationale en internationale congressen heb mogen bijwonen. Dit heeft mijn wetenschappelijk inzicht verruimd.

De leden van de beoordelingscommissie, Prof. dr. Geert-Jan Dinant, Prof. dr. Frank Buntinx, Prof. dr. Anna Falanga, Dr. Pieter Willem Kamphuisen en Prof. dr. Peter de Leeuw wil ik bedanken voor hun bereidheid mijn proefschrift te lezen en te beoordelen.

Een groot gedeelte van dit proefschrift komt voort uit het Amuse-2 project. Het Amuse-project is een samenwerkingsverband tussen 3 universiteiten: de universiteit van Amsterdam, de universiteit van Utrecht en universiteit Maastricht. Als eerste wil ik hier graag mijn medepromovendi uit Utrecht en Amsterdam bedanken: Geert-Jan Geersing en Wim Lucassen. Beste Geert-Jan, beste Wim, ik kwam pas bij de projectgroep toen jullie al een dik half jaar onderweg waren. Dank voor jullie hartelijke welkom en het mij wegwijs maken in de wereld van de huisarts en de wereld van de diagnostiek van longembolie. Dank voor de gezellige en leerzame overleggen. Ik heb onze samenwerking als zeer prettig ervaren. Ook wil ik de senior begeleiders uit Utrecht en Amsterdam bedanken: Prof. dr. Karel Moons, Prof. dr. Arno Hoes, Dr. Ruud Oudega, Prof. dr. Harry Büller en Prof. dr. Henk van Weert. Tot slot gaat hier speciale dank uit naar Marion de Mooij. Beste Marion, jouw hulp was onmisbaar in de dataverzameling van Amuse-2 in Zuidoost-Nederland. Dank voor het vele werk dat je verzet hebt. Jij hebt een belangrijke rol gespeeld in het enthousiasmeren van de huisartsen voor Amuse-2 en hebt voor een zo nauwkeurig mogelijke dataverzameling gezorgd. Ook dank voor de vele gezellige uurtjes die we samen doorgebracht hebben. We konden goed met elkaar praten en hebben heel fijn samengewerkt.

I also would like to thank dr. Carrier and dr. Wells for the opportunity to visit the Ottawa Hospital Research Institute and to investigate the safety of outpatient treatment in pulmonary embolism in Ottawa. I am grateful for your support. Dear dr. Wells, dear Phil, thank you for your enthusiastic response to my request to visit Ottawa and thank you for your help in arranging my stay. Dear dr. Carrier, dear Marc, thank you for your warm welcome when I arrived in Ottawa. I remember our first meeting at the airport. To make sure that I felt at home you brought some groceries. Also thanks for your supervision. Your input during our meetings and discussions helped me to conduct the research. Your comments on my articles helped me to be more focused and improved my writing skills. I hope we will continue to cooperate in the future. Finally, I would also like to thank Esteban Gandara. Dear Esteban, thank you for the critical comments on the research project and the pleasant dinners. It was nice sharing an office with you.

Ook wil ik hier Tiny Wouters en Charles Hilkens bedanken. Beste Tiny, hartelijk dank voor het verzorgen van de lay-out van mijn proefschrift. Beste Charles, jou wil ontzettend bedanken voor de het ontwerpen van de kaft. Zonder jullie bijdrage was het eindresultaat niet zo mooi geweest. 
Ook wil ik Yvonne Leenders van het secretariaat van epidemiologie danken voor het regelen van praktische zaken omtrent het afronden van het proefschrift.

Daarnaast waren en ook allerlei mensen die niet direct bij het promotieproject betrokken waren, maar waar ik wel veel aan heb gehad.

Allereerst de mensen van het secretariaat van huisartsgeneeskunde. Bij jullie kon ik altijd terecht met praktische vragen. Met name Ine Siegelaer wil ik bedanken dat ze, naast de spil van de afdeling, ook iemand is die altijd voor iedereen een luisterend oor heeft. Vooral de laatste paar maanden heb ik hier gebruik van gemaakt. Ine, ik wil je laten weten dat het mij heel goed heeft gedaan om bij jou terecht te kunnen met mijn verhaal.

Met wie ik de afgelopen 4 jaar ook lief en leed heb gedeeld zijn de mede-promovendi van huisartsgeneeskunde. Sil, Janaica, Martine, Tineke, Mandy, Viola, Esther, Joris, Merijn, Luc, Eva en Eefje: dank voor de fijne tijd die wij samen hebben doorgebracht. Beste Sil, bijna 4 jaar lang hebben wij onze werkkamer met elkaar gedeeld. Ik had me geen beter kamergenootje kunnen voorstellen. Soms was het tijd om hard door te werken, maar we maakten ook regelmatig tijd vrij voor gezellige praatjes, diepgaande discussies of het luisteren naar muziek. Ik hoop dat we elkaar nog zo af en toe blijven zien en op de hoogte blijven van de belangrijke gebeurtenissen in elkaars leven. Beste Esther, sinds een jaar heb jij de werkplek van Sil ingenomen. Ik ben blij met jou als nieuw kamergenootje. Ook wij verzetten af en toe onze gedachten door gezellig te kletsen. Een apart woord wil ik ook nog richten tot Janaica Grispen. Lieve Janaica, jij was de sociale spil onder de promovendi van de tweede verdieping bij huisartsgeneeskunde. Wij hebben samen heel wat gezellige uurtjes doorgebracht. We hebben veel gelachen, maar ook samen gehuild. Het maakte niet uit hoe druk je was, je maakte altijd tijd vrij om me bij een kopje thee mijn verhaal te laten doen. De laatste tijd hebben we ons contact voortgezet in een gezellige gezamenlijke lunch af en toe. Ik hoop dat we dit nog lang blijven doen.

Ook wil ik graag de mensen van het laboratorium voor klinische trombose en hemostase bedanken. Zoals eerder gezegd heb ik veel geleerd van de dinsdagochtendbesprekingen. Door jullie ervaringen te delen hebben jullie mij een kijkje laten nemen in de keuken van basaal en biochemisch onderzoek op het gebied van trombose en hemostase. Ook wil ik jullie bedanken voor de gezelligheid tijdens de congresbezoeken in o.a. Boston, Kyoto en Liverpool. Het is fijn om met zo'n leuke groep mensen op pad te gaan.

De leden van Journal Club Maastricht wil ik graag bedanken voor de gezellige etentjes, leuke activiteiten en levendige discussies. Het is fijn om met jullie ook buiten werktijd over de wetenschap te filosoferen.

Tot slot wil ik graag een aantal dierbare mensen bedanken die mij gevormd hebben. Ik ben gezegend met aantal goede vriendschappen waar ik ontzettend dankbaar voor ben. Zonder anderen tekort te doen, wil ik een aantal mensen bedanken, die in het bijzonder hebben bijgedragen aan dit eindresultaat: Linda Dauwerse-Boersma, Suzanne van der Helm, Nicole Borghans-Laumen en Netty Beckers. Lieve Linda, wij 
hebben eenzelfde carrièrepad gekozen en hebben elkaar daarin gesteund. Op de middelbare school kenden we elkaar wel, maar gingen nog niet zoveel met elkaar om. Onze vriendschap kwam pas tot stand in het propedeusejaar van Gezondheidswetenschappen op Universiteit Maastricht. Na de propedeuse behaald te hebben, hebben wij samen besloten dat we graag wat meer praktijkervaring wilden opdoen en zijn overgestapt naar hogeschool Zuyd voor de verpleegkunde-opleiding. Hier hebben we samen veel meegemaakt en ik weet zeker dat onze verpleegkundige achtergrond een belangrijke bijdrage heeft geleverd in onze vorming tot wetenschappers. Na de HBO-V zijn we samen de cursus methodologie en statistiek gaan volgen op Universiteit Maastricht om zo toegelaten te worden tot een master-opleiding. Jij koos voor zorgwetenschappen, ik heb gekozen voor epidemiologie. Nu we allebei aan het einde van ons promotieproject zijn, denk ik dat we met veel trots kunnen terugkijken op wat we bereikt hebben. Ook al zien we elkaar tegenwoordig niet meer zo heel vaak, ik hoop dat onze vriendschap nog lang blijft bestaan.

Lieve Suzanne, jij vertelt regelmatig dat je mij nog steeds als 6-jarig meisje ziet binnenkomen in het leslokaal van de muziekschool in Sittard. Een meisje met een rode strik in haar haren dat graag blokfluit wilde leren spelen. Jij hebt me echter veel meer geleerd dan het maken van muziek. Ik wil je graag bedanken dat je mij altijd aangemoedigd hebt om het beste uit mezelf te halen. Jij hebt een rotsvast vertrouwen in mijn kunnen en stimuleerde me om mijn eigen weg te kiezen. Ik heb bewondering voor hoe krachtig jij in het leven staat. Van mijn blokfluitlerares ben jij uitgegroeid tot een ware vriendin. Ik hoop dat we nog vaak samen zullen fluiten en kletsen.

Lieve Nicole, lieve Netty, jullie zijn mijn paranimfen. Twee betere vriendinnen dan jullie dan ik me niet wensen. Beiden zo verschillend, maar beiden zo belangrijk voor mij. Twee vriendschappen door dik en dun. Lieve Nicole, dank voor alle gezellige en mooie momenten samen. Wat is het fijn om zowel de kleine als grote gebeurtenissen in het leven te delen met iemand zoals jij. Ik zie al helemaal voor me hoe we over tig jaren als twee oude besjes elkaar verhalen vertellen over de middelbare schooltijd, onze reis naar Wenen en Budapest, hoe we beiden gingen studeren en op onszelf gingen wonen, de trouwdag van ieder, de wens om een gezin te stichten en misschien ook wel over hoe jij paranimf was bij de openbare verdediging van mijn proefschrift. Lieve Nicole, ik ben ontzettend dankbaar voor onze vriendschap en hoop dat zich de komende jaren nog maar meer zal verdiepen. Lieve Netty, ook wij hebben al veel samen meegemaakt. Vanaf dag 1 van de brugklas waren we onafscheidelijk. Wat hebben wij veel plezier gehad tijdens onze middelbare schooltijd, met name tijdens de muzieklessen en de repetities van het Serviam-koor. Later heeft onze vriendschap zich verdiept en nu vinden we onder het genot van een kopje thee een luisterend oor bij elkaar. Ik bewonder jouw krachtige persoonlijkheid. Jij laat je niet snel door iets of iemand van de wijs brengen. Lieve Netty, onze vriendschap is me ontzettend dierbaar en ik hoop dat we nog lang samen thee drinken! 
Dan wil ik nog mijn familie en schoonfamilie bedanken voor de steun en fijne contacten de afgelopen jaren. Van beide kanten prijs ik me gelukkig met een fijne en hechte familie. Het is fijn te weten dat er zoveel mensen achter je staan. Een speciaal woord van dank wil ik richten tot ome Rein en tante Marie-José. Ik was nog maar net in de familie toen jullie mij vertelden graag een financiële bijdrage te willen leveren aan mijn proefschrift. Mijn dank hiervoor is groot. Tante Marie-José, het is jammer dat het niet zo heeft mogen zijn dat $u$ deze bijzondere dag nog mag meemaken. Ik heb $u$ leren kennen als een bijzondere en sterke vrouw met een grote interesse in alles en iedereen. Ik weet zeker dat $\mathrm{u}$ het heel fijn had gevonden hier samen met ons te zijn. Dat geldt ook voor opa. Lieve oma, ik weet dat $u$, nog meer dan ons allemaal, opa mist. Vooral op speciale gelegenheden zoals deze. Ik weet echter zeker dat opa het heel fijn vindt dat $u$ nog even bij ons blijft en bijzondere gebeurtenissen van de kinderen, kleinkinderen en achterkleinkinderen kan meemaken.

Lieve schoonouders, het is nu ongeveer 4 jaar geleden dat jullie me een warm welkom gaven in jullie familie en ik me thuis mag voelen in Oirsbeek. Ik wil jullie bedanken voor alle steun die jullie mij en Frank geven. We weten dat we altijd bij u terecht kunnen.

Lieve mama en papa, jullie hebben mij de basis gegeven om uit te groeien tot de persoon die ik nu ben. Misschien is dit de juiste gelegenheid om jullie te laten weten dat ik me altijd ontzettend geliefd en thuis heb gevoeld bij jullie. Jullie hebben er alles aan gedaan om Ellen en mij groot te brengen tot verstandige en gelukkige vrouwen die stevig in hun schoenen staan. Jullie hebben ons geleerd bescheiden te zijn en klaar te staan voor andere mensen. Dat is een groot goed. Lieve papa en mama, dank voor alle kansen en mogelijkheden die jullie mij hebben gegeven.

Lieve Ellen, ik vind het moeilijk in woorden uit te drukken wat jij voor mij betekent. Jij bent niet alleen mijn grote zus, maar ook mijn vriendin, mijn sportmaatje en in veel opzichten mijn voorbeeld. Samen met Marcel, Sem en Cas vorm je een gelukkig gezin waar Frank en ik altijd welkom zijn. Ik kan bij veel mensen terecht, maar deel alles het liefste eerst met jou.

Lieve Frank, wij zeggen wel eens tegen elkaar "hadden we elkaar maar eerder ontmoet". Dit zegt wellicht genoeg over hoe graag we bij elkaar zijn. Wij voelen ons bij elkaar thuis en geven elkaar de ruimte voor ontwikkeling. Lieve Frank, ik kan niet beschrijven hoe fijn ik het vind dat jij mijn man bent. Dank voor al je steun afgelopen tijd. Ik hoop dat we vele mooie jaren samen tegemoet gaan waarin we steeds dichter naar elkaar toegroeien. 



\section{Publications}




\section{International peer-reviewed publications}

Lucassen WA, Beenen LF, Buller HR, Erkens PMG, Schaefer-Prokop CM, van den Berk $I A$, et al. Concerns in using multi-detector computed tomography for diagnosing pulmonary embolism in daily practice. A cross-sectional analysis using expert opinion as reference standard. Thromb Res. 2012.

Geersing GJ, Erkens PMG, Lucassen WA, Buller HR, Cate HT, Hoes AW, et al. Safe exclusion of pulmonary embolism using the Wells rule and qualitative D-dimer testing in primary care: prospective cohort study. BMJ 2012;345:e6564.

Van Es J, Mos I, Douma R, Erkens PMG, Durian M, Nizet T, et al. The combination of four different clinical decision rules and an age-adjusted $D$-dimer cut-off increases the number of patients in whom acute pulmonary embolism can safely be excluded. Thromb Haemost 2012;107:167-171.

Erkens PMG, Ten Cate H, Buller HR, Prins MH. Benchmark for time in therapeutic range in venous thromboembolism: a systematic review and meta-analysis. PLoS One 2012;7:e42269.

Winckers K, Ten Cate-Hoek AJ, Beekers KC, Erkens PMG, Hamulyak K, Ten Cate H, et al. Impaired tissue factor pathway inhibitor function is associated with recurrent venous thromboembolism in patients with first unprovoked deep venous thrombosis. J Thromb Haemost 2012;10:2208-2211.

Lucassen WAM, Geersing GJ, Erkens PMG, Reitsma JB, Moons KGM, Büller HR, Van Weert HCPM. Clinical Decision Rules for excluding pulmonary embolism: A MetaAnalysis. Ann Int Med. 2011;155:448-460.

Erkens PMG, Gandara E, Wells P, Shen AY, Bose G, Le Gal G, Rodger M, Prins MH, Carrier $M$. Does the pulmonary embolism severity index accurately identify low risk patients eligible for outpatient treatment? Thromb Res 2011; 129:710-714.

Douma RA, Mos IC, Erkens PMG, Nizet TA, Durian MF, Hovens MM, et al. Performance of 4 clinical decision rules in the diagnostic management of acute pulmonary embolism: A prospective cohort study. Ann Intern Med 2011;154: 709-718.

Gandara E, Bose G, Erkens PMG, Rodgers M, Carrier M, Wells P. Outcomes of saddle pulmonary embolism: a nested case-control study. J Thromb Haemost. 2011;9: 867-869. 
Merry AH, Erkens PMG, Boer JM, Schouten LJ, Feskens EJ, Verschuren WM, Gorgels $A P$, van den Brandt PA. Co-occurrence of metabolic factors and the risk of coronary heart disease: A prospective cohort study in the Netherlands. Int J Cardiol 2010;155: 223-229.

Lemmert ME, Janata A, Erkens PMG, Russell JK, Gehman S, Nammi K, Crijns HJ, Sterz F, Gorgels AP. Detection of ventricular ectopy by a novel miniature electrocardiogram recorder. J Electrocardiol 2011;44:222-228.

Erkens PMG, Prins MH. Fixed dose subcutaneous low molecular weight heparins versus adjusted dose unfractionated heparin for venous thromboembolism. Cochrane Database Syst Rev. 2010:CD001100.

Erkens PMG, Gandara E, Wells P, Shen AY, Bose G, Le Gal G, Rodger M, Prins MH, Carrier M. Safety of outpatient treatment in acute pulmonary embolism. J Thromb Haemost 2010:8:2412-2417.

\section{National publications}

Erkens PMG. Thuisbehandeling bij longembolie. Tromnibus 2010:38: 46-48.

Mos IC, Douma RA, Erkens PMG, Nizet TA, Durian MF, Hovens MM, et al. Betrouwbaarheid klinische beslisregels bij diagnostiek van acute longembolie. Ned Tijdschr Geneeskd 2012;156:A4216. 
Curriculum Vitae 


\section{Curriculum Vitae}

Petra Mathilda Gerardus Erkens was born on November 12, 1981 in Sittard, in the Netherlands. She completed secondary school (Gymnasium) at the Trevianum Scholengroep Sittard in 2000. In the same year she started her study Health Sciences at Maastricht University. After completing her first year of Health Sciences, she transferred to HBO-V (bachelor) where she graduated with distinction as a registered nurse (level 5). After het HBO-V, Petra spent six months as a volunteer nurse in a governmental hospital in Pretoria, South Africa. When she returned to the Netherlands, she began working as a research nurse at

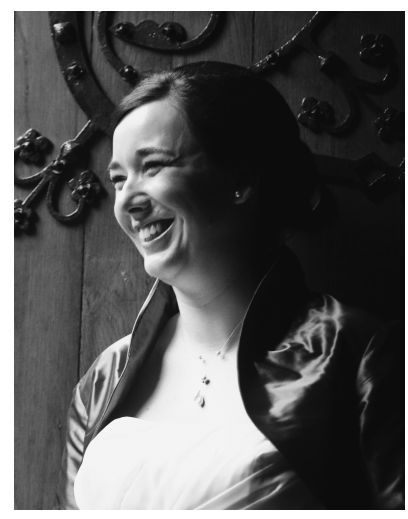
the cardiology department of the academic hospital in Maastricht. At the same time, she was admitted to the Master of Epidemiology (Health Sciences) where she graduated in 2008. During this master, she fulfilled her internship at the department of Epidemiology of Maastricht University, resulting in the master-thesis "Clustering of metabolic factors and the risk of coronary heart disease: a prospective cohort study in the Netherlands." After graduating, Petra started working as a PhD student at the department of General Practice (School for Public Health and Primary Care (CAPHRI) and Cardiovascular Research Institute Maastricht (CARIM)) in June 2008 resulting in this thesis. Her PhD trajectory revolved around two main projects which were aimed at investigating the safety of diagnosing pulmonary embolism in primary care and the safety of outpatient treatment in patients with acute pulmonary embolism. From February until July 2010, she worked at the Ottawa Hospital Research Institute, Ontario, Canada. Recently, she was offered a post-doctoral position at CAPHRI. With the acquired postdoctoral grant she will investigate the effectiveness of novel anticoagulants in everyday clinical practice mainly focussing on medication nonadherence. Since September 2012 she is also employed at Hogeschool Zuyd as a teacher in nursing.

Petra is happily married to Frank Douven. Beyond her work she enjoys playing the recorder, reading and travelling. 